\title{
THE.BOOK.OF NATURE.STUDY
}

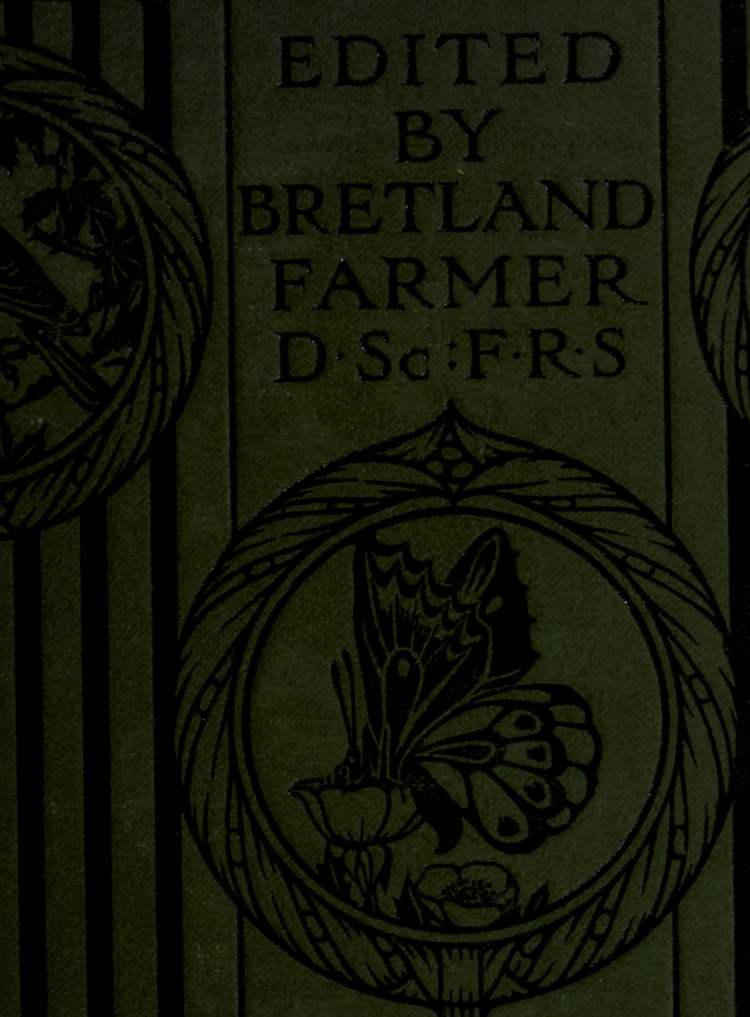




\section{DISSECTED MODEL OF A PIGEON}

(BY EDWIN NOBLE)

A :-The External Parts of a Pigeon.-I. Crcwn. 2. Forehead. 3. Cere: an area cf bare skin found only in birds, such as Pigeons, Hawks and Eagles, and Parrots. 4. Beak. 5. Nape. 6. 'Ih"oat. 7. Neck. 8. Base cf Neck. 9. Scapulars. Io. Back. II. Wing Coverts. I2. Grealer, or Major Coverts. 13. Primaries, or Wing-Quills of the Hand. I4. 'Tail. I5. Secondaries, or Wing-Quills of the Forearm. I6. Abdomen. 17. Breast.

B :-Diagram sliowing tile Pterylosis, or Distribution of the

FEATHERs. - I. Head Tract. 2. Ventral Neck Tract. 3. Dorsal

Neck Tract. 4. Spinal Tract. 5. Ventral Tract. 6. Wing Tract. 7. Femoral Tract. 8. Leg Tract. 9. Oil-Gland-very small in the Pigeon. Note the bare, featherless spaces. These are known as the "Apteria," the feather tracts as the "Pteryla." "These tracts vary greatly in different species of birds, as may be seen by comparing, say, a sparrow, a fowl, and a pigeon.

C :-DIAgkaM of TIIE SkELeton of a Pigeon.-I. Orbit or Socket of the eye. 2. Brain Case. 3. Upper Jaw. 4. Lower law. These two jaws form the "Beak." 5. Neck Vertebrze. 6. Shoulder-blade, concealing the Back-bone. 7. Upper Arm Bone.

8. Forearm. 9. Hand. Io. Furcula or "Merrythought." Ir. Keel of Breast-bone or Sternum 12. Hip Girdle, r3. Femur or 'Thigh bone, 14. Tibia or Shank Bone. I5. TarsoMetatarsus or Foot Bones-all that is generally seen of the leg, except the toes, in the living bird. I6. 'Tces. I7. 'Tail Bones, the last of which is forned by a welding together of several bones to form a large flat plate known as the Pygostyle, and which supports the tail feathers.

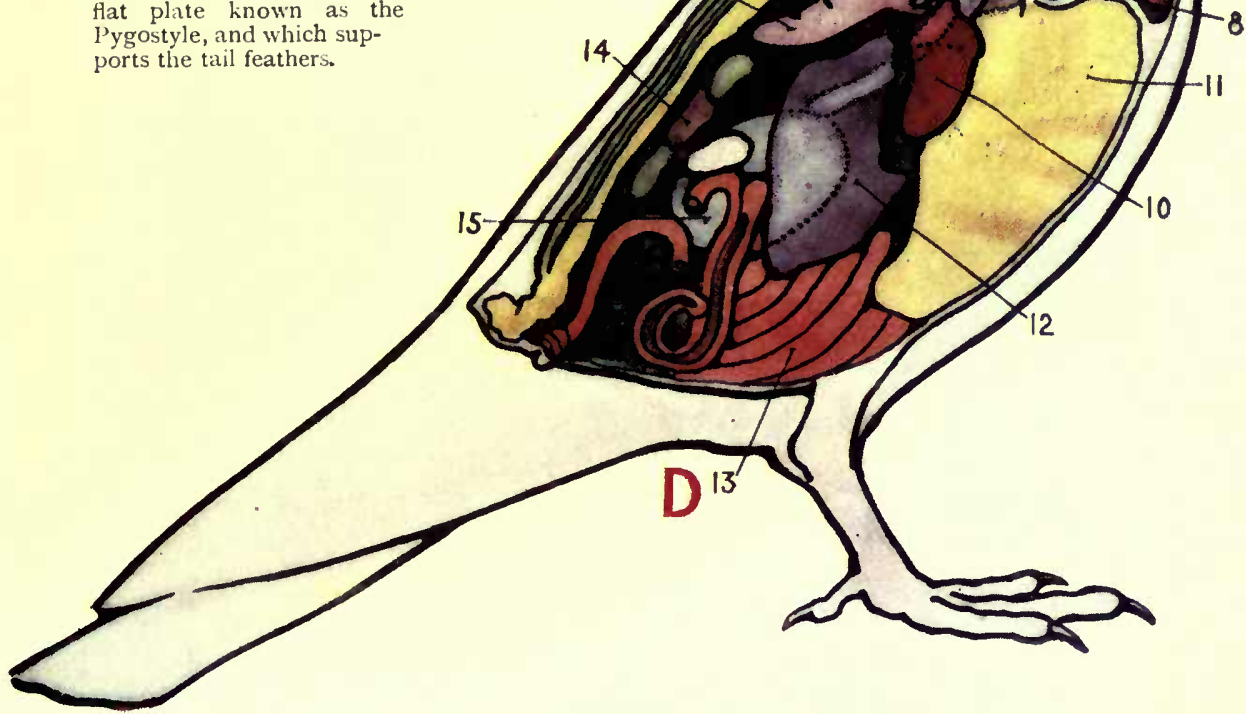

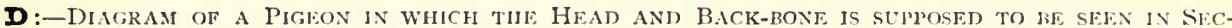

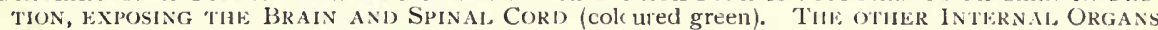
ARE MUCH AS WOULD BE SEEN IF THE SIDE OF THE BODY WAS REMOVED, (Bones are ccloured yellow.)-I. Skull. 2. Brain. 3. Spinal Cord. 4. Back-bone, along which the Spinal Cord runs. 5. Tongue. 6. Windpipe. 7. Gullet, down which the food passes. A piece of the wall has been cut away from the upper end to show the interior of the tube. 8 . The Crop. 'The outer wall of this has been cut away. During life the Crop is capabie of being distended to an enormous extent. $8^{1}$. Represents the outer wall of the first portion of the Stomach, which is continued backwards into the Gizzard, as shown by the dotted line. The front end of the Gizzard is also indicated by dotted lines, since it is partly concealed by the Liver. 9. Lungs. Io. Heart. II. Kcel of the B-east-bone. I2. Liver. I3. Intestines. I4. Kidneys. I5. Hinder portion of Gizzard. 

A :-The Lxternal Parts of a Pigeon.-- I. Crcwn. 2. Forehead. 3. Cere: an area cf bare skin found only in biras, such as Pigeons, Hawks and Eagles, and Parrots. 4. Beak. 5. Nape. 6. Th"oat. 7. Neck. 8. Base of Neck. 9. Scapulats. 10. Back. Ir. IVing Coverts. I2. Greater, or Major Coverts. 13. Primaries, or Wing-Quills of the Hand. 14. Tail. I5. Secondaries, or Wing-Quills of the Forearm. I6. Abdomen. I7. Breast.

B :-Diagran showing the Pterylosis, or Distribution ol tilH FEATHERs. - 1. Head Tract. 2. Ventral Neck Tract. 3. Dorsal Neck Tract. 4. Spinal Tract. 5. Ventral Tract. 6. Wing Tract. 7. Femoral Tract. 8. Leg Tract. 9. Oil-Gland-very small in the Pigeon. Note the bare, featherless spaces. These are known as the "Apteria," the feather tracts as the "Pterylae." These tracts vary greatly in different species of birds, as may be seen by comparing, say, a sparrow, a fowl, and a pigeon.

C :-DIAGRAM OF THE SKELETON OF A PIGEON.-I. Orbit or Socket of the eye. 2. Brain Case. 3. Upper Jaw. 4. Lower Jaw. These two jaws form the "Beak." 5. Neck Vertebræ. 6. Shoulder-blade, concealing the Back-bone. 7. Upper Arm Bone. 8. Forearm. 9. Hand. Io. Furcula or "Merrythought." Ir. Keel of Breast-bone or Sternum. 12. Hip Girdle. 13. Femur or Thigh bone, 14. Tibia or Shank Bone. I5. TarsoMetatarsus or Foot Bones-all that is yenerally seen of the leg, except the toes, in the living bird. 16. 'Tces. 17. Tail Bones, the last of wlich is iormed by a welding together of several bones to form a large flat plate known as the Pygostyle, and which supports the tail feathers.

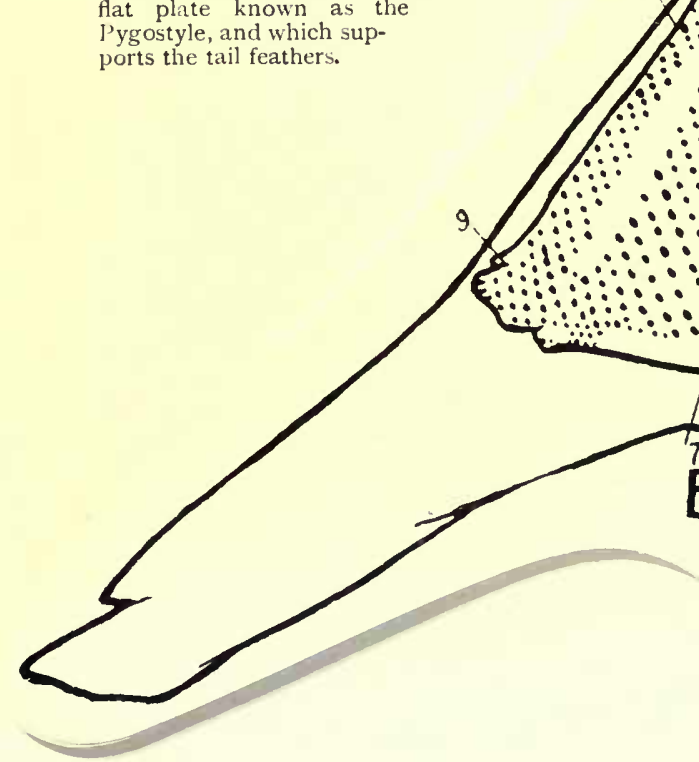

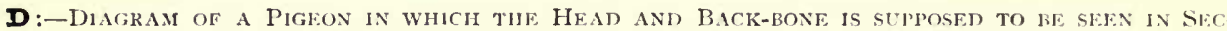
TION, EXPOSING THE BRAIN AND SPINAL CORD (colcured green). THE OTHER INTERNAL, ORGaNS ARE, MUCH AS WOULD RE SEEN IF THE SIDE OF THE BODY WAS RENOVED. (Bones are ccloured yellow.)-I. Skull, 2. Brain. 3. Spinal Cord. 4. Back-bone, along which the Spinal Cord runs. 5. Tongue. 6. Windpipe. 7. Gullet, down which the food passes. A piece of the wall has been cut away from the upper end to show the interior of the tube. 8. The Crop. The outer wall of this has been cut away. During life the Crop is capable of being distended to an enormous extent. $8^{1}$. Represents the outer wall of the first portion of the Stomach, which is continued backwards into the Gizzard, as shown by the dotted line. The front end of the Gizzard is also indicated by dotted lines, since it is partly concealed by the Liver. 9. Iungs. ro. Heart. Ir. Kcel of the B-east-bone. I2. Liver. 13. Intestines. I4. Kidneys. 15. IHinder portion of Gizzard. 

(BY EDWIN NOBLE)

A.- - The Exteknal Parts of a Pigeon. - I. Crcwn. 2. Forehead. 3. Cere: an area cf bare skin found only in birds, such as Pigeons, Hawks and Eagles, and Parrots. 4. Beak. 5. Nape. 6. Th oat. 7. Neck. 8. Base of Neck. 9. Scapula!s. ro. Back. II. Wing Coverts. I2. Greater, or Major Coverts. 13. Primaries, or Wing-Quills of the Hand. I4. 'Tail. I5. Secondaries, or Wing-Quills of the Forearm. r6. Abdomen. 17. Breast.

B :-Diagram silowing tile Pterylosis, or Distribution of tile liEATHERs, - 1. Head Tract. 2. Ventral Neck Tract. 3. Dorsal Neck Tract. 4. Spinal 'Tract. 5. Ventral 'Tract. 6. Wing Tract. 7. Femoral Tract. 8. Leg Tract. 9. Oil-Gland-very small in the Pigeon. Note the bare, featherless spaces. 'These are known as the "Apteria," the feather tracts as the "Pterylae." These tracts vary greatly in different species of birds, as may be seen by comparing, say, a sparrow, a fowl, and a pigeon.

C :- DIAGkaM (OF THE SkEleton of a Pigeon,- - Orbit or Socket of the eye. 2. Brain Case. 3. Upper Jaw. 4. Lower Jaw. These two jaws form the "Beak." 5. Neck Vertebrae. 6. Shoulder-blade, concealing the Back-bone. 7. Upper Arm Bone. 8. Forearm. 9. Hand, Io. Furcula or "Merrythought." Ix. Keel of Breast-bone or Sternum. 12. Hip Girdle. I3. Femur or Thigh bone. 14. Tibia or Shank Bone. I5. TarsoMetatarsus or Foot Bones-all that is generally seen of the leg, except the toes, in the living bird. 16. 'Tces. 17. Tail Bones, the last of which is formed by a welding together of several bones to form a large flat plate known as the Pygostyle, and which supports the tail feathers.
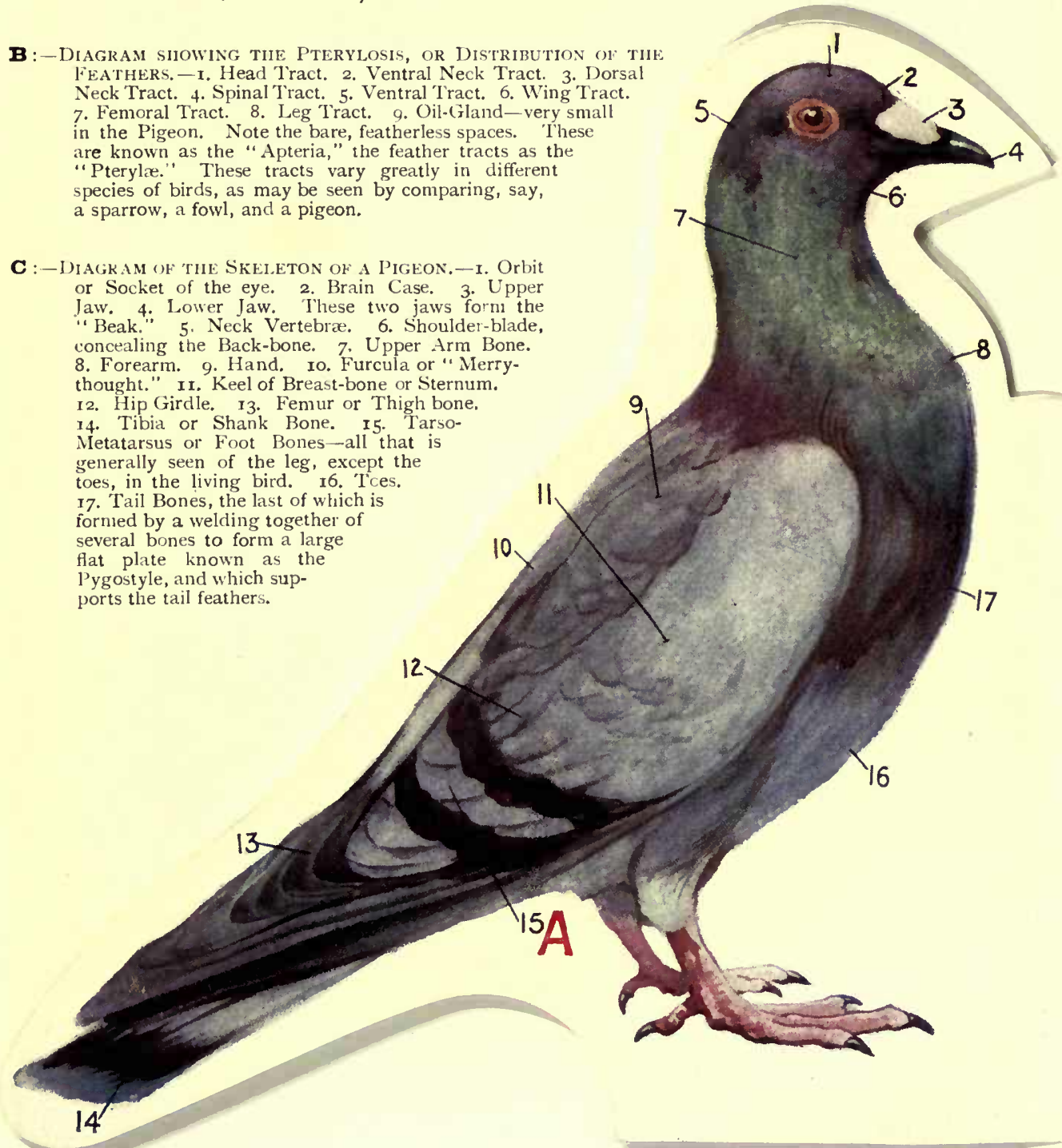

THE BOOK OF NATURE STUDY 




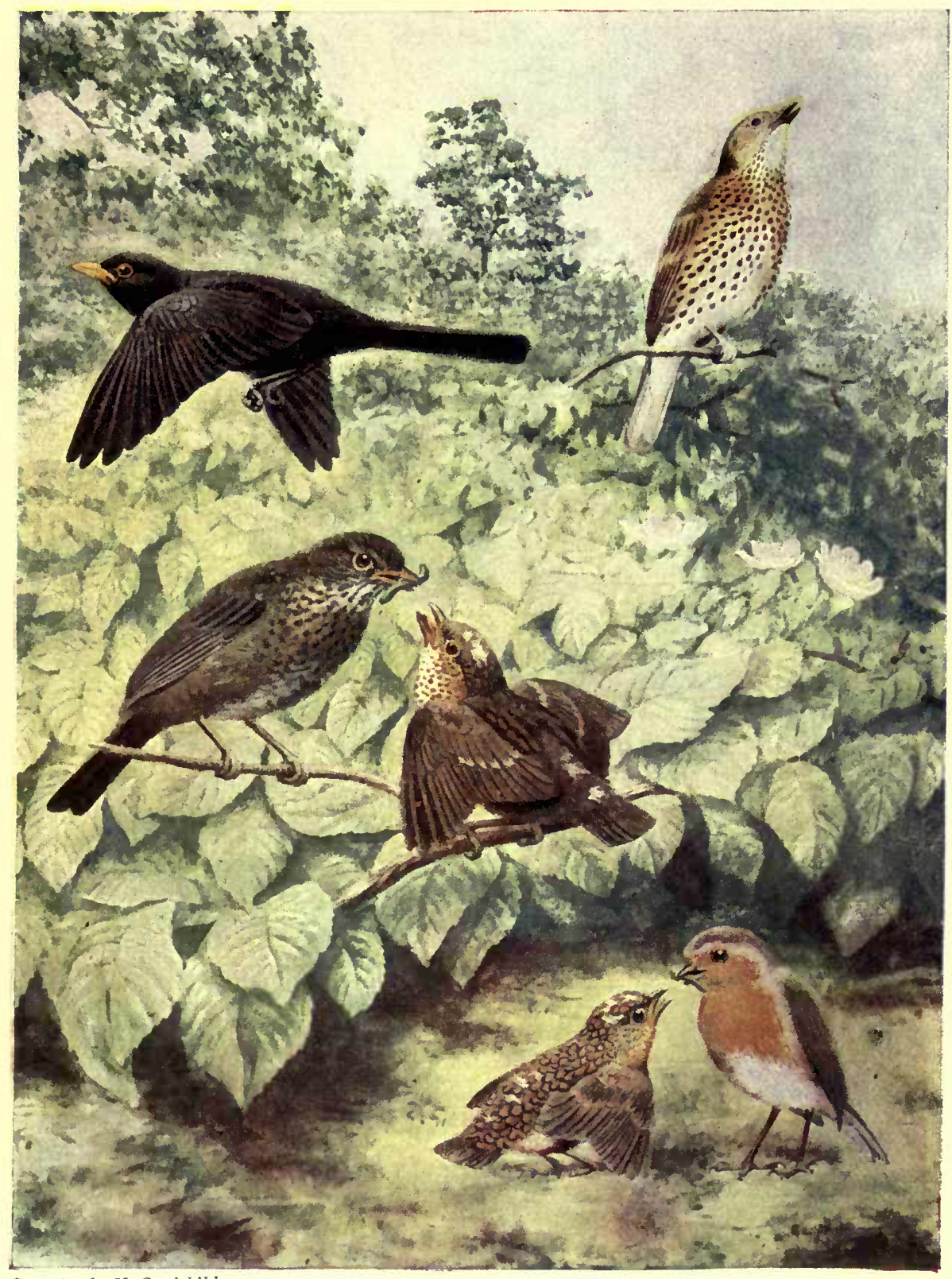

D, aring by $H$. Goodchild.

\section{BIRDS IN SUMMER-TIME}

This picture illustrates the differences in plumage between male, female, and young described on p. 87. Male blackbird flying: female feeding its young. Here young resemble the female. The thrush is shown singing : in this species male, female, and young are alike. In the robin male and female are alike and the young different. 


\section{THE BOOK OF}

NATURE STUDY

EDITED BY

\section{(Sir) J. BRETLAND FARMER \\ M.A., D.Sc.(Oxon.)., F.R.S.}

PROFESSOR OF BOTANY, ROYAL COLLEGE OF SCIENCE, LONDON

ASSISTED BY

A STAFF OF SPECIALISTS

FULLY ILLUSTRATED

VOL. I

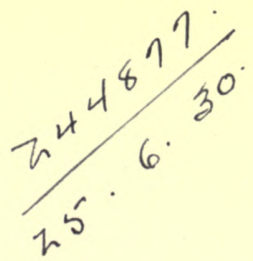

LONDON :

THE CAXTON PUBLISHING COMPANY CLUN HOUSE, SURREY STREET, W.C. 



\section{THE CONTRIBUTORS}

J. ARTHUR ThOMSON, M.A., Professor of Natural History in the University of Aberdeen.

W. P. PYCRAFT, F.Z.S., Assistant in Charge of Osteological Collections, British Museum (Natural History).

W. W. WATTS, M.A., M.Sc., F.R.S., Professor of Geology, Royal College of Science, London.

W. H. LANG, M.B., D.Sc., Professor of Cryptogamic Botany in the University of Manchester.

A. D. HALL, M.A., Director of the Experimental Station at Rothamsted.

OSWALD H. LATTER, M.A.(Oxon.), Senior Science Master at Charterhouse School.

MARION I. NEWBIGIN, D.Sc., Lecturer on Zoology, Edinburgh College of Medicine for Women; Author of "Life by the Seashore," etc.

Miss CHARLOTTE L. LAURIE, of Cheltenham Ladies' College; Author of "Elementary Text-Book of Botany."

FRANK CAVERS, D.Sc., F.L.S., Professor of Biology, Hartley University College, Southampton.

J. E. HENNESEY, B.A., B.Sc., formerly Principal of the Lady Warwick Agricultural School, Author of "The School Garden." 


\section{PREFACE}

IN most matters of importance there are various ways of attacking the main problems that come up for solution. The subject of education forms no exception to the rule, and different experts-and, it may be added, faddists also-have strenuously advocated mutually exclusive methods as alone capable of leading to satisfactory results. The numerous exponents cannot all be right, and perhaps none of them are altogether wrong in their ideas. Even those who only aspire to fill the pupil with certain definite information, to be used for examination or other purposes, are able to urge that at anyrate they escape the charge of indefiniteriess of aim which too often lies at the door of those who cry for education rather than instruction.

The ideal course is that which would succeed in combining both results, and whilst enlarging the intellectual horizon at the same time manages to assure the solid asset of useful knowledge.

But during the earlier years of life a boy or girl easily picks up and assimilates information,- - witness the tenacity with which the knowledge acquired in youth is retained in after life. The matter of vital importance during this period is so to impart instruction that the appetite for learning which is the natural heritage of almost every child shall not be blunted by satiety or destroyed by improper forcing. This lamentable result may be as easily achieved by cramming with peptonised doses of information, so that the power of independent assimilation becomes atrophied, as by the old-fashioned application of over-strenuous mental discipline, which creates a distaste for all forms of intellectual exercise.

Amongst the studies that deserve to take a high rank in the educational subjects, that of Nature Study ought to occupy a high place, especially in the case of young people. It is concerned with all the phenomena of the world around us, and its problems are those which confront us everywhere in our daily life. But regarded from the educational standpoint, its value largely depends on the use that is made of it by the teacher. A principal object which should never be lost sight of is the stimulation of the power of independent inquiry and observation on the part of the children themselves. It is of little or no use for the teacher to attempt to teach it. The objects themselves should be the teachers, and the business of the schoolmaster or mistress really lies in explaining to the pupils the rules of the game. Nature only speaks to those who know how to listen and how to question, but 
those who have once learnt this lesson have thereby obtained possession of a key to knowledge that will fit many locks and disclose the secrets of many mysteries.

Many teachers fail with their students from various causes, and thus Nature Study itself has undeservedly suffered in reputation. I am here only concerned with one of these causes, it consists in the ignorance of the subject. As in other branches cf study, the teacher ought to be ahead of his pupils, although he still must ever remain himself a learner. One of the main objects that has been kept in view during the preparation of these volumes has been to place the necessary information in such a form as to be accessible to the teacher. Of course, finality is not aimed at, for the subject itself is infinite, and the perusal neither of this nor of any other book can of itself make a competent teacher of any one unless he is prepared to do his own part, and will observe and study the natural objects around him at first hand.

What it is hoped to accomplish is to render the way of setting about the work more easy, by putting at the disposal of all who are interested in nature reliable information not hitherto available in a sufficiently accessible form. That the book will escape criticism is neither to be expected nor desired. The field itself is so immense that omissions must necessarily occur, and the method of treatment that has, after mature consideration, been adopted, naturally involves apparent duplication in some instance. These difficulties are inherent in the subject, and perhaps the utility of the work as a whole will not greatly suffer thereby. But at least it is hoped that it may be found helpful to teachers, and interesting to that considerable body of men and women who take a keen interest in the wonders of nature that everywhere surround us.

It is a pleasant duty to acknowledge the helpiul suggestions which have been received from numerous friends and colleagues, and in this relation special thanks are due to Professor Hickson, F.R.S., for his valuable aid and advice during the critical period while the general plan of the work was under consideration. To Miss Kate Hall and to Mr. H. E. Turner, the Treasurer and Secretary respectively of the School Nature Study Union, I am greatly indebted for material assistance in drawing up the scheme of the book, and also during the subsequent stages of its preparation.

J. BRETLAND FARMER.

IMPERIAL COLLEgE OF

Science and Technology. 


\section{CONTENTS OF VOLUME I}

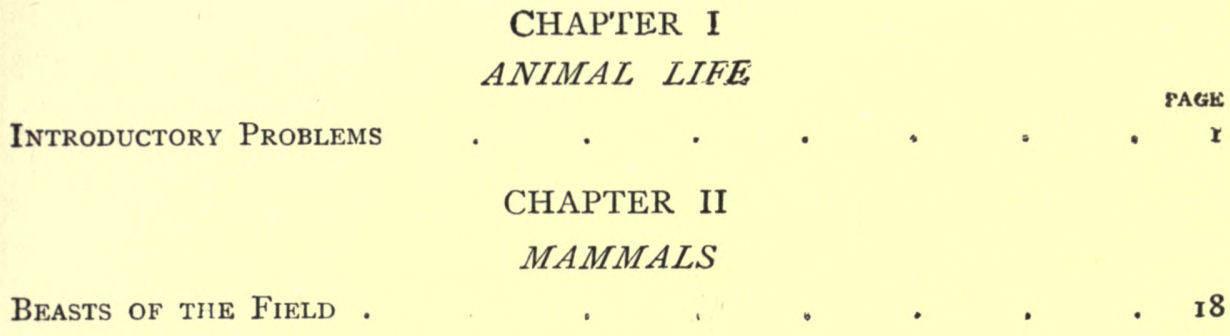

CHAPTER III

Some Common Animals-Cats and Dogs . $\quad$, $\quad{ }^{2} 5$

CHAPTER IV

The Rodents or "Gnawing" Animals . $\quad$. $\quad . \quad$. 28

CHAPTER V

Hoofed Animals-Horses, Oxen, and Swine $\quad . \quad$. $\quad . \quad 32$

CHAPTER VI

Some Remarkable Types, and what they Teach • . . . $\quad 43$

CHAPTER VII

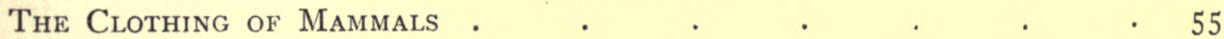

CHAPTER VIII

Liveries and their Meaning: The Coloration of Adult Mammals 59

CHAPTER IX

Liveries and their Meaning: The Coloration of Young Mammals . 65

CHAPTER X

BIRDS

The Essential Characters of Birds, and a General Outline of their

Structure . $\quad . \quad$. $\quad . \quad$.

CHAP'TER XI

Some Common British Birds-Seasonal Changes of Plumage • • 79 


\section{CHAPTER XII}

PAGE

Food and Feeding

\section{CHAPTER XIII}

Nests and Eggs, and Nestling Bird's

CHAPTER XIV

Migration

CHAPTER XV

REPTILES, FISH, ETC.

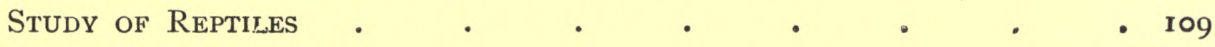

\section{CHAPTER XVI}

The Study of Amphibians-The Living Frog-External FeaturesThe Frog-A "Cold-Blooded" Animal-The Year's Life of The FROG-LIFE-History

\section{CHAPTER XVII}

Study of Fishes-First Study: The Living Fish-Second Study: The

External Characters of Fishes-Third Study: The Life-Histories

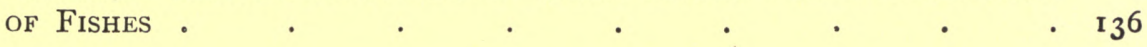

CHAPTER XVIII

The Lower Vertebrates-Cyclostomes or Round-Mouths-The LanceLets-The Sea-Squirts or Tunicates . . . . .

CHAPTER XIX

INSECTS, SPIDERS, WORMS, ETC.

EARTHWORMS

CHAPTER XX

The C'ockroach

CHAPTER XXI

EARWIGS

CHAPTER XXII

The large Cabbage White Butterfly * * , . . I8I

CHAPTER XXIII

WASPS 


\section{LIST OF PLATES-VOLUME I}

\section{COLOURED PLATES}

Dissected Model of Pigeon .

PAGE

Birds in Summer Time

Different Types of Mammals

Highland Animals in Winter

Highland Animals in Summer

Ruff and Reeve in Autumn .

Ruffs in Summer Dress “Displayed”

\section{BLACK AND WHITE PLATES}

TyPes of Dogs .

Nestling Thrushes-Golden Eagle.$\quad$, . . . 68

Pigeons-Two and Seven Days Old . • . . 72

TyPes of Pigeons . . . . . . . . . 76

Young Barn OWL-Young Fheasants . . . . . 80

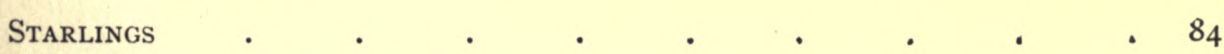

Nest and Eggs of Swallow and of Golden-Crested Wren • $\quad 9^{8}$

Nest and Eggs of Ringed Plover . . . . . . . 100

YOUNG SPARROW-HawkS.$\quad$. . . . . . . . . 102

Nest of Long-tailed Tit-Nest of Thrush . . . . . 104

The Common English Lizard (Lacerta vivipara)-Slow Worms (Anguis fragilis), Two Colour Varieties-The Common Grass Snake (Tropidonotus natrix)_EgGS of THE Grass SNAKE . . . . . II 2 
Adders (Vipera berus), Male and Female-The Rare Smooth Snake (Coronella lavis)-Rattle of Rattlesnake . . . . II6

Common ToAd (Bufo vulgaris)-COMmon Frog (Rana temporaria)-ToAd

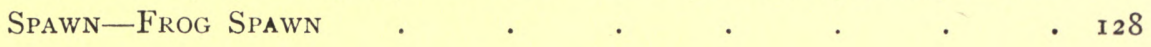

Male Crested Newt (Triton cristatus)-Three-Spined Stickleback (Gastrosteus aculeatus)-Minnows (Leuciscus phoxinus). . . . . I44

EARWIG-Wing OF EARWIG-Nest of EARWIG-QueEN WASP-Male AND Female Cockroach

Large Cabbage White Butterfly, successive Phases • . 184 


\title{
THE BOOK OF NATURE STUDY
}

\author{
ANIMAL LIFE \\ CHAPTER I \\ INTRODUCTORY PROBLEMS \\ By J. Arthur Thomson, M.A., \\ Professor of Natural History, University of Aberdeen.
}

The Naturalist's Four Chief Questions.-It may be useful to teachers to point out that the naturalist asks four chief questions - the answers to which, all very imperfect, are unified into a science of lifelore or biology.

The first question is-What is this? an inquiry into form and structure. What is this living creature in itself and in its parts? What is it as we see it with our own lenses only, and as we see it when we put other lenses in front of ours? What is it as a thing by itself, and when compared with its fellows and kindred ?

The second question is-How does this act? an inquiry into habits and functions. How does this living creature behave as it does ? What is its business? How does it keep agoing and set other creatures like itself agoing ? How does it get on ? What is the " particular go" of it?

The third question is-Whence is this? an inquiry into development and history. Where did this living creature come from ? How did it begin? What was it like when it was young? What are the chapters in its growth, and the crises in its lifehistory? What is known of the history of its race?

The fourth question is-How has this come to be as it is? an inquiry into causes. What factors have led to this living voL. I-I 
creature being what it is, where it is, as it is ; in short, what have been the factors in its evolution.

Now, it need hardly be said that these questions cannot be answered to children, though, as a matter of fact, children are continually asking them ! They are the fundamental questions of the science of biology, which is not for children. But it is the teacher's business to have clearly in his mind what the fundamental questions are, to make himself acquainted so far as may be with the partial answers that are at present possible, and to understand the method of arriving at these. He will then be able to encourage his pupils to put these questions, and, while recognising the impossibility of answering them fully, to guide them to find out provisional answers for themselves, answers which, though they may not go far, must yet be true as far as they go. This is the only and true method of instruction in Nature Study.

The aim of this introductory chapter is to try to expound certain general themes which must form part of the intellectual background of successful nature study in the field of animal life. If the teacher is not going to fumble with what he touches he must have his mind in order. Nature study is an intelligent outlook on the whole natural world around us, especially as regards its everyday happenings throughout the year, and part of the confessed difficulty about it is that it means having the mind in order in regard to many different sets of facts.

As regards animal life, the teacher should in particular think over the following general themes, to each of which we have devoted a section in this introductory chapter :-

I. The characteristics of living creatures.

2. The everyday activities of animals.

3. The behaviour of animals.

4. The periods of life.

5. The resemblances and differences between plants and animals.

6. Inter-relations.

Section I.-The Characteristics of Living Creatures.-Everyone feels that plants and animals are very different from things which are not living, but no one is wise enough to tell what 
the most essential difference is. The teacher who knows his business will certainly not trouble the young mind with attempts at defining life; but, as a real acquaintance with living creatures grows wider and deeper, he may help the pupils to feel more vividly and precisely that plants and animals have more in common with them than stones or clouds or machines have. $\mathrm{He}$ may help the senior pupils to feel the difficulty of arriving at any sort of idea of what livingness means. The following summary may be found useful.

(a) From the Biologist's Poini of View.-Living creatures have the power of growing, of growing not as a snowball grows, but by a unifying incorporation; nor even as a crystal grows, at the expense of dissolved material chemically the same as itself, but at the expense of material quite different from itself. The grass grows at the expense of air, water, and salts, which, with the sun's help, it lifts into the circle of life, and at the expense of the grass the weaned foal grows into a horse. [Show the growth of a crystal of alum. Contrast different kinds of food.]

Another characteristic of living creatures is their cyclical development. The germ of a plant or animal develops quickly or slowly into an adult; this gives origin to new lives, and then there is a quick or slow down-grade ending in death. Out of the apparent simplicity of the embryo the obvious complexity of the full-grown creature develops; but, as Huxley put it, "no sooner has the edifice, reared with such exact elaboration, attained completeness than it begins to crumble." We find notliving things passing from one form to another-the water vapour gathering around dust-particles becomes mist, which rises into a cloud, which is dissolved in raindrops, which freeze into hailstones, which melt into water, and so on ; but in the development of the living creatures there is orderly progress, in part regulated from within, and there is a continuation of the race though the individuals die. [Arrange a series showing transformations in not-living things, e.g. vapour, fluid, solid forms of the same substance. Arrange a series showing the development of a plant or animal, e.g. seed, seedling, sapling, flowering branch; or, the life-history of a butterfly or beetle. 
To illustrate growth without marked change, it is useful to have a series showing different stages, e.g. of a common shell or of the adolescent shore-crab.]

Another characteristic of living creatures of all sorts and sizes is their power of effective response. The barrel of gunpowder responds to a spark, but it responds self-destructively. The living creature's response is usually self-preservative or, in any case, in the direction of self-preservation. It may not be always successful in its answer, especially when it gets into unwonted conditions, but it is characteristically effective. It may be killed by a flash of lightning-to that no answer is possible, but in the ordinary course of its life it is always giving answers which make for continuance or betterment. Moreover, it does not merely react to outside stimulus, it acts. It does things in a sense which cannot be said of a lifeless object. [Throw a piece of potassium on a basin of water, and show it rushing about, fizzing and flaring until it goes out. Contrast this with the movements of a whirligig beetle (Gyrinus natator), which does not "go out" for a long time. Its activity is rich in effective responses. Show the effective responses in some plants, e.g. the tendril coiling round a support, or the stigma of Mimulus closing on the pollen.]

Without going further into the subject, we may sum up by saying that living creatures have the power of growing, of cyclical development, and of giving effective responses. But these characteristics may be brought together under the general idea that living creatures are like ourselves in having, each according to its measure, a persistent unified activity, which, in its higher reaches at least, is worthy of being called behaviour. So we come back to what the young child would most naturally say: that living things differ from not-living things in being like ourselves. [Illustrate with reference to the behaviour of common animals, and show that the same sort of thing is seen, within limits, in plants, e.g. in their movements. It need hardly be said that there should be no mention in class work of such technical phrases as "cyclical development" and "effective response," and that the three characteristics should be suggested merely by questioning the pupils after showing significant contrasts. such as the growing 
crystal and the growing caterpillar, the piece of potassium and the whirligig beetle.]

(b) From the Physicist's Point of View.-The living creature is like some wonderful kind of engine or machine, but it is more efficient. Like an engine it transforms matter and energy, but it does so more economically. It is a self-stoking, self-repairing, self-preservative, self-adjusting, self-increasing, self-reproducing engine! It has a remarkable power of accumulating and storing energy, of taking rests, of " acting of its own accord," of profiting by experience. In comparing a living creature with a machine, which is a very useful analogy to work out with pupils advanced enough to understand it, it should always be remembered that a machine is hardly a fair sample of the inorganic world, since it is the embodiment of a human thought.

(c) From the Chemist's Point of View.-The component elements of living creatures are just the common elements found in their surroundings, but the "make-up" of the compounds which form the physical basis of life is very intricate. The chemical elements which enter into the composition of organisms are: carbon, hydrogen, oxygen, nitrogen, sulphur, phosphorus, chlorine, potassium, sodium, calcium, magnesium, and iron; and there may be others. Of these elements the first five enter into the composition of the most characteristic of organic compounds which are invariably present in living creatures, namely, the proteids, such as the albumin of eggs, the hæmoglobin of our blood, or the gluten of wheat. It is probable that living matter is a mixture of proteids, owing its virtue to their co-operative interaction, just as the secret of a firm's success may depend not on any one partner by himself, but on the combination of talents. In the living body we can trace a number of chemical processes which follow one another in a sort of routine. We can trace the raw material of food being digested and incorporated into the living body; we can detect the breaking-down of complex substances and the getting rid of waste; but we cannot redescribe the unified life of the creature in terms of chemical formulæ. It seems certain, however, and this is perhaps the most significant feature from the chemist's point of view, that there is a twofold 
process of building up and breaking down, of construction and destruction, and that ferments play a very important part. [If there is sufficient knowledge of chemistry, arrange a series of carbon compounds, from relatively simple ones to the height of complexity in proteids. Thus the formula of egg albumin is often stated as $\mathrm{C}_{204} \mathrm{H}_{322} \mathrm{~N}_{52} \mathrm{O}_{68} \mathrm{~S}_{2}$. Compare the body with a manufactory, noting the raw materials, their early transformations, the finished products, and the waste products. But we have very little knowledge as yet of the "secret room" in the manufactory where the gist of the business is hidden.]

Summary.-Although no one is wise enough to tell completely what is meant by the simple word alive, it is safe to say that active life involves the following facts-(a) The living organism has the power of growth at the expense of material different from itself. (b) The living organism has usually the power of reproducing other organisms like itself. (c) The living organism is subject to ceaseless chemical change, in which the complex substances known as proteids are essentially involved, and yet it has the power of persistence, of remaining more or less the same for prolonged periods. (d) The living organism gives effective responses to external stimuli; it has a power of control and selfregulation, it has a unified behaviour.

Section 2.-The Everyday Activities of Animals.-There is a contrast between everyday activities, which are always going on, and the periodic activities of growing and reproducing.

The everyday activities or functions of the animal body are five. There are the two "master-activities" of contractility and of irritability, of the muscular and of the nervous systems respectively, of moving and feeling in the wide sense. These make life worth living. On a different plane are the three " auxiliary" or "sustentative functions" which keep the two master-activities agoing. These are nutrition, including the ingestion, digestion, and final incorporation or absorption of food; respiration, including the absorption of oxygen (really a gaseous food) to keep the vital combustion agoing, and the elimination of carbon dioxide (really a gaseous waste); and excretion, the filtering out of the nitrogenous waste,-part of the ashes of the living fire. 


\section{INTRODUCTORY PROBLEMS}

There are so many excellent introductions to the study of physiology, of which Huxley's Elementary Lessons remains best, that we need not expand this section. It is very important that the pupils should be helped to clear ideas in regard to the everyday functions of contractility, irritability, nutrition, respiration, and excretion, and there are many simple and innocent practical experiments which are of use. It is not much that the pupil should blow his breath into lime water, and by seeing it become cloudy, infer that he breathes out carbon dioxide, but it is of more value than many definitions of respiration. It is instructive to show artificial digestion in a test-tube, to demonstrate that it may mean making a very solid piece of food fluid and diffusible, and to show that the same occurs on the leaf of the butterwort on the moor. The teacher should show at least a dozen of these simple experiments before he allows the pupils to speak of " the functions of the animal body."

The Physical Basis of these Activities. -When we take an animal to pieces we find, unless it be one of the very simple animals, that it consists of numerous organs such as brain, heart, stomach, and so on. Penetrating somewhat deeper, we find that these organs are built up of various kinds of tissue,-nervous, muscular, glandular, connective, and the like. But a tissue is composed of numerous similar unit-corpuscles or unit-areas of living matterthe cells, and each cell is a little world in itself. If we compare an animal to a city, an organ is like a region of the city given over to some particular occupation or industry, here a block of government offices, and there a manufacturing quarter; a tissue is comparable to a street of similar houses or workshops; a cell is an individual house or workshop, and the inhabitants or workers are the particles of living matter. The history of the science shows that there has been a gradually deepening analysis, though research at every level still continues, and must for a very long time continue.

The physiologist who studies vital activity must pass from his observation of the animal as a unity with certain habits, to consider it in succession as an engine of organs, as a web of tissues, as a city of cells, and as a whirlpool of living matter.

School studies, recapitulating the history of the science, 
should have primarily to do with intact creatures whose habits are observed. But it must be borne in mind that this is only a beginning; judiciously chosen opportunity must be taken to show that the life of the animal as a whole is the sum of the activities of its parts, although in a way that we do not understand it always seems to be more than this, just as the action of a society as a whole always seems more than the sum of the actions of its component individuals. In the deepest sense we may say that there is in both cases an esprit de corps that counts.

Another important point is this, that just as we must try to deepen our study of an animal's behaviour by inquiring into the activities of its parts, so we must remember that there is a "higher physiology" than that of the individual. The animal is probably one of a pair; it has a mate or mates, it may have a family, it may be a member of a community, it is a unit in a species, it is one of the components of a large Fauna. This study of the relations of animals to their kin, the study of their family and social life, is of great interest, and should bulk largely in a Nature-Study course.

Relation of Animals to their Surroundings.-The organism lives in dependence on an appropriate environment. It cannot live normally except in certain variable conditions of nutrition, aeration, moisture, pressure, temperature, illumination, etc. All these influences make up its environment, and function is for the most part action and reaction between the organism and its environment. We may express this diagrammatically.
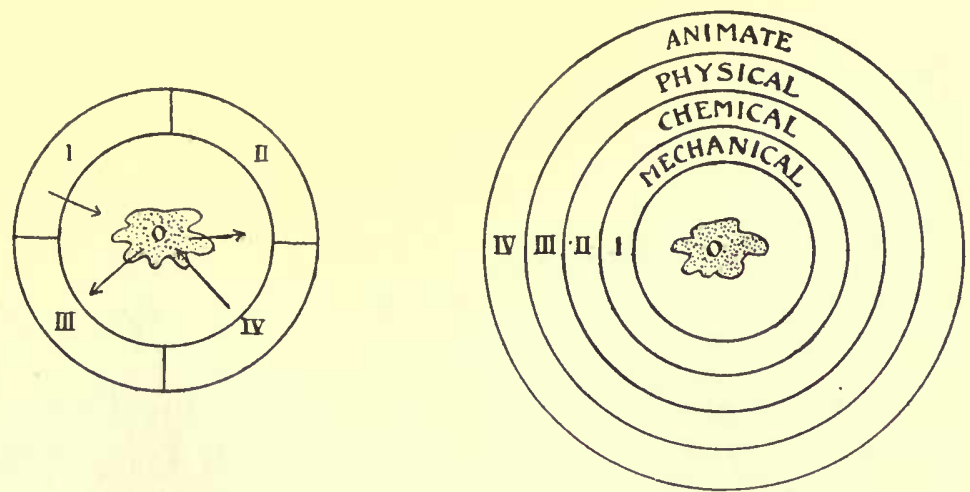

FIG. I.

O, Organism surrounded by its environment. The arrows indicate action and reaction.
$\mathrm{O}$, Organism surrounded by successive spheres which indicate its environment. 
Just as in human affairs we are always thinking of people, place, and work, so in biology we are always thinking of organisms, environment, and function.

Sometimes it seems to us as if the living creatures were thralls in the grip of a tyrannous environment, and we use the words in the order-environment, function, organisms. At other times, particularly among the animals with better brains, it seems to us as if the living creatures were to a remarkable degree masters of their fate, selecting their environment, using it, modifying it. We then use the words in the order-organisms, function, environment.

The circular diagram suggests an analysis of the surroundings of an animal into successive spheres of influence-(I.) Mechanical, such as pressures, gravity, currents, etc.; (II.) Chemical, such as the nature of the food and drink, the salinity of the water, the composition of the soil; (III.) Physical, such as the conditions of heat, light, and electricity ; and (IV.) Animate, the direct influence of neighbours, fellows, messmates, parasites, etc.

It need hardly be pointed out that there are relations between a living creature and its surroundings which are normal and usual, and that changes in these relations may be followed by temporary or permanent, individual or racial adjustment on the part of the organism, including, of course, any device by which the organism evades the change altogether. In other cases the relation between an animal and its surroundings is too subtle to admit of more than a slight change. More than that is fatal.

Section 3.-The Behaviour of Animals.-In spring and summer the school nature study should include much observation - as far as possible in the open air-of the works and ways of animals, such as ants, bees, wasps, spiders, earthworms, snails, birds. Their behaviour may be conveniently studied under the heads :-

Seeking for food, preparing it, storing it.

Making shelters, hiding-places, homes.

Adjusting themselves to their inanimate surroundings, e.g. in migration, concealment, change of colour.

Adjusting themselves to other creatures, e.g. in combat.

Finding mates, and it may be "courting" them.

Preparing for, feeding, protecting, even teaching their young. 
It is interesting and suggestive to find among animals the analogues of human industries-hunting, fishing, shepherding, farming, storing, making homes, etc.

The mental aspect of animal behaviour is elusive and difficult, and the teacher must try to avoid the extreme of reading the man into the beast, endowing the bee or the bird with the best human attributes, and the other extreme of thinking and speaking of the creature as if it were an automatic machine. Of the two extremes, the second is the worse, for the fundamental fallacy in regard to living creatures is to ignore their creativeness.

It may be useful to point out that animal activities occupy, as it were, successive areas on a long inclined plane, and may be thus arranged. But this is of no use unless the teacher can follow it up by reading such a luminiferous book as Lloyd Morgan's Habit and Instinct.

7. Rational conduct in man requiring conceptual inference.

6. Intelligent behaviour, requiring perceptual inference.

5. Habitual behaviour, which originally required intelligent control.

4. Instinctive behaviour, as in ants and bees.

3. Complex reflex actions, as in walking.

2. Simple reflex actions, e.g. the knee-jerk.

I. Automatic internal activities, e.g. the beating of the heart.

A Scheme of Study.-It often happens that living specimens of a peculiarly interesting kind are available for study close by the school, or may be had as loans for exhibition in school, and yet they are not adequately utilised for lack of a scheme. There are many possible schemes, and the best one is probably that which the teacher thinks out for himself. The point is to get into the habit of almost automatically asking a certain rational set of questions in regard to an animal, to have a method of intelligent inquiry.

Professor M. F. Guyer writes : "Animals, from their own point of view, have two and only two occupations in the world. These are (I) to care for themselves, and (2) to care for their offspring. Consequently, every important thing to be seen about an animal 
has to do with one or the other of these pursuits." Professor Guyer's scheme of study, slightly modified as to details, is as follows :-

\section{The Business of Animals.}

I. To care for themselves.

(a) Food.-What do they eat? How do they find it? How do they get to it? When do they feed ? How are the mouth parts and other parts suited for getting and using the food, e.g. catching, killing, eating ? Do they use any peculiar devices, e.g., lying in wait? Do they use things outside themselves, such as snares, in getting their food? Do they swallow it, chew it, suck it, or what? Do they store food?

(b) Self-protection.-What enemies have they ? Do they seek to escape from them, or do they try to cope with them? Have they armour or weapons or both? Are they palatable? Have they any special habits that are self-preservative, such as changing colour quickly, "feigning death," rolling themselves up into a ball, burrowing, coming out at night? Are they helped by special fitness of structure, e.g. colourresemblance or form-resemblance to other things? Do they help one another? Are they social or solitary? Have they a home or shelter? What special risks are associated with their life-history? What special risks are associated with their habitat?

(c) Adjustment to Physical Surroundings.-Where do they live? Why here and not there? How are they specially fitted for their particular habitat? Do they act upon their surroundings in any marked manner? Are they directly changed by changes in their surroundings? How are they adjusted to vicissitudes, such as cold, heat, drought, storms, the seasons? How long do they live? 
II. To care for their offspring.

Do they lay eggs? If so, where, when, and how ? Do they bring forth young ones as such? Are these miniatures of the parents, or are they at first very unlike the parents? How do the parents secure the safety of their eggs or young ones? How many do they produce at one time? Do they feed their young, guard them, tend them, teach them? For how long do the young ones remain immature? What are the relations between the two parents, if there are two parents? Do both help to care for the young?

Section 4.-The Periods of Life.-Every organism reproduced in the ordinary way begins its individual life as a fertilised egg-cell. This divides and redivides, the resulting cells begin to grow and continue to divide, they group themselves in layers which are variously pouched and folded, division of labour sets in, and apparent simplicity is replaced by obvious complexity. We speak of the developing animal as an embryo, until it is " hatched," i.e. freed from the egg envelopes. When the young creature that emerges from the egg is very unlike the parentbuilt on a different architectural plan-it is called a larva, and in such cases (e.g. caterpillars, tadpoles) there has to be a profound structural change (a metamorphosis) before the distinctive characters of the fully formed type begin to be assumed. After these are attained there is a longer or shorter period of growth or adolescence, which continues until the sexual maturity is attained. In the majority of cases the advent of reproductive power is associated with the limit of growth, that is, with reaching a definite size-probably the most useful and effective size for the type. Then follows a longer and shorter period of maturity, of full vigour both in work and reproduction. Sooner or later the arrears of bodily wear and tear and the expenses of reproduction begin to tell, waste is no longer quite made good by repair, and the animal passes into senescence, ending in death. It is useful to try to make curves expressing in diagrammatic form the different kinds of life-histories. There may be a long 
youthful period and a very short period of maturity, as in the case of may-flies or ephemerids, many of which spend two or three years as larvæ in the water, and not more than two or three days as adults in the air. Or conversely, there may be a rapid development and a short youth, followed by a long period of maturity, as in the case of many birds and mammals. In other cases, as in most fishes, there is no definite limit of growth, and the animal goes on for years steadily growing larger and larger.

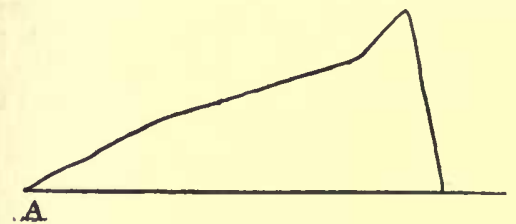

Long adolescence. Short maturity. Death soon after maturity.

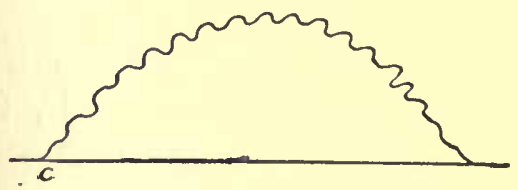

Minor waves on general life curve.

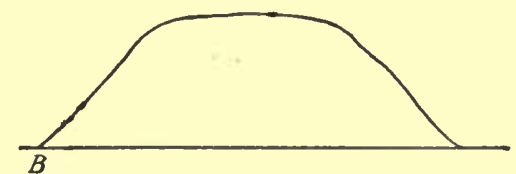

Short adolescence. Long period of maturity. Gradual senescence.

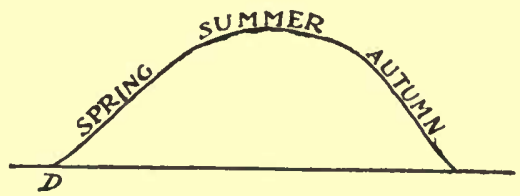

Seasonal curve.

Fig. 2.

We suggest this as a graphic method, and leave the idea to be elaborated. It should be pointed out-(I) that a similar curve may be used to express the year's life of an animal, summer being the period of maximum vigour at the crest of the curve ; (2) that when the animal lives for many years the fluctuations of its rate of growth, etc. (literally registered in the case of fishes in the lines on the scales) may be expressed by minor waves on the general curve (as in Fig. 2, C.) ; (3) that very few wild animals show any traces of degeneracy even when they live for many years,- they have a senescence without senility; and (4) that it is important to distinguish violent death (which befalls such a large proportion of wild animals) from microbic death due to poisoning by parasites, and from natural death due to the accumulation of the effects of wear and tear.

Section 5.-Resemblances and Differences Between Plants and Animals. - (a) Resemblances in Function.-That the 
life of plants is essentially like that of animals has been recognised since Claude Bernard wrote his famous book, Phénomènes de la vie communs aux animaux et aux végétaux. The beech tree feeds and grows, digests and breathes, as really as does the squirrel on its branches. In regard to none of the main functions except excretion is there any essential difference, though there are, of course, great differences in detail. Many simple plants swim about actively; young shoots and roots also move; and there are many cases in which even the full-grown parts of plants exhibit movement. The tendrils of the pea, the leaves of the sensitive plant, the tentacles of the sundew, the stamens of the rock-rose, the stigma of the musk, and many other plant structures exhibit marked sensitiveness. It is instructive to take a case like that of Venus's Fly-trap (Dionaa muscipula), which closes its leaves on flies. There one finds not only sensitiveness, but specialised sensitiveness, for the plant's tactile hairs do not respond to every kind of touch; one observes curious phenomena almost like memory; one sees rapid movement, and finds that this is associated with an electrical change comparable to that observed when an animal muscle contracts; one finds a digestive ferment not unlike that of the animal stomach. It is important, too, to make quite clear-and illustrative experiments are easy-that if we have in a room at night a burning candle, a growing plant, and, say, a mouse, all three are using up the oxygen of the air and returning to it the carbonic dioxide formed as a waste in the combustion of carbon compounds.

(b) Resemblance in Structure.-The simplest plants (Protophyta), like the simplest animals (Protozoa), are single cells, unit corpuscles of living matter (often very elaborate in their own way); all other plants (Metaphyta) and all other animals (Metazoa) are built up of numerous cells and modifications of cells. In short, all living creatures have a cellular structure. This general conclusion is part of the cell theory or cell doctrine (I838). It may be illustrated, when a microscope is available, by showing the similarity between a piece of epidermis from a plant and another piece from an animal, or by comparing a section of a soft stem with a section showing the supporting skeletal rod (notochord) of an embryo fish. In any case, it is 


\begin{tabular}{|c|c|c|c|c|c|c|c|c|}
\hline 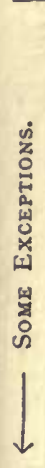 & & 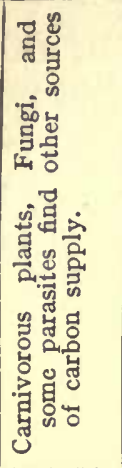 & 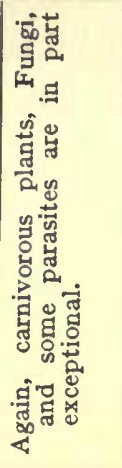 & 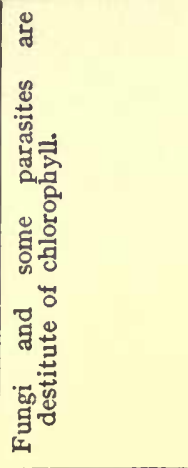 & 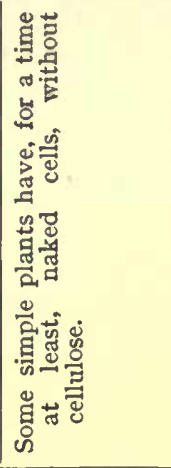 & & & 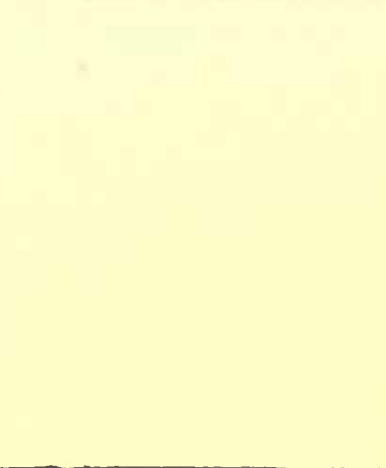 \\
\hline 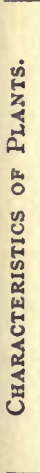 & 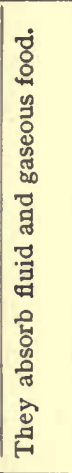 & 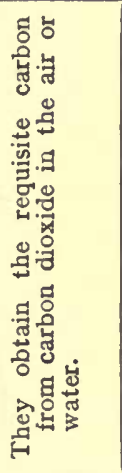 & 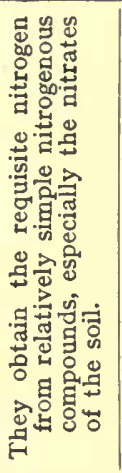 & 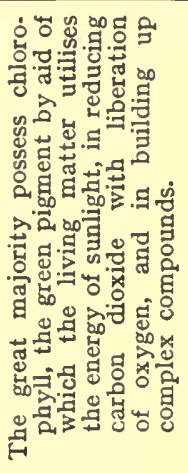 & 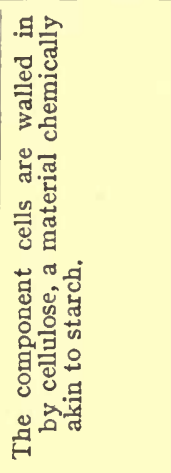 & 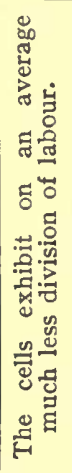 & 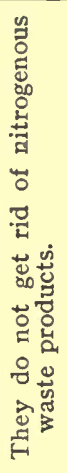 & 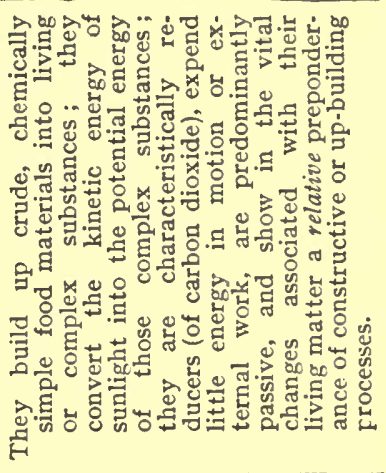 \\
\hline 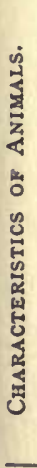 & 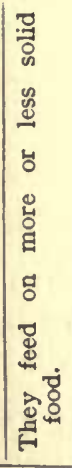 & 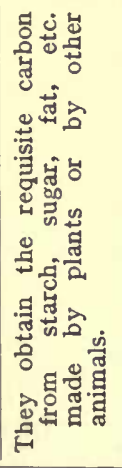 & 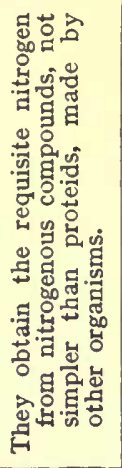 & 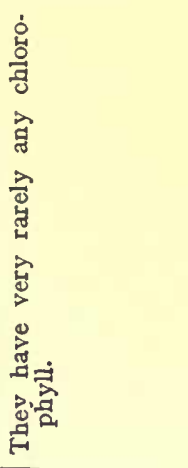 & 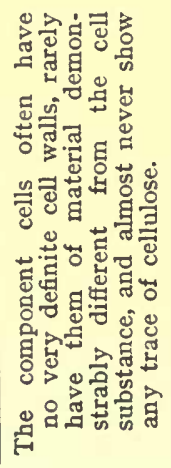 & 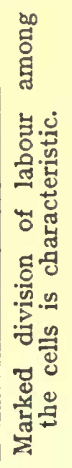 & 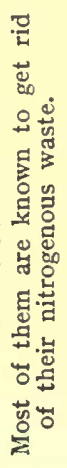 & 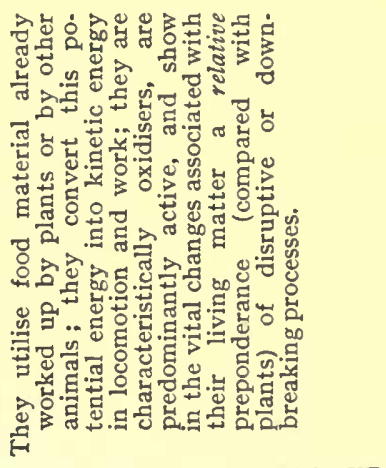 \\
\hline 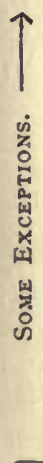 & 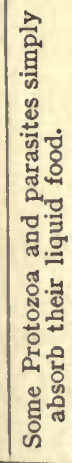 & 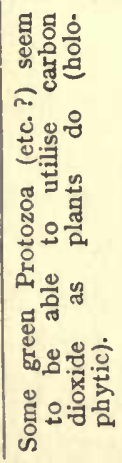 & 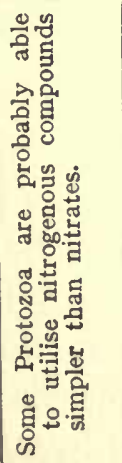 & 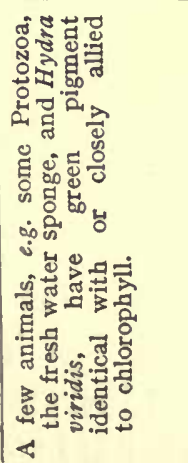 & 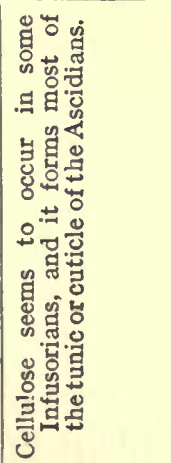 & & & \\
\hline
\end{tabular}


easy to draw a slide over the lips dislodging some of the flat epithelial cells, and to compare these with a strip of transparent skin peeled off a tulip leaf.

(c) Resemblance in Development.-When we trace the beech tree back to the beginning of its life we find that the sapling grew from a seedling, which came from an embryo within the seed, and that this embryo arose from a unit element or egg-cell fertilised by intimate union with another element derived from the pollen grain. When we trace the squirrel back to the beginning of its life we find that it also arises from a unit element or egg-cell, borne by the female parent, which is fertilised by intimate union with a male cell or spermatozoon-produced by the male parent. Indeed, all many-celled plants and animals begin as fertilised egg-cells, except in cases of virgin birth (parthenogenesis), or of asexual reproduction. From the egg-cell, which divides and redivides after fertilisation, the body of the plant or animal is built up of continued division, arrangement, and modification of cells.

Summary.-Plants and animals resemble one another in their essential functions, in their cellular structure, and in their manner of development.

Contrasts.-While there is no absolute distinction between plants and animals, they represent divergent branches of a Vshaped genealogical tree. It is easy to distinguish extremes like bird and daisy, less easy to contrast sponge and mushroom, and well-nigh impossible to decide whether some very simple forms have a bias towards plants or towards animals. We cannot do more than state average distinctions.

As it is unnatural to the child's mind to care much about the difficulty of finding absolute distinctions between two kinds of creatures which seem as different as possible, we propose to condense the time-honoured discussion into a table (page I5).

Section 6.-Inter-Relations.-Much more important from the nature study outlook than "the distinctions between plants and animals" are their inter-relations. (a) Plants are able to feed on air, water, and salts, but animals have no such power of living on the inorganic; it follows, therefore, that in the long run animal life depends on plant life for its continuance.

(b) The 
dead animal rots away, that is, it is reduced by bacteria to relatively simple salts and gases which may form the food of plants. (c) Green plants are able, with the help of the sunlight, to utilise the carbon dioxide which is given off as a waste gas from animals. (This waste gas is also necessarily produced by plants, but this is disguised during the day by the peculiar nutritive process, the first step in which is the reduction of carbon dioxide. The liberation of carbon dioxide by plants must be studied in parts which are not green, e.g. seeds, or at night, when the nutritive process has stopped.) (d) There is an inter-relation of incalculable practical importance between insects and flowers, since the insect visitors secure pollination. (e) There are scores of other familiar inter-relations of great interest, such as those implied in the diet of carnivorous plants, in the formation of galls, in the remarkable mutually beneficial partnership between certain unicellular algæ and certain animals (Symbiosis).

The study of the inter-relations among animals is not less fascinating. We may refer to the occurrence of quaint partnerships, as of crocodile and crocodile-bird; the closer "commensalism " illustrated by certain hermit-crabs and their companion sea-anemones; the frequent occurrence of parasitism; such quaint phenomena as are presented by the existence of " guests," "pets," and even "domestic animals " among ants; the establishment of complex domestic and social relations, and so on.

It may be said that of all the general ideas that it is useful for the teacher to be at home with in relation to nature study, there is none so fundamental as this idea of the web of life, the working out of which was one of the most important of Darwin's contributions to science. It comes to this, that no plant or animal lives or dies to itself.

Bibliography.-Gamble's Animal Life (London, 1908); Thomson's Study of Animal Life (John Murray, London); and Science of Life (Blackie \& Son, Glasgow). 


\begin{abstract}
M A M M A LS
By W. P. Pycraft, F.Z.S.

Assistant in Charge of the Osteological Collections, British Museum (Natural History)
\end{abstract}

\title{
CHAPTER II
}

\section{Beasts of THE Field}

THAT Nature Study, properly taught, is one of the best possible means of training children to use their powers of observation, and of inculcating precise methods of thinking, there can be no question. But, in one particular, those who have undertaken this very difficult task seem to have adopted a quite inexplicable position. Briefly, they have chosen, most unreasonably, to foster the old and most confusing use of the term animal. The writer of these lines is almost daily brought into contact, in an official capacity, with teachers who use this word as though it designated, not all living organisms which cannot be described as plants, but only such as horses, oxen, dogs, and so on ; the rest of the animal kingdom being made up according to this standard, of birds, reptiles, fishes and so on.

But surely if children are to be taught to value the use of words, and to be methodical and discriminating in that use, it is time that this state of things was changed; that, in short, they should be made to understand, and grow familiar with, the use of the word Mammal as a word of the same value as bird, reptile, fish, etc. They should be taught that an elephant and eel are alike animals, but that the one belongs to the group of animals known as mammals, and the other to the group known as fishes.

It is assumed that the aim of the teachers of Nature Study is to inculcate, as we have already remarked, habits of observation; and further, to enable their scholars to take a deeper interest in living creatures. This they cannot effectually do unless they can form a mental image of the essential differences between the 
different types of animals. We say the essential differences advisedly; for there should be no sort of attempt to cram children with the dry facts of the dissecting-room or the technical details of the text-books. The broad facts must suffice, such as will bring home to their minds the definite relationship which animals-and plants too for that matter-bear to their external surroundings: the significance of the shapes of animals and their distinctive and varying methods of doing the same thing; whether this relates to motion, feeding, breathing, or avoiding enemies.

But this knowledge is not to be imparted in the form of cutand-dried facts, to be committed to memory and produced by suitable questions. Rather, children must be taught to absorb these matters through the stimulus of a real interest. But if they are not to unlearn much of what they have acquired, they must be trained to think clearly. And this brings us back to our point-the slovenly use of words. To-day the word "Mammal" has almost an uncouth sound to many, but only because it is unfamiliar. Those who cannot overcome their objection, however, may substitute the word beast. But this is open to many obvious objections. It is, however, far preferable to the misuse of the term " animal," for the reasons already pointed out.

What, then, are "Mammals"?

In a word, "Mammals" are animals which nourish their young by milk, and whose red blood-corpuscles have no nucleus or " kernel." They form a group quite distinct from all other animals.

Of the many other characters which they share in common it should be sufficient, for the purposes of this book, to give but a few of the more important. Of these the bony framework, or skeleton, may very properly be taken first. As this presents a remarkable range of differences in structural details-a feature which is true of all the other parts of the body-this framework will be described only in general terms in this chapter. And it will be the aim of later chapters to bring out the various ways in which this skeleton, and the various other parts of the body which clothe it, have become changed in accordance with what we may briefly, if vaguely for the present, describe as the force of circumstances. 
The Skeleton.-Let us begin with the skull. The skull of the mammal may at once be distinguished from that of all other

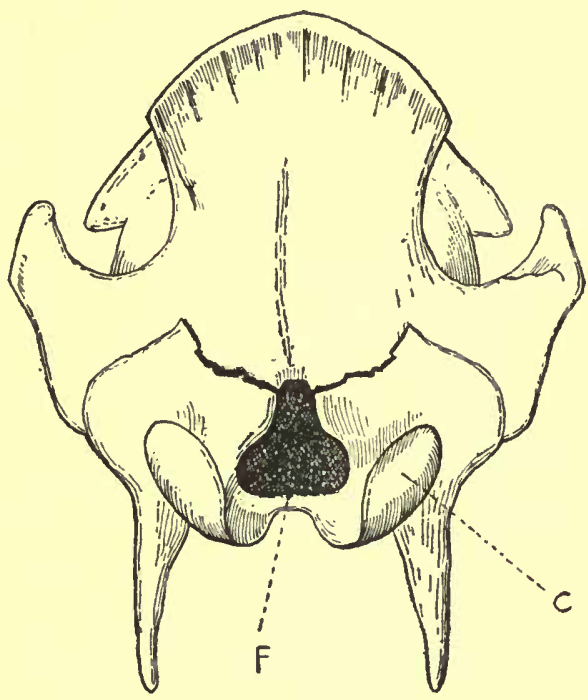

Fig. 3.-Back of the skull of a pig to show the bony "bosses" or "condyles" for the attachment of the vertebral column. C, condyle; F, foramen magnum, the aperture by which the spinal cord passes into the brain. animals-except frogs and toads and their kind - by the fact that it joins the backbone or spinal column by means of a pair of bony " bosses," known as the condyles, placed one on each side of the opening through which the spinal cord, or "marrow," passes from the brain (Fig. 3). Next, it is to be noted, the lower jaw is hinged directly on to the skull, not by means of an intermediate and generally loosely slung bone, as in birds and reptiles, for example. Then the lower jaw itself is composed, as to its right and left halves, of a single bone, and not of several pieces, as it is again in birds and reptiles (Fig. 4). Finally, the number and relations of the several bones which form the cranium or brain case, and the upper jaws, differ in many very important particulars from what obtains in other vertebrated animals. But these are details which are of far too technical a character to be described here.

In nearly all mammals the jaws are armed with teeth which, in some groups, are all of the same pattern, as in the curious sloths and armadillos, and in the dolphins and porpoises; but as a rule these teeth present considerable difference in size and shape in different regions of the jaw, according to the peculiar food of the animal and the method of feeding. These differences are well seen in the dog, for example (Fig. 4). Here in the front of the jaws, on the right and left sides of the head respectively, will be seen three small teeth, known as the "incisors" or "cutting" teeth (Fig. 4, i) ; next follows a long and powerful tooth known as the "canine." Behind this come four teeth having 
peculiar pointed crowns known as the "pre-molars," and two much larger "molars." These pre-molars and molars form the "cheek-teeth." Their work is to chew up the food torn off by the cutting teeth. The study of the different forms of teeth

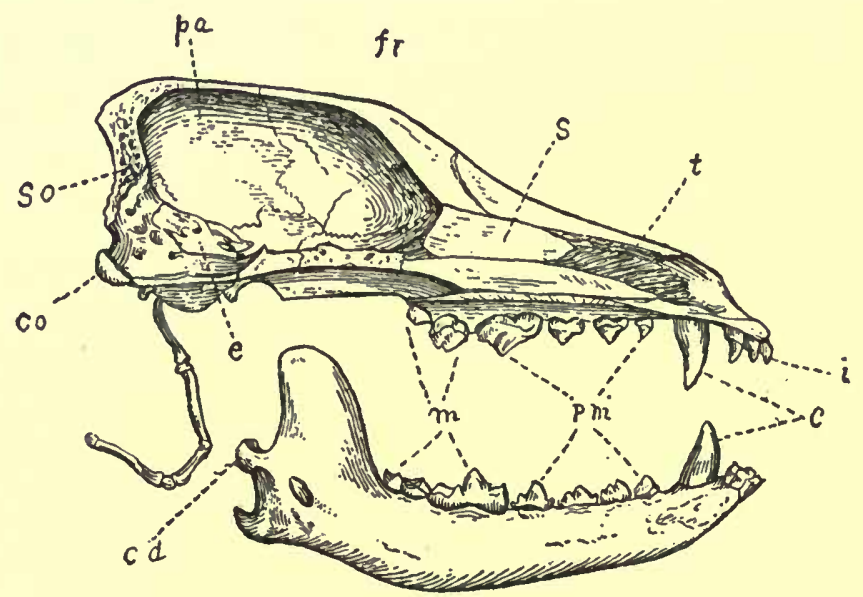

FIG. 4.-Section of the skull of a dog showing the different forms of the teeth, the general features of the skull. $i$, incisors ; $c$, canines ; $p m$, pre-molars ; $m$, molarsthe pre-molars and molars form the "cheek-teeth"; $c d$, condyle of lower jaw for attachment to the skull; co, condyle of skull for articulation with spinal column; so, supra-occipital bone; $p a$, parietal bone ; fr, frontal bone ; $e$, bones of middle or internal ear; $s$, septum of nose ; $t$, "turbinals," the skeleton which supports the mucous membrane of the nose bearing nerves of scent, etc.

and their uses is one of the greatest interest, and something on this head will be found later in these chapters.

At the time of birth mammals are toothless. Very soon, however, teeth make their appearance, and these as a rule are shed, and replaced by a permanent set. Because the first set appear during the time that the animal is being fed upon milk they are known as the " milk-teeth."

The backbone, or spinal column, as may be seen in the outline drawing (p. 33), is made up of a series of separate bones having a more or less barrel-shaped body, and supporting an arch of bone (Fig. 5). In the living animal these barrel-shaped pieces form a long more or less curved rod, and their separate arches form a tube through which runs the spinal cord,-the great nerve supply, from which run the nerves which control the movements of the body and limbs, and convey the sensations. 
The backbone or spinal column differs from that of birds in one or two important particulars. In the first place, with

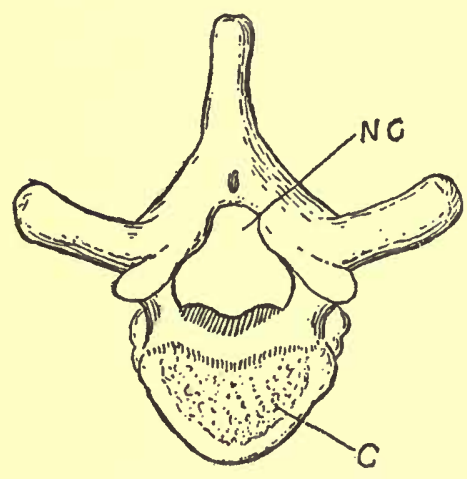

FIG. 5.-A vertebra from the spinal column of a man, showing the form of the solid body, or "centrum," and of the arches which protect the spinal cord.

a few rare exceptions, the number of the neck bones is always seven. And this is true alike of the giraffe, and the whale wherein in the living animal no visible neck is traceable. In the second place, the bones of the back, at least as far as the hip-girdle, to be described presently, are always separate. In birds, in quite a large number of groups, more or fewer of the bones are welded together toform asolidmass.

The vertebræ from the base of the neck to the middle of the trunk support the long curved rods of bone known as the ribs, which afford protection to the vital organs of the body-the heart and lungs, and digestive organs. The lower ends of these ribs are attached to the breast-bone or sternum, so that the organs just referred to are enclosed within a bony cage.

The scapulæ or blade-bones (p. 33), which form the supports for the fore-legs, and the pelvic bones, which similarly support the hind-limbs, differ fundamentally from those of birds, but these differences are hardly matters with which children need be troubled.

The limb bones, though differing markedly from those of birds, are composed of the same elements, as will be shown later. In most mammals the number of the toes has undergone more or less reduction. Originally five in number, as a rule, the foreor hind-feet, as the case may be, will be found to have fewer, and they may even be reduced to a single toe on each foot, as in the case of the horse. The bony framework of the limbs varies greatly among different groups of animals, as may be seen, for instance, by comparing the skeletons of say a lion, a seal, and a horse; the differences observable being related to the very different functions which these limbs have to perform. Birds and men alone walk upon the hind-limbs. Such mammals as progress 
upon two legs do so by leaping. The different parts of the fore and hind-limbs, and their several relationships to limbs of different types, will be explained on pages 35 and 44 .

During life these bones are clothed with flesh, and this "flesh," if carefully examined, will be found to be made up of an enormous number of separate bundles, eacin of which is again made up of a yet greater number of delicate fibres. Further, it will be found that each bundle is connected with at least two separate bones, and hence it is said to have an origin and an insertion. This arrangement is related to the fact that each of these bundles has the power of rapidly shortening or contracting when stimulated by its special nerve, and by this contraction the muscle moves that bone to which it is fixed at its insertion. To the orderly movement of these muscles the power of walking, breathing, eating, and so on is due. ${ }^{1}$

The muscles of the limbs commonly end in "tendons." That is to say, the muscle tapers off and passes into a different form of tissue, no longer "fleshy" but glistening, white and fibrous, and forming strong, elastic cords (see p. 27). This enables a great economy to be effected, not only in weight but also in bulk.

The Body Covering.-The skin in most mammals is covered with hair; but in many, as will be shown in a later chapter, other and often very remarkable coverings are found. Herein mammals differ from birds, wherein the body is without exception covered after the same fashion-by feathers.

The Heart and Lungs.-All mammals breathe by lungs, and have a heart made up of four separate chambers, whereby the blood can be thoroughly purified, which is not the case with the "cold-blooded" reptiles, wherein the heart has but three chambers.

The heart and lungs in mammals are enclosed within a separate chamber occupying the fore part of the body, or thorax (chest), and this chamber is shut off from the rest of the body cavity by a muscular partition known as the diaphragm or " midriff,"-an arrangement which is found in no other animals.

${ }^{1}$ Children might well be set to watch the swelling of the biceps muscle of the arm, when the hand is drawn up towards the shoulder; by way of an object lesson as to the significance of the "flesh" of animals, and as to the way in which this mass of flesh or " muscle" acts when, by the stimulus of the will, its fibres contract. 
The Senses. - The sense of touch is situated in the skin of the body generally, but is especially acute in the lips, the end of the snout, and the extremities of the limbs. In many animals it is further assisted by long, stiff hairs arranged around the mouth, as in the so-called "whiskers" or "vibrissæ" of the cat.

While in most mammals the sense of sight is well developed, there are many species which are almost blind; the bat and the mole, for example, having eyes so small as to require careful search for their discovery.

Similarly, the sense of smell is possessed by all the Mammalia, except perhaps the toothed whales. In some beasts it is extremely well developed. Dogs, for example, have so acute a power of scent that they can trace odours quite unappreciable to the human nose. Most of the hoofed animals, too, have a keen sense of smell. This sense is of great importance, for thereby many animals have to depend thereon to find their prey or to avoid their enemies.

Hearing is generally well developed among mammals. As an aid thereto many have developed very large external ears, which are capable of being turned in various directions to catch the sounds, as in the ass and horse. In the antelopes the ears are sometimes of great length, but the African elephant holds one of the highest places in this matter, since the ears in some races may attain a length of as much as six feet. But the animal with the longest ears, relatively to its size, is the little long-eared bat of our country-side, for herein this most useful sound conductor is longer than the whole body! (see p. 45).

Those species which live entirely in the water, such as seals and whales, and the mole among the land-dwellers, have no external ears whatever; and probably for the following reasons. To the mole external ears would be much in the way, for it spends nearly its whole life in underground burrows ; while to sea-dwellers, like seals and whales, projecting ears would be of little or no value; on the contrary, they would be rather in the way during rapid movement through the water. Such sound as it may be necessary for these creatures to perceive is conveyed through a very small tube leading from the surface of the head to the organ of hearing within the skull (Fig. I4, p. 49). 


\section{CHAPTER III}

\section{Some Common Animals-Cats and Dogs}

HAVING now traced the main outlines of the structure of the animals which make up the class Mammalia, an attempt may be made to indicate the different types of mammals which have come into being. From the evidence afforded, on the one hand by fossils, and on the other by the study of the early stages of development, and of the anatomy of the adult stages of these various types, we learn that they have arisen by a process of slow and orderly growth from ancestors of more simple character. Thus the ancestors of the deer had no antlers; the ancestors of the elephants were quite small creatures resembling the "dassies" of South Africa - the "coney" of the Bible; the ancestors of the horses were little bigger than a good-sized dog, and possessed five toes on each foot. Further, creatures now so unlike as horses and hoofed animals generally, on the one hand, and the carnivorous types, such as bears and lions on the other, can be traced to a common ancestral type. Evidence in support of this can be found in the more advanced scientific text-books, or in, say, the British Museum. The purpose of these chapters is to show the uniformity of plan which may be traced in the framework of the most unlike types; and to indicate the ends which have been gained, so to speak, by the departures from the common ancestral type, now in one direction, now in another.

No better beginning could probably be made than by comparing such familiar animals as the cat and the dog.

Cats and Dogs Contrasted. - These two animals, it should be noted, have for countless generations been the constant companions of man. In the course of time, man, by careful breeding, has done much to change the external form and increase the docility and usefulness of the dog, but has succeeded in effecting but little change in the cat. And this because the dog, like man, 
is a creature of gregarious instincts: in a wild state, living in packs under a leader; in domestication, and divorced from his kind, clinging to human societies. The cat is by nature a solitary animal, used at all times to fend for itself, and hence incapable of being trained, as dogs are trained, to minister to man's needs.

The different breeds of dogs which are to be met with to-day have nearly all sprung from the wolf. Some races have, however, probably been derived from the fox, and jackal. From these primitive stocks, however, man has bred a great and striking variety of forms, ranging in size from " toy " dogs, such as Maltese terriers and Japanese spaniels only a few inches high, to the great deerhounds, danes, mastiffs and Newfoundland dogs: while extremes of form are well illustrated by such types as bull-dogs, bloodhounds and dachshunds, hairless dogs, skye terriers, and " corded" poodles.

Cats and dogs are both flesh-eaters, and prefer living prey to carrion; and while the dog hunts by scent, the cat and its kind hunt by sight. The various races of wild dogs hunt, as we have remarked, by day and in packs, and their prey, when overtaken, is pulled down by numbers and torn in pieces, hence they have developed great speed in running, and have long jaws armed with powerful teeth. The feet play no part in holding the prey, and hence are provided only with blunt claws to protect the toes.

The cat, on the other hand, after the manner of its kind, hunts alone, by stealth, and at nightfall. Hiding in some spot where experience has shown prey will pass, it springs upon its victim with a sudden bound, and, fastening itself thereto by means of powerful and sharp claws, disables or kills, by a well directed grip of the jaws. The larger cats, such as lions and tigers, often kill their prey by a blow of the fore-paw ; the smaller cats, however, commonly stun their victim, and then, before killing, play with it, as cats, for example, play with a mouse.

Being nocturnal, the eyes of cats differ from those of dogs in that the pupil of the eye is more sensitive to strong light. Consequently in daylight this takes the form of a vertical slit, as the light wanes this slit opens till finally the pupil is circular and of great size. Similarly, the claws being used for the capture of prey, provision has to be made to keep them sharp. To this 
end they have become " retractile," or capable of being drawn up into a sheath, so that the points shall not be worn down in walking (Fig. 6). As the jaws are not used to pull down the prey they are shorter than in the dog, while the teeth are fewer but more powerful.

The large and small cats differ in one very interesting particular in their method of feeding; for while lions and tigers, for example, grip their food between the fore-limbs and tear off lumps of flesh with the teeth, the smaller cats tuck away the fore-limbs under the body, and shear off the flesh from the bones by means of the scissor-like " cheek-teeth." But both large and small cats agree with one another, and differ from the dog, in the extreme roughness of the tongue, which is beset with numerous hard, pointed bodies, giving the tongue the character of a rasp, whereby the last particle of flesh may be licked off the bones of their victims.

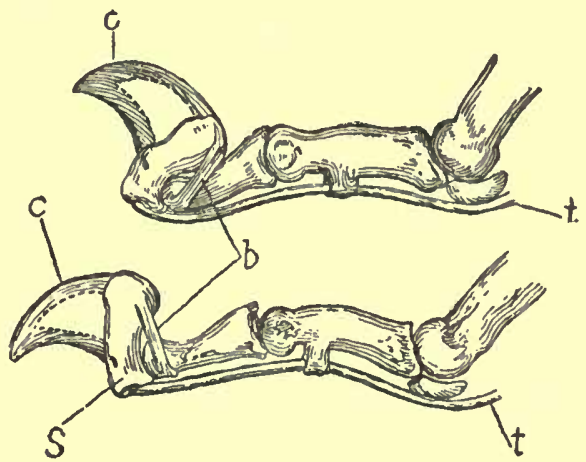

FIG. 6.-The toes of a lion, showing the position of the claw when extended and when retracted. $c$, horny sheath of claw ; $s$, the bony claw, the base of which is surrounded by a bony collar affording attachment to the horny sheath; $t$, the tendon which brings the claw into use; $b$, the tendon by which it is pulled back.

Dogs are more or less whole coloured, and, except hyænas, are never striped. Cats are generally either striped or blotched. When, as in the lion or puma, the adults are whole coloured, the young are striped and blotched.

The young of both the cat and the dog for some time after birth are perfectly helpless, and for many days cannot even see, the eyelids being sealed up. When first cpened the eyes are blue in colour, though later they change either to a dark brown or, as in the cat tribe, to some shade of yeliow or green. 


\section{CHAPTER IV}

\section{The Rodents or "Gnawing” Animals}

THE peculiarities of the flesh-eating, or carnivorous cat and dog, and their kind, will be the more readily appreciated if contrasted with, say, the herbivorous animals on which they feed when in a wild state.

The rabbit and the mouse well serve this purpose. Creatures of relatively low intelligence, they have, from the persecution to which they are constantly subjected from carnivorous animals of all kinds, both winged and four-footed, adopted a more or less nocturnal habit, passing the day in burrows or in holes of some kind.

Rabbits and most kinds of mice shun the neighbourhood of man. But the "common" mouse has now become almost parasitic on man, being rarely found away from barns or the actual dwellings of his arch enemy! But while the mouse is everywhere detested, the rabbit is more or less carefully preserved, being valued as food; so much so, indeed, that by careful breeding man has succeeded in raising up several wellmarked domesticated races of rabbits, which differ in several striking particulars from the wild parent stock,-the great "lopeared" rabbit and the white angoras and Himalayan rabbits being examples of this kind.

The rabbit and the mouse are types of that great group known as the Rodents, or gnawing animals, which may be at once distinguished by the peculiar character of the teeth.

In the first place, the "incisor" or " cutting" teeth, which are borne by the front of the jaws, are peculiar in that they are continuously growing at their bases, and as continually wearing away along their cutting edges.

This wearing away, it should be remarked, takes place in such a manner that the cutting edges of the teeth are kept sharp 


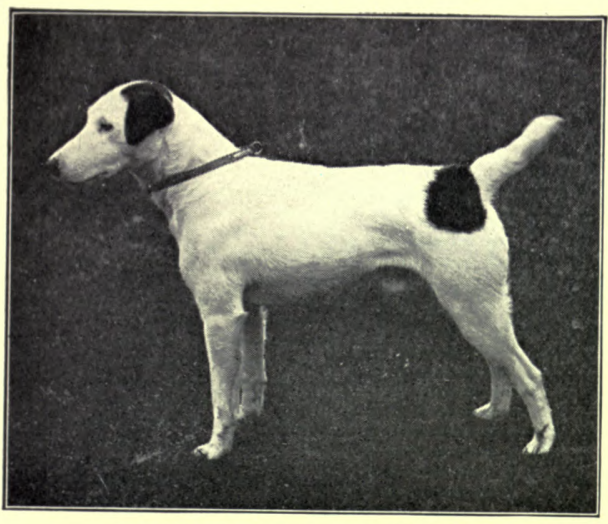

SMOOTH FOX-TERRIER

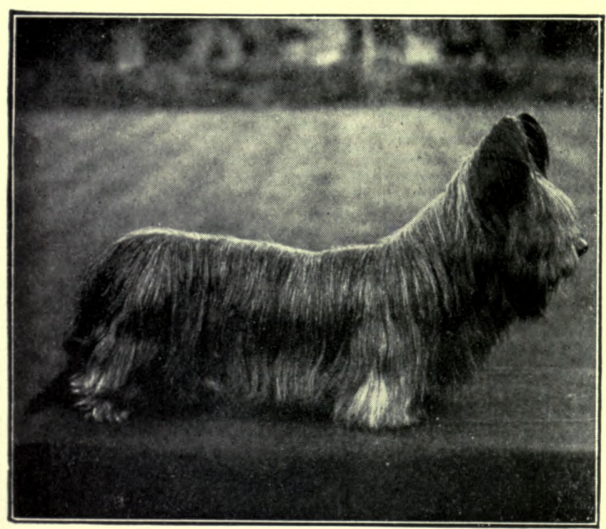

SKYE-TERRIER

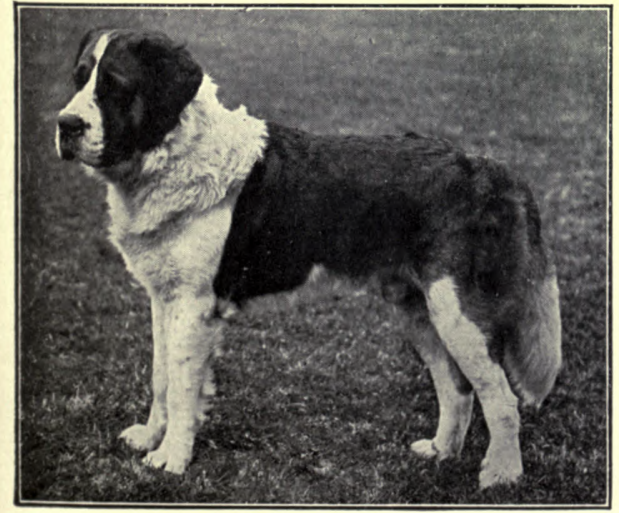

ST. BERNARD

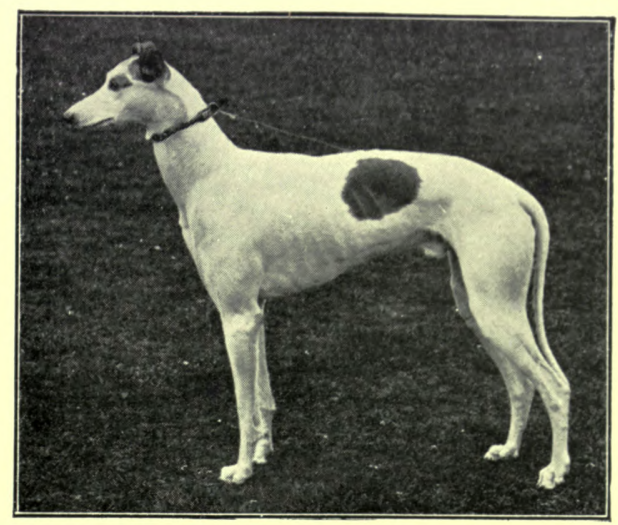

GREYHOUND

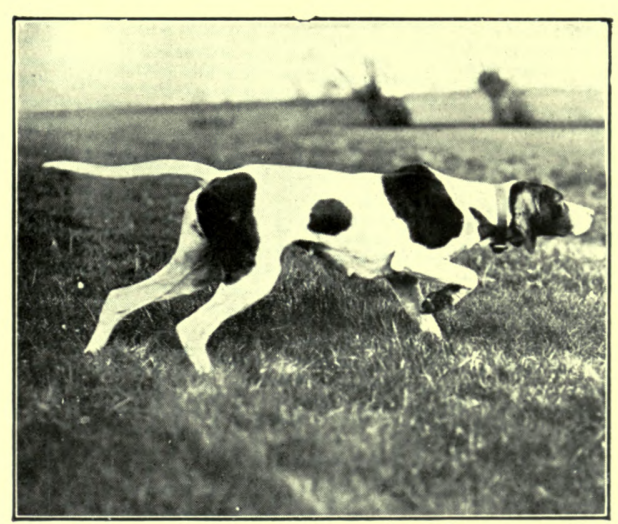

POINTER

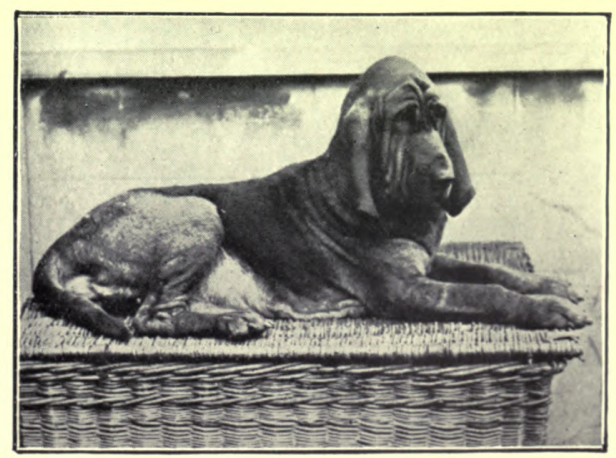

BLOODHOUND 

and chisel-like; and this because the front surface of the tooth is coated with an exceedingly hard layer of "enamel," while the tissue of the tooth behind this layer is softer and more easily worn by the grinding action of the jaws and the consequent chafing of the opposed teeth. Thus provided these animals are enabled, by that curious biting movement known as " gnawing," to attack and demolish hard-coated seeds or nuts of various kinds, as well as the bark of trees and other vegetable matter. Immediately behind the "incisors" there is a big, toothless gap, beyond which come the cheek teeth or grinders, whose surfaces are thrown into a series of ridges admirably adapted for the reduction of the long "shavings " of food passed into the mouth by the actions of these incisors. But the rabbit and hare, it is to be noticed, are peculiar among the rodents, in that, behind the large pair of incisors common to all the tribe, they have a pair of very small teeth, the use of which is problematical.

The power of continuous growth possessed by these teeth is not altogether an unmixed blessing, for should either or both of the teeth of the upper or lower jaw happen to become displaced, as by biting on a stone, whereby the edges no longer oppose those of the opposite series, they go on growing till eventually they form a circle, and re-entering the skull cause death-where this does not occur earlier from starvation.

The mouse and the rabbit differ again in some other striking particulars. Thus in the mouse the feet are bare, in the rabbit they are thickly covered in hair, even the soles being thus clad. The mouse has short ears and a long scaly tail, the rabbit long ears and a short bushy tail. The tail of the rabbit, moreover, like that of the hare, is white beneath, and this it is supposed for a very useful purpose. Briefly, it is used as a danger signal, for, as we have already remarked, the rabbit is very largely a night feeding animal, and in a wild state, lives in companies, in "warrens." On the least alarm a mad rush is made for the burrows, and each, bounding along, cocks up the tail over the back, exposing to the full the white surface. This, showing conspicuously in the gloaming, serves as a guide to those behind; thus each helps the other towards safety.

The hare, to which reference has been made, differs, it should 
be noted from the rabbit, not only in its larger size and different coloration, but also in its much longer legs. This latter character is associated with the very different mode of life led by the two species. The rabbit is gregarious, living in colonies underground-known as warrens-and, straying but a short distance from home, needs no great powers of speed. The hare, on the other hand, leads a solitary life, and does not burrow, but spends the day crouching in some sheltered spot known as its "form." When danger threatens, it endeavours to evade discovery by crouching close to the ground, which in its coloration it commonly resembles. Should this device fail it resorts to flight, and develops on such occasions marvellous powers of speed and endurance. And there is another striking difference between the hare and the rabbit, which must be set down to the very different habits of the two animals. This concerns the very different condition of the young at birth. Young rabbits, snugly tucked away in a warm burrow, are born blind and naked, and remain helpless for some time. Young hares, which have to put up with a nursery liable at any moment to discovery by prowling enemies, are born thickly clad and with their eyes open, and are soon able to run about.

Before leaving the subject of rodents a word should be said about rats, since these furnish a very instructive lesson as to the way in which one animal may displace another over large areas.

The rat now universally met with throughout the British Islands is the brown rat, or, as it is sometimes but erroneously called, the Hanoverian rat and the Norway rat. This pest is believed to have come originally from Chinese Mongolia, from whence it has spread, by man's agency, all over the civilised world, travelling in ships and merchandise. It seems to have gained a footing into this country somewhere about I728 or I729, meeting on its arrival with the smaller, native black rat, which it has now almost completely exterminated, though a few of this indigenous species are still to be met with at sea-port towns, such as Great Yarmouth, in Norfolk; and in Liverpool. The migration of this large and more aggressive species from Central Asia is well attested, for large hordes were seen migrating westwards about the year I727, when, crossing the Volga, they quickly populated the whole 
of Russia, and later the rest of Europe. They appear to have reached Paris about $I 750$.

It is a more omnivorous feeder than the black rat, and more easily adapts itself to varied conditions, thriving in the dwellings and sewers of great cities, no less than in farm-buildings and on the banks of rivers. It is a bold and fierce animal, and will not scruple to attack even human beings when " cornered."

Mice and rats, like rabbits, are nocturnal animals, and this because, being defenceless, they are subjected to fewer enemies and have better chances of escape by night than by day. But cats, owls and foxes levy heavy toll on them nevertheless. By day, however, they would have far more foes to contend with.

The selected types of rodents which we have just briefly surveyed, it should be remarked, acquired their structural peculiarities as they became more and more perfectly adapted to their special methods of feeding. From the small size of these creatures, nuts, roots, and so on could not be taken whole into the mouth and ground up by the crushing teeth, as with the larger vegetable feeders ; and this same diminutiveness compelled them to adopt stealthy habits to avoid enemies. By way of contrast, then, attention should now be turned to the giants, relatively speaking, among the vegetable feeders. And of these the horse and the ox may well serve as types. 


\section{CHAPTER V}

\section{Hoofed Animals-Horses, Oxen, and Swine}

THE animals which form the subject of this chapter are gregarious animals, - that is to say, they live in herds when in a wild state. Further, they too, like the mice and rabbits, etc., are harassed by carnivorous animals, such as lions, tigers, wolves and so on. Being defenceless, their only chance of escape is by flight, and hence they have acquired great running powers.

The ancestors of these animals, as the records of fossils show, were very small creatures, and, among other things, differed from their descendants in having five toes on each foot. Gradually these have become reduced in number to a single toe, as in the case of the horse, and four toes as in the ox and its relatives. But of these four toes only two are functional, or serve to support the body, the remaining two being now too shrunken to reach the ground. These toes, both in the ox and horse, are peculiar in that they are encased each in a large box-like "hoof" of horn, which is nothing more than an enormously developed nail or claw.

The horse, with its relatives the ass and the zebra, is unique among mammals in having but a single functional toe, and this answers to the third or middle finger and toe of the human hand and foot. Our nail answers to the hoof. But to bring home the really remarkable characters of the horse's limbs, they should be compared in some detail with those of the human subject. Take the fore-limb of the horse and the arm of man, for instance (Fig. 7). The upper arm, the region from the shoulder to the elbow of man, is in the horse concealed, only the elbow appearing below the trunk : that region of the human arm which lies between the elbow and the wrist answers to the "leg" of the horse from the elbow to the "knee," which is in reality the rerist. That portion of the third finger which lies embedded in the palm of the 


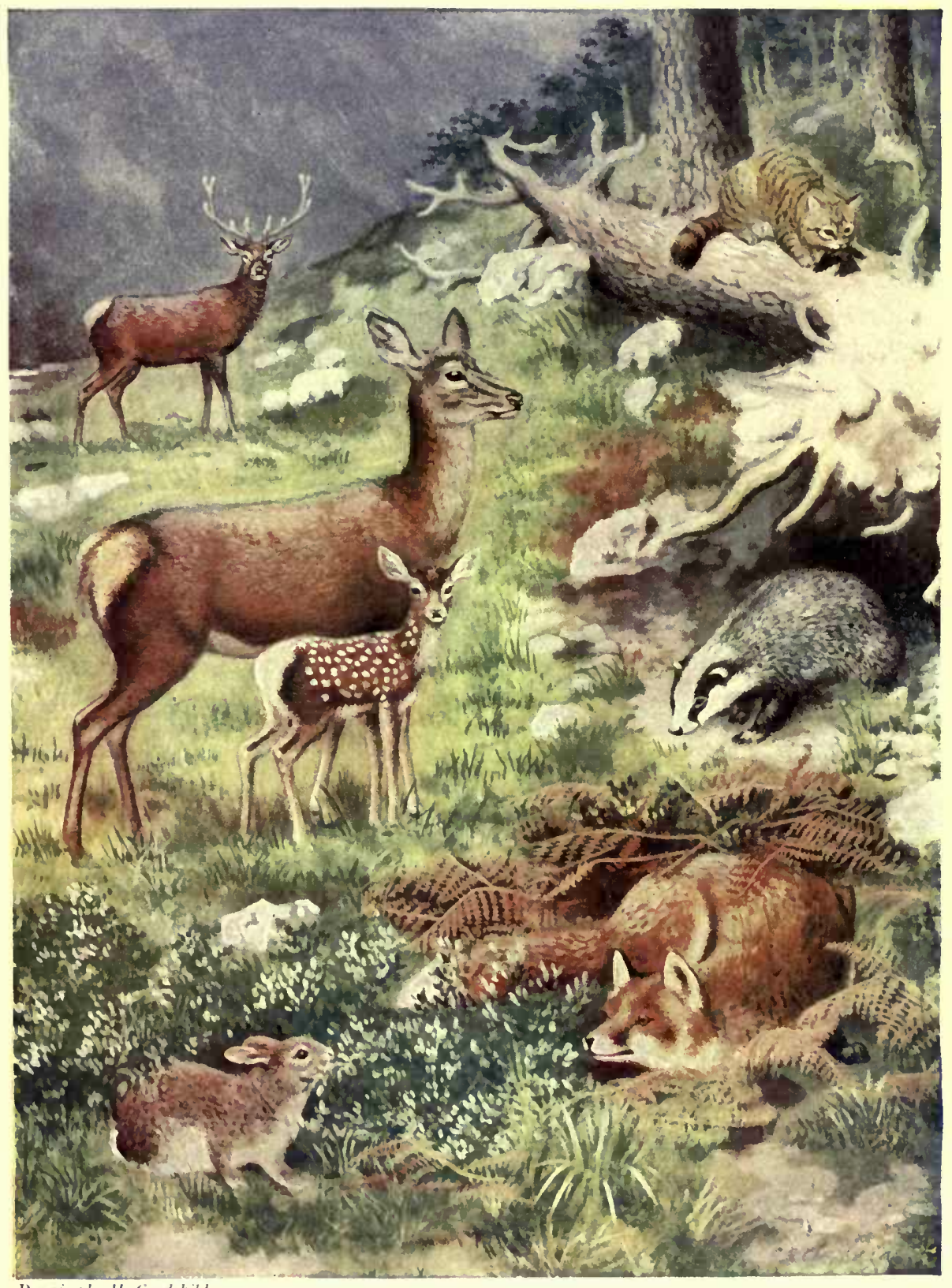

Drawing by $\mathrm{H}$. Goodchild.

DIFFERENT TYPES OF MAMMALS

lied-deer.

Stag, hind, and fawn.

Rabbit.

(Vegretable feeders.)

Wild-cat,

Badger.

Fox.

(Flesh-caters.) 
hand answers to the "cannon" bone of the horse, or the region from the "knee" (wrist) to the fetlock-joint, while the free finger of man answers to the fetlock region and hoof of the horse. These relations should be studied in Fig. 7. Similarly, only the end of the thigh-bone of the horse projects beyond the belly. The

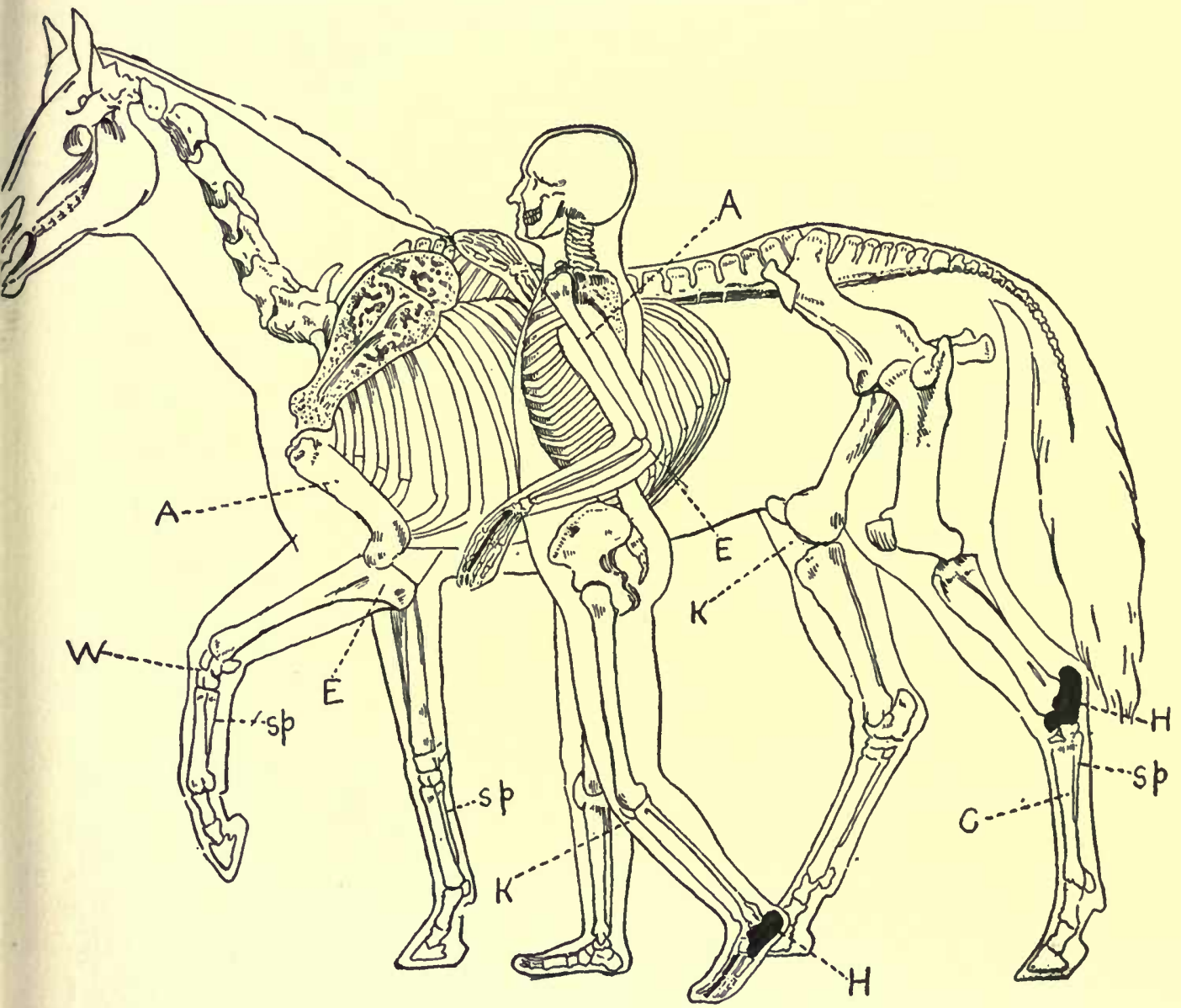

Fig. 7.-Skeleton of man and horse compared, to show the relative differences in the form and position of the bones ; the horse represents the extreme development of quadrupedal locomotion, that of the man the extreme development of bipedal locomotion. (After Flower.) The closely dotted bone is the shoulder-blade.

"stifle-joint" of the horse answers to the "knee" of man. The region from the stifle-joint to the "hock" answers to the leg of man from the knee to the ankle,-which is the "hock" of the horse. The bone supporting the third toe, that which lies VOL. 1. -3 
embedded in the sole of the human foot, answers to the "cannon". bone, which lies between the "hock" (ankle) and the fetlock; and the bones from the fetlock to the hoof similarly answer to the toe of the human foot. A reference to Figs. 7 and 8 should make this clear.

A comparison of the foot of the horse with that of the dog on the one hand, and of man on the other, will bring out yet further interesting facts.

The horse, we have remarked, walks upon the tip of the third toe, all the other toes having vanished. The dog, however, walks

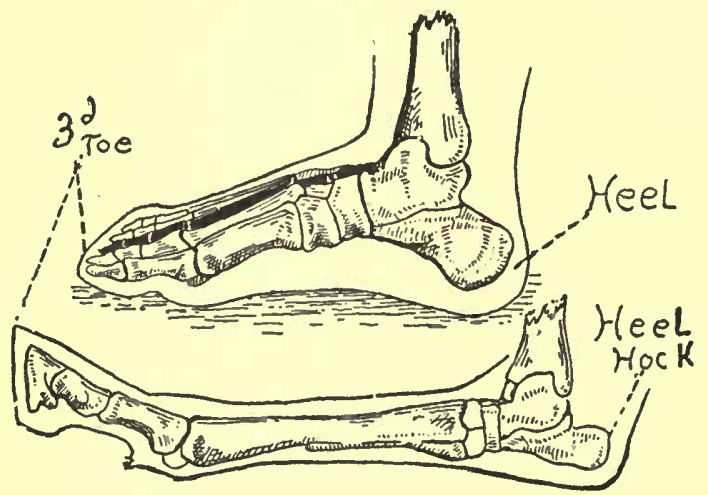

FIG. 8.-Bones of the foot of the horse and man compared; note that what answer to the bones of the sole of the foot in man, in the horse form the lower portion of the "leg." The third toe in the upper figure is marked in solid black. upon the whole under surface of the toes, which are provided with swollen cushions, or pads of fat held in a fibrous meshwork, so as to reduce jarring (Fig. 9, P). These pads serve the purpose, in short, of the pneumatic tyres placed on wheels. But what answers to the palm of the hand and the sole of the foot never touches the ground. It would seem the ancestors of the horse also walked upon the whole under surface of the toes, since a careful search among the hair of the hind surface of the fetlock will reveal a small bare surface which answers really to the foot pad of the dog. A reference to the figures given herewith (Fig. 9) should make this clear. This bare surface in the horse is known as the "ergot."

Yet another peculiarity of the horse's leg demands notice. Every one will have noticed, on the inner aspect of the foreand hind-legs of the horse, a long, oval patch of bare skin which projects from the surface of the leg for some distance, and is of a hard, horny consistence. These patches are known as the "chestnuts," or " callosities" of the horse. On the fore-leg these 
chestnuts are found above the wrist joint or "knee"; on the hind-limb they occur below the hock-joint (Fig. 9, C). Until recently their existence was a great puzzle, but it is now held that they are the last remnants of glands which discharged some scented fluid whereby the members of the herd could find one another when separated. They may be likened to dead volcanoes. In asses and zebras the hind callosity is always wanting. But this, it may be remarked, is not the only distinguishing mark between the horse on the one hand, and the asses and zebras on the other. For the first named is peculiar
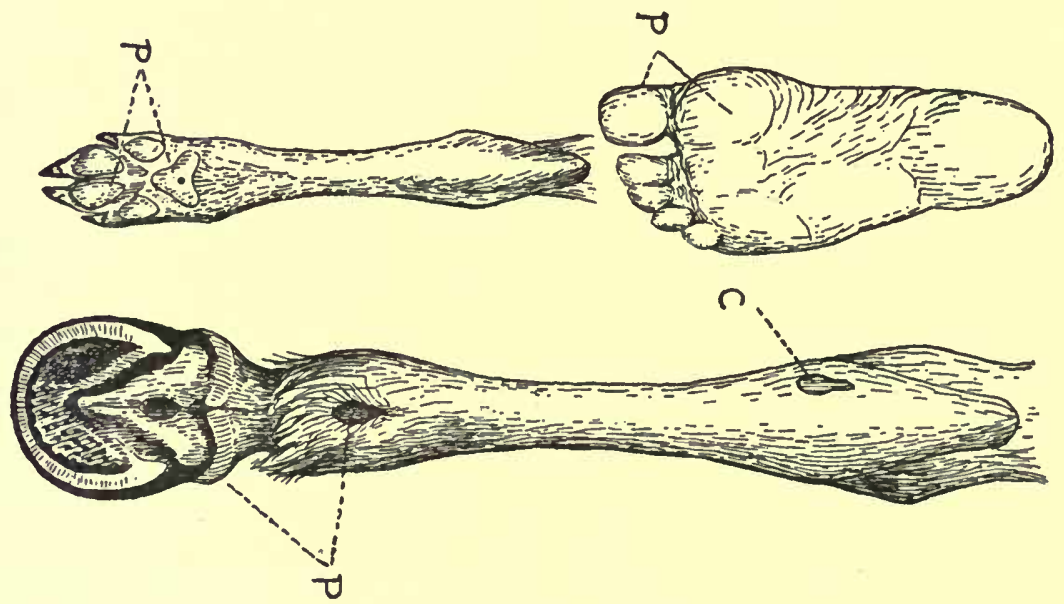

FIG. 9. -The sole of the foot of a man, a dog, and a horse-the latter answering to the "back of the lower part of the leg" to show the pads described in the text. C, the "chestnut." P, pads.

in its shorter ears and broader hoofs, and in having the long hairs of the tail continued quite up to its base.

The remarkably lengthened hand and foot of the horseand this applies also of course to the asses and zebras-have been developed in response to the increasing need for speed in flight from enemies, as the ancestral horses in their wandering after food in level and open plains became more and more exposed to the attacks of carnivorous foes. All that now remains of the second and fourth digits of the fore- and hind-limbs are slender rod-like bones known as "splints" (Fig. 7, sp). The oxen, antelopes, and deer, for example, have retained the third and fourth digits as functional members, while the second 
and fifth are now reduced to vestiges. In other respects the limbs agree with those of the horse.

The teeth of the horse demand special mention. As in the case of the rodents-rabbit and mouse-there is a great toothless gap between the incisor or cutting teeth in the front of the jaws, and the "cheek" teeth, or grinders; though small, and now useless "canine" or "eye" teeth, are met with in some horses and deer. Horses use their lips in feeding, grasping the grass therewith, and thrusting it between the teeth. The jaws closing tightly on the intended mouthful, the stalks are torn from their roots by a jerk of the head, and passed on to the grinders and reduced to fragments. And herein horses differ conspicuously fron: cattle, deer and antelopes. In these animals there are no cutting teeth in the upper jaw, their place being taken by a soft pad; but, as in the horse, there is a gap between the cutting teeth and the grinders. But instead of the lips the tongue is used to draw the food into the mouth, and to enable it to do this the more effectually its surface is covered with rough points, all directed towards the throat, just as is the tongue of the lion and the cat.

Oxen, deer and antelopes are, as is well known, peculiar in that they " chew the cud," or " ruminate." Thereby they are enabled to rapidly devour a large quantity of food and then retire into some retreat secure from enemies, such as lions or tigers, for example, and quietly digest it. This work of digestion is rather a complex process; and, to effect this, the stomach has become divided into a number of separate compartments-four, to be quite precise (Fig. IO). As the food is swallowed it passes into the first portion of the stomach, the "rumen" or " paunch," where it undergoes a softening process ; this completed, it is brought up again, bit by bit, into the mouth with a kind of " hiccough," and there chewed in the slow and deliberate manner so familiar to those who have watched cows and sheep when lying down in the shade after browsing. As each mouthful is reduced to pulp there is a pause, when, if the animal be carefully watched, this mouthful will be seen to pass down the gullet to the stomach, to be succeeded immediately by a second bolus. Each bolus is prepared by passing the food from 


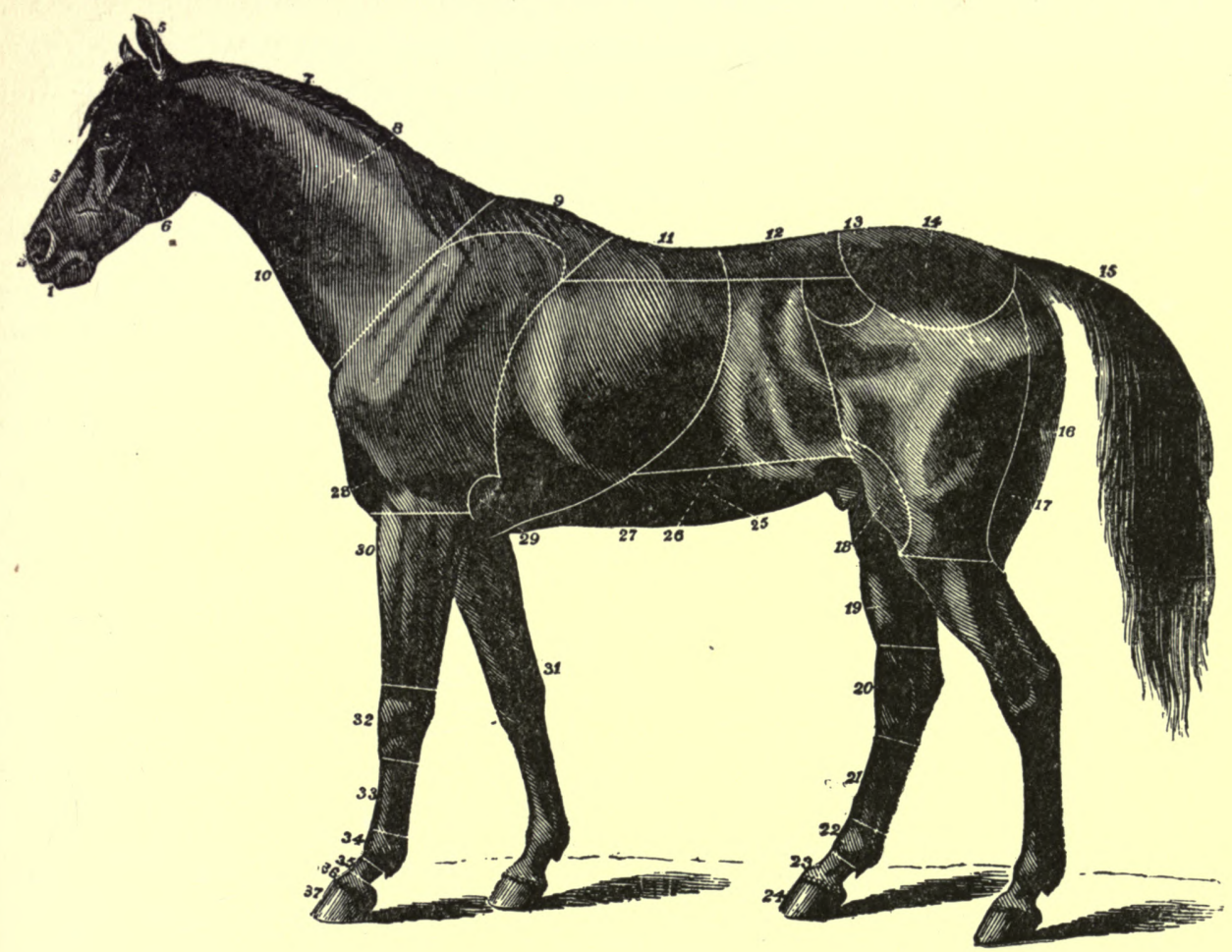

FIG. 9A.

THE PARTS OF THE HORSE.

I. Lips

2. Nostrils.

3. Nose.

4. Forelock.

5. Ear.

6. Cheek.

7. Crest.

8. Neck.

9. Withers.

Io. Throat.

II. Back.

I2. Loins.

I3. Haunch.
I4. Croup.

I 5. Tail.

16. Thigh.

I7. Buttock.

I8. Stifle.

I9. Leg.

2o. Hock.

2I. Cannon.

22. Fetlock.

23. Pastern.

24. Foot.

25. Abdomen.
26. Flank.

27. Chest.

28. Shoulder.

29. Elbow.

30. Fore-arm.

3I. Chestnut.

32. Knee.

33. Cannon.

34. Fetlock.

35. Pastern.

36. Coronet.

37. Foot. 
the paunch into the second division of the stomach or " honeycomb bag" - so called from the fact that its walls resemble honey-comb in shape (Fig. Io, ret). Here it is pressed into the shape required and sent up the gullet again. On its return it passes into the third division or " many-plies" (Fig. Io, $p s$ ), and from thence into the "abomasum," or "reed" (Fig. Io $a b$ ), where the real work of digestion goes on.

Though the ox and the deer have a formidable armature of horns on the head, the horns are conspicuously different in character. Thus these weapons in the ox are formed by bony

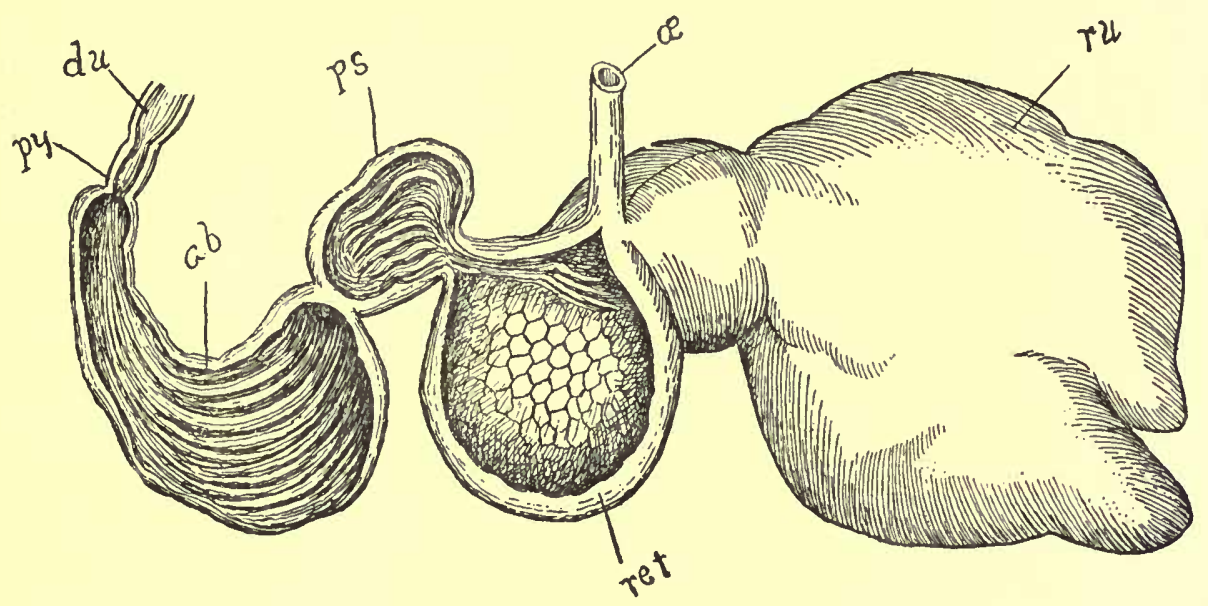

FIG. 10.-Dissection of the stomach of an ox, to show the separate chambers of the stomach. $r u$, rumen or paunch; ret, reticulum or "honeycomb"; $p s$, psalterium or "many-plies"; $a b$, abomasum, the third or digestive stomach ; $\not p y$, the valve shutting off the abomasum from the intestine; $d u$, duodenum, the first portion of the intestine ; $\alpha$, œsophagus, or gullet down which the food is passed from the mouth into the stomach.

outgrowths from the skull, and are encased in an outer sheath of horn; and hence the ox, together with the sheep, goats and antelopes, are known as "hollow-horned" ruminants. The horns in these animals develop early in life, and are permanent structures. In the deer, on the other hand, the horns or "antlers" are shed annually, and renewed again a few weeks afterwards. They differ from the horns of ruminants in that when full grown they have no outer case or sheath, but during growth they are covered with a growth of short hairs known as the "velvet," 
which peels off as soon as the growth has come to an end. Finally, while the horns of deer are always more or less elaborately branched, those of oxen, sheep and antelopes, are never branched, though they may be twisted and curled in various ways.

It is interesting to note that the only deer which have ever been domesticated and made subservient to man's needs are the reindeer; and these differ in no way from the wild parent stock. Goats, sheep and oxen, and horses, on the other hand, man has not only completely domesticated, but has also succeeded in bending so far to his own will that he has created several distinct races, which exist nowhere else but in domestication.

Among horses, for example, we have such widely different breeds as the race-horse and the dray-horse: the one the embodiment of speed, the other of power. The dray-horse is the giant among horses, while at the other extreme we have the diminutive Shetland pony, little bigger than a large dog. Of cattle such breeds may be noted as Highland, shorthorn, Hereford and Alderney, all of which bear horns, and the "polled" races, which are hornless - there are no hornless cattle in a wild state. Sheep, too, are represented by many breeds, such as the Norfolk, Leicester and Merino races, and besides these are many others. The woolly coat of the sheep is entirely a product of the breeder, wild sheep having a hairy coat, as have the domesticated races of sheep of tropical countries, which are bred solely for the sake of food. All wild sheep are horned, but many domesticated races are hornless, a result achieved by man's care in breeding.

Swine.-Though the wild boar has long since become extinct in the British Islands, pigs of many breeds, which have descended therefrom, are to be met with everywhere. As object lessons for teaching purposes they provide some very valuable material, though those who are engaged in the work of teaching Nature Study in large towns must perforce depend for the most part on pictures for their lessons. They can, however, with no great difficulty, obtain portions of skeletons, such as skulls and limb-bones, and bristles, and so on, which will prove exceedingly useful. We would suggest, indeed, that specimens of the skulls and limbs, at any rate, should be procured of as many 
different mammals as possible, for in the hands of an enthusiastic teacher these dry bones may indeed be made to live. The different forms of teeth, and their relation to the food and habits of the creatures to which they belong, are matters of the highest interest and importance. Skulls of small animals, both of birds and mammals, can be readily made by maceration in cold water, or more quickly by slow boiling, or rather simmering, in water to which a trace of soda has been added. Of course great care must be taken to preserve all teeth or loose bones which may become detached in the process. But this by the way. Our conversation is of pigs, the only animals which are credited with the power of seeing the wind!

The pig is a member of the order Ungulata-or hoofed animals. And it belongs, like the oxen, sheep and deer, to the "even-toed" group of that order. That is to say, it has a "cloven" hoof. The horse, on the other hand, with the pig-like tapir, and the rhinoceros, for example, belongs to the " odd-toed" solid-hoofed group of this order, wherein the third toe is always larger than the rest, and symmetrical in itself. Where four toes are present, as in the fore-foot of the tapir, the outer toe, which always answers to the fifth toe, is always small. In the horse, as we have already pointed out, this reduction in the number of the toes has gone still further, only the third being left. In itself the number of the toes is no very important matter, but it becomes important when the reasons for this reduction are taken into account. Thus, the ancestors of these animals were short-legged, and lived in swamps and marshy ground. As they gradually moved to drier land, affording less cover, greater speed, as in the case of the horse, became necessary. And hence the legs became longer, and more work was thrown on the larger third toe. The other toes, becoming less and less useful, gradually diminished, and finally disappeared.

All the various races or breeds of domesticated pigs are descended either from the wild boar of Europe or the wild pig of India.

The commonest types of these domesticated races are white in colour, and but scantily clothed with hair; but in cold climates a thick coat is developed, and this is supplemented by a welldeveloped under-fur. 
In the course of domestication various breeds, as we have already indicated, have been brought into being, and these vary greatly in size and in details of shape and colour, some breeds being black. But the most important changes which they have undergone are to be found in the shape of the head, which in some breeds is excessively short, the snout being quite near the eyes, and the increased tendency to produce fat. Further, while the young of wild swine are always striped, the young of domesticated pigs are whole-coloured, - white or black, as the case may be. Occasionally spotted breeds are met with.

The domesticated breeds of the pig display considerable degeneration in the matter of their tusks. These, in the males of wild pigs, are formidable weapons.

While the oxen, sheep and deer, for example, have no cutting teeth in the upper jaw, these are always found in the pig. Then, again, the grinding teeth of the pig are of a quite different character to the similar teeth in the oxen and sheep, which, it will be remembered, are ruminating or cud-chewing animals. The pig is a non-ruminant, and feeds on roots; while the ruminating animals obtain their food by browsing.

The pig in a wild state obtains most of its food by turning up the soil by means of its snout, which is protected by a very tough skin, and is further strengthened by means of a special rounded mass of bone embedded in its substance. The domesticated breeds retain this habit of "rooting," and in consequence metal rings are commonly fastened through the end of the snout so as to render this pastime too painful to be persisted in.

The "tusks" of the pig, to which reference has been made, answer to the canine teeth so tremendously developed in the lion and tiger. But they are peculiar in that the "tusk" of the upper jaw, in the pig, curve outwards and upwards from the mouth, so that their tips chafe against the tips of the lower pair of tusks, and thus the edges of the tusks of both jaws are kept sharp. If, however, from any accidental cause these teeth are not constantly worn down by friction one against another, they grow into a complete circle, till finally the point of the tooth returns and penetrates the jaw. The natives of the Fiji Islands make use of this fact to produce one of their most treasured ornaments-a 
circular boar's tusk. The upper canine teeth are extracted and the lower ones are allowed to grow till they assume the desired form !

The general shape of the domesticated pig is too well known to need description; but though it has undergone more or less change in the course of this domestication, this is chiefly in the development of fat. This shape, then, is to be associated with the habits of life followed by its wild ancestors.

The wild pig generally frequents marshy places, where there is plenty of cover, and where the nature of the ground is favourable to their peculiar method of feeding. The mornings and evenings are the times when they venture forth in quest of food, the middle of the day being spent, as a rule, in seclusion amid rank grass or other suitable cover.

The females and young usually associate in herds or " droves," while the males lead a more or less solitary life.

Wild boars were once common in the British Islands, but have now been extinct for centuries. They still existed in Oxford in I339, and in Suffolk in I572; while in Chartley Forest, in Staffordshire, they held out till I593. In Scotland and Ireland they lingered still longer, but there is no record of their final extermination.

Wherever pigs have been introduced into small islands by settlers they have in every case destroyed all ground-breeding birds by devouring their eggs, for the pig is an omnivorous feeder, though roots form the staple diet both of wild pigs and those which have escaped from domestication. A comparison should be made between the teeth of the pig and those, say, of the sheep, since specimens of both can easily be obtained. The very striking differences which obtain between the "grinders" of the omnivorous pig and the cud-chewing sheep will illustrate the relation which obtains between the form of the teeth and the nature of the food.

In India pigs are hunted, and afford excellent sport; and though " pig-sticking " is one of the most exciting of all forms of hunting, it is attended with no inconsiderable danger, for when at bay the wild boar fights with great ferocity and pluck, using its tusks, which are keen as razors, with terrible effect. Even the tiger is sometimes worsted by a battle with the wild boar. 


\section{CHAPTER VI}

\section{Some Remarkable Types, and what they Teach}

So far the creatures which have been discussed have belonged to more or less familiar types, easily met with; being either domesticated or nearly related to domesticated forms.

In the present chapter it is proposed briefly to describe one or two of the more remarkable modifications of form which certain mammals have undergone, whereby they have either become adapted to live in some environment otherwise uninhabitable, or have adopted, so to speak, unusual methods of locomotion, apparently by the exaggeration of slight structural peculiarities possessed by their ancestors.

One of the most striking instances of modifications of this kind is happily furnished by one of the commonest of the wild creatures of these islands-the bat. Even in large towns such as London, bats are by no means rare in the quieter streets, especially in a neighbourhood where there are many trees.

The bat is the only mammal which has acquired the power of true flight; the fore-limbs, as in the case of the birds, having become transformed into wings. But these wings, it should be pointed out, differ fundamentally from those of birds (Fig. II). They are formed, in short, by a delicate fold of skin stretched between enormously elongated and slender supports formed by the bones of the fingers, and extending inwards along the sides of the body so as to include the hind-limbs and tail, as in Fig. I2. So absolutely dependent on their wings have the bats become that they have lost the power of walking. At best they can but shuffle along the ground. The hind-limbs have degenerated, and serve now as supports to the wing, and to this end have become so shifted in position that the knees turn outwards instead of forwards. 
But there are yet other peculiarities about the bats. They are, it will be remembered, creatures of the night, emerging from their hiding-places only after the shades of evening have fallen. Now animals which have adopted this habit do one of two things - they either develop enormously large eyes, or suppress them altogether, developing a delicate sense of touch by way of compensation. The eyes of the bat appear to be well on the way towards suppression, for they have become reduced to mere pinpoints, which probably serve but for little else than to distinguish

a

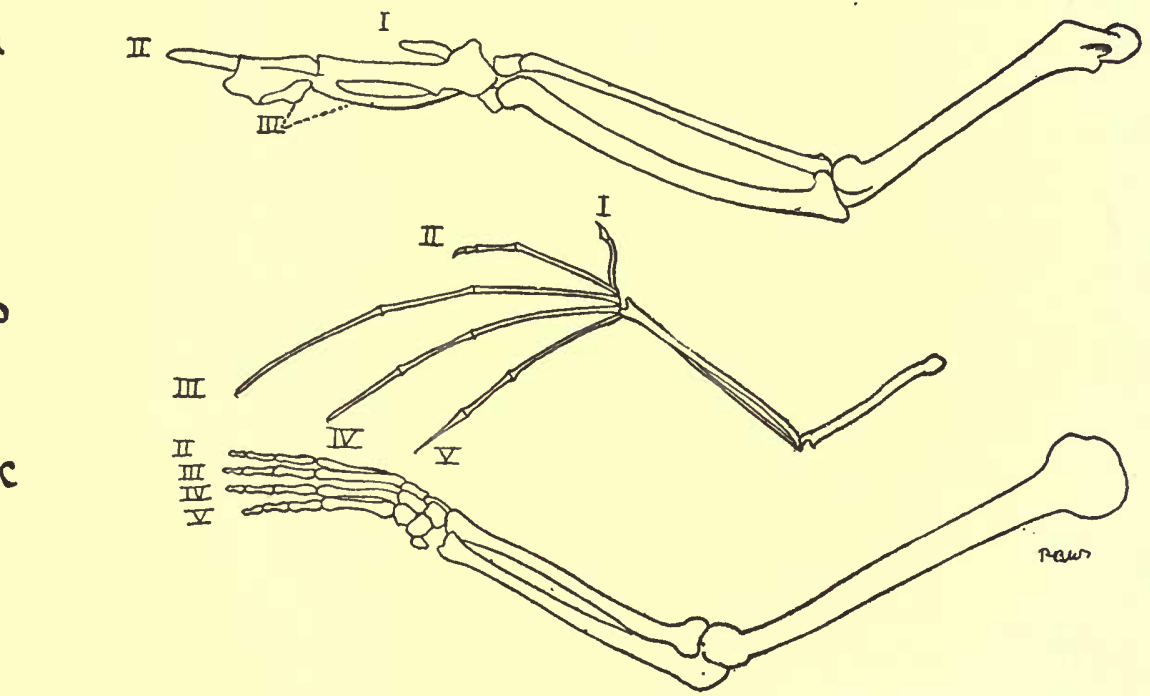

b

FIG. I I.- $a$, Fore-limb (wing) of a bird ; $b$, fore-limb (wing) of a bat ; $c$, fore-limb

(arm) of a man. These three figures are contrasted to show the two widely different ways in which an originally five-fingered fore-leg has been transformed to fulfil the purposes of flight on the one hand, and of a grasping organ on the other. I. II. III. IV. V.=digits (fingers) I-5. In the bird the thumb (digit I.) and the third finger (digit III.) have been greatly reduced.

light from darkness. Compensation for the loss of sight has been found in an excessive sensitiveness of the wing-membranes and the folds of skin which form the external ears. Some species have developed additional skin-folds in the region of the nose, which have very often a very complex character, as may be seen, for example, in the horse-shoe bat. Bats which have been deprived of sight have been known to make their way about a darkened room in which had been placed a maze of entangle- 
ments in the shape of fine threads, yet they flew in and out of this tangle without once touching a single thread.

When at rest bats usually hang head downwards, suspended by their hind-legs, though this position is occasionally reversed, when the claw upon the thumb is used for suspension.

During the winter bats hibernate; that is to say, they pass

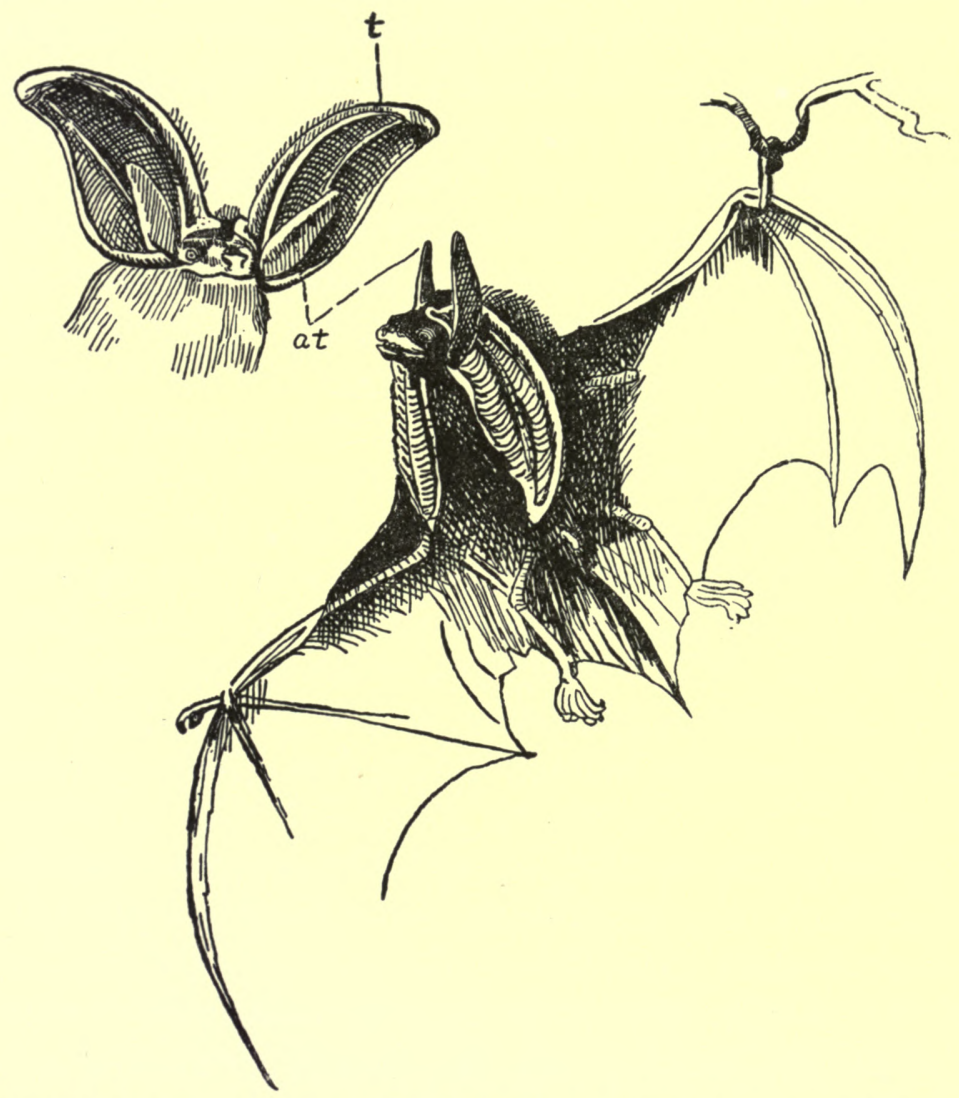

FIG. 12.-The long-eared bat, to show the enormous size of the ears. The outer and larger portion of the ear "tragus" can be folded back when the animal is at rest, leaving the antitragus in a vertical position, and simulating a true ear. (After Sir Harry Johnston.)

the colder months in a state of torpor; though fine mild days, even in mid-winter, will draw them forth for an hour or two.

Hollow trees, the roofs of houses, crevices in rocks and caves form the sleeping and hibernating places of these creatures; 
and in such retreats they have sometimes been discovered in incredible numbers.

They feed, as might be supposed, only when on the wing, their prey being beetles and small flies, such as commonly swarm in the air during the summer and early autumn months.

Among those who delight to watch the singularly silent flight, with its amazingly rapid twists and turns, there appear to be few who can hear the curiously shrill screech of delight which these animals from time to time give forth. The sound is a short, sharp, creaking note, and must be listened for expectantly.

While most animals leave their young in places of safety while they roam abroad in search of food, the young of the bat clings to its mother's body from the moment it is born till it has acquired strength enough to fly, grasping her by means of the claws of the hind-feet and the claw on the thumb.

Bats are creatures by no means easily captured, but they may be found by careful search in suitable localities, and will prove most valuable object lessons. They should, however, be held captive only for a day or two, for they can never be kept alive very long, owing to their voracious appetites. During this period of durance vile, however, they should be fed on a liberal supply of raw meat, minced fine, and it should be remembered that a bat will consume its own weight in food during twenty-four hours.

The peculiarities of the bat will become the more apparent by passing from one extreme to another-from the bat to the mole, for example.

If the bat is the child of the air, the mole is no less the child of the earth, for most of its life is passed underground. In acquiring the power to live in such an environment, changes of structure as profound as those which characterise the bats have been made. Thus the body has assumed the form of a pointed cylinder, while the fore-limbs have become so shortened that only the hands are visible externally. The hind-limbs are relatively small and weak.

Into the nature of the various peculiarities of the skeleton of the mole it will obviously be unnecessary to enter here. But attention should certainly be drawn to the enormous size of the 
curiously shovel-like hands of this creature, the width of which has been further increased by the presence of a semicircular rod bone placed along the inner side of the palm, while the nails have been strengthened to form powerful claws for digging purposes. In Fig. I3 the skeleton of the fore-limbs and their supporting girdles have been shown, and comparison therewith and the wing of the bat should be made.

Thus fashioned, the mole is able to make its way underground with the most wonderful ease, and, in light soils, with astonishing speed, the body being driven forwards by means of the great hands. During the summer months it displays marvellous activity, wandering about just beneath the surface of the ground in search of worms, and the larvæ of the many different kinds of insects which lurk there. Its appetite is insatiable; but this, remembering the enormous expenditure of energy necessary

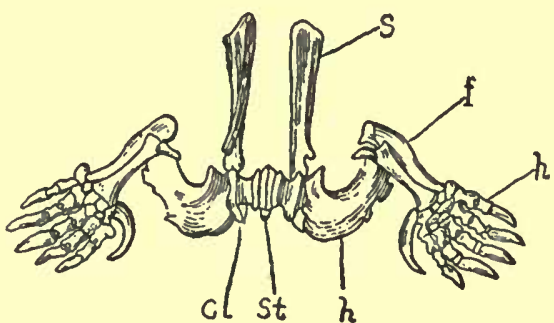

FIG. I3.-The shoulder, girdle and limbs of a mole, to show the enormous size of the hands and the peculiarly shortened and thickened arm and forearm.

to procure this food, is not to be wondered at. For, similarly, it may be remarked, the appetite of the navvy, or of those leading strenuous outdoor lives, is greater than of those whose occupation is sedentary, and requires little bodily exertion.

For the winter months the mole constructs for itself a somewhat complicated dwelling-place. Briefly, this consists of a central chamber and numerous galleries leading therefrom, some of which lead directly to the surface, affording escape to the upper world when necessary. The familiar "mole-hills" which dot the land where moles are at all numerous, mark the sites of these "fortresses," as they are called; the hill being formed by the earth thrown up during the work of excavating. The female in the spring constructs a separate "fortress," in some sheltered situation, which is larger but less complicated than that built by the male. The central chamber forms the nursery, and is accordingly filled with fine grass and leaves, amid which the young nestle. 
There remain yet one or two other peculiarities of the mole which demand special notice. In the first place, the eyes have become reduced to the merest vestiges, so that they must be carefully sought for among the fur, when they will be found as two tiny black points. It is obvious that large eyes would not only be useless to a creature living underground, but they would be a source of danger, since the soil could not be kept from their surfaces if they were opened. Secondly, there are no external ears. These also would be constantly exposed to injury, and would further impede progress. Finally, the fur differs from that of other animals in that it can be brushed, and made to lie, either backwards or forwards, with equal ease, the separate hairs of the coat being thicker in the middle than at the base or tip. Obviously, this is an advantage to an animal which, when moving quickly forwards, may have to retreat speedily backwards in a passage too small to make turning round possible.

How completely the shapes of animals are determined by their mode of life is further illustrated by the whales and porpoises.

Our forefathers, like many people to-day, regarded these creatures as fish. Yet they are indubitable mammals, as their anatomy incontestably proves. Thus the skeleton, nervous system, heart and blood vessels, all differ absolutely from those of the fishes, and agree with all other mammals. Like all the mammalia, their young are nourished on milk; and, like all the mammalia, they breathe by lungs, and not by gills, as in fishes. But they are mammals which have become slowly transformed into creatures of fish-like form by reason of their exclusively aquatic habits. Though to-day only minute vestiges of the hind-limbs are found embedded within the muscles of the body wall, there is no doubt but that the remote ancestors of these animals possessed four limbs, and lived upon dry land. The evidence for this would be too technical for the purpose of this book. Suffice it here to outline the chief peculiarities of whales and porpoises as we know them to-day.

In the first place, they have lost all trace of hairs on the body, the skin now being black in colour, and of wonderful smoothness. The fore-limbs have become modified to form swimming organs 
or " paddles," while the tail has developed a pair of fleshy "flukes" (Fig. I4), which are placed in a horizontal plane, thereby differing from the tail of fishes, which is vertical. And the reason for this is not difficult to trace. Fishes breathe the oxygen suspended in the water, and consequently do not need to come periodically to the surface for air ; and thus it is that the tail of the fish is contrived to drive the body straight forwards. The whale, on the other hand, must breathe atmospheric air; accordingly the "flukes" of the tail are horizontal in position, thereby driving the body up to the surface for air, and down into the depths for food.

While the porpoises and some whales have the jaws armed

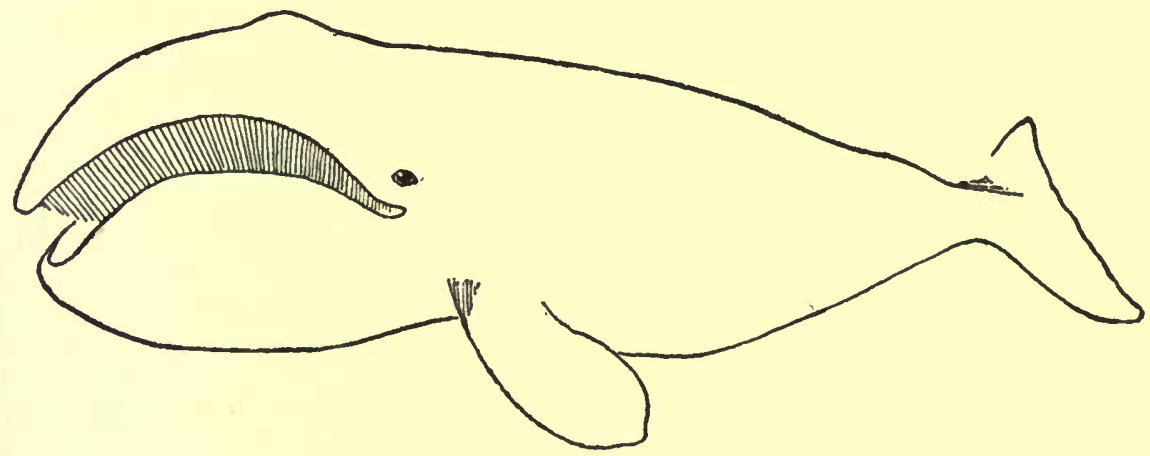

Fig. 14.-The Greenland whale, showing how the body-originally supported on four legs-has become transformed by the adoption of an aquatic life. The small dot behind the eye is the aperture of the ear.

with teeth, some whales have supplanted the teeth-which still appear in the unborn young-by long, horny, fringed plates, the so-called whalebone. These plates, set closely together, have their inner edge fringed, whereby they act as strainers. For these whales feed upon small molluscs and other marine organisms which swarm in the seas frequented by these leviathans. When feeding, the whale suddenly opens its mouth, which is immediately filled by the inrush of water and the organisms floating therein. When the mouth is closed, the tongue, which is fleshy and of great size, is forced up towards the roof of the mouth, and, as a consequence, drives out the water between the plates of "whalebone" or "baleen," as it voL. $1 .-4$ 
is called, leaving the solid matter behind to be swallowed. The loss of hair, and the consequent loss of warmth, has been compensated for by the development of a layer of fat of enormous thickness just beneath the skin; while in the sperm-whale the top of the head is loaded with oil to an enormous thickness, and this, which is of great commercial value, has caused these animals to be so ruthlessly persecuted that they are now in danger of extinction.

The whale, it should be remarked, has now become so perfectly fitted to live in the water that it can no longer live on land, and when stranded in shallow water, as sometimes happens, it speedily dies.

The seal (Fig. I5) presents a most interesting half-way stage between the whale on the one hand and land animals on the

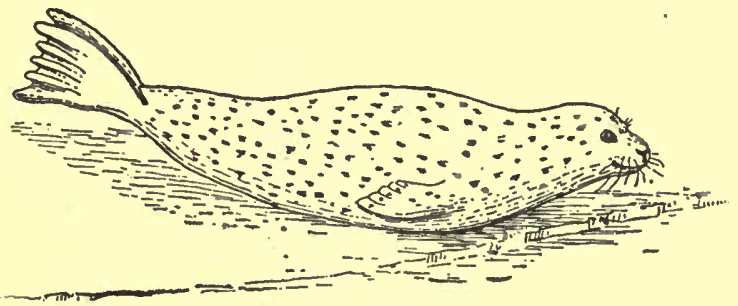

FIG. 15.-The common seal, showing the gradual transformation of the limbs into paddles. other. Essentially a seadweller, the whole of its food is obtained from the water, and this, since it consists exclusively of living fish, at least in the seals common on British coasts, must be chased under water with considerable skill and agility. But when not feeding the greater part of its time is passed ashore, or at least resting on rocks overhanging the sea.

And just as the seal is less exclusively aquatic than the whale, so it has undergone less striking modifications of its bodily structure. The clothing of hair, for example, has been retained, but the external ears have been lost. The channel leading to the inner ear, the organ of hearing proper, is of considerable size, and in consequence muscles have been developed whereby this entrance may be closed when the animal is under water.

The most striking of the changes which this creature has undergone are to be found in the fore- and hind-limbs, which now have the form of "flippers" or swimming organs, which are but 
of small service when on land. Only the fore-limbs indeed are ever used during this time, the hind-limbs having lost the power of being turned forwards or of taking any part in the support of the body, as may be seen in Fig. I5.

The teeth of the seal are peculiar in that there are no specially modified " cheek-teeth" such as are met with in cats and dogs, and other flesh- and fish-eating animals related thereto. But such teeth are not needed, since the prey is swallowed whole and not torn in pieces first.

Seals are to be met with occasionally on the south coast of England, but they are common along parts of the Scottish and Irish coasts.

The "eared-seals" or "sea-lions" differ from the seals just described, being less modified or less "specialised" in that, among other things, they retain traces of an outer ear, and can turn the hind-limbs forwards so as to aid in walking when on land. The "fur-seals" from which the sealskin sold by furriers and milliners is obtained are " eared-seals."

A word about "sealskin" fur. This is furnished by the "eared-seals." But the fur of commerce represents, not the outer coat seen on the living animals, but the close-set, velvety under fur, which in these seals is remarkably well developed. The outer portion of the fur is composed of rather coarse hair, and this must all be removed by the furrier before the fur is ready for market. An under fur of this kind is developed by a number of different animals, as, for example, in the beaver and the North American musk-rat. The skins of this latter indeed are commonly treated like the skins of the sea-lion, when the resultant under-fur is sold for real "sealskin"!

So far, in the animals dealt with in this chapter, attention has been drawn to the sum of all their characters and peculiarities, rather than to any special feature. But habits of observation in children will be materially quickened if their attention is drawn towards certain everyday aspects of animal life which commonly pass unnoticed, because too familiar to seem to call for comment.

Take the question of locomotion. The fact that mankind 
walks upon two legs and a dog upon four is one which escapes comment, because the rule is universal. Yet a moment's reflection shows that these two very different modes of progression are of stupendous importance. For thereby the fore-limbs in the one have become available for service on the head, while in the other they are employed exclusively in the support of the body. But to effect this emancipation of the fore-limbs the most profound structural changes in man's bodily framework have taken place. The muscles of the thighs, for example, have been enormously increased, while the curvature of the backbone

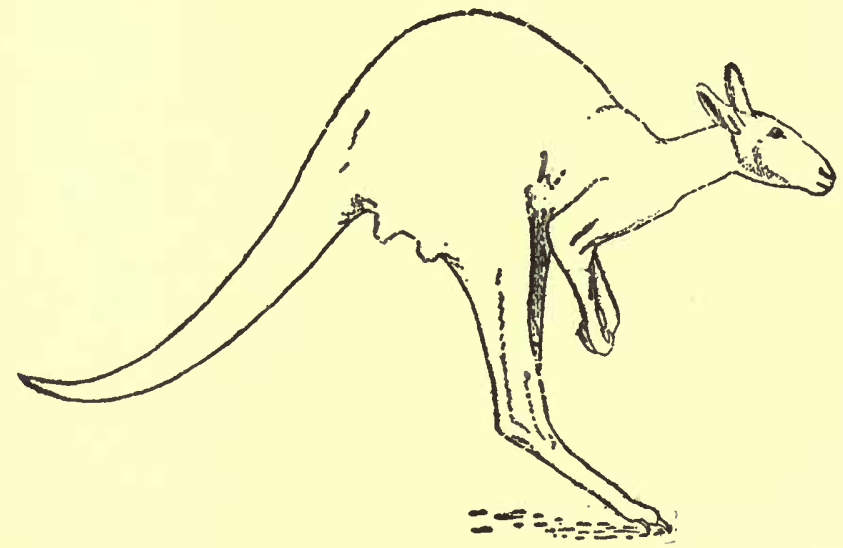

FIG. I6.-Kangaroo in the act of leaping. Note the enormous size of the hind-legs and tail.

and the poise of the head have been no less materially changed when compared with that of the dog.

The development of this bipedal method of locomotion was a very gradual and laborious process. A very interesting stage in this development may be studied in the monkeys, more especially in the higher apes, such as in the chimpanzee and orang, for example. Here the fore-limbs, as in man, have assumed the form of "hands and arms," but in walking the hands are still indispensable, the weight of the body being thrown upon the backs of the fingers, which are bent towards the palms of the hands, while the body is swung between the arms, as though the creature walked on crutches. But this method of progression is only possible where the legs are extremely short, 
as in the apes in question, so that when the body is held in an upright position the fingers reach to the middle of the calf. On occasion, and for a few yards, these apes can walk on the hindlimbs alone, but with difficulty. When at rest, however, the hands are used, as in man, for conveying food to the mouth, and for other purposes. They are also used for climbing.

The only other land mammals which are bipedal are the kangaroos and the jerboas, and certain other little animals closely related thereto. In these animals, and especially in the kangaroos and jerboas, the hind-legs are of great length, enabling the ground to be covered by a series of leaps often of prodigious length (Fig. I6). The tail in these leapers is of great length, and strong enough to form a support to the body when at rest-it forms the third leg of a tripod. In the kangaroo, indeed, it serves as a "leg" during walking, which is performed "on all-fours," and after the following fashion. First the fore-legs are put down, then the hind-legs are brought forward, one on each side of the fore-legs, the body and hind-legs being at the same time lifted off the ground and driven forward by means of the tail. Then the fore-limbs are thrust forward for a second step, and so on.

In the rabbit and hare we have an indication of the stages by which this two-legged stage came about, since in these animals, and especially in the hare, the hind-legs are much longer than the fore-legs.

In the bipedal whales and porpoises it is the fore-limbs which become specially developed, while the hind-legs have totally disappeared. These fore-limbs are, however, used, not as supports to the body-which is sufficiently buoyed up by the water-but as balancing organs.

While most four-legged animals, it will be noticed, move the right fore-leg and the left hind-leg forwards, more or less in unison, some animals, such as the tiger, camel and giraffe, move the right fore- and right hind-leg in unison-that is not the fore- and hind-legs of opposite but of the same sides. Some breeds of horses, known as " pacers," have this peculiar method of walking and running.

Flight, as a means of locomotion among the mammalia, we have already discussed, but we propose to return to this theme for 
the purpose of mentioning a very extraordinary way of parachuting practised by several different species of mammals, not at all related to one another!

The so-called "flight" is performed by leaping into the air from a height and gradually drifting downwards, the body being supported by a broad fold of skin running down each side of the body between the fore- and hind-limbs, which are at this time fully extended so as to stretch the membrane to its widest extent.

The "flying lemms" of Madagascar, creatures related to the burrowing mole and the prickly'hedgehog, are the most expert performers at this spurious flight, covering 70 yards at a leap. The flying squirrels of Africa, India, North America, and Eastern Europe are, however, capable of leaping as much as 30 yards. Besides these, two widely different kinds of parachuting animals, there is yet a third group, belonging to the great order of Marsupials or pouched animals, to which the kangaroo belongs. These are the "flying phalangers" ; all small creatures, but of great beauty. One need scarcely say, these curiously modified creatures can only live where there are great forests. All are vegetable feeders, but the phalangers appear to be the most dainty of all in the selection of their diet, since they feed only on flowers, honey, and insects. 


\section{CHAPTER VII}

\section{The Clothing of Mammals}

THE subject of the external covering of the body of the animals which make up the class mammalia has so far been but very briefly touched upon, and this for the reason that it demands a whole chapter to itself.

While birds present an absolute uniformity in the matter of the covering of the body, the mammalia exhibit the widest possible differences in this respect; the range and nature of these differences are herewith to be briefly outlined.

In the majority of mammals the surface of the body is protected from the extremes of temperature by a covering of more or less thread-like, horny outgrowths of the skin, known as hair. Unlike the feathers of birds, the hair of mammals is, in the first place, uniformly distributed over the body; and, in the second, may become profoundly modified, so as to assume the forms which we know respectively as wool, bristles and spines. But, besides, the bodies of some mammalia are encased in yet other and more markedly peculiar outgrowths of the skin, to be described presently.

The hair, it should be noted, may assume different characters in the same animal, as in the horse, for instance, where, along the ridge of the neck, and on the tail, it becomes greatly lengthened and coarse in character, forming what are known as the mane and tail, while in some breeds of domesticated horses it grows to an extreme length on the lower part of the legs. In many animals the hair assumes a peculiarly soft and often velvety character, and this is known as fur. In many fur-bearing animals, and in some others, which would normally be described as "hairy," there is found beneath the outer coat a short inner coat of fur, and this is known as the "under-fur." The fur of the seal is of this latter kind, while squirrel, sable, bear and fox fur is formed by the outer coat. 
Attention should be drawn to the fact that the direction of the hair varies much on different parts of the body in most mammals. In the horse, for instance, most of the hair slopes backwards on the trunk, and downwards on the legs. But on the chest, behind the arm and on the flanks, near the hind-leg, the hair forms "whorls," or slopes directly upwards, as may be seen by an inspection of the nearest cab-horse.

The length of the hair is more or less directly related to the temperature of the animal's environment; thus the tiger in India, for example, has relatively short hair, the tiger of the cold regions of Manchuria has an extremely thick coat; even in England many species, such as squirrels, for example, develop a thick, long-haired coat for the winter.

In some animals the hair attains a great length and a peculiar texture, known as wool, as in the sheep, for example; but in hot countries the sheep are short-haired.

The common hedgehog of our countryside exhibits to perfection a very remarkable modification of this hairy covering. Herein, the upper surface of the body is covered with a really formidable armature of stiff and sharp-pointed spines, which form the only protection which this otherwise defenceless creature possesses. When threatened, instead of running away, it rolls up till the body forms a prickly ball such as few enemies care to attack, and in this position it remains till danger has passed. The porcupine possesses an even greater development of these spines, which attain to a very considerable length and thickness; here, however, the fore-part of the body is hairy, but the hairs become gradually thicker and longer towards the back, so that a perfect gradation between hair and spines may be found. The porcupine, however, does not roll up after the fashion of the hedgehog when threatened, but turns its back towards the foe, and sets all its spear-like shafts on end-a device which appears to be quite effective. In passing it may be remarked that the hedgehog and porcupine are in no way related. Each has, as it were, hit upon the same method of defence; and this is true of certain species of mice, whose backs bristle with spines, though these are not very long. At one time it was believed that the porcupine possessed the power of 
shooting these spines at their enemies, and to a distance of several feet; but this is not so. When alarmed, old spines frequently fall out, as the attempt is made to "bristle up" and look dangerous, and hence the idea that they were forcibly ejected.

The curious ant-eating pangolins of Africa have a yet more remarkable covering, the body being encased in horny scales, as may be seen in Fig. I7. These scales are really formed by masses of hair cemented together, and between each scale a few ordinary hairs are always to be found. But the pangolins are not the only animals that have adopted cemented hairs as an

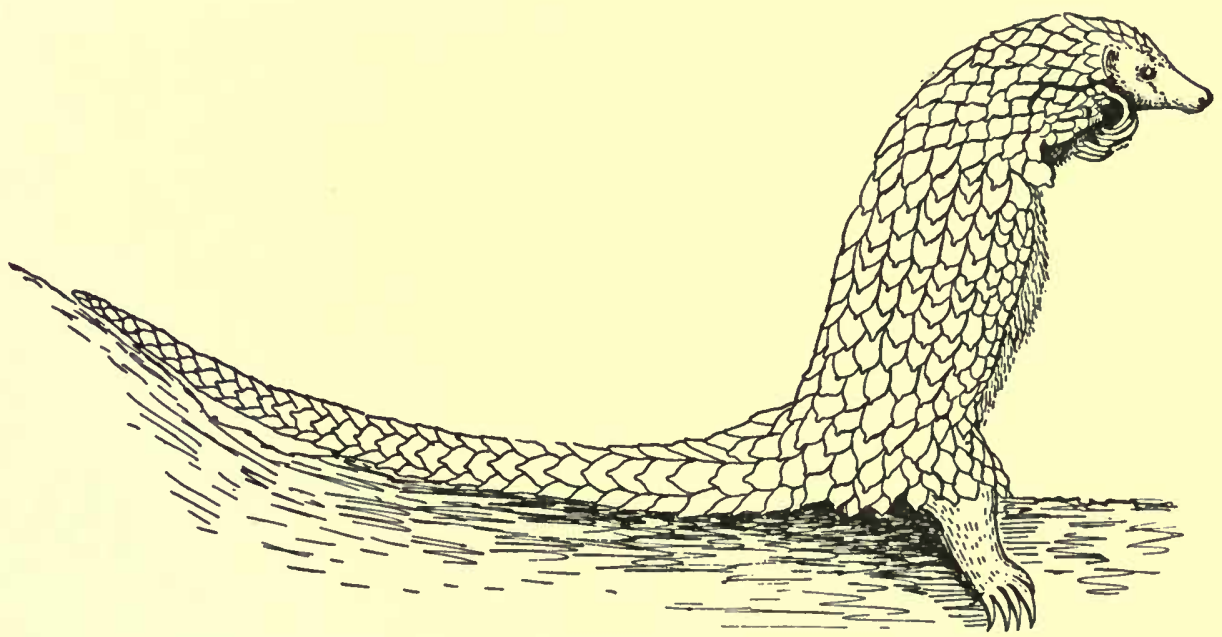

FIG. 17.-The African pangolin, wherein the hairy covering has been replaced by overlapping scales.

armature against attack, for the huge rhinoceros has developed the same device, the great horns which surmount the snout being similarly formed, as a section of a piece of the horn will show when placed under the microscope. But while the scales of the pangolin serve as a protective armour, the horn or horns - for some species have two horns-of the rhinoceros are used as weapons of offence. At any rate this is true of the two-horned African species, but it is doubtful whether the Indian species ever uses this weapon after this fashion. It seems, on the contrary, to trust to a pair of triangular and sharp-pointed tusks lodged in the lower jaw.

In some mammals the skin is largely replaced by bony plates, 
as in the armadillos of South America. These bony plates form a great shield over the back, and a large oval plate on the head. But the middle portion of the back shield, between the fore- and hind-limbs, is made up of a series of rings, so that the animal is enabled thereby to roll itself up into a ball, practically defying attack. This is its only means of defence against enemies, for it cannot run very fast, and has no teeth, such as would be of use in fighting.

Finally, we come to the whales, porpoises and dolphins, whose bodies are absolutely naked, the skin being exceedingly smooth and glossy, thereby reducing friction to a minimum during their movements through the water. Compensation for this loss of hair is made, as we have already remarked, by a tremendously thick layer of fat immediately under the skin. 


\section{CHAPTER VIII}

\section{Liveries and their Meaning: The Coloration of Adult Mammals}

THAT the coloration of mammals in a wild state plays an important part in their life-history, is a fact by no means generally realised. But illustrations of this are to be found even among species commonly to be met with in Great Britain. As might be expected, of course, this coloration is of less importance in some cases than others.

No better object lesson of the way in which closely related animals, and even animals of the same species, may differ in this matter of the coloration of their coats, is to be found than in the common domesticated cat. But before proceeding to illustrate this, it should be remarked that between coloration and colour there is a distinct difference. For by coloration is meant the general effect of contrasted colours-when present; the effect produced by the pattern of the coat.

The cat, to which reference has just been made, admirably illustrates this difference in pattern, which applies both to races of the same species, as well as to different, though closely related species.

All the various breeds, or races, of the domesticated cat are probably descendants of a common wild species, though in this point authorities are not quite agreed. Now of these breeds, the best known, because the commonest, is that generally described as the "tabby." Herein the general ground colour of the coat is grey, relieved by more or less continuous transverse bars of black. But, besides this, cats may frequently be met with wherein the dark markings have a quite different arrangement. Without minutely describing this pattern, let it be sufficient to remark that in this type the irregular transverse bars, or vertical bars, along the sides of the animal, are replaced by an oblong 
patch of black more or less completely encircled by a broad black ring. The stripes down the centre of the back also differ in width and number. Those who are engaged in training the powers of children's observation would do well to set their charges to work in collecting notes on the cats they meet with, in regard to this peculiarity of marking, which is well shown in our illustration. It is curious that no really intermediate conditions occur even when cats have descended from parents of opposite types. Persian cats, owing to the length of hair, do not well show either types of pattern.

Attention should also be drawn to the different colours of horses -bay, brown, chestnut, black, roan- "blue " and "strawberry" -white and dappled grey; and it should be pointed out that no wild races show these colours.

As a rule, the colours of mammals, as of birds, bear a more or less close relation to the surroundings or "environment " in which the creature lives; the coloration being of such a nature as to cause it to harmonise more or less completely with the ground, or vegetation. Thereby the animal is enabled to escape observation, and thus either to avoid enemies or to secure prey by creeping up unawares. Thus we have "protective resemblances" and "aggressive resemblances," according as they serve for offensive or defensive purposes. And it will further generally be found that the upper part of the body is much darker in colour than the under part. And for this reason. The darker upper parts, being exposed to the light, are rendered lighter and less conspicuous, while the lighter colour of the under parts destroys the shadow which by the relation of the body to the ground is unavoidable. Thus, by toning down the upper surface and lightening up the under surface, the general effect of solidity is cancelled, and the animal enjoys a measure of invisibility which is truly surprising, as those who have suddenly flushed hares and rabbits know ; for so long as they lie still they are almost invisible.

But there are some notable and puzzling exceptions to this rule ; though these, being natives of other and far-distant countries, are not generally to be met with save in Zoological Gardens or in a wild state. The curious ratel of Africa may be cited as a case 
in point. Here, the upper surface of the body is of a hoary grey colour, while the under surface is of a jet black, and the two are divided by a white line! So far no explanation of this exceptional coloration has been suggested ; and, before this explanation can be forthcoming, travellers must make careful observations on ratels in a wild state.

Protective coloration sometimes assumes a character which seems at first sight but little likely to deserve this appellation. What, for instance, could appear more conspicuous than the striped coat of the zebra? Yet, as a matter of fact, the broad black-and-white vertical bars of this animal, so striking and arresting in a Zoological Garden, tell a very different story when the animal is met with in a wild state. The zebra, it must be remembered, is a defenceless animal, and is always exposed to attack from the lion. This is especially the case during the night, for being a day-feeder the night is generally passed in sleep. In the absence of starlight, or of a full moon, darkness affords a sufficient protection from surprise; but during bright starlight or moonlight, there would be, one would imagine, little chance of creatures of such large bulk and conspicuous markings escaping discovery. In reality, however, these broadly contrasted bands, so far from being conspicuous, actually form a mantle of invisibility! If the black stripes were more numerous the animal would be seen as a black mass; if the white dominated, as a white mass; but their proportion is so beautifully balanced that, even at close range, the body exactly matches the arid ground as seen by moonlight! The stripes of the tiger similarly provide invisibility. The tawny black-barred hide of this ravenous creature so completely matches the reed-stems and dead vegetation amid which he crouches, that detection is almost impossible by his unsuspecting prey, and thereby he is enabled to spring upon his victims unawares. Here, then, we see the same colour device adopted to achieve opposite ends-in the one case to enable a defenceless creature to avoid its dreaded and all-powerful enemy ; in the other, to enable the slayer to creep stealthily upon his unsuspecting victims! Before proceeding to cite yet further cases of similar devices to avoid enemies on the one side, or to escape foes on the other, it should be remarked that transverse striping 
of this kind is exceedingly rare among the mammalia. The curious little zebra-antelope of West Africa (Cephalopus doria) is broadly striped with black, and so also is one of the civet tribe known as Hardwicke's civet, and the fierce thylacine, a dog-like animal of Australia.

The zebra and the tiger are both " protectively" coloured, though in the one case this livery has been assumed for the purposes of passive defence, and in the other for aggressive purposes. The hare and the stoat, creatures which are to be met with throughout Great Britain, afford equally striking examples of these two types of coloration. There are two species of hare in Great Britain, one known as the common hare (Lepus europaus), the other as the mountain hare (L. timidus). In summer both are brown and resemble, very closely, the clods of earth or dead vegetation amid which they generally crouch. Thereby they escape the prying eyes of the numerous enemies by which they are surrounded-eagles, hawks, foxes and stoats, for example; or at least a very large number escape detection. These creatures need concealment to enable them to rest, otherwise they would be subjected to a constant harrying; so soon as they move they become at once conspicuous, but a moving animal has at least a sporting chance of escape, and in any case no amount of protective coloration-of resemblance to their surroundings - would be of any service to an animal in motion. Consequently these protective liveries have come about by the slaughter of all those individuals who were strikingly different in hue from their surroundings, and the escape of those in proportion as they resembled those surroundings.

Similarly, the fox and stoat are protectively coloured, but for aggressive furposes, that is to say, so that they may creep up unawares on such victims as they by chance discover. But in countries where the winter is long and severe, and consequently when for many months much snow falls and remains long on the ground, brown hares on the one hand and brown foxes and stoats on the other, would be extremely conspicuous; and in consequence both pursuer and pursued have to adopt white liveries. In the Highlands of Scotland only one species of hare is met with-the 


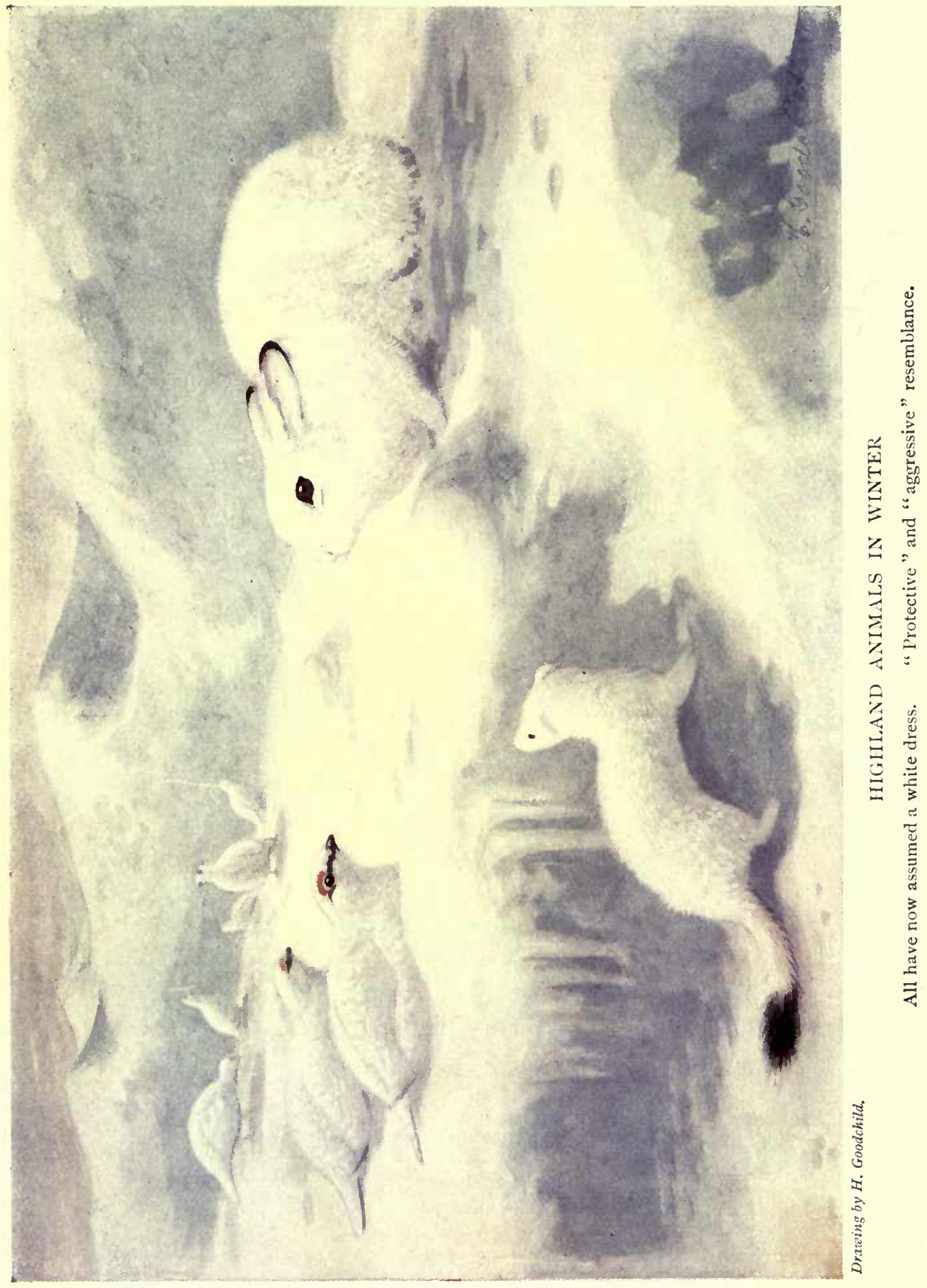




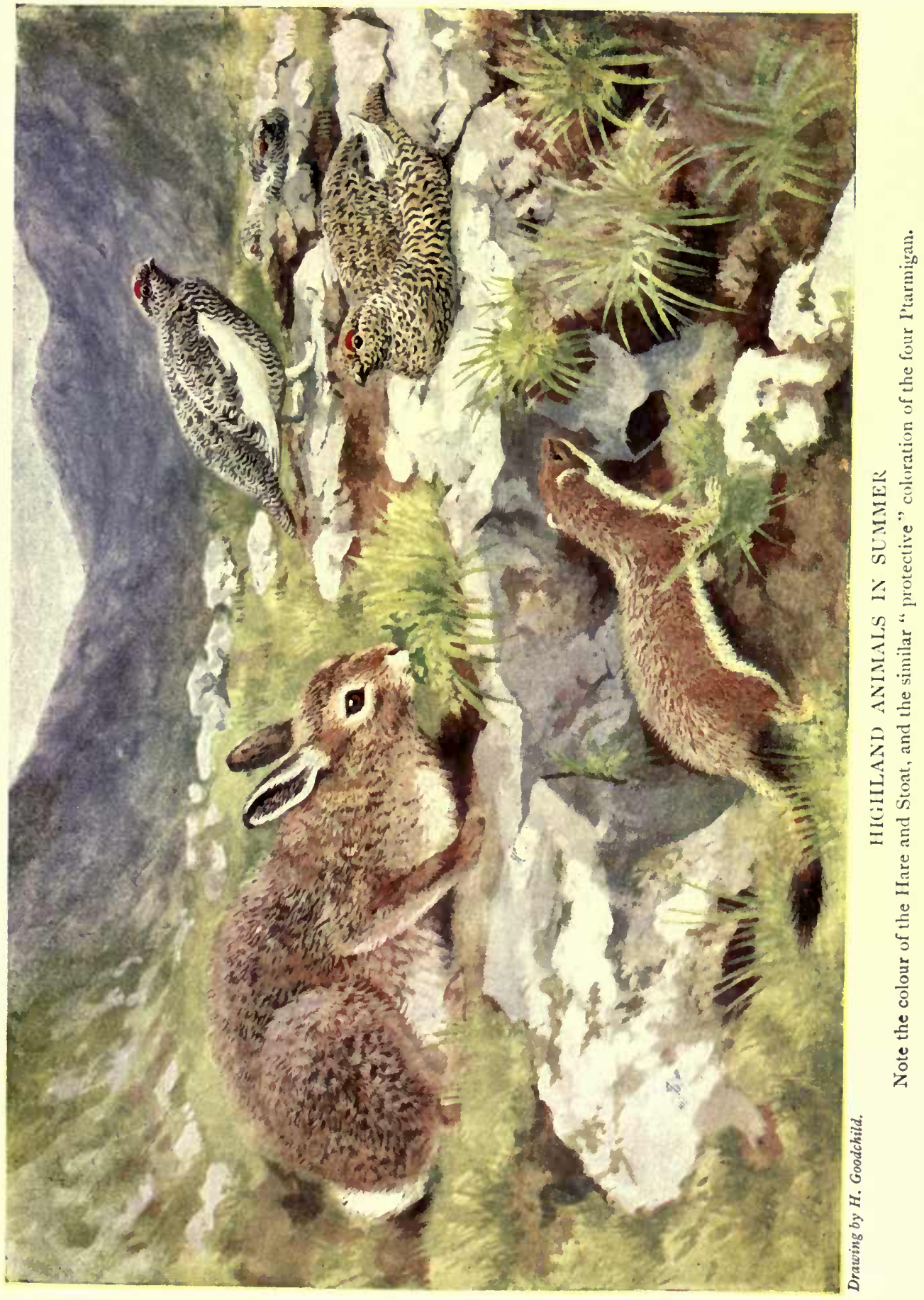


mountain hare-and this accordingly turns white; and thus the stoat has to effect a similar change, only the tip of the tail retaining its normal black colour. In Ireland, where this hare also occurs, no such change in these animals takes place-because snow rarely falls, and still more rarely remains long.

In yet more northern regions of Europe this same species of hare is found, and here the fox (which is of a different species to the British fox) as well as the stoat, turns white.

Even more remarkable perhaps is the coloration of that strange animal known as the skunk; a creature which occurs both in North and South America. This beast--one of the carnivorous animals-is most conspicuously marked with black and white, and, what is more, instead of endeavouring to conceal itself, it walks abroad with the greatest ostentation. But woe betide the man or beast which approaches it too nearly, for without the slightest warning it ejects a liquid spray of the most offensive and overpowering description; so much so that no assailant would dare to repeat an attempt at hostilities. Coloration of this kind is known as "warning coloration," and is far more effectual than an armature of teeth or claws would be, for no danger of personal conflict is run with its possible danger of personal damage. Now and again, of course, a skunk is killed by the sudden rush of some inexperienced animal, such as a dog or wolf, but the inevitable spray of this vile scent would effectually deter the victim from ever again repeating the experiment, however many opportunities it might have! And thereby, though one individual lost its life, all others of this species would escape attack from this particular animal.

But besides stripes and patches of colour, spots play an equally important part in the coloration of animals. The spots of the leopard and jaguar, for instance, enable these creatures to find perfect concealment amid the jungles in which they live; the light spots blending with the surrounding spots of sunlight which penetrate the foliage of the forest, thereby rendering the bulky bodies of these animals practically invisible, so that their prey approaches to within striking distance before suspecting danger. Many deer are also spotted, and it is to be noted that in deer so 
marked which live in temperate climates, the spots disappear in the autumn, when the longer winter coat is assumed. And this apparently because amid leafless trees a spotted animal would be conspicuous. At any rate in tropical countries spotted deer remain so the year round.

Sometimes quite unexpected relations are met with in regard to the coloration of animals. Thus white cats occasionally have blue eyes, and when this combination occurs a further peculiarity is met with-such cats are always deaf ! " Tortoise-shell " cats, so-called from the curious mixture of yellow, black and white which they exhibit, are always females. In certain parts of Virginia only black pigs can be kept; and this because they alone are unaffected by feeding on the roots of a certain plant which grows there (Lachnanthes tinctoria) which colours the bones pink; and further, in all but black pigs causes the hoofs to drop off! Similarly, in the Tarentino only black sheep can be kept, all white sheep being speedily killed by eating another poisonous plant (Hypericum crispum) which does not affect black sheep.

Finally, the markings, or patterns, on the hides of mammals in a wild state are always more or less symmetrical ; never forming irregular blotches as in domesticated cattle, for instance. There are, of course, a few exceptions to every rule. Thus the hyæna-dog has irregular markings, but species which do not conform to the rule just given can be reckoned on the fingers of one hand. 


\section{CHAPTER IX}

\section{Liveries AND their Meaning: The Coloration of Young Mammals}

YouNG mammals, like young birds, often differ conspicuously from their parents in their coloration. But while in the adults this coloration appears to bear some direct relation to the needs of the environment, in young animals it appears, at least in many cases, to be, so to speak, reminiscent ; that is to say, it appears rather to be due to the temporary revival of a livery worn by the adults of earlier generations. Repetitions of such ancestral characters, that is to say, the temporary assumption by young animals of characters, which persisted through the lifetime of their ancestors, are common among all groups of the animal kingdom. The young of whalebone whales, for example, have teeth in the jaws which never cut the gums, and are finally absorbed; the beaks of nestling humming-birds and of young spoonbills are short, and quite unlike those of their parents.

These ancestral traits are well illustrated by the coloration of young mammals. Young lions, for instance, are conspicuously spotted and often inconspicuously striped, while the adult lion, as is well known, is whole coloured. And from this we may assume that lions have descended from spotted ancestors, which in turn may have descended from striped ancestors. This may be inferred from the fact that the spotted patterns of many animals are derived from the breaking up of stripes. This is seen in the evolution of the patterns which adorn lizards, for example; and in the similar evolution of the coloration of the down in the nestling stages of certain birds. Thus, all the more primitive or ancient types of birds have striped nestlings. In such a group as that which includes plover tribe and gulls we can trace the steps of this evolution of pattern.

VOL. I. -5 
The young of the woodcock, for instance, are broadly striped, like young game-birds such as pheasants; in some near allies of the woodcock, and in the gulls, the down plumage is mottled, and the mottling shows indisputable evidence of having been derived from the breaking up of stripes; while, finally, the mottling disappears, leaving a whole-coloured dress as in the skua-gulls.

Among mammals, the young of the wild boar are striped, the adult is whole-coloured: and the young of many wholecoloured deer are spotted. In some species of the latter, moreover, the spots are ranged in lines, and often run together to form more or less perfect stripes. Foals, it may be remarked, frequently show traces of stripes, suggesting the origin of our whole-coloured horses from striped ancestors. As a rule, this striping is confined to a band along the back and across the shoulders, and bands across the legs ; markings which are retained with some frequency, it may be remarked, in asses throughout life. But in some young horses the hindquarters are also striped.

But the young of some whole-coloured mammals, it must be remarked, differ from their parent in hue. Thus young foxes are at first of a uniform smoke-grey colour, wherein they rather recall the wolf. After a few weeks, however, the characteristic fox-red appears. The young of the common seal, again, is markedly different from the adult in coloration.

That these colours displayed by the young do really indicate ancestral colours is indirectly supported by one or two facts of another kind. Thus, young elephants at birth are thickly covered with hair, while the adult is for the most part hairless; and we know that one of the ancestral and now extinct elephants, known as the Mammoth, throughout life was thickly hair-clad; just as, to turn from external to internal characters, the temporarily separate foot bones of the young bird recall the permanently separate foot bones of their fossil ancestors (p. 74).

It may well be, however, that peculiar coloration of the young which has just been described still plays a really useful part, and hence has been preserved. These young animals, in short, retain, or rather pass through other ancestral stages besides those of colour and physical structure. That is to say, they may repeat the habit of evading enemies which obtained in 
their adult ancestors which wore a similar livery ; the coloration may be the outward and visible sign of the inward and psychical grace! For these same young, when danger threatens, are often left by their parents to fend for themselves. Later, when they have acquired the later habits of their parents, the coloration associated with the earlier and different behaviour is put away.

This, of course, is mere hypothesis, but it serves to bring out the deep interest which is attached to such an apparently simple thing as the colour of an animal's skin.

Those engaged in the teaching of Nature Study would do well at any rate to draw the attention of children to this matter. They should be taught to observe the stripes of donkeys, and to keep a lookout for similar markings in horses. These stripes, by the way, are rare in horses, but common, though by no means universal, in asses. Young lions can only be seen in Museums and Zoological Gardens, but young deer and young foxes may at least occasionally be met with.

In the coloured plate illustrating different types of Mammals the young of the red-deer is shown, which, in being spotted, differs conspicuously from the adult deer; in which the male only, it should be noted, is provided with antlers. In earlier days these animals formed the prey of the wolf, from which escape was only possible by flight. Hence the long legs of the young, to enable it to keep pace with its parents.

On the opposite side of this picture are shown the stealthy, tree-climbing cat; the burrowing badger, partly flesh-eating and partly vegetarian; and the wily fox, which is wholly carnivorous.

Bibliography.-R. Lydekker, British Mammals (Lloyd's Natural History Series); R. Lydekker, "Mammals," The Royal Natural History (Warne \& Co.); Flower and Lydekker, Mammals, Living and Extinct (A. H. Black); E. Ray Lankester, Extinct Animals (Constable \& Co.); R. Lydekker, Geographical History of Mammals (Cambridge University Press); W. L. Sclater, The Geography of Mammals (Kegan Paul \& Co.); W. Flower, The Horse (Macmillan \& Co., Nature Series); R. Lydekker, Guide to the Specimens of the Horse Family (British Museum), and Guide to the Domesticated Animals in the British Museum (British Museum). 


\section{BIR D S}

Bir W. P. Pycraft, F.Z.S.

Assistant in Charge of the Osteological Collections, British Museum

(Natural History)

\section{CHAPTER $\mathrm{X}$}

The Essential Characters of Birds, and a General Outline OF THEIR STRUCTURE

To properly appreciate the position which birds hold in the animal kingdom, and their relation to other animals, a clear idea of their essential characters is necessary ; but it is not proposed here to enter into details of anatomy which concern the specialist.

Birds, then, hold a unique position in the animal kingdom ; and this because of the peculiar structure of the outer covering of the body, which is composed, invariably, of the peculiar horny outgrowths known as feathers. By this character alone they may be at once distinguished from all other animals.

While they, in common with the animals of the class Mammalia (p. I9), have a four-chambered heart and warm blood, they are yet, as a matter of fact, very closely related to the reptiles, creatures of a, lower grade in the scale of life.

The many characters which birds share in common with reptiles happily are of a kind which demand no deep anatomical knowledge to appreciate. They may indeed be very well used to serve as a demonstration of the way in which animals are classified, or placed together in the order of their relationship as nearly as this can be found.

Birds and reptiles agree, then, in having but a single spherical "boss" (condyle) to the skull whereby this articulates with, or is hinged on to, the neck; and in the structure of the shoulder 


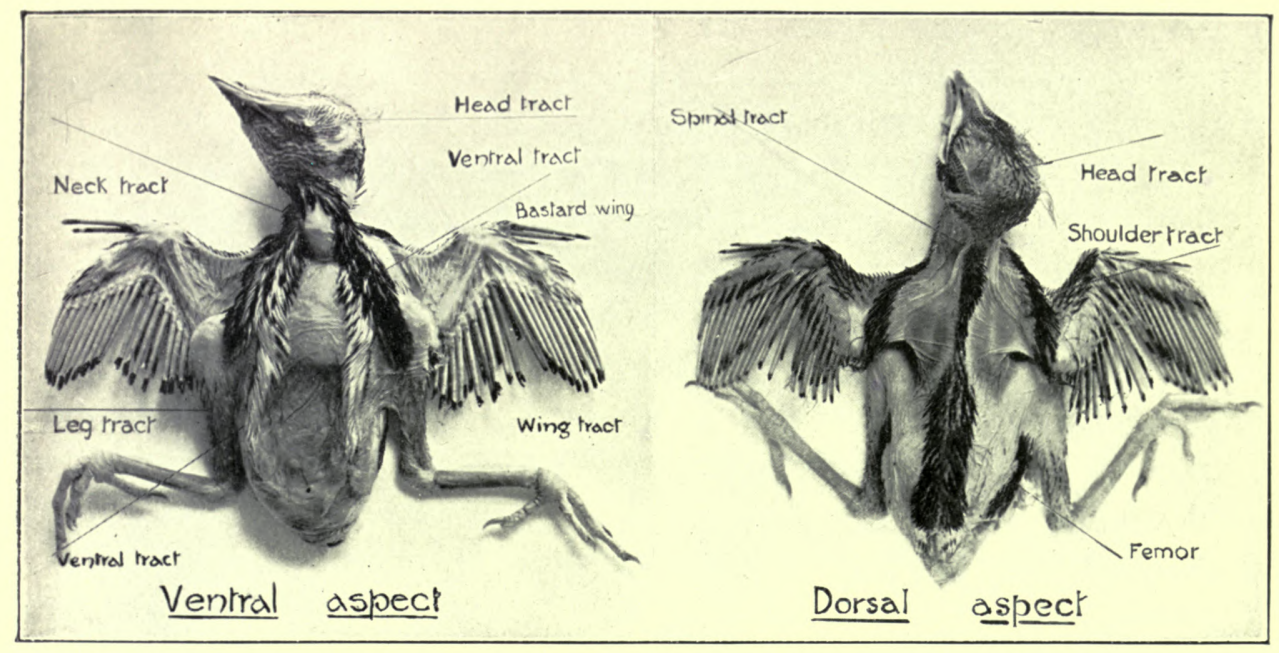

\section{NESTLING THRUSHES}

Showing the distribution of the feathers over the body, and the large featherless spaces cr "apteria."

The feather tracts are here very narrow and the spaces very wide: in the pigeons exactly the reverse is the case. See Model.

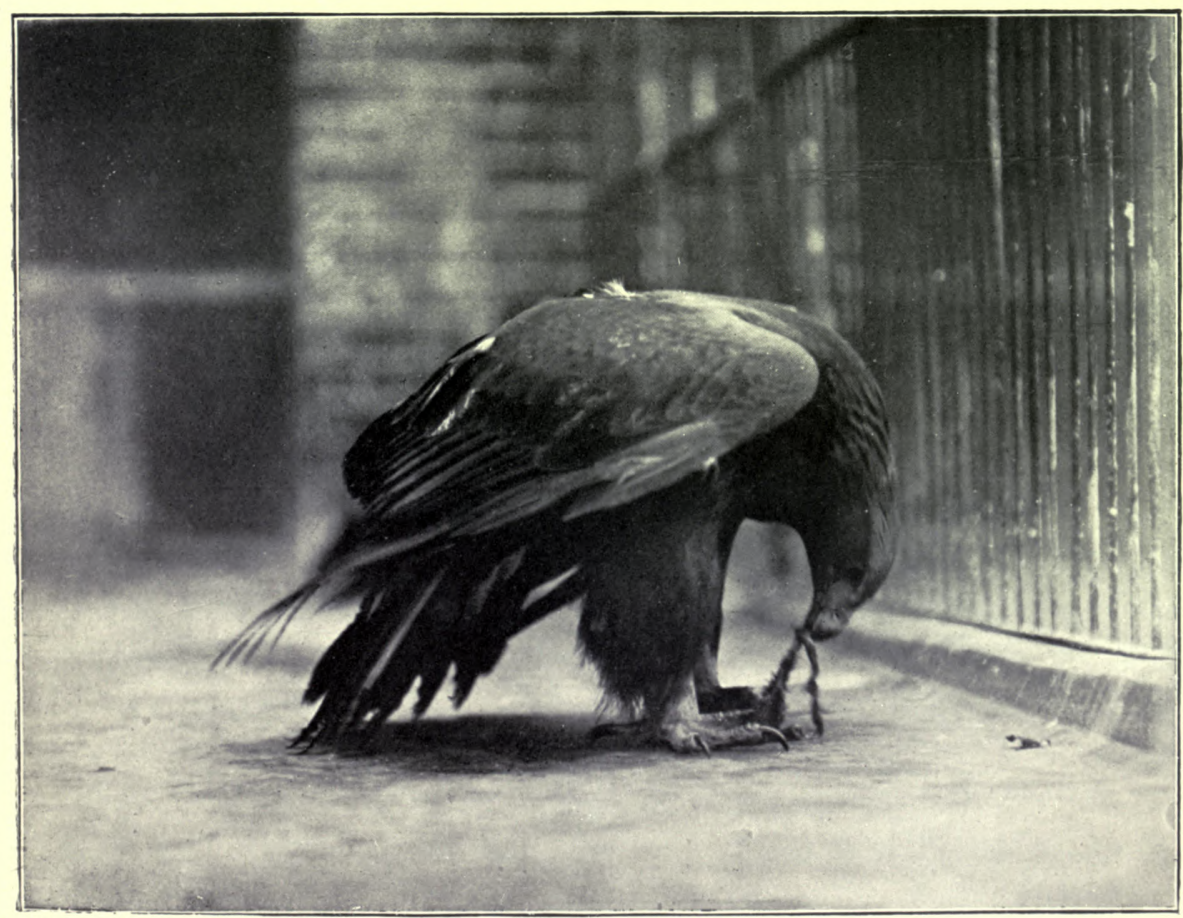

Photo by Henry Irving, Horley.

GOLDEN EAGLE

Showing the method of tearing up the food. 

and hip-girdles-the supports for the limbs. The hind-limb, moreover, is especially reptilian, and this because of the formation of the ankle-joint, which is formed between two rows of ankle bones-traceable only in the very early stages of development, and not between the uppermost row of ankle bones and the shank of the leg, as in mammals (see also p. 74).

But in the structure of the fore-limb, no less than in the peculiar character of the covering of the body, birds stand alone among the vertebrates. This limb has become transformed into a wing, so that when on the ground the body is supported entirely by the hind-limbs.

Although the jaws of birds, as is shown by fossil remains, were originally implanted with teeth, they are, in modern birds, toothless and encased in horn.

Such, in brief, are the essential characters of birds, the characters which go to distinguish birds from all other vertebrates. But a better grip will be gained of the deeper meaning of these characters, and of the bird's place in Nature, if these and some other structural features are examined a little more in detail.

By way of a commencement, it will perhaps be best to begin with the more familiar :-

Feathers.-Feathers, then, although they completely clothe the head, neck and trunk, and may even extend down to the very tips of the toes, are not distributed evenly over the surface of the body, as is, say the hair of a dog, or as are the scales of reptiles. But they are arranged along definite areas or tracts, known as pterylæ, leaving more or less extensive bare spaces, the "apteria." In such birds as the thrush or sparrow the tracts are narrow and the space wide, but in the ducks, for instance, on the other hand, the tracts are of enormous width. The general arrangement of these tracts will be seen in the accompanying photograph. What their purpose may be no one has yet discovered.

As touching the different kinds of feathers it will suffice to say, that the most important are the "contour"-feathers, or those which form the outline of the body; the down-feathers, which answer to the under-fur of mammals, and which occur only in birds such as hawks and eagles, gulls, ducks and swans, 
for instance; and the filo-plumes. These last are the long hairlike feathers seen in the common fowl after being plucked for

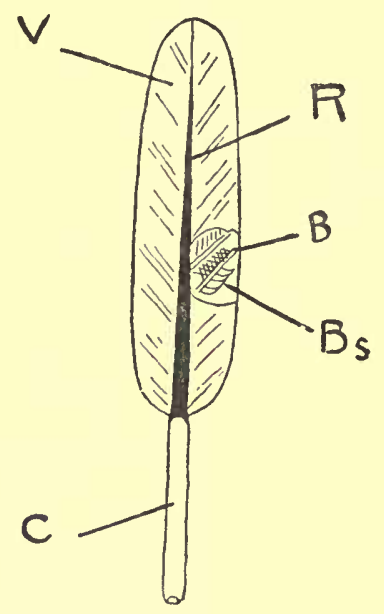

FIG. I8.-Diagram of a contour-feather, showing its several parts. C, calamus or quill; $\mathrm{R}$, rhachis or shaft; $\mathrm{V}$, vane formed by- $\mathrm{B}$, rami or barbs; $\mathrm{Bs}$, radii or barbules, which are shown slightly magnified in the area enclosed by semicircles, and highly magnified in Fig. 19.
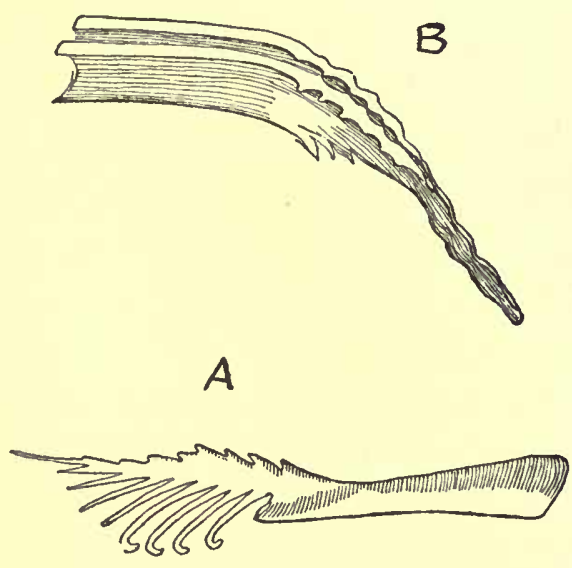

FIG. 19.-Barbules or radii removed from the ramus or barb, slightly magnified. A, shows one of the anterior seriesthat pointing towards the top of the feather; $B$, shows two of the posterior, or hinder series. These may be seen in their natural relations in Fig. 20.

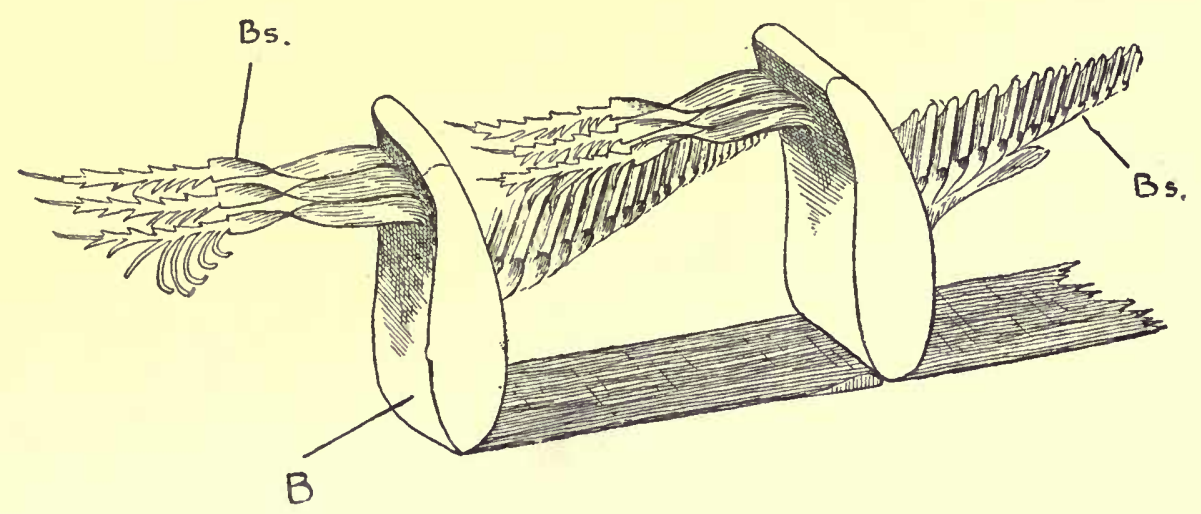

FIG. 20.-A highly magnified section through two rami or barbs, showing the radii or barbules in their natural position. The section has been taken parallel with the barbules of the anterior series, and hence of necessity the posterior barbules are shown in cross section. A reference to the area enclosed by semicircle in Fig. I 8 should make this clear. Note the way in which the hooklets are thrust down into the trough formed by the in-curved blades of the posterior series. 
table. The eyelashes and the bristles round the gape of birds appear to be modified filo-plumes. In some birds, such as herons, a peculiar kind of down is met with known as " powder down," because it breaks up on being touched into a fine powder. This occurs in dense masses on the breast and thighs, or, as in certain hawks and parrots, in isolated tufts, and is of unknown function.

The typical contour-feather is composed of a central axis, divisible into (a) a calamus or quill (Fig. I8) and ( $\beta$ ) a rhachis or shaft (Fig. I8). Along the latter are ranged a series of long, slender, flattened rods known as barbs (Fig. I8, B), which are held together by a complicated system of hooks known as the barbules (Fig. I8, Bs). Each barb bears two rows of barbules of quite different structure, those pointing towards the tip of the feather being provided with long, slender hooklets (Fig. I9, A), while those pointing towards the base of the feather have the form of a series of scrolls, and into the upper edges of these scrolls the hooklets are thrust (Fig. 20).

Thereby, as we have just indicated, the whole series of separate barbs is knit together, so to speak, so as to form a continuous web, which can only be broken with difficulty; and this web forms what is known as the "vane" or "vexillum" of the feather (Fig. I8, V).

At the base of the shaft of the contour-feathers of most birds there will be found a second smaller shaft, bearing a downy vane known as the after-shaft (Fig. 2I, A). What purpose it serves, or why it should be present, no one has yet been able to say. In "game-birds," such as

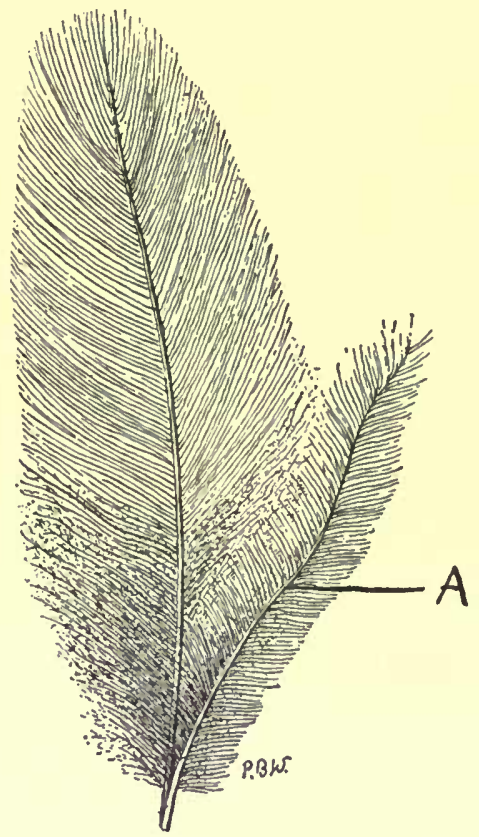

FIG. 2I.-A contour - feather of a pheasant, showing the large aftershaft A.

the pheasant, or in the common fowl, this after-shaft is quite large (Fig. 2I), while in perching-birds it is either reduced to a mere 
vestige or is wanting altogether. In pigeons and owls it is also wanting. In some of the ostrich tribe, such as the emu and

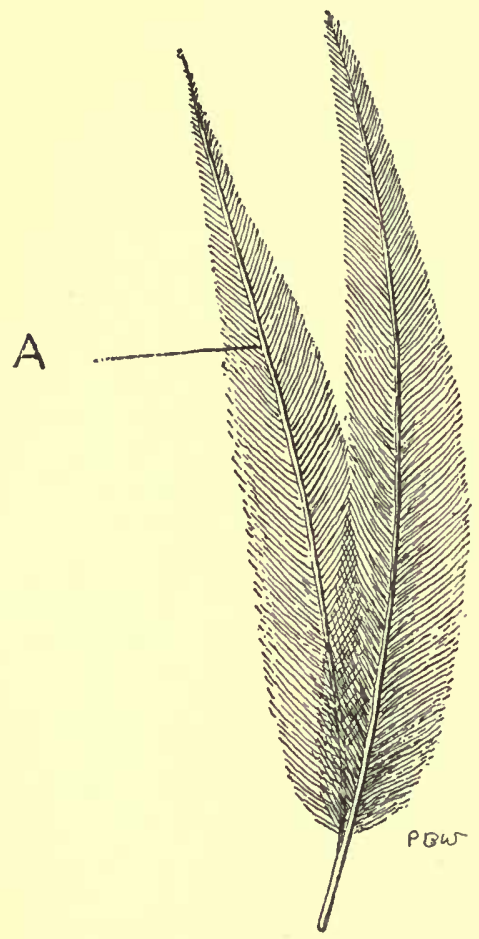

Fig. 22.-A contour-feather of an emu, showing the after-shaft as large as the main-shaft. cassowary, it is as long as the main feather (Fig. 22). Finally, the great fight-feathers of the wing and the large tail-feathers never develop an after-shaft.

The downy covering of nestling birds should be briefly referred to. This covering, in birds which are active at birth, is more feather-like than that which clothes nestlings which remain long in the nest, such as owls and petrels, for example.

Since the nestling periods present one of the most interesting and most instructive phases of bird-life, some effort should be made, even in town schools, to secure one or two of the more striking types of nestlings.

Young pigeons are not difficult to procure, and these are interesting as showing a degenerate down plumage, the down tufts being reduced to hair-like threads; while in young sparrows and young crows no down is ever developed (see p. I02).

But besides these-which should be kept for permanent reference, preferably in a bottle of spirits, or failing that should be stuffed-examples should be obtained of, say, a nestling of the common pheasant, or of the common fowl, and of a duckling, these showing, in addition to the peculiarities of plumage, interesting differences in the development of the wings (p. I02).

In most of these young birds, in the young pigeon, for example, it will be noticed that the nestling down feathers are shed in a very peculiar way, inasmuch as they do not drop out, but are thrust out upon the tips of the succeeding permanent feathers, whereupon they may remain for some time. 


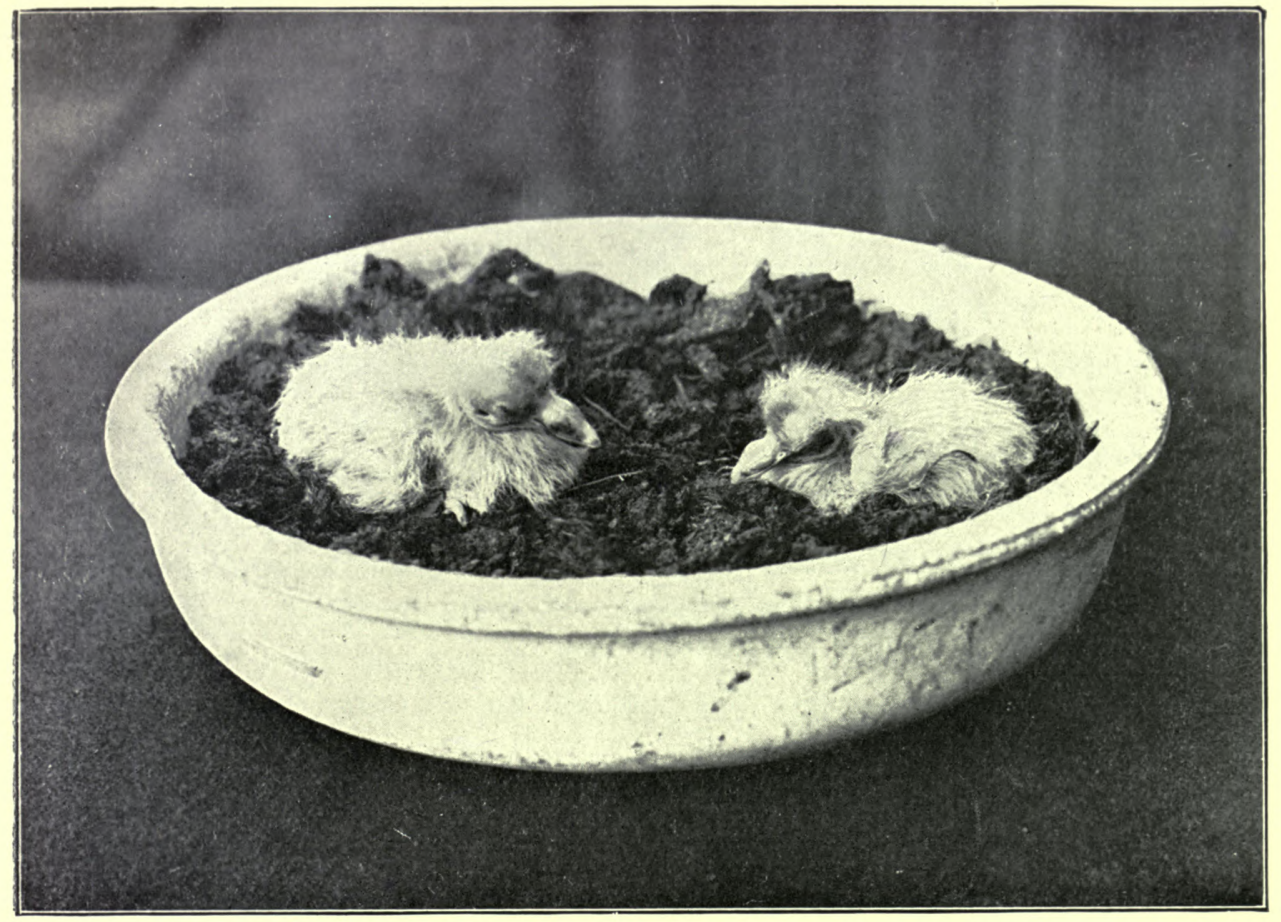

PIGEONS TWO DAYS OLD

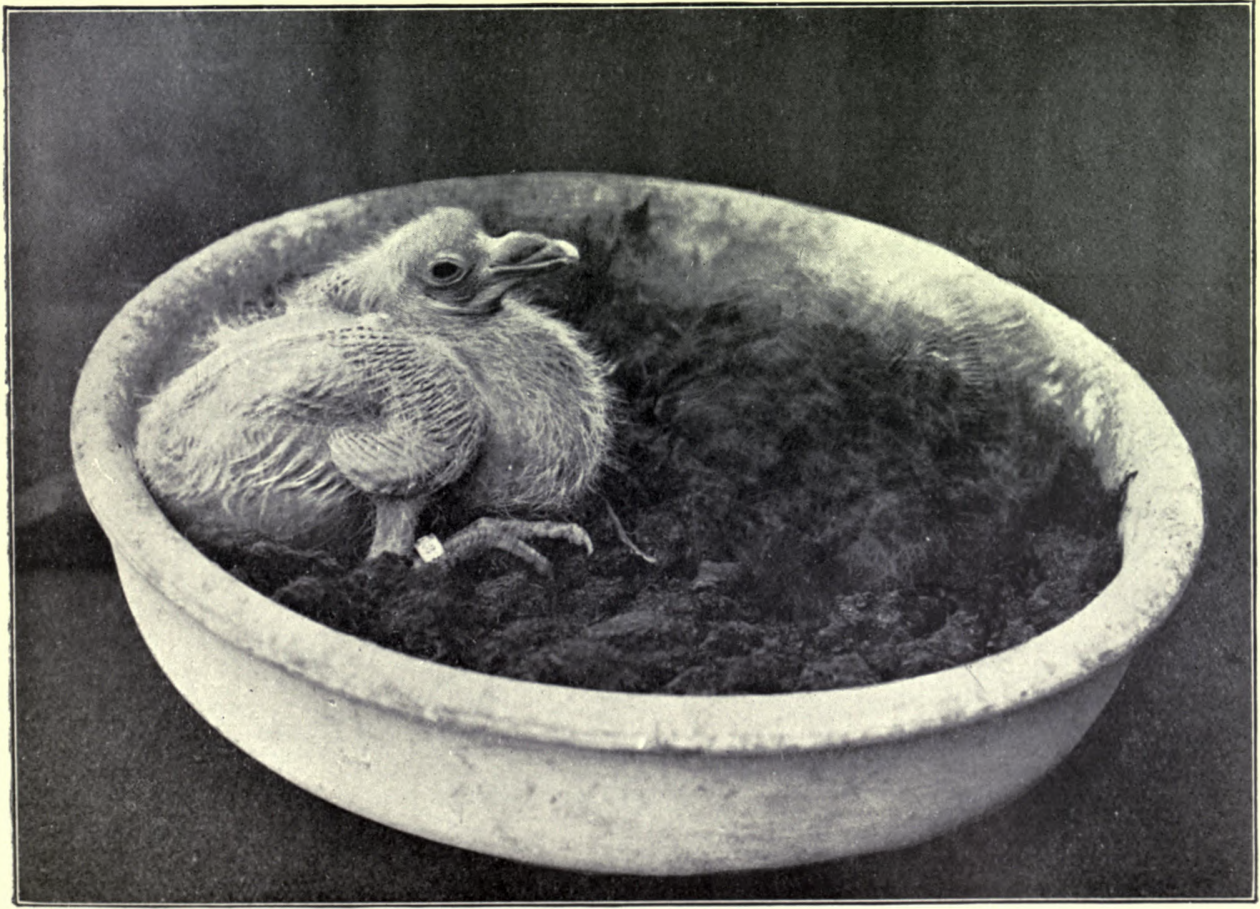

PIGEON SEVEN DAYS OLD 

The Skeleton.-As touching the skeleton of birds only a few words are necessary. In the first place, it should be remarked that birds' bones are exceedingly light, being more or less filled with air supplied from the air-sacs; but the bones of the wing and legs, in some birds, such as the goose tribe, and the swallow, for example, are filled with marrow. If the bones of any part of the skeleton which lodges air be examined, large cavities will be found therein - these are the air chambers.

Birds are remarkable for the great length and flexibility of the neck, which enables the head to reach every part of the body whereby the feathers may be " preened " and kept in good order. The fact that the skull joins the neck by means of a single ball and socket joint only-instead of by a double joint as in mammals (Fig. 3, p. 20) (dog, cat)-adds still further to its mobility. The number of separate bones in the neck varies from twelve to twenty-four. In mammals there are but seven vertebræ, alike in the short-necked whale and the long-necked giraffe.

The fore-limb has undergone great modifications, in so far as the hand is concerned (Model C. 8-9). Only three fingers are present. Of these the first or thumb (Model C.) is reduced and a mere stump, while the second and third are welded together to form a double rod (Model C. 9), but finger number 3 has become greatly reduced. A reference to text (Fig. II) will make this more apparent. This transformation of what was once a five-fingered hand has come about the better to support the great "quill" or "flight-feathers" (Fig. 23), this limb being no longer used for the support of the body when on the ground.

The breast-bone and the bones of the shoulder-girdle have undergone great changes to enable them to support the wings during flight.

The breast-bone, which is slung on to the body by means of the ribs, is a broad plate of bone, down the middle of the under surface of which there runs a long "keel" to which the great breast-muscles are attached, which move the wings.

The shoulder-girdle bones are concerned with the support of the wings. They comprise the scapula or blade-bone (Model C. 6), 
a pair of stout pillar-like bones (coracoids) (Model C.), and the horse-shoe like " merry-thought" or furcula (Model C. Io).

The hind-limbs are supported by a great pelvis (Model C. I2). The chief peculiarity of these limbs lies in their lower extremities. There are no separate ankle bones for example. Of the two rows of bones which make up this series, one row becomes welded or fused with the "shank" of the leg (tibia) (Model C. I4), while

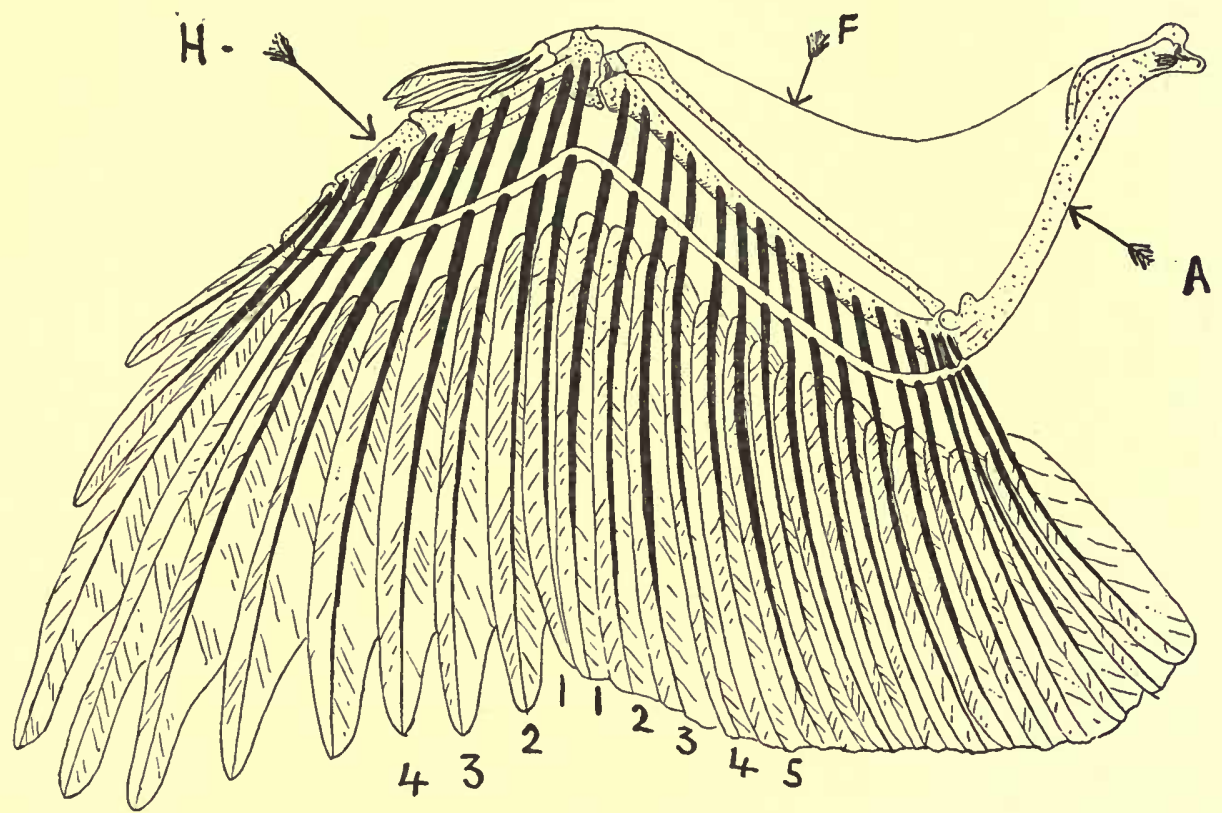

FIG. 23.-Upper surface of a bird's wing, prepared to show the relation of the large "quill" or flight-feathers to the skeleton. A, the arm, of which the humerus forms the support. $F$, forearm; this contains two supporting rods, the radius and the ulna, the last-named forming the support for the great flight or quill-feathers known as the secondaries, $\mathrm{I}, 2,3,4,5$. H, the hand, containing the bones representing the thumb and and and 3 rd fingers. The thumb bears four small stiff, quill-like feathers known as the bastard-wing. The 2 nd and 3 rd fingers support the flight-feathers of the hand, marked $1-4$. Of these I-6 rest upon the bases of digits 2 and 3, 7 rests upon the tiny remnant of digit 3 , and conceals it ; 8, 9 and Io, I I rest upon the penultimate and ultimate points of digit 2 . The narrow white band through which the bases of the quills pass represents a band of tendon helping to keep the feathers in position.

the other row is welded to the bones of the middle of the foot (metatarsals) (Model C. I5). Of the original five toes but four remain, and these answer to the great toe and succeeding toes of the foot in man. 
The bones which support these toes, the bones which answer to those which contribute to form the sole of the foot in man, are four in number. They are known as the metatarsals. The first is detachable, and reduced to a mere vestige; while the remaining three have become welded together to form a single, cylindrical shaft, known as the tarso-metatarsus, because the upper end of this shaft is formed by the lower row of ankle bones or " tarsal" bones. These, however, in the adult bird have become welded one to another, and, with the long metatarsals, to form one solid shaft. In the very young bird all these bones are separate, and even in the nestling stage this compound nature can be traced. For the row of ankle bones just referred to will be found forming a separate plate capping the end of the shaft, while the shaft itself will display traces of the three bones of which it is made up.

Some effort should be made to add the skeleton of the leg of, say, a common fowl of about six to eight weeks old, to the specimens used for teaching in the school museum. This compound shaft, which forms the lower portion of the leg in the living bird, is commonly clothed in scales and often brightly coloured.

Further, attention should be drawn to the fact that birds walk upon their toes, and that what answers to the sole of the foot in man forms what is commonly known as the "leg" in birds. Only in a very few birds does the bird's heel ever come near the ground, and no bird is really plantigrade, that is to say no bird walks on the sole of its foot.

The eyes of birds, it may be remarked, like those of reptiles, are surrounded by a ring of bony plates, which in some species, such as eagle and owls, are of considerable size. But these plates do not, strictly speaking, form part of the true skeleton.

The Alimentary System.-The organs which perform the work of collecting, preparing, and digesting the food present but few characters which can afford useful knowledge to those who are seeking to acquire only the elements of ornithology.

In studying this aspect of the birds' economy it must be borne in mind that birds do not, and cannot, masticate their food- 
being toothless. In the majority of cases it is swallowed whole ; but many birds, as hawks and eagles, tear their prey in pieces when too large to be swallowed whole.

The solid and often large pieces of food thus necessarily swallowed are passed, in a large number of birds, into a dilatation

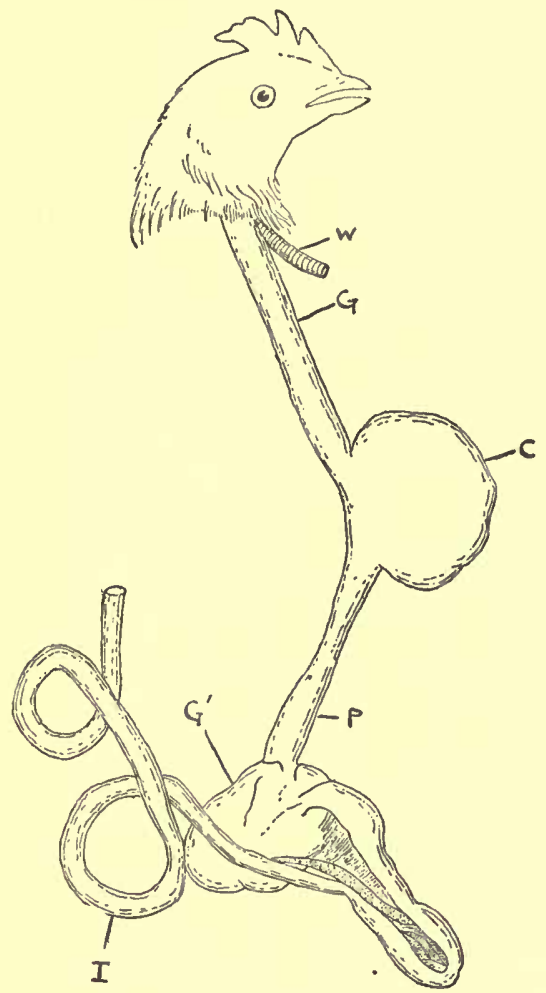

FIG. 24.-The crop and gizzard of a fowl, to show their general form and relations. W, trachea or windpipe; $\mathrm{G}$, gullet or œesophagus ; $\mathrm{P}$, proventriculus; $\mathrm{G}^{1}$, gizzard ; $\mathrm{I}$, intestine. of the gullet known as the "crop" (Model D. 8). Here it is often retained in large quantities before being passed on to the stomach, in order that it may be softened, or because of the necessity of taking in, at once, more food than can be immediately dealt with by the stomach.

This crop is very thin walled, and while in some birds it takes a spherical form, as in the game birds (Text, Fig. 24), in others, as in pigeons, it is bilobed. From the crop the food passes on to the "proventriculus" (Model D. 8). This is distinguished from the gullet chiefly by its thickened walls, which are crowded with glands secreting the digestive juices. This proventriculus is to be regarded as the anterior end, or first portion, of a complex stomach. For the hinder end of this organ, in grain-eating birds, has been modified to form what is known as a "gizzard" (Model D. I5). Herein the walls are of great thickness, and very muscular, while the cavity they enclose is lined with a thick, horny layer, thrown into folds, or provided with dense opposing surfaces in the form of pads, as in the common fowl and swan (Text, Fig. 25). Here grain and other hard food is ground into minute pieces by means of small stones swallowed by the bird for this purpose. 


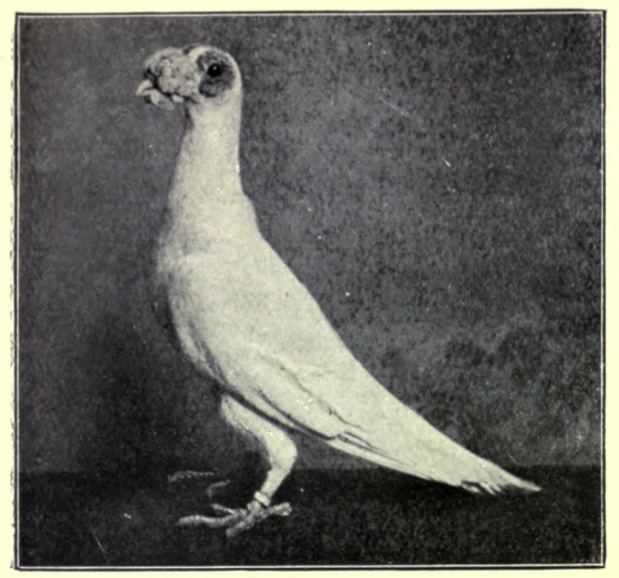

CARRIER

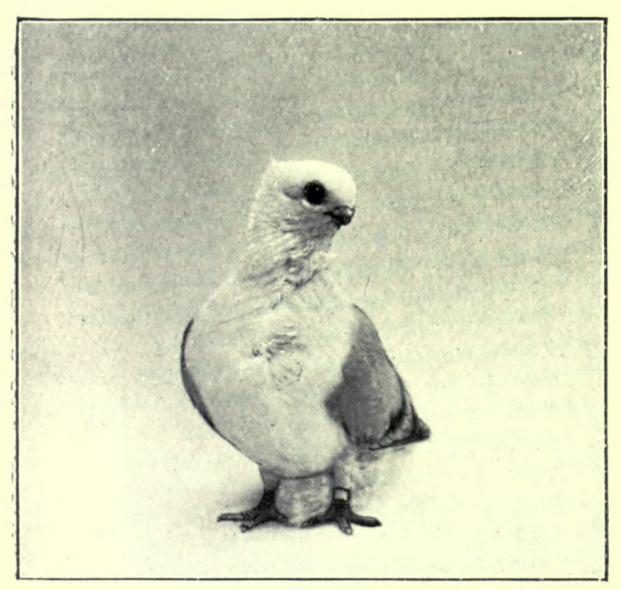

TURBIT

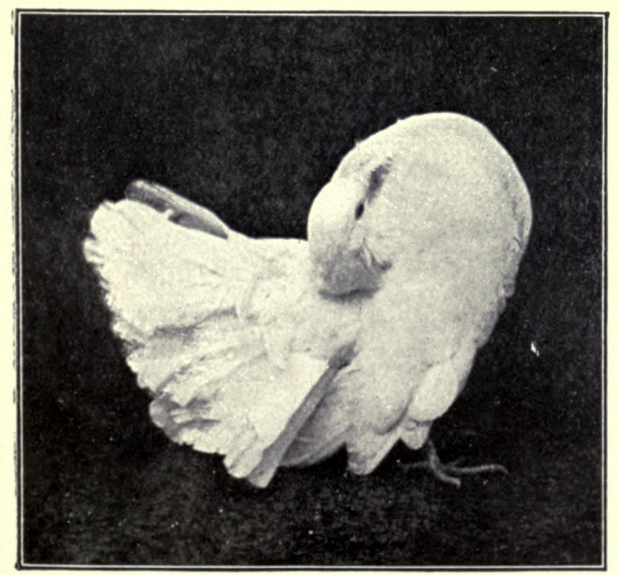

FANTAIL

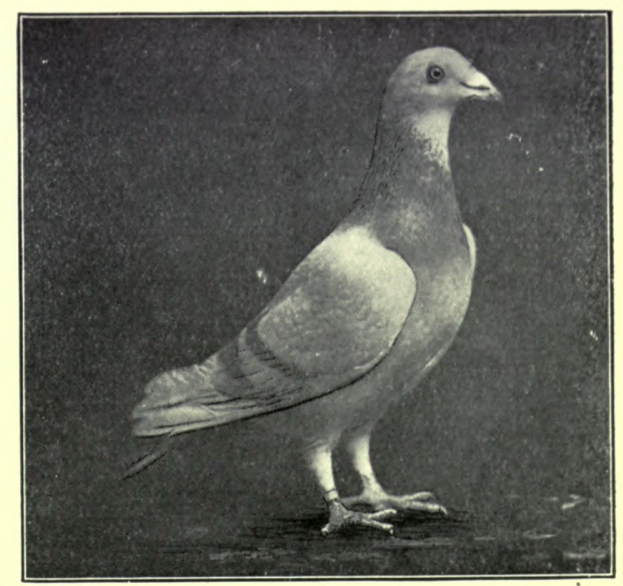

BLUE-ROCK

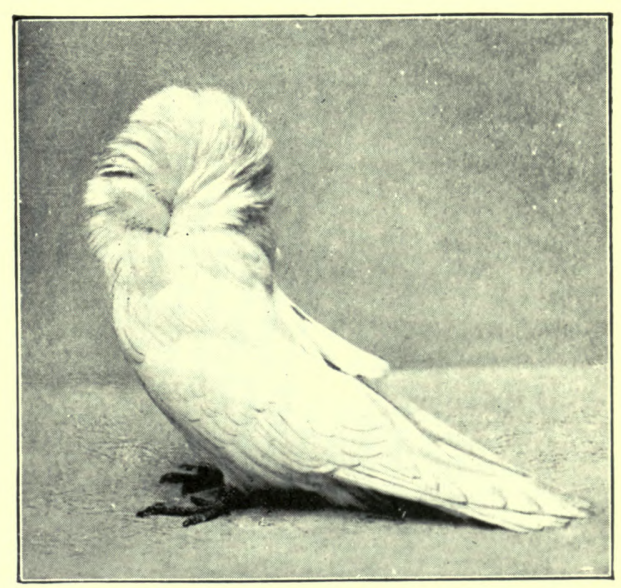

JACOBIN

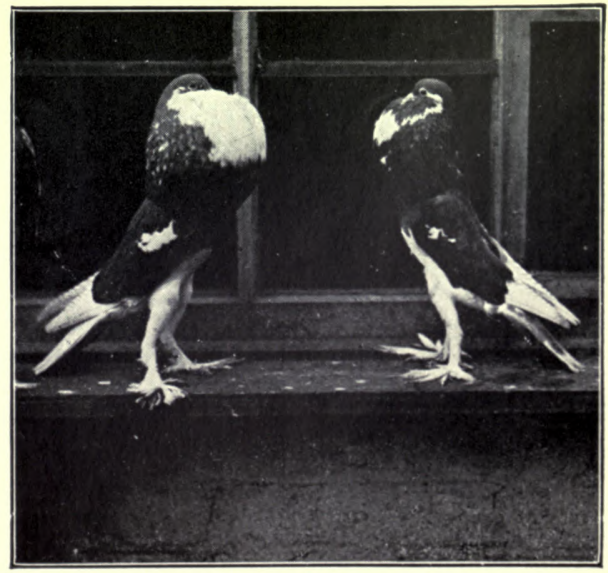

POUTERS 


$$
\text { . }
$$


Thus prepared, the food is passed into the intestines (Model I. E. 35-4I), where all that is nutritious is absorbed, either by the blood or special vessels forming what is known as the "lacteal" system; the undigestible residue, passing into the "large intestine" or " rectum" is finally expelled.

Birds, it should be noted; which feed on fish have very long intestines, and the walls thereof of great thickness, thereby they are protected from injury by broken fishbones. Grain-eating birds have similarly long intestines; in fruitand in insect-eating birds the intestines are very short and thin walled.

Into the hinder end of the large intestine the ducts of the kidneys open, and the ducts of the generative organs conveying the sperms, or eggs, as the case may be.

The Lungs and Air-Sacs.-The lungs of birds do not hang freely in the cavity of the thorax, but are attached to its roof (Model D. 9). They are further peculiar in that they give off diverticula, or pouches, known as air-sacs, which contain large stores of respiratory air. They are to be found on each side of the body cavity, and in between the " merry-thought." If chromic or picric acid be forced with a syringe into the windpipe, these sacs can be filled, when, after a few hours, their walls will be hardened so that on dissection these cavities can be readily studied. The

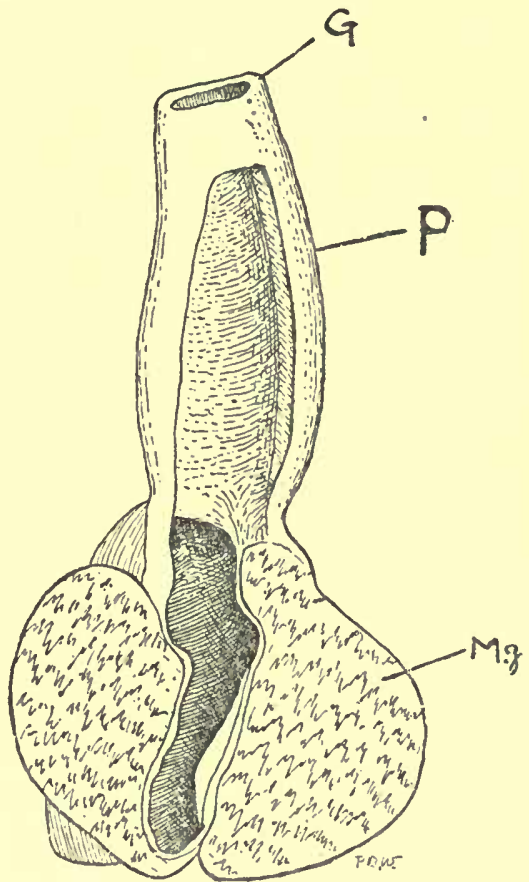

FIG. 25.-A section through the lower end of the gullet and gizzard of a swan, to show the great thickness of the muscular walls of the gizzard, the cavity of which is shown by the deep shading. $G$, gullet; $P$, the region known as the "proventriculus." The walls of this region are thick, and supplied with numerous digestive glands. $\mathrm{Mg}$, muscular wall of gizzard. air from these air-sacs finds its way all over the skeleton in many birds, the bones being hollow. In some species, however, certain bones are filled with marrow, as in the humerus of the swallow. 
The air-sacs do not, as was supposed, serve the purpose of rendering the body lighter during flight, but rather to contain reserves of breathing air during flight.

In some birds, it should be remarked, yet other air-containing vessels have been developed. In the emu, for instance, a great air-bag is given off from a slit in the windpipe, near the middle of the neck, and this serves apparently to increase the sound of the voice. In some other birds, again, the gullet is made to serve the purpose of a wind-bag, and is inflated at the will of the bird, when it desires to draw increased attention to itself. The pouter pigeon, for example, inflates the crop to an enormous extent, and so also do some near relatives of the grouse tribe, natives of North America.

In birds like the gannet of our coasts the whole body is encased in a mass of small air-containing cavities placed just under the skin.

Birds of the ostrich tribe, it is interesting to notice, still retain the internal air-sacs, though they have long since lost the power of flight.

The Heart.-The heart (Model D. Io) of birds contains four chambers as in mammals. Thereby a perfect oxidation of the blood is possible, and hence a higher temperature than in reptiles, wherein the heart has but three chambers. But the blood of birds is of a higher temperature than in mammals, while it differs further in that the oxygen-carrying cells or red corpuscles have a nucleus therein agreeing with the blood cells of Reptilia. 


\section{CHAPTER XI}

\section{Some Common BRitish Birds}

OUR commonest British birds afford the very best of materials for those engaged in the teaching of "Nature Study." For birds, though presenting a remarkable uniformity in so far as their general characteristics are concerned, have proved plastic enough in adapting themselves to various modes of life, thereby lessening the struggle for existence.

The forest and the swamp, the desert and the fertile plain, the mountain, inland streams, and the open sea, are alike seized upon by birds. But according as they elect to live in the one or the other, so they have to adapt themselves to the physical conditions of each environment. That is to say, the desert-dwelling birds must conform in coloration to their arid surroundings, the stream-dweller must be able to wade or swim, while such as live by rapine must develop sharp-pointed beaks and claws, and great powers of flight. But these points will become more clear as we proceed. In some birds this adaptation is striking in character, in others less so. But besides the physical characters which distinguish different groups of birds, there are also seasonal changes of plumage to be studied, and the differences which commonly distinguish the sexes, and birds of different ages.

In so far as the practical work of teaching is concerned, those who live in towns are placed at a distinct disadvantage. But even the largest towns are never altogether bird-less. The house-sparrow, like the poor, is always with us; and besides, the starling and thrush are occasional visitors. But in most towns the list is a much larger one; while, in the public parks various kinds of water-fowl and peacocks are commonly kept, and failing these there are always pigeons and other domesticated birds.

Having in view the needs of teachers both in town and country, 
it is proposed here to take the common sparrow as an object lesson.

This bird, it should be remarked, is a member of that great group known as the "Passeres" or perching-birds. Ranging in size from the tiny gold-crested neen, one of the smallest of living birds, to the giant of the tribe, the raven, all agree in having more numerous voice muscles than any other birds; and they have besides yet other anatomical characters in common, which demand no reference here. But this much should be remarked. All have relatively short legs, and the toes arranged on a model, which shows that perching rather than walking is their primary purpose.

This great Passerine assemblage, which represents about onehalf of all the known birds - that is to say, of the I3,000 species which had been described, about 6000 are Passerine birds-can be split up into many groups; and of these the "finch-like" birds form a very large proportion. To this finch group the sparrow belongs; and the main characteristic of this group is the conical-shaped beak, the sheath of which is of considerable hardness. Such a beak is admirably suited for picking up and crushing seeds. And if a large series of finch-like birds is examined a surprising range in size will be found, the hawfinches possessing the largest of all; these birds being able to crush seeds that few other birds could manage. Thereby it should be noticed they can continue to live in areas thickly populated by their near relatives without adding to the struggle for existence, since they are enabled to " tap" food supplies which their neighbours must perforce leave untouched.

In the matter of plumage the common sparrow presents some extremely interesting points, and to properly appreciate these, a comparison should be made with its near relative the tree-sparrow.

In the first place, then, the sexes in the common sparrow are dissimilar, the female being much more soberly clad than her mate. The most striking features of the male are the black throat and the rich mottling of russet and black on the upper parts; the crown of the head, it should be especially noticed, is grey, bordered on each side by a band of russet; while across the wings runs a bar of white. 


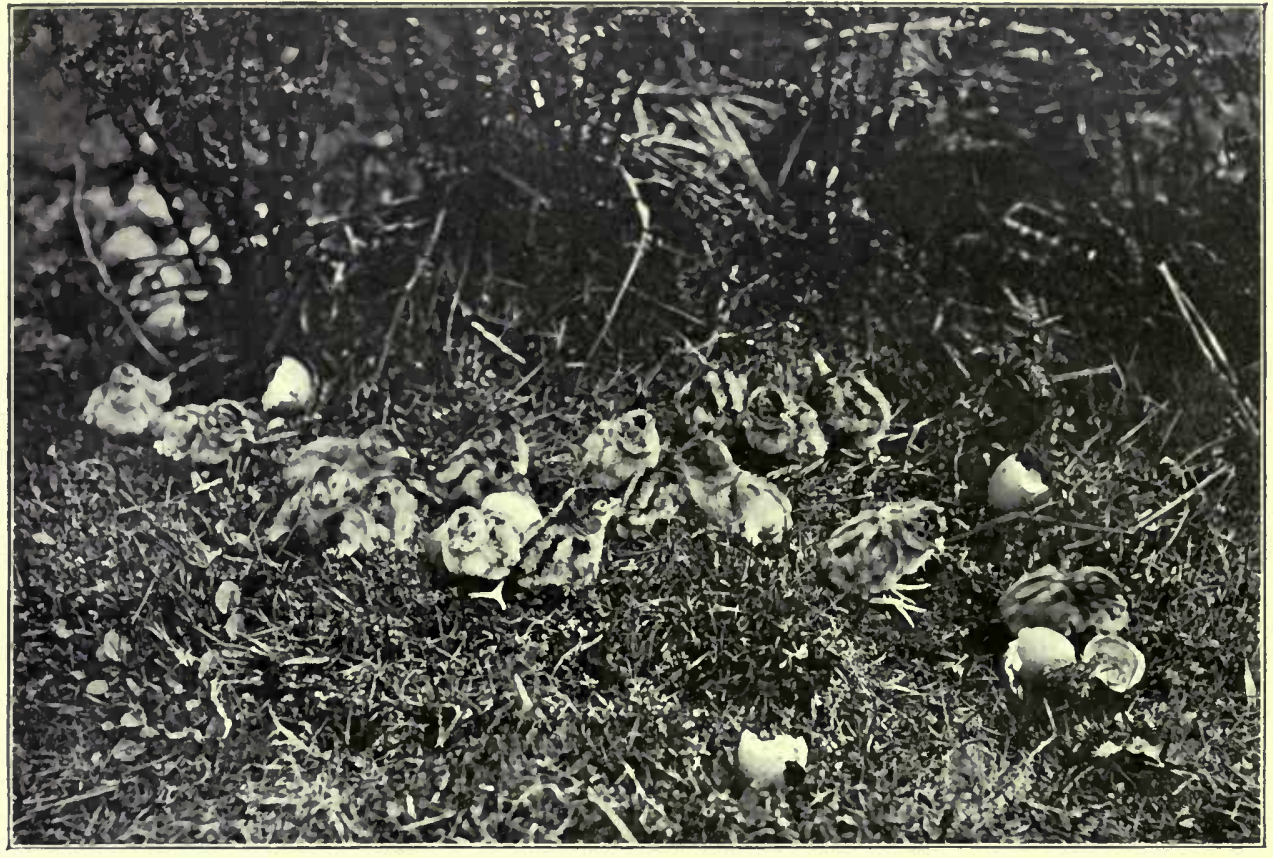

Photo by Charles Reid.

YOUNG PIIIASANTS

Showing the striped down.

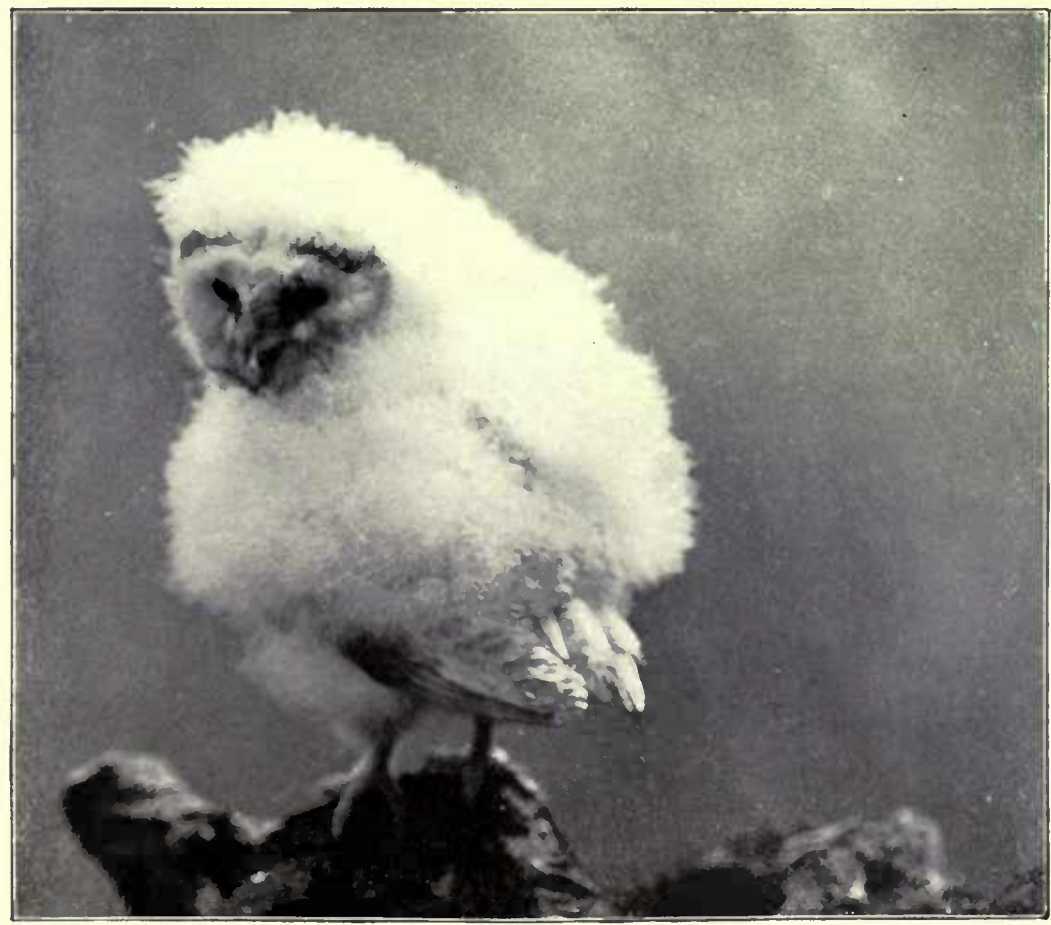

Photo by J. T. Newman.

YOUNG BARN OWL

Showing the first traces of the wing and tail feathers 

In the tree-sparrow, on the other hand, the sexes are alike in colour, and therefore indistinguishable externally. From the house-sparrow this species may be readily distinguished by its slightly smaller size, and in having the whole of the crown russet colour, two white wing-bars, and a black patch on the sides of the neck.

Why, in species so closely related, there should be such a marked dissimilarity in the coloration of the sexes is at present a mystery. And here may be mentioned a "law" as to the coloration of the sexes which is of peculiar interest. As a rule, the sexes are dissimilar, and the male is the brighter. In such cases the young in their first plumage resemble the female. Where the sexes are alike in colour the young either have a livery of their own, which is always dull-as in the case of the starling-or they resemble their parents, lacking perhaps something of their brilliance, as in young kingfishers.

In comparing the house- with the tree-sparrow attention should be drawn to the marked difference of disposition of the two species. For the house-sparrow may almost be called a parasite, never leaving the neighbourhood of human habitations. Wherever man has established himself, there, throughout the old world, will the house-sparrow, or some sub-specific race thereof, be found. Pugnacious in character, it drives away other and more desirable species; and by its numbers makes itself a nuisance, since it has developed an insatiable appetite for corn, levying a heavy toll wherever this is grown; while it makes no adequate return in the destruction of noxious insects. Insect food, indeed, is a diet they never partake of, though for a week or two they select this for the nourishment of their young.

The tree-sparrow, on the other hand, seems to shun the society of man, frequenting rather the pollard willows along the edges of the streams. But it is extremely local in its distribution, and is nowhere numerous. As a matter of fact, it may well be that the retiring habits of the tree-sparrow are rather the consequence of necessity, imposed upon it by the tyrannical house-sparrow. At any rate in some Eastern countries, and especially in China, the tree-sparrow replaces the house-sparrow, and displays the same preference for human habitations.

vol. I. -6 
The thrush and the blackbird afford by contrast some interesting data. Both are examples of birds which for the most part prefer animal food, such as worms and snails, though ripe fruit possesses for them an irresistible attraction, so that, when fruit is plentiful, large numbers congregate to the feast, and thereby may inflict serious loss on the grower.

The thrush shows a great fondness for snails, and these are detached from the shells by an ingenious device, the bird carrying its victims to some large stone, against which the shell is beaten until reduced to fragments. Around these slaughterhouses of the thrush there may be seen large accumulations of such broken shells. Worms are sought for, and dragged from their burrows with great skill, as anyone may judge who tries to perform a like feat without breaking the worm in two. In accordance, then, with the nature of their food the beaks of these birds have the character of a pair of forceps, contrasting strongly with the crushing jaws of the sparrow.

In the matter of plumage these two species are interesting, since in the thrush both sexes and the young wear the same livery. In the blackbird, on the other hand, the male is of sable hue with a golden yellow beak, while the female is of a dark brown colour, with a horn-coloured beak. The young resemble the female, but, it should be noted, have the throat more spotted and the back streaked with rufous (see coloured plate).

Though the thrush and blackbird are resident species, they migrate to a certain extent. Indeed, in some districts these birds are conspicuous by their absence from October to January. But besides these resident birds, large numbers reach our shores from the Continent during the autumn months. On this matter, however, see page I04.

Both the thrush and the blackbird are great songsters, and here again they differ markedly from the sparrow, which is songless.

The robin is a favourite with all children. But they, like their elders, are generally not aware that, in this bird, the sexes are externally indistinguishable. What are commonly supposed to be female robins are the young in their first plumage, wherein the breast is buff-coloured and spotted, as also is the back. This 
mottled dress of the young is one of the characters which shows that the robin is a member of the thrush tribe: all the young of which, and the adults of such species as the common thrush, missel-thrush, fieldfare and redwing - all British birds - are spotted.

Several interesting facts can be brought out in the life-history of the common starling, and especially in the matter of the changes of plumage which this species displays. These, however, will be described presently.

Fceding mainly on insects, starlings are useful allies of the farmer and gardener: but they have a habit of collecting in vast flocks. And where such flocks occur in the neighbourhood of reedbeds they may do considerable damage, since, choosing these beds as desirable roosting-places, they break down the reeds by reason of their great numbers and thereby destroy a very valuable crop, since reeds are still largely employed for thatching purposes.

A horde of starlings on the wing is one of the finest sights which this country affords to those who have a love for natural history. For these flocks, each of which may number many thousands of birds, contrive, as by some concerted signal, to change their shape with the most amazing unison and speednow forming a dense cloud high in the air, now rushing downwards, spreading the while into a vast sheet, till finally, trailing out like some giant streamer, the host melts into thin air !

The Shapes of Birds. - The fact that the shapes of birds, no less than of other animals, are largely determined by their mode of life, should be specially mentioned. One or two most striking illustrations of this are to be found among our British birds. The swallow and the swift, for example, are not in the least related, yet they bear a most striking general resemblance. Both obtain their food on the wing, preying upon flies and other small winged insects. Both, therefore, have need of the same requirements-powerful wings and great speed. The owls again so closely resemble the hawks that, by the older naturalists, they were always associated therewith; the owls forming the " nocturnal," the hawks and eagles the "diurnal" birds of prey. Yet these two are not even remotely related; the owls being near relations of the night-jars. The petrels, again, of which the storm-petrel or "Mother Carey's Chicken," the fulmar, and the 
Manx-shearwater, may be taken as examples, are commonly supposed to be related to the gulls. This is not so, however; for the gulls are closely related to the plovers, of which the green plover or lapwing may be taken as an example. Externally the petrel may always be distinguished by the fact that the nostrils open in the form of a pair of tubes, while in the gulls they are represented by long slits in the middle of the beak. These superficial resemblances, then, are further instances of "adaptation" to which reference has already been made (p. 79).

On Flight. - This chapter must needs contain a brief summary of the more important facts concerning flight, at least in so far as its simpler problems are concerned.

But to appreciate the nature of the flight of birds a clear understanding of the main structural characters of the wing is necessary. This is a compound organ consisting of (I) a bony, jointed rod-the "skeleton" of the wing; and (2) the membranes supported thereby.

This skeleton has already been described, and the "membranes" which it supports have also been described, in so far as their general structural characters are concerned, for these membranes are formed by feathers, albeit specially modified feathers.

We say "specially modified" feathers advisedly, because, in the matter of their arrangement, their length, shape and size, and in their great strength, they show that they have been moulded, or modified, to serve the mechanical requirements of flight.

Let us examine their feathers then, both in their relation to the bony, jointed rod which supports them, and to one another.

In Fig. 23 (p. 74) it will be noted that these feathers are distributed along the fore-arm and hand, and that while those of the fore-arm are separated by fairly wide spaces, on the hand they are closely crowded together-at least at their attachment to the skeleton. Then it will be noted that they overlap one another, and this so that the outer edge of each overlaps the inner border of the feather next in front, and this, as will be shown presently, is a most important point. Next, as to number and shape. In the first particular there is a wide range; the smallest wings having as 


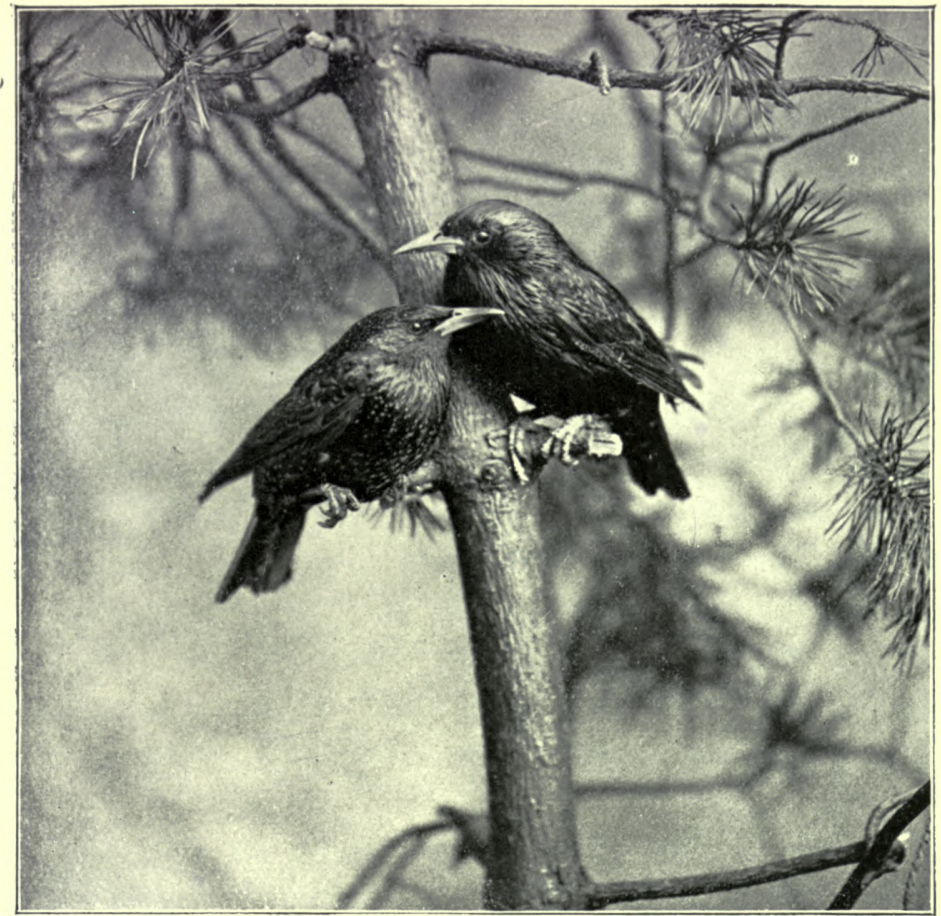

Photo by Charles Reid.

STARLINGS

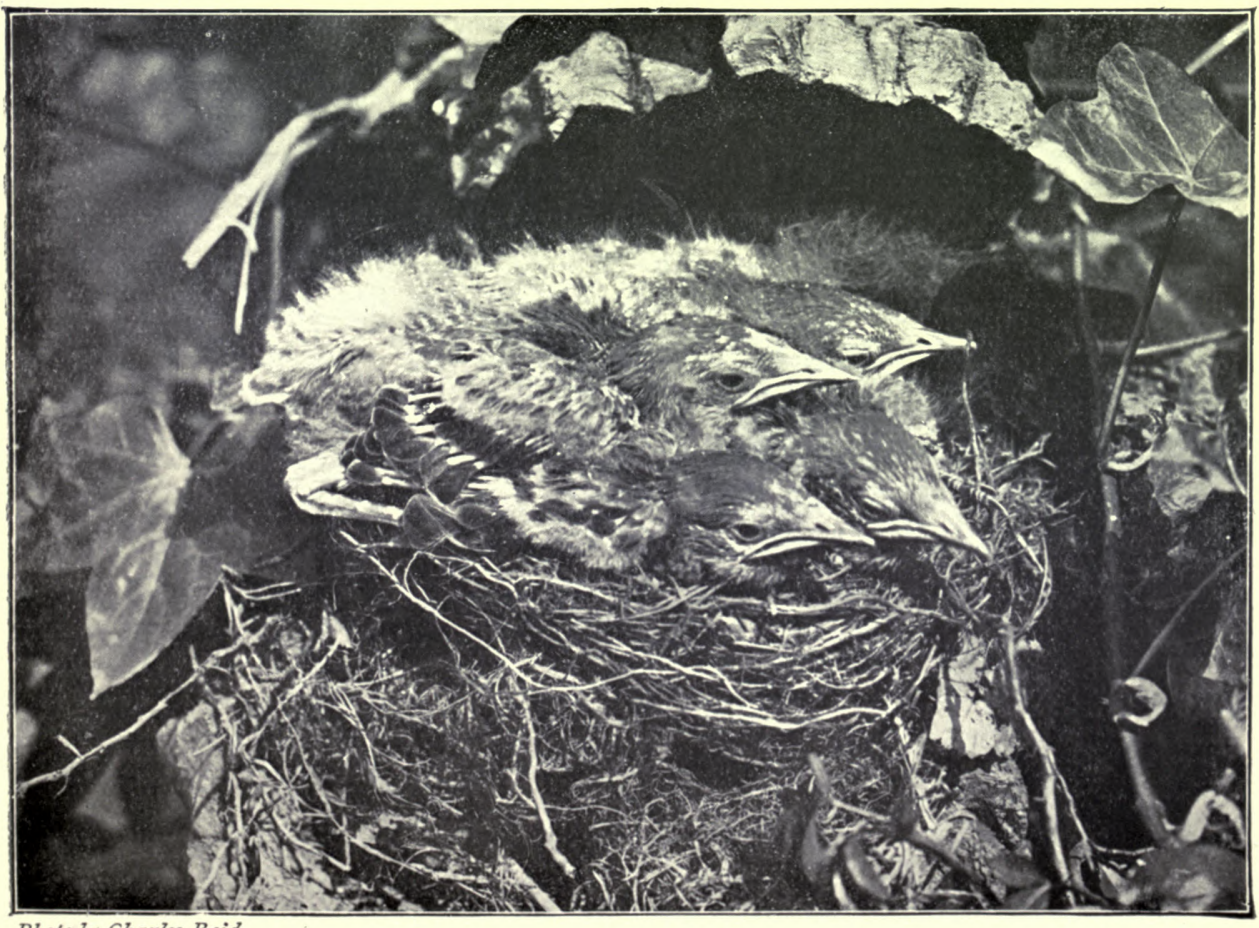


few as sixteen, the largest as many as fifty of these " quills." But there is a great constancy about the number of the quills borne on the hand. These are known as the " primaries" or " primary quills," and never exceed twelve in number, or fall below ten. So that the range in this difference of thirty-four is due to the variations presented by the quills of the fore-arm, which are known as the " secondary "quills, or " secondaries." When the fore-arm is short there are few of these; as the length of this support increases, so the number of the secondaries increases. Next it will be noticed that while the secondary quills are peculiar in that the "vane" is of equal extent on both sides of the shaft in the primaries, the outer vane is much narrower. Finally, in the outermost primaries the inner and outer webs are often deeply hollowed so as to give the wing, when fully extended, a curiously fringed appearance, as in the crow when flying, for example.

These long feathers, when the wing is extended, form, on either side of the body, a broad flat sheet comparable to that of the bat's wing (p. 44), but with this very important difference. The bat's wing is formed by a delicate sheet of skin stretched between long and very delicate fingers; and any extensive injury to such a wing would be irreparable, rendering its possessor helpless. The bird's wing, on the other hand, being made up of a series of separate parts, is easily repaired should any one of these parts become injured in any way.

But more than this, the bird's wing is superior to that of the bat in this: that the resistance offered to the air in flight is less, and for this reason. It will be remembered that the quill feathers of the wing have a peculiar overlap, whereby the free edges of every quill, when the wing is examined from its upper surface, overlap the inner edge of the feather next outside it. Now, when the wing is raised for the upstroke the air is driven through it ; that is to say, it escapes by the pressure exerted on the inner webs of the feathers. But on the down-stroke the resistance of the air to the under surface of the wing forces the free edges of the quills upwards, and so presses them against the outer edge of the feather to its inner side, thereby offering a perfectly unyielding surface to the air. By this arrangement the resistance to the air on the up-stroke is 
reduced to a minimum, while its resistance on the down-stroke has as much force as in the wing of the bat.

It is suggested that those who desire to demonstrate this point should procure, say, a sparrow or pigeon recently killed, when the foregoing remarks can be followed out and tested. It is impossible, indeed, to really grasp the full meaning of this mechanism from mere description, however carefully they may be written or read.

So much, then, for the wing as a part of the machinery of flight. The driving power is furnished by the breast muscles, which are relatively of enormous size, covering the whole of the breast-bone, and being further provided with an additional surface for attachment in the shape of a median " keel "- - the bony plate running down the middle of the breast-bone.

Birds which live in areas free from enemies, and containing an abundant and constant supply of food which can be picked up off the ground without the need of foraging over extensive tracts of country, gradually cease to fly, and in consequence these muscles and the supporting keel of the breast-bone slowly undergo degeneration, until its flight is lost completely,-as, for example, in the owl-parrot, where but a vestige of the keel remains; or in the ostrich tribe, where even this has vanished.

It should be pointed out, then, that a bird's standard of efficiency in the matter of flight is determined, more or less exactly, by the stimulus of external circumstances,- - the necessity of taking long flights to obtain food or escape the rigour of climate or the attacks of enemies.

Attention may further be drawn to the fact that birds which spend much of their time on the wing have long pointed wings, as in the swifts, swallows, gannets and albatrosses; while, on the other hand, birds which fly but little, or live in forests or amid thick undergrowth, have short rounded wings, such as in the tawny owl, wren and game-birds.

The penguins occupy a unique position among birds, their wings having become transformed into swimming paddles answering to those of whales and turtles, in so far as their shape is concerned. But whereas in the penguins and turtles these paddles 


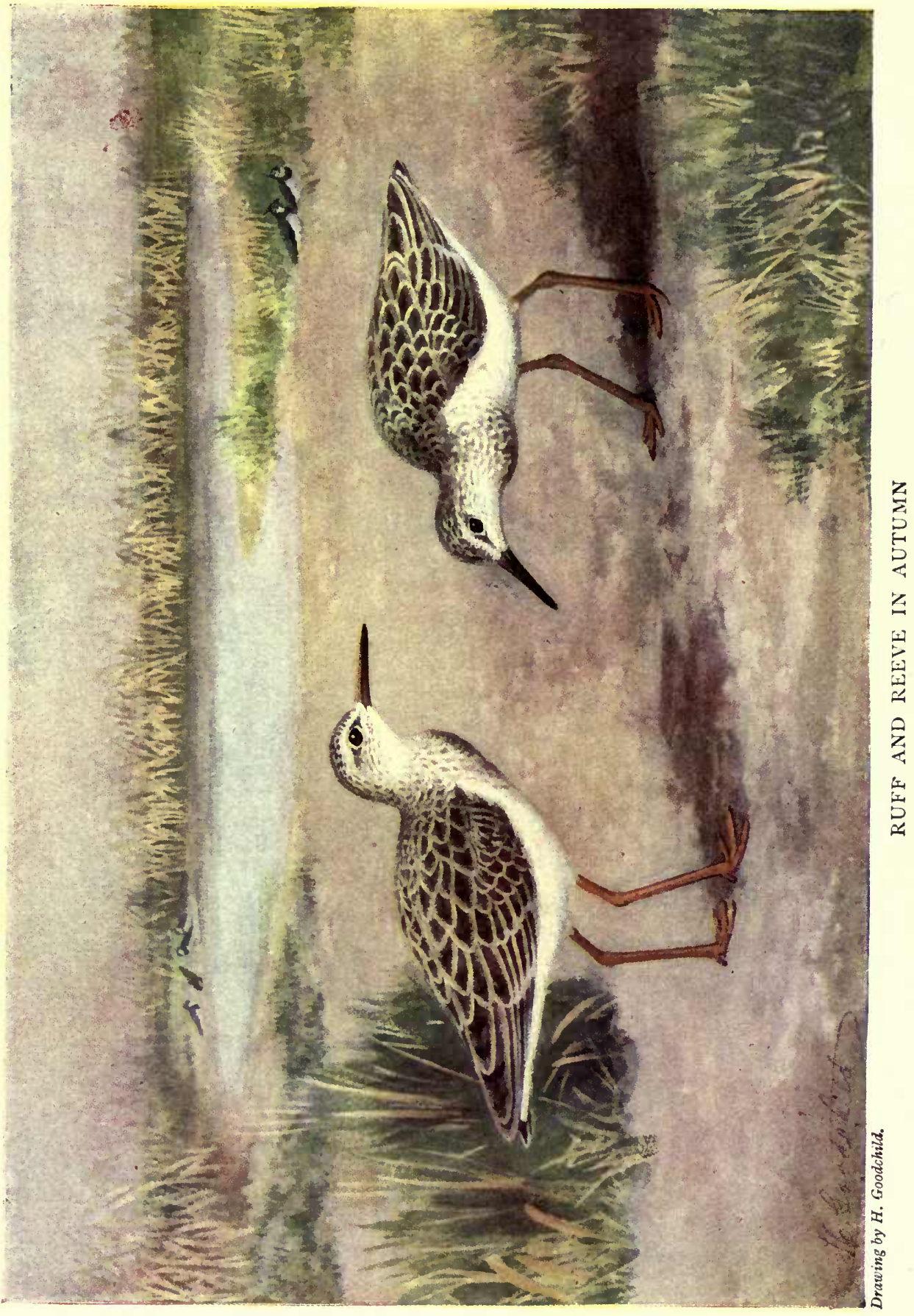




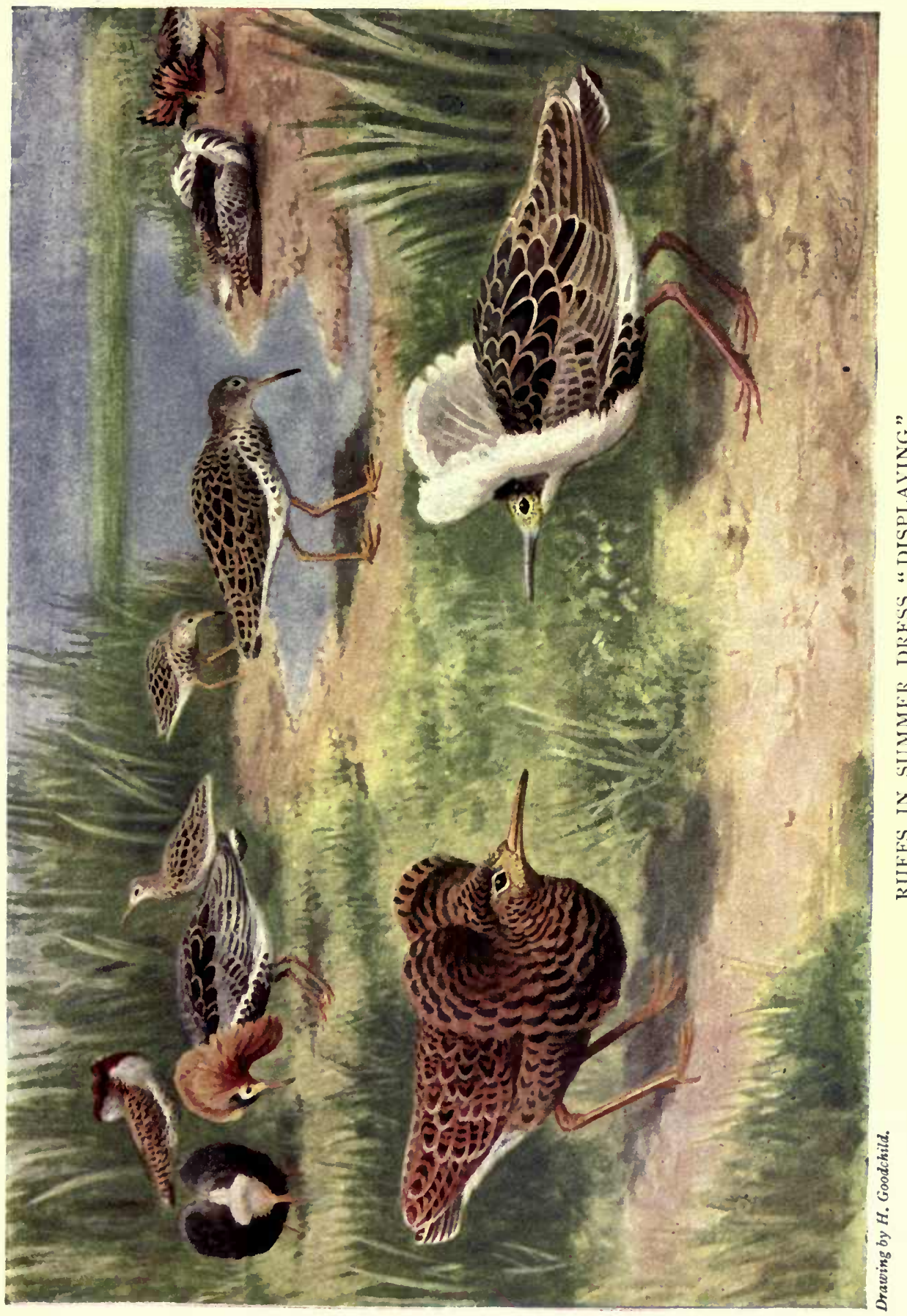



are used as organs of locomotion, in the whales they serve as balancers.

The fashion in which birds carry their legs during flight should be specially noticed. The "perching-birds" or "Passeres" alone draw up the feet close to the abdomen, others carry them stretched out under the tail, as may easily be seen in gulls and herons, or stuck out on each side as in the short-legged puffins.

The carriage of the neck similarly varies. Thus in the herons it is bent up, so that the head touches the back, while in the storks, and in the goose and its relatives the ducks and swans, it is carried stretched out at its full length.

Birds prefer to fly against the wind; and, while some can only sustain flight by a vigorous use of the wings, others contrive to sail over large areas without a single wing-beat. The sparrow and the gull afford interesting contrasts of this kind.

Some birds can hover stationary over a given spot for a very considerable time; and this is especially true of the kestrel, one of our commonest hawks, which, on account of this habit, is known as the "Wind-hover." This power is of immense advantage, for thereby the bird is enabled to thoroughly search the ground for food before passing on.

\section{Seasonal Changes of Plumage}

That many birds assume two very distinct liveries in the course of the year, while others, as the spring approaches, become perceptibly brighter in hue, is a matter of common knowledge. But the means by which their changes are affected are by no means so well known.

The common sparrow displays seasonal changes of plumage to which special attention should be directed. In the spring the male develops a conspicuous black throat, and is generally much more vividly coloured than during the autumn and winter months. This change is due to a very curious cause. If a bird be examined directly after the autumn moult the feathers of the throat will be found to be black throughout their length, save at the tips, which are greyish-white; while, similarly, the feathers of the head, and upper parts generally, have a tawny fringe. As the 
winter progresses these fringes wear away, so that by the spring the more strongly coloured portions of the feathers are fully exposed. The red breast of the linnet is gained in an exactly' similar way.

The common starling again affords another valuable illustration. Both sexes of this bird are coloured alike, and possess distinct "summer" and "winter" plumages. These, as in the case of the sparrow, are gained, not by a change of raiment, but by the wearing away of the tips of the feathers. After the autumn moult, those of the upper surface are tipped with golden-

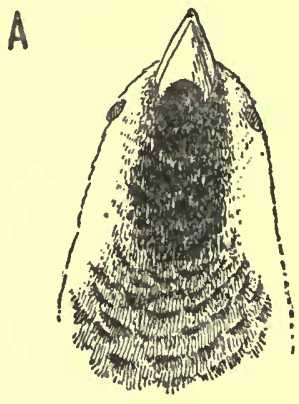

FIG. 26A.-Throat of common sparrow (male) after the autumn moult, showing how the black throat is masked by the grey edges to the new feathers.

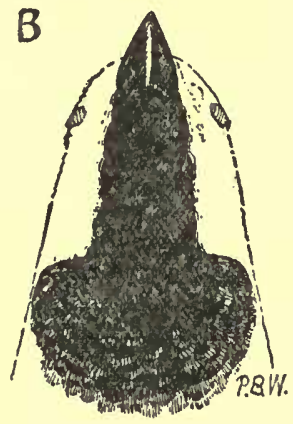

Fig. 26B.-Throat of the same bird in the spring, when the grey edges of the feathers have worn off, exposing the black central portions of the feathers.

brown and those of the under surface with white, giving the birds a speckled appearance. During the winter months, however, these tips are gradually worn off, so that in the spring and summer months a spotless, glossy, black plumage, with steelreflections, replaces the earlier spotted dress. The young birds, till the autumn moults, wear a brown livery.

By way of contrast it should be pointed out that in many other birds, which similarly display a more brightly coloured livery in the spring than that worn during the winter months, this brighter garb is assumed, not by the wearing away of the tips of the feathers, but by a complete " moult." The dunlin, for instance-one of our small shore birds-has the upper-parts grey and the under-parts white in winter. But in the spring, by 
means of this moulting process, the upper-parts come to assume a golden-brown colour, mottled with black, while the throat and breast become jet-black. In the autumn these feathers are shed, and replaced by the grey and white dress of winter.

While some birds attain the plumage of the fully mature bird at the end of the first year, or earlier, many are several years acquiring the adult dress. In the black-backed and herring-

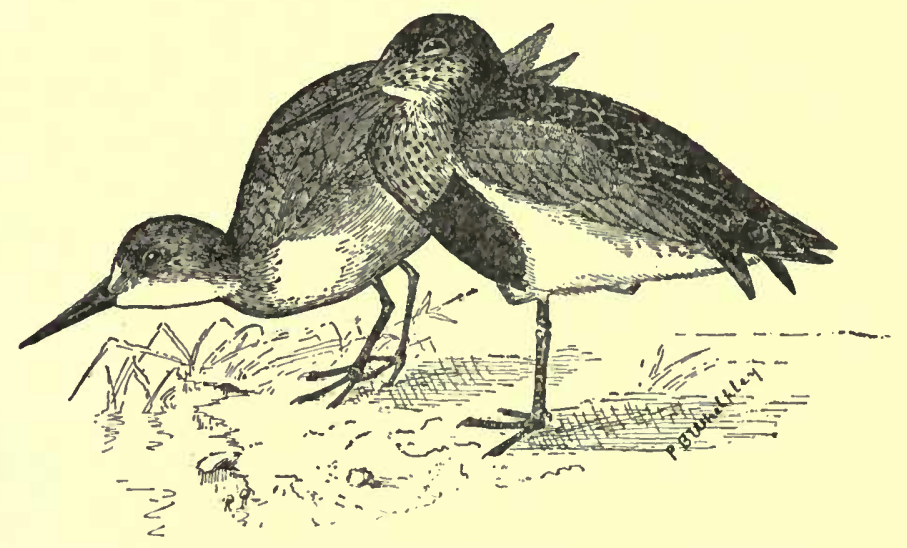

FIG. 27.-Dunlin showing summer and winter plumages.

gulls, for example, the adult dress is not attained until the third year, or even later. The immature birds wear a mottled dress of grey and brown, which almost imperceptibly changes into the pure hues of black and white, or pearl-grey and white, as the case may be, of the full-grown bird.

How striking the change may be between the summer and winter plumages is shown in the coloured plates representing the ruffs and reeves. This wondrous "ruff" which encircles the neck is never alike in two individuals, and is worn only during the spring and summer months; and when this is assumed, the feathers round the beak are shed, and replaced by warty outgrowths of skin of an orange colour. Only the males wear this "ruff" - hence their name; the females are known as the "reeves." At one time common in our fen-lands, they are now met with only on rare occasions. Drainage and egg-" collectors" are responsible for their extermination. 


\section{CHAPTER XII}

\section{Food AND FEeding}

THERE is an intimate relation between the structure of the beak and feet and the food which birds eat.

Only a very few birds use the feet in conveying food to the mouth; but this is done by parrots, some of the smaller owls and hawks, and the purple gallinule-a kind of large waterhen. Many birds, however, hold the food down with the feet while tearing it to pieces with the beak, as in the hawks and crows, for example.

While the earliest known fossil birds were provided with teeth, modern birds have the jaws ensheathed in horn; and these sheaths take very varied forms, in accordance with the nature of the food.

In birds of the finch tribe, such as the sparrow, the hornencased jaws, which form what is known as the "beak," have a conical form, and are moved by strong muscles capable of crushing small seeds. This crushing apparatus is still further developed in the hawfinch, wherein three large horny "bosses" having striated surfaces are to be found within the mouth. Two of these are placed on the lower jaw, near the gape, while the third forms a long cushion on the roof of the mouth. Hard-coated seeds are held between this curious crushing vice and broken with ease. In the hawks, on the other hand, the beak has the upper jaw hooked, and this is used as a tearing instrument whereby flesh of animals is rent in pieces.

The ducks have the inner edges of the jaws provided with narrow plates or "lamellæ." In the shoveller-duck these plates are very long, and in their function recall the "baleen" plates of whales. And the use to which these plates are put in these two very different creatures is the same-they act as strainers, 
allowing water taken in at the mouth to pass out, while retaining the small particles of food taken in with each gulp. The expulsion of the water is performed by raising the tongue, which, as in all the ducks, and the "whale-bone" whales, is extremely large and fleshy. In fish-eating ducks, such as the merganser, the beak is long and narrow, while the plates along the edges of the beak take the form of conical, horny teeth well calculated to hold a slippery prey. In some other fish-eating birds, however, as in the darter, the edges of the beak are armed with needle-like points, and in yet others these edges are serrated as in the gannet. The herons, which are fish eaters, have a dagger-like beak. Birds like the woodcock and snipe, which obtain their food by probing in mud, have the beak of great length, and probe-like; but so constructed that the tip of the upper jaw can be raised when buried deep in the soil. Being richly supplied with nerves, it further acts as an organ of touch, so that when it comes in contact with a worm the tip of the jaw is raised just far enough to grasp the worm and press it against the lower jaw, when it is withdrawn. But for this contrivance it would be necessary to thrust aside the whole mass of mud opposed to the buried beak, a task too great for so slender an organ. Humming-birds have a similar style-shaped beak, but this is used for a quite different purpose ; inasmuch as it is thrust up into the tubular corollas of flowers in search of insects which are drawn into the mouth mixed with honey by means of the tongue, which has a curious and complicated structure contrived to effect this purpose. In some birds, as in the spoonbill, the beak is flattened from above downwards; in others it is curved upwards as in the avocet, or downwards as in the curlew; while the most remarkable beak of all is that of the tern, known as the "scissor-bill." Herein the lower jaw is longer than the upper, while both are laterally compressed to the thinness of a knife-blade. This most curious bird feeds on fish, and procures its food by swimming along the surface of the water with the tip of the lower jaw submerged. As a shoal of fishes is passed over, one often is caught up by this ploughshare, and driven within the grasp of the upper jaw, where it is quickly seized and passed backwards into the mouth. 


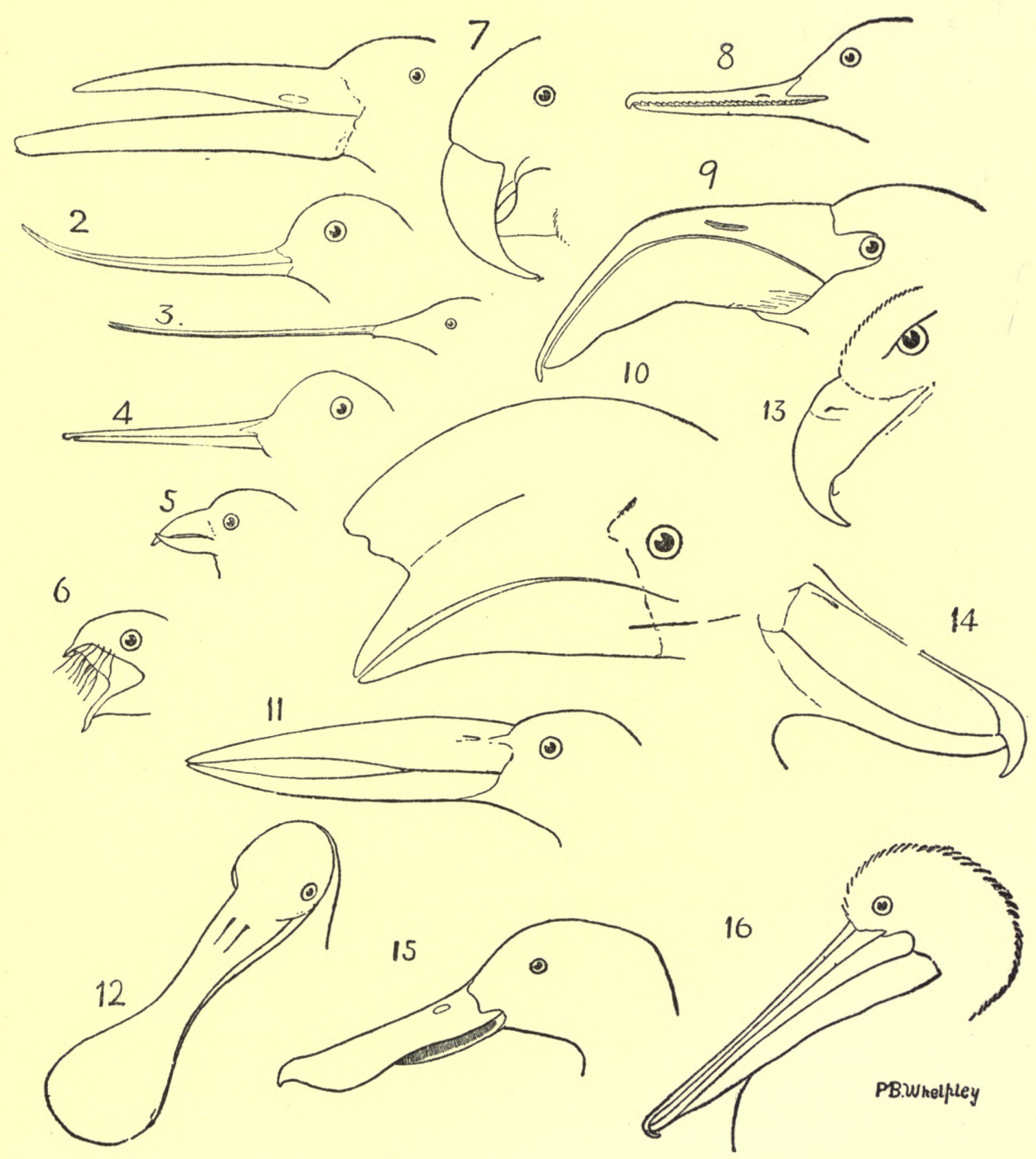

Fig. 28.-Types of Beak.

r. Scissor-bill.

2. Avocet.

3. Humming-bird.

4. Woodcock.
5. Crossbill.

6. Nightjar

7. Parrot.

8. Merganser.
9. Flamingo.

ı. Hornbill.

I I. Openbill.

I2. Spoonbill.
I3. Eagle.

I4. Shoebill Stork.

I5. Shoveller Duck. I6. Pelican.

The beak of the Shoveller Duck, with its lateral fringe of plate along the sides, should be contrasted with the beak of the Merganser, a fish-eating duck, wherein the beak is narrow and straight and armed with horny teeth. 
The nightjars, swifts, and swallows have extremely short beaks and enormously wide mouths. These birds feed upon insects, which they pursue during free flight. Here a large beak is not wanted; the prey is snapped up and passed into the mouth at once. To facilitate this method of feeding, the mouth of the nightjar is fringed with very strong bristles. In Fig. 28 these various forms of beak may be more carefully studied.

Reference has already been made to the use of the tongue in feeding; we return to the matter here to refer to the wonderful tongue of the woodpeckers. This is cylindrical in shape, and of great length. Worked by powerful muscles attached to

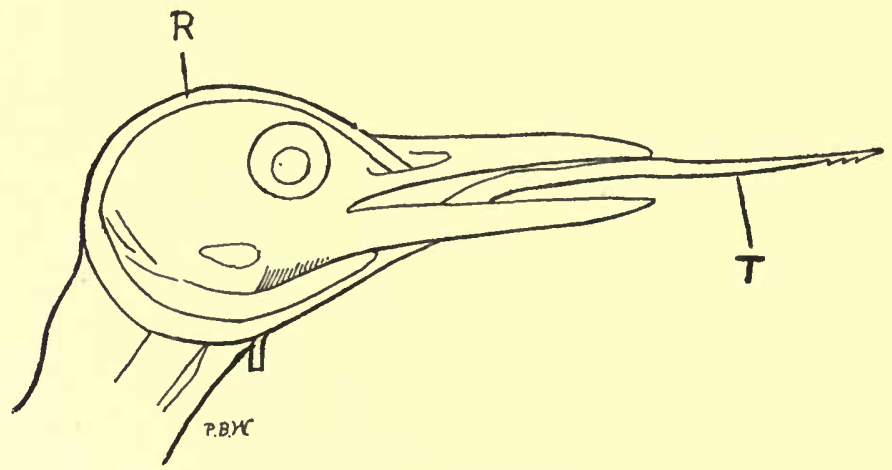

FIG. 29.-Dissection of the head of a woodpecker, to show the great length of the tongue, the bony supports or "roots" of which are so long that they have to be carried round the back of the head, and over the crown, finally passing to rest in a chamber formed in the beak.

long and slender supports known as the tongue- or hyoid-bones, this organ can be thrust far out of the mouth when feeding. At this time it is covered with a very sticky juice having the tenacity of bird-lime, which is formed by a large pair of glands placed on each side of the lower jaw. Thus coated it forms a most effective weapon when thrust into a crowd of antsupon which the woodpeckers largely feed-or darted out upon such other insects as may be deemed delectable morsels; for there is no escape for the victim touched by this extremely active and worm-like death-trap; and the struggling bodies are swiftly borne back to destruction.

Some birds contrive to hold food in the mouth immediately 
under the tongue, the skin forming the floor of the mouth being, in this region, more or less distensible. Thereby they are enabled to carry away food either for their young, for the purpose of hiding up for future use, or for greater leisure in eating. In many of the crow tribe and in the swifts such temporary pouches are found. But in the pelicans this pouch assumes huge proportions, and is capable of holding a large quantity of fish.

These varied types of beak have apparently come into being through the action of natural selection, which favours the development and perpetuation of variations in the several directions of these peculiar modifications.

The development of the beak in certain directions has, in many cases, been accompanied by peculiar modifications in other parts of the body-a lengthening of the neck and legs, for example, or changes in the form of the feet.

The plover tribe afford some interesting instances of this. The small ringed-plover met with commonly among sandy tracks has a short beak and neck and short legs. The curlews and redshanks, which frequent marshy districts and estuaries, procure much of their food by wading in shallow water, and hence have developed long beaks and necks and long legs, and in the stilt-plovers these legs have attained a quite remarkable length. But in the snipe and woodcock the beak is of great length, while the legs are relatively short. These birds, however, are not waders, but use the beak as a probe ; that is to say, as an organ of touch and prehension, when thrust deep down into very soft and often semi-fluid mud. In the eagles and hawks the hook-like beak is seconded by short legs and long toes armed with powerful talons, wherewith the prey is held fast while being torn in pieces. In most water-birds the toes are joined by a web, but this is by no means essential for swimming and diving. Thus the common water-hen or " moor-hen" is both an expert swimmer and diver, yet the toes are remarkable for their great length and slenderness, the web being conspicuous by its absence. In the grebes and coots, which are no less expert divers, the toes are provided with broad lobes. Birds of the kingfisher tribe, which use the feet but little, and only for grasping boughs when at rest, the three front toes are 


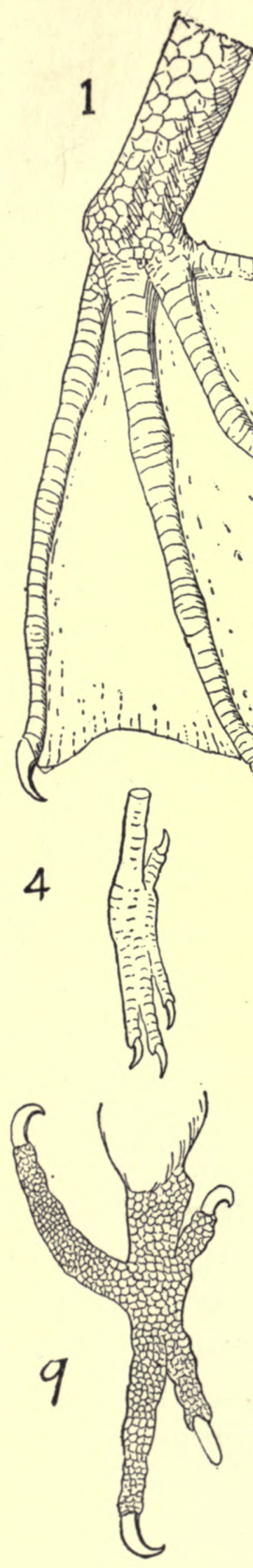

Pelican (tolipalmate)

2. Hawk (raptorial).

3 Heron (wading).

6. Black Grouse (rasorial).

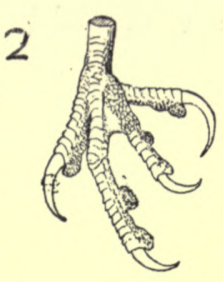

Y
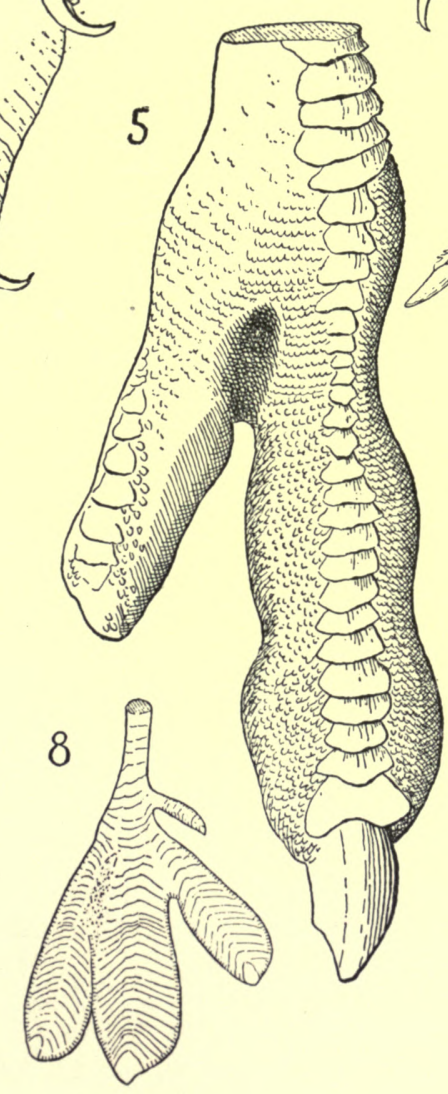

FIG. 30.

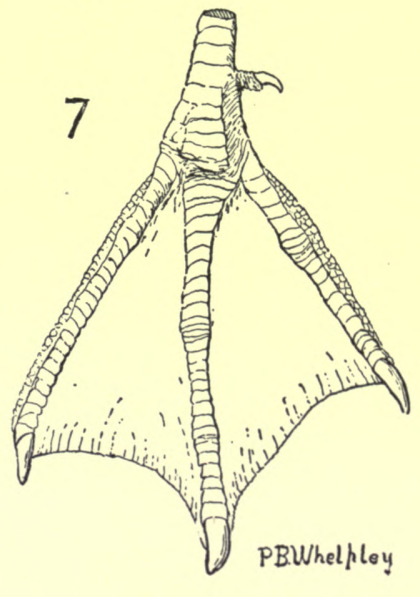

4. Kingfisher (syndactyle). 7. Duck (natatorial).

5. Ostrich (cursorial). 8. Grebe (lobate).

9. Parrot (zygodactyle).

$3^{a}$. The claw of the middle toe, to show the "comb" along its inner edge. 
closely bound together throughout the greater part of their length, and hence the foot is said to be syndactyle. In the

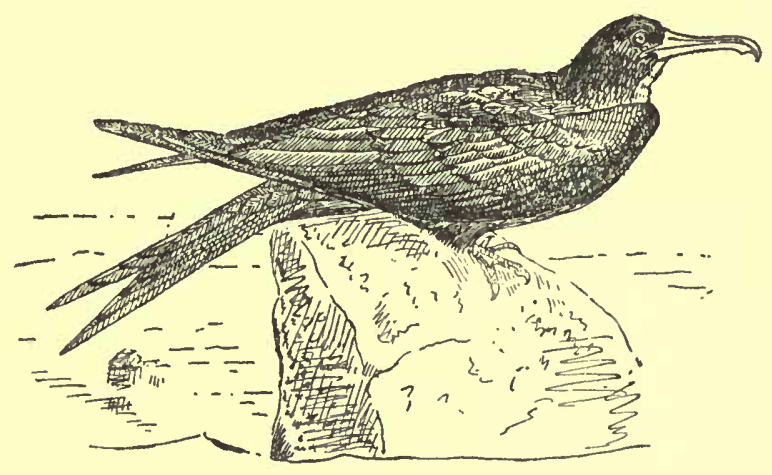

A

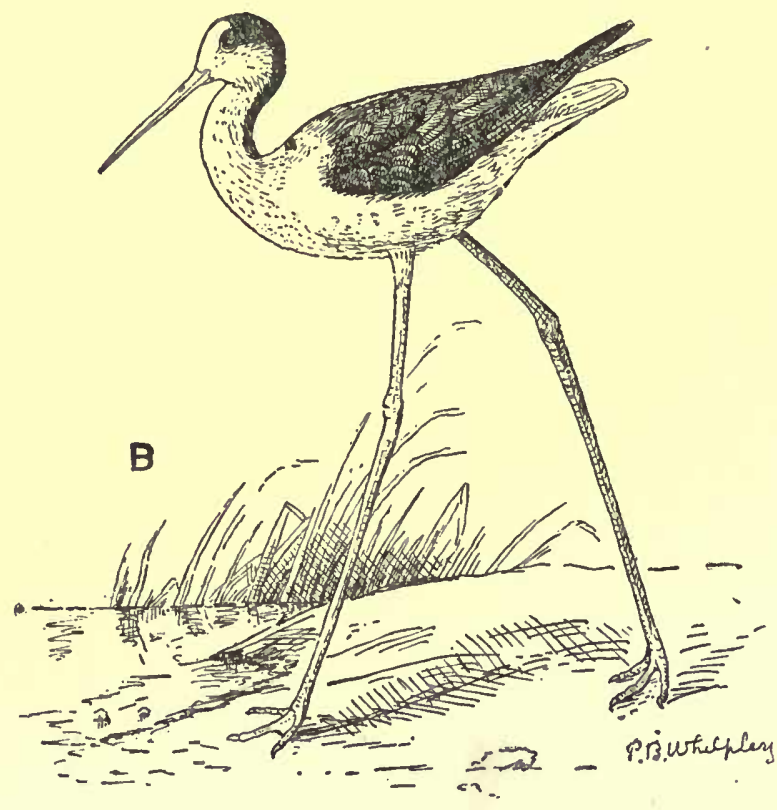

FIG. 31.-A, frigate bird, showing the reduced size of the legs; $B$, stilt, showing legs of enormous length, developed for wading purposes.

climbing birds, such as woodpeckers and parrots, on the other hand, the toes are yoked together in pairs, two behind and two in front, -hence the foot is said to be "zygodactyle" or yoketoed.

While in the majority of birds the beak is used solely as an instrument for the manipulation of the food, in some, as in parrots, it is made to play an important part in locomotion, as every one who has ever seen a parrot climb knows. Similarly, the feet though primarily subservient to locomotion, may, as we have seen, be used for holding prey, or even to convey food to the mouth, as in parrots. But in some birds they are further modified so as to form powerful weapons of offence, as, for example, in the barn-donr fowl and 
the pheasants, wherein the leg is armed with formidable spurs. In the cassowary the claw of the inner toe is of enormous size, and this is used as a weapon of offence.

Some birds, on the other hand, have the wing armed with spurs, as in the spur-winged plovers and spur-winged goose; or large, bony knobs may take the place of spurs, as in swans, and the extinct solitaire, a gigantic fossil pigeon. These weapons are used by the males in fighting rivals.

How nicely the balance of Nature is adjusted, how exactly the various organs of the body reflect the uses to which they are put, increasing as required, in size or strength, or on the other hand decreasing as the need therefor grows less, is well reflected in the relative length of the legs in the frigate birdone of the gannet tribe-and in the stilt-one of the plover tribe.

The frigate bird passes the greater part of its life on the wing, and consequently has no use for legs save as supports while resting. As a consequence these legs have dwindled in size till little more than the feet remain; while the wings have increased enormously. In the stilt the wings are only of moderate size, while the legs, which are used for wading in deep water in search of food, are of prodigious length. The different forms of the beak and feet (pp. 92 and 95) illustrate this lesson no less clearly.

But the wings are no less instructive in this connection, and the attention of children may profitably be drawn to, say, the long, pointed wings of the swift, and the short rounded wings of the wren. The former is a bird which obtains its food entirely while on the wing and rarely alights upon the ground, while the latter is a bird which seldom flies, and never far, save when on migration. Swifts which happen to be born with wings below the standard die from lack of ability to obtain food. Flight being unnecessary to the wren, there is no demand for large wings. 


\section{CHAPTER XIII}

\section{Nests and Eggs, and Nestling Birds}

BIRDS, like reptiles, are egg-laying animals; but unlike reptiles, they have to brood these eggs. For the sake of safety during this process of hatching the majority of species deposit their eggs in some kind of a nest, and in the construction of this many have acquired a most amazing skill. Some species, however, lay their eggs on the bare ground, as in the case of the nightjar and the guillemot, for example, among British birds.

The simplest kind of nest is that made by many of the plover tribe, which find a slight hollow scraped in the ground or some natural hollow all sufficient for this purpose. Generally, however, this hollow is surrounded by a few stones, while some species go further and interpose a few bits of dried grass between the eggs and the ground. With some birds, pigeons for example, a slight platform of sticks is made in the branches of a tree. More elaborate are the nests of such birds as the thrushes, which weave a cup-shaped nest of dried grass mixed with mud, and lined with fine grass, as in the blackbird. But even closely related species differ in their method of nest building, as, for instance, in the case of the song-thrush, which lines the nest with mud, cow-dung, and decayed wood, a mixture which when dry is perfectly water-tight, so that in very wet seasons the nest becomes water-logged and the eggs addled. The chaffinch is a much more skilful architect, the outer walls of the nest being formed of moss, spider-webs, and lichen cunningly interwoven, while the lining is formed of horse-hair.

The use of spider-webs and cotton-down and vegetable matter of a like nature, for the sake of forming a kind of felt, has been adopted by many species of the smaller birds all over the world; and the employment of spider-webs for attaching lichen to the outer face of the nest is a device which has similarly 


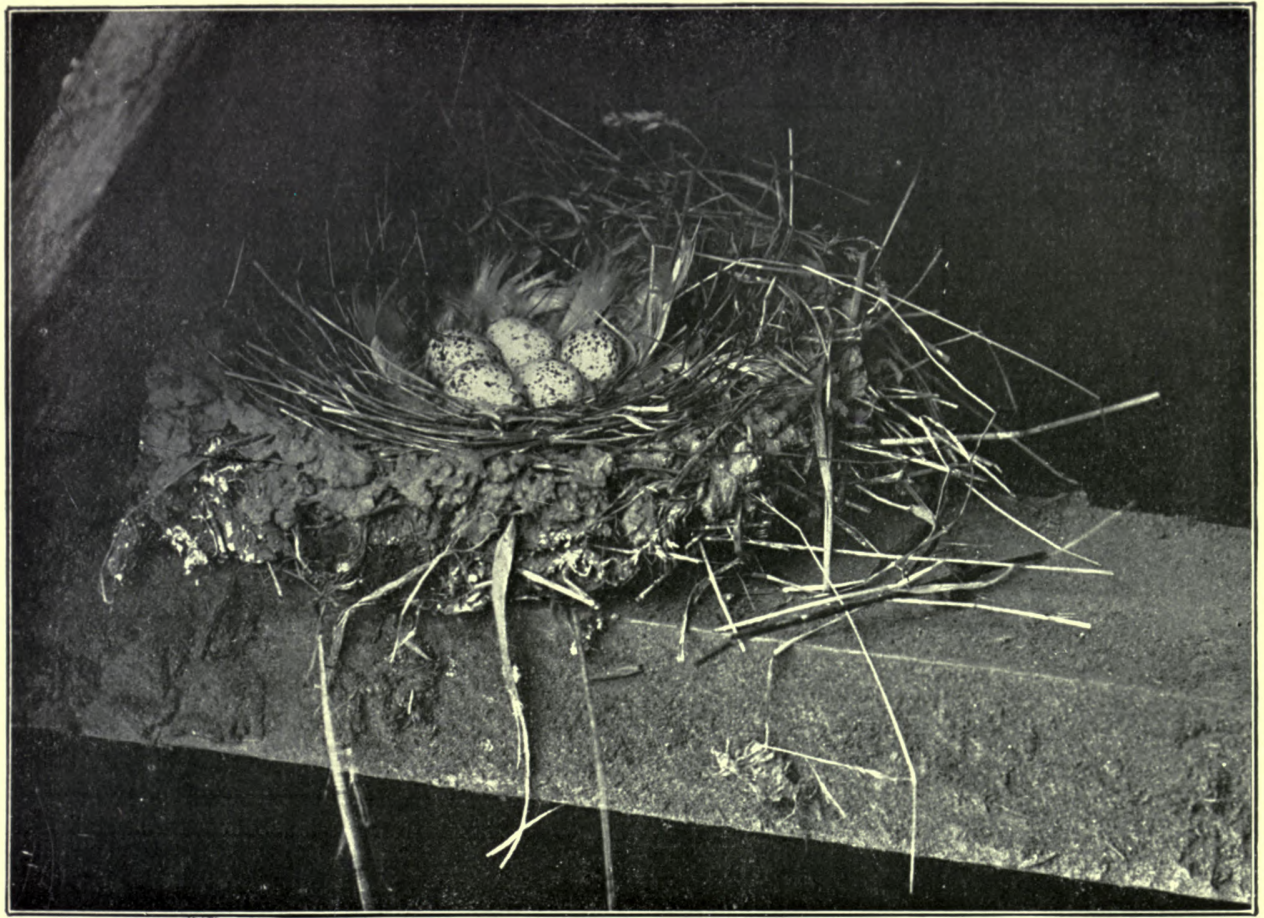

Photo by Charles Reid.

NEST AND EGGS OF THE SWALLOW

Note the lining of fine grass and feathers.

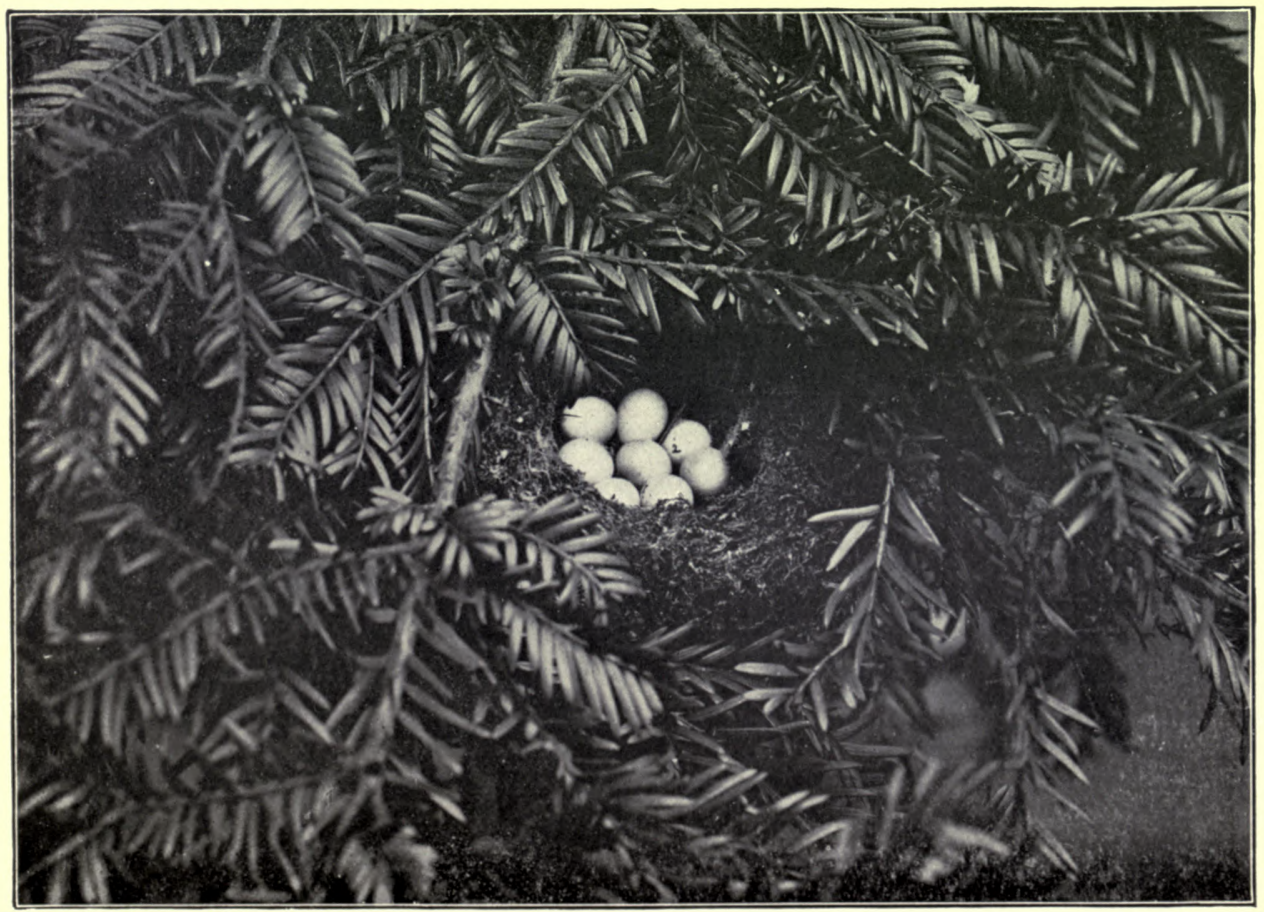

Photo by Charles Rezd.

NEST AND EGGS OF THE GOLDEN-CRESTED WREN 
been adopted by birds in various countries. No finer example of such workmanship could be found than that furnished by the nest of the British long-tailed tit-mouse. The use of such materials secures for the nest a practical immunity from detection, since, so constructed, it harmonises so perfectly with its immediate surroundings as to be almost invisible.

While the majority of nests are more or less cup-shaped, some are "domed"; that is to say, they are provided with a roof, so that the nest is more or less globular in shape. The nest of the long-tailed tit-mouse is of this kind. The magpie builds a domed nest. Large in size, and composed externally of sticks, this roof is so deftly constructed as to make it almost impregnable save to human egg-stealers.

Though many birds use mud after the fashion of mortar, to hold other materials together, some species construct their nests entirely of mud. And of such nests no better example could be found than are afforded by our native swallow and martin; and these will be too familiar to need description. This mud is generally gathered from roadside puddles or the edges of ponds. A certain amount of saliva seems to be used to add to the adhesiveness of the mud. It is interesting, therefore, to note that in certain species of swifts, known as the edible swifts, natives of the islands of the Pacific and Indian Oceans, the glands which form this saliva have so enormously developed as to secrete a flow sufficiently copious to form the whole of the material of the nest. These nests form a valuable article of commerce, being highly esteemed by the Chinese, who concoct therefrom the soup known as birds'-nests soup!

The number of instances wherein birds make what may be called a "personal" contribution to their nests is rare. But, in addition to the instance of the swift, we have the practice of the ducks, where the female denudes her breast of down to form a covering for her eggs, and the no less curious custom of some kingfishers-the fish-eating species-which deposit their eggs on a mass of the bones and other hard parts of the fishes and other creatures which form their prey. These dejecta are thrown up from the mouth in the form of pellets.

The site of the nest varies much: according to the exigencies 
of the breeding ground, or, often, to the individual idiosyncrasies of the builder, as in the case of the wild-duck, for example, which normally builds on the ground, but will occasionally lay its eggs in trees. Herons normally build in trees, but where these are wanting they will place their nest upon the ground. Cormorants and gannets, again, nest either on the ground or in trees, as necessity demands; and many similar instances might be quoted.

Birds which build cup-shaped nests in trees or shrubs usually place them in the fork of a branch, but some species suspend them from the under side of a bough; as, for example, in our golden-crested wren and the golden oriole, which occasionally visits these islands. The reed-warbler has adopted a different plan. Here the nest is built between the upright stems of three or four tall reeds in some reed-bed, so that the reeds have the appearance of growing through the sides of the nest. The cup-shaped cavity is very deep, a precaution which prevents the eggs falling out when the reeds are bent low by the wind.

A considerable number of species lay their eggs in holes of trees or on the ground. Commonly a natural cavity is chosen, or one excavated by some other animal ; but where such readymade borings are not to be had they will drill these for themselves. Some species appear always to adopt the latter course; and one of the most skilful of such tunnel makers is the little sand-martin, a bird which has apparently but the feeblest of tools for such a purpose, the beak and feet being alike small and delicate. Yet this species will drive a tunnel a yard or more in length through a sand-bank, forming a chamber at the end wherein, on a few straws and feathers, the eggs are laid.

Birds' Eggs. - Like the eggs of crocodiles and tortoises, among the reptiles, the eggs of birds are enclosed in a hard, calcareous shell; but whereas the eggs of all reptiles have a white shell, those of birds are as a rule variously coloured, the significance of which fact will be referred to presently. Birds' eggs further differ from those of reptiles in that they must be incubated by the warmth of the parent's body, a process known as " brooding." During the breeding season the abdomen of the sitting bird 


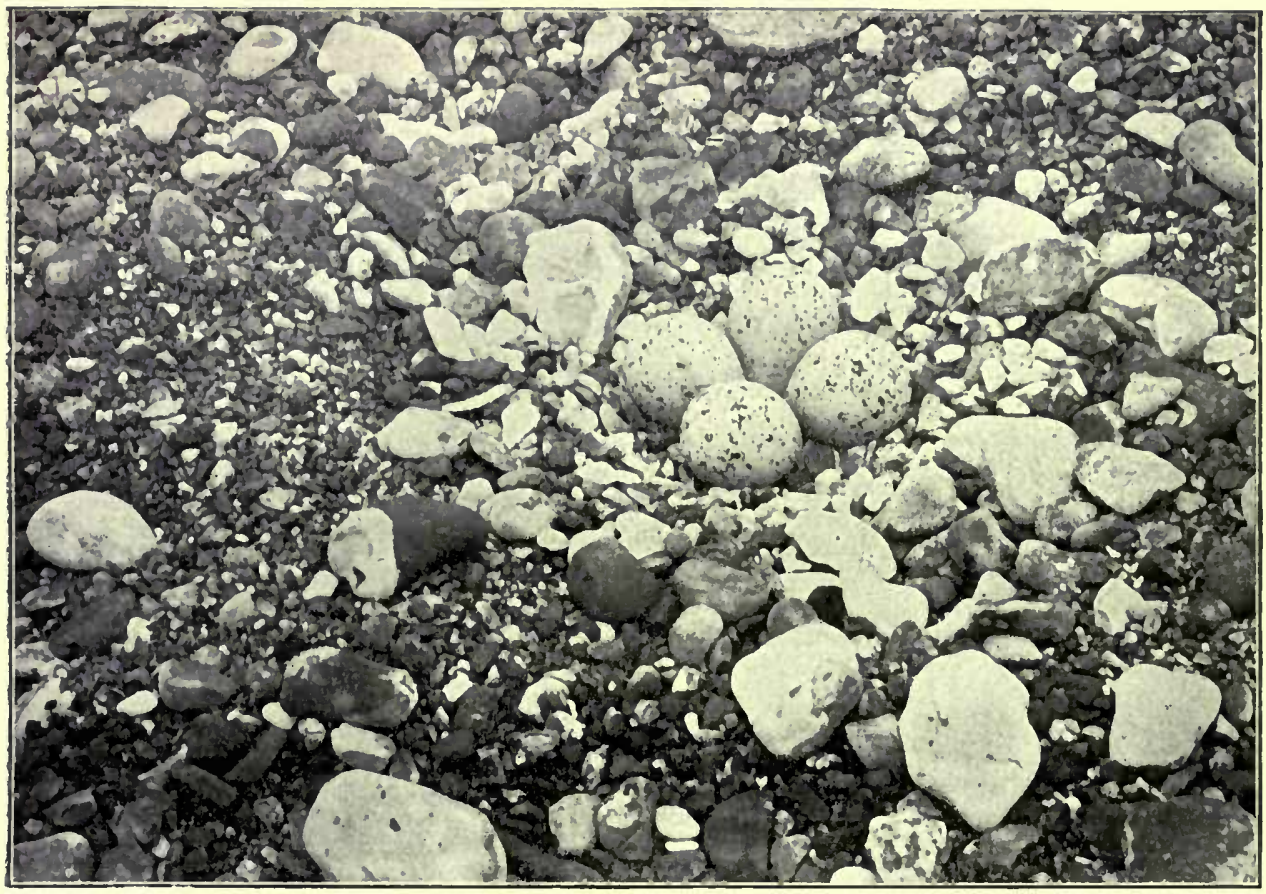

Photo by Colthrup.

NEST AND EGGS OF RINGED PLOVER ON BEACH

Note the resemblance of the eggs to the surrounding pebbles. The "nest," such at it is, has been formed of a collection of small stones, and is hardly distinguishable.

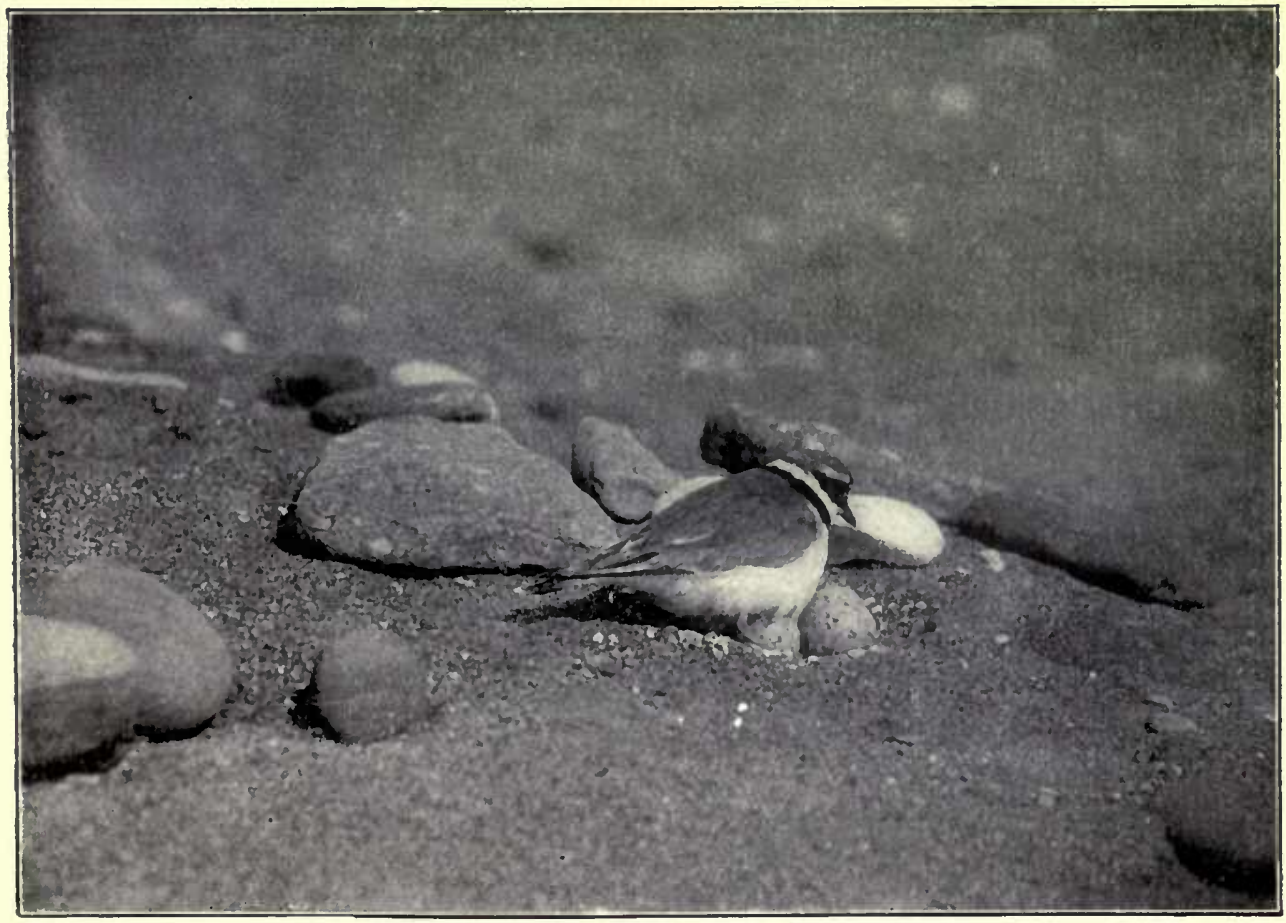

Photo by Oxley Grabham. 

becomes red, inflamed by the accumulation of blood contained in certain of the abdominal veins, and a consequent increase of temperature. Such inflamed areas are known as " brood spots." When this area is normally covered with feathers these are shed to facilitate the brooding.

While many reptiles may lay as many as sixty eggs, birds never lay more than twenty, as in some of the game-birds; but a far smaller number is the rule. Thus the guillemots, auks and petrels lay but a single egg during the breeding season, though this will be replaced if, by accident or other causes, destroyed. Pigeons never lay more than two; plovers four.

For the most part the external layers of the shell of birds' eggs are more or less highly coloured. Among birds which build no nests, but lay their eggs in slight depressions in the ground, as in gulls and plovers, the coloration of the shell harmonises so perfectly with the surroundings as to be almost invisible. Where, however, the eggs are deposited in a more or less bulky nest the colours may often be relatively conspicuous, as in the blue eggs of the thrush and hedge-sparrow. But in these cases the protective coloration is transferred to the exterior of the nest; for unless this is rendered as inconspicuous as may be, no amount of protective coloration which the eggs might possess would be of any service.

When the eggs are laid in holes and other dimly lighted places the shells are white, and this because eggs having coloured shells would inevitably be smashed sooner or later by the sitting bird, which, returning to the nest, would be unable to see the eggs in so uncertain a light, and would thus break them in the endeavour to settle down. White shells, on the contrary, in such a situation would be visible. That this is so is shown by the case of the puffin. This bird lays its eggs in a burrow, and the shell is white. But this whiteness is formed by a thick chalky layer which, on being scraped away, reveals a coloured shell.

There are some birds, it should be remarked, which are exceptions to the rule just laid down, as, for example, many pigeons, such as the wood-pigeon, which constructs a flimsy nest of sticks in the topmost branches of some tall tree. But here they are too high up to be in danger of enemies from below, while the 
leafy branches more or less conceal them from wandering eggstealing birds above. Other pigeons, however, lay their eggs in caves, as the rock-pigeon; or in burrows, as the stock-dove; so that we may perhaps assume the custom of building of nests in trees is a comparatively recent custom.

Nestling Birds.-Few themes in ornithology can be made more interesting or more instructive than the subject of nestling birds.

These can be divided into two classes-those which on hatching are blind, naked and helpless, and those which are thickly clothed with down and able to run about from the moment they leave the shell. The latter represents the more ancient condition. Young chickens, and young ducks, present two distinct types of such active nestlings; and they differ strikingly in one important particular-to wit, the methods by which they escape their enemies. Young chickens to-day, in this respect, differ in no way from their wild relatives the jungle-fowl, or from young pheasants, partridges and grouse. In all these it is necessary that the power of flight should be acquired at the earliest possible moment, and consequently the development of the wings is pushed forward with extraordinary rapidity, so much so that in many species the young can fly at eighteen hours old, and long before the down feathers of the rest of the body are lost. Young ducks, like the young of wild geese and swans, on the other hand, seek safety by swimming, and consequently the wings develop exceedingly slowly, so much so that the body is feathered long before the wings acquire their quills, so that when nearly full grown they are to all intents and purposes wingless.

Another feature of young chickens should be noticed. In some breeds the nestlings are striped, a broad dark band down the middle of the back being especially conspicuous. The young of all wild game-birds, young grebes, and the young of the ostrich tribe are all striped; the stripes in the grebes and ostriches being more numerous than in the species just referred to. These markings, like the stripes of zebras, conspicuous though they appear when in a museum, or in captive birds, have really a protective 


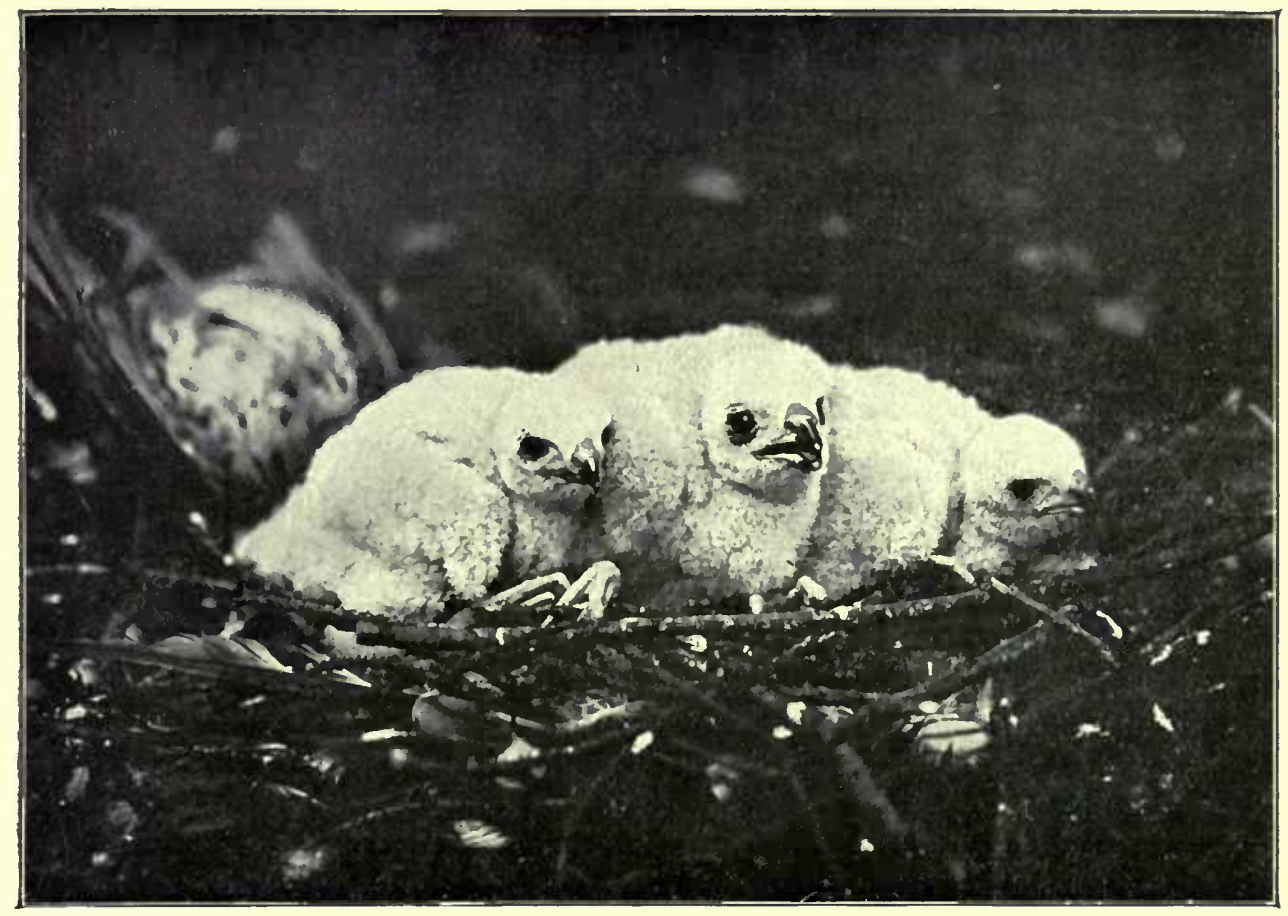

Photo by J. T. Nezuman, Berkhampstead.

YOUNG SPARROWIIIVKS

Note the shortness of the down, as compared with the Young Barn Owl.

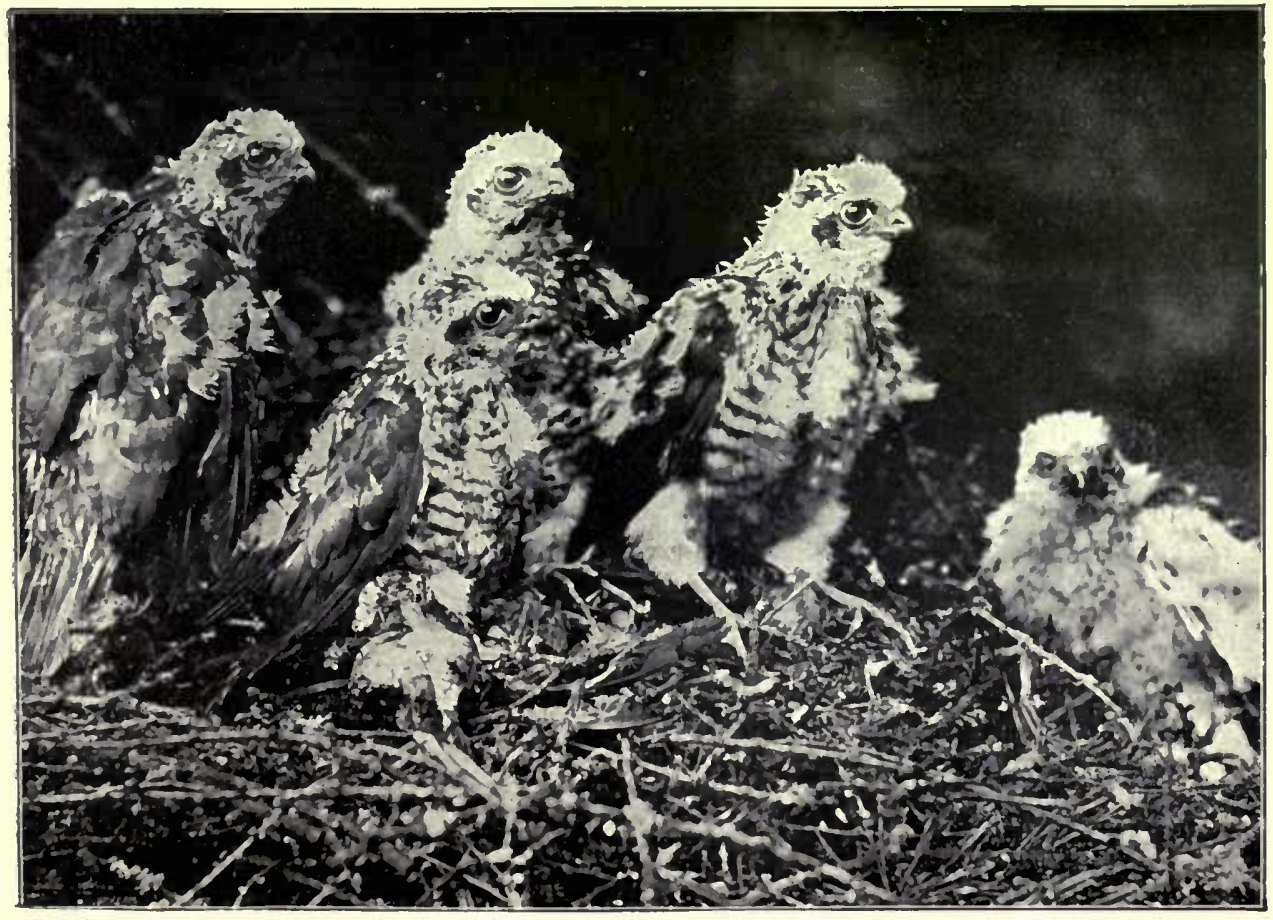

Photo by Charles Reud.

YOUNG SPARROWIAWKS

Showing the last relics of the down. 

value, the combination of dark and light stripes giving a blurred image, thereby rendering the individuals so marked invisible at a short distance, and hence concealing them from their enemies (see also pp. 65, 66).

Where the young are hatched in a helpless condition they are generally naked, or at most have but a few weak down-tufts along the upper surface of the body, and insufficient to form a covering. Young sparrows and young crows are absolutely naked; young thrushes generally have a few weak down-tufts on the head and shoulders.

Another peculiarity of these young birds, and indeed of the young of all the Passerine or "perching-birds," is found in the development of broad, fleshy folds along the sides of the beak. These folds, which are generally of a bright orange-yellow, increase the size of the gape of the mouth, and apparently assist the parent bird when placing food in the mouth. In the picture of the young starlings (p. 84) some indication of these fleshy folds remains, but they speedily disappear on the development of the feathers. In many young Passerine birds the roof of the mouth and the tongue are spotted with black, and these spots are made more conspicuous because set on a bright yellow or red background; or they may be white on a black background.

The accompanying photographs of the young owl (p. 80) and young sparrow-hawks (p. Io2) well illustrate the gradual way in which the down is displaced by the feathers.

The young of birds which run about almost from the moment they are hatched are generally capable of feeding themselves under the guidance of their parents. But in some cases the day is spent in haunts remote from the feeding ground, which is resorted to at dusk. This distance being too great for the young to travel, they are carried by their parents. Woodcock in Scotland, for instance, often rest by day in high ground, and descend at night to low swampy districts where alone they can feed. In such cases they carry the young down at night, and bear them back in the morning! 


\section{CHAPTER XIV}

\section{MigRATION}

THE study of the migration of birds bristles with difficulties, even when prosecuted under the most favourable circumstances. Yet even the teacher in large towns may find some evidences of the periodical arrival and departure of different species of birds. Starlings and the thrush tribe will afford the readiest examples; but even in large cities like London many species are met with during the spring and autumn that are seen at no other time in the year. In Battersea Park, London, for instance, no less than thirty species of birds have been met with by the writer during the last year or so in a wild state. And among the more interesting of them may be mentioned the wheatear, redstart, whinchat, wren, yellow wag-tail, spotted flycatcher, swallow, and housemartin, swift, nightjar and common sandpiper. In the nature of things these birds cannot breed here, but appear suddenly and as suddenly vanish during the spring and autumn months.

But we know that ten miles out of London all these birds may be met with, if sought for in suitable localities, throughout the summer, and that before the winter sets in all will have disappeared. Whence have they gone? Whither do they go ? These questions cannot even now be answered fully, though the study of the emigration and immigration of our native birds has been prosecuted with untiring zeal by generations of ornithologists. Nevertheless their labours on the subject of migration have provided us with some very remarkable facts which, as incentives to observation and the study of geography, would be hard to beat.

The many problems raised by a study of the phenomena of migration obviously cannot be analysed here, and it is proposed, therefore, to do no more than sum up the essence of the facts brought to light.

Briefly, of the three hundred species of birds which are entitled 


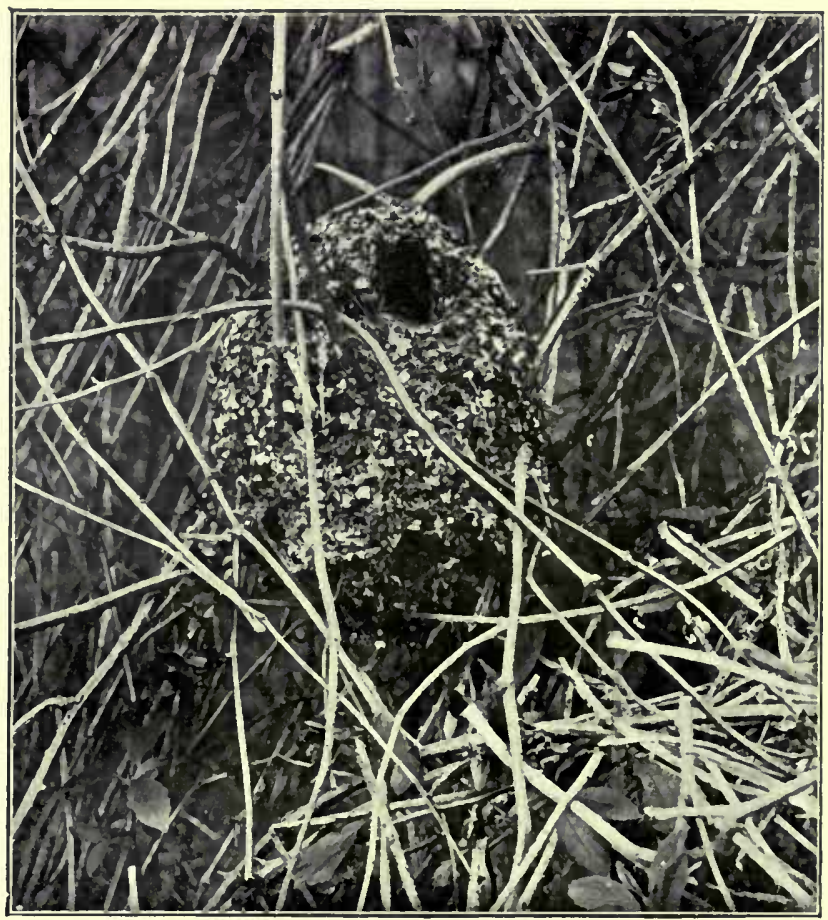

Photo by A. Forrester.

NEST OF LONG-TAILED TIT

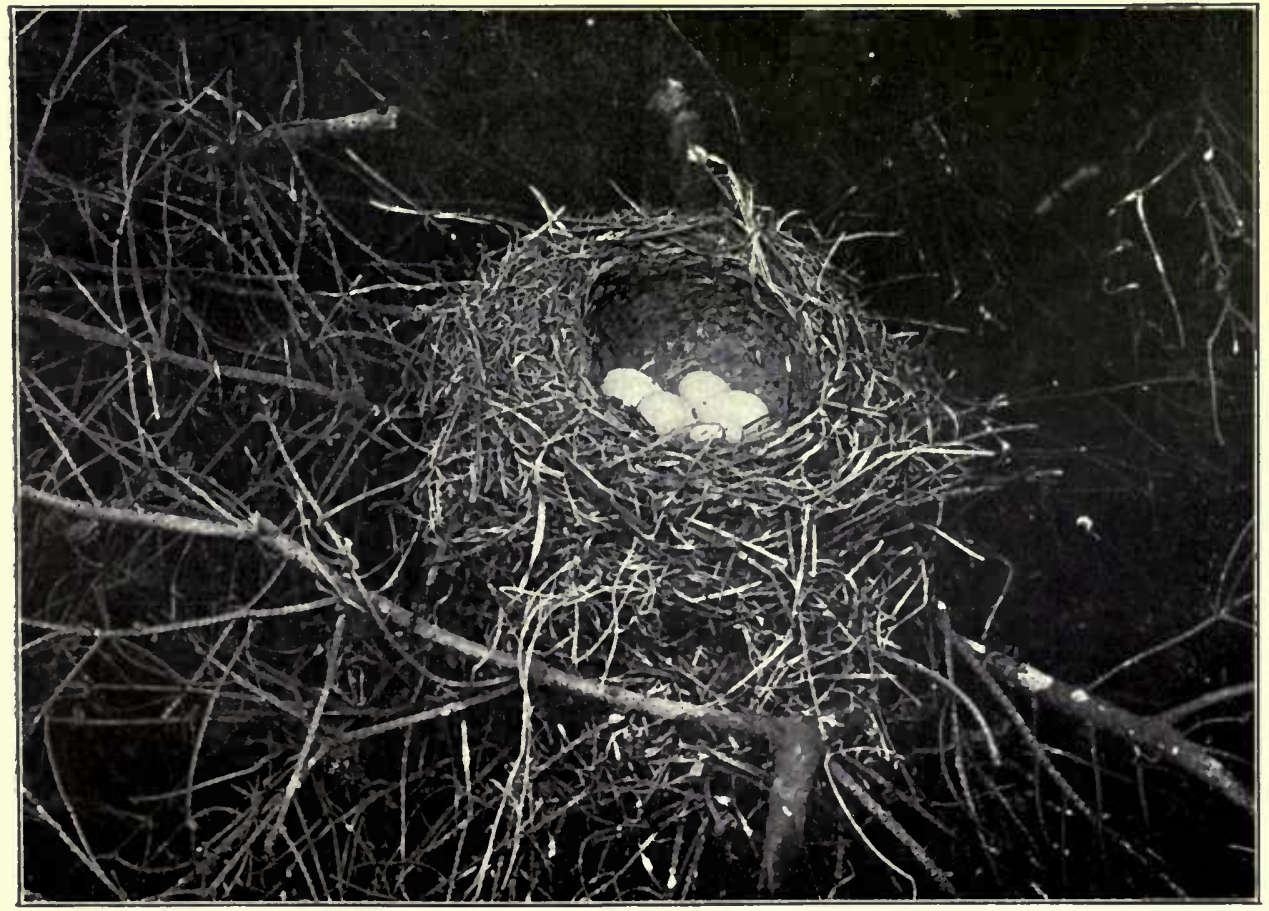

Photo by Charles Reid. 

to the rank of "British birds," a very large proportion are migrants; but while some come to us in the spring, remain to breed, and depart in the autumn, others come to us in the autumn and depart in spring.

These movements are due, not to matters of temperature, but of food. A large proportion of our summer migrants are insect eaters, and since they cannot procure enough food during the winter months to sustain life, they are driven to such regions where a supply of food can be depended upon. The birds that come to us in the autumn do so to escape the rigours of a winter more severe than ours, and the consequent failure of food. And this is further demonstrated by the fact that hard weather in the northern parts of our islands drives the birds wintering there, residents and migrants, farther and farther south. When, in an unusually severe winter, the whole country is more or less laid under snow and ice, then these fugitives die in thousands, not of cold, but of starvation, being unable to dig through the frozen earth for food.

Thus, then, migration is indirectly due to temperature, as may be shown in the case of insectivorous birds, for the insects upon which they feed die in the autumn, leaving eggs to hatch out on the return of congenial weather. And so it comes about that migration routes must run north and south, as indeed is actually the case.

The swallow may serve as a good example of this. This bird during the summer months ranges over the whole of Europe, and winters in Africa, some on the West Coast, others on the East, these last following the Nile Valley and eventually reaching the Cape. The evidence so far collected shows pretty conclusively that the swallows which winter in West Africa are those which passed the summer in Great Britain and the more western parts of Europe, while those which travel down the east side of Africa are birds which spent the summer months in Eastern Europe. The swallows of Asia, as one would expect, winter in India and Burma; similarly, the swallows of North America pass southwards into Brazil.

Most of our summer migrants, it should be noted-the cuckoo, swift, warblers, chats, wagtails, and so on-winter in Africa. 
Though undoubtedly the problems of migration are such as can at all times be profitably discussed, yet this is a theme which, just because of its many difficulties, is best attacked when migratory movements are actually taking place,-as in the months of March, April and May, and again in August, September and October, when the greatest activity is being displayed.

The earlier months just enumerated are marked by the departure of birds which have wintered with us for their more northern breeding quarters; and the arrival of the species which will spend the summer here. During the autumn months this order of coming and going is reversed.

But these movements must be carefully sought for, especially by those who do not have the good fortune to live near the sea and on the lines of migration. The dwellers inland rarely see more evidence of these arrivals and departures than is afforded by stragglers. On certain parts of the coast, however, especially in the east and south coasts during the autumn, larks, crows and other birds may be observed landing, tired and hungry, in continuous streams, often for days on end; while the departure of the swallows may similarly be watched in Cornwall. Since, however, they take their leave in the darkness of the night, the actual departure cannot be witnessed, but for days beforehand these birds collect in great bands.

The most favourable places for the study of actual migration are lighthouses. Here, especially on stormy nights during the autumn, immigrating birds, such as larks, thrushes and starlings, are encountered in thousands. The poor birds, dazzled by the light, fly round and round the lantern for hours, beating their wings against the glass; thousands fall to the rocks below, and thousands more into the sea, so that the mortality in a single night may reach an appalling total. During this time, too, hosts of plovers of various kinds wheel round and round, rending the air with their cries, and apparently unable to resist the fascination of the light. Even in London on dark nights the cries of migrating bands of plovers passing over the city may plainly be heard.

As a rule, birds fly high during migration. But should this take place during a gale they will fly so low that they barely top 
the crests of the waves, and thus apparently escape the full force of the wind.

The main facts with regard to the migration of birds, and the sorting out of our resident and migratory species, can be best brought home perhaps by inducing children to draw up lists of the birds to be met with month by month, or at any rate periodically. The "absentees" from such lists, which will soon be noticeable, must then be accounted for. During the autumn, for instance, they should be bidden to look out for the arrival of the redwing, fieldfare and hooded crow, for instance. Even city dwellers may expect to find these in the larger public parks, as well as starlings and other birds which during the summer move out into the country. With the return of spring a host of arrivals are to be sought for, such as the swallow, martin, sandmartin, the wheatear, the various kinds of warblers-among them the nightingale and the blackcap; the cuckoo, swift, nightjar, and so on.

The males of many species, it should be remarked, arrive first, while in the autumn, strange though it may seem, the young birds of many species leave in bands,--before the parents in some species, after them in others.

Wonderful as this migratory instinct undoubtedly is, and mysterious as is the faculty which guides them so unerringly over trackless wastes of water, it is really yet no more strange than are the migrations of the far less intelligent fishes, such as of the herring and the salmon; or of the marvellous journeys performed by the young eels, which, hatched in the profound depths of the ocean, yet find their way in the most extraordinary manner to the coasts of the nearest mainland. This goal attained, they seek out, and ascend, the rivers, there to attain maturity, and at last descend to the sea again and lay their eggs and-die. No adult eel ever returns, yet their young continue to ascend the streams which their parents but a few months before deserted, unaided save by that elusive faculty which we call instinct!

Biblography.-Howard Saunders, Manual of British Birds (Gurney \& Jackson); A. Newton, Dictionary of Birds; W. P. Pycraft, The Story of Bird Life (Newnes Useful Library Series); W. P. Pyeraft, A Book of Birds (Appleton \& Co.); F. W. Headley, Structure and Life of Birds; E. L. Turner, Home-Life of Marsh Birds 
(Witherby \& Co.); J. M. Boraston, Birds by Land and Sea (John Lane \& Co.); K. H. Job, Wild Wings (Constable \& Co.); W. W. Fowler, Summer Studies of Birds and Books (Macmillan); F. Finn, Ornithological and Other Oddities (John Lane); R. B. Lodge, Pictures of Bird Life, (Bousfield \& Co.).

General-containing references to habits of both Mammals and Birds :-C. Darwin, The Descent of Man (John Murray); Animals and Plants under Domestication (John Murray); Ingersoll, The Wit of the Wild (Fisher Unwin); J. A. Thomson, Natural History of the Year (A. Melrose): J. A. Thomson, The Study of Animal Life (John Murray); K. Semper, Animal Life (Kegan Paul \& Co.); Milnes Marshall, Biological Lectures and Addresses (David Nutt \& Co.); E. B. Poulton, The Colours of Animals (Kegan Paul \& Co., International Science Series); F. E. Beddard, Animal Coloration (Sonnenschein); M. J. Newbiggin, Colour in Nature (John Murray); Thomson Seton, Lives of the Hunted (Nutt \& Co.). 


\title{
REPTILES, AMPHIBIANS, FISHES, AND THE LOWER VERTEBRATES
}

\author{
By J. Arthur Thomson, M.A. \\ Professor of Natural History, University of Aberdeen
}

\section{CHAPTER XV \\ STUDY OF REPTILES}

Reptiles are so few and far between in Britain that they cannot bulk largely in school Nature Study. But, partly because they are comparatively rare, they excite strong interest, and every opportunity of studying them should be utilised.

The diverse animals-tortoises, lizards, snakes, crocodilians, and Sphenodon-which are classed together as Reptiles, are the modern descendants of those vertebrates which first became quite independent of the water, and began to follow the hint given by their forerunners, the Amphibians, of possessing the dry land. While almost all Amphibians spend at least their youth in the water, breathing by gills, this is not necessary for Reptiles, in which the newly hatched animal breathes by lungs, and the unhatched embryo by having blood-vessels spread out on a delicate birth-robe or fœtal membrane (the allantois). As in still higher vertebrates, gill-slits are present in the embryo, remarkable reminiscences of aquatic ancestry, but they are not used in respiration, and there is no trace of gills.

Reptiles seem to form among vertebrates a great central assemblage, like "worms" among invertebrates, more like a number of classes than a single class, exhibiting close affinities with Birds, somewhat less close with Mammals. The five orders or subclasses which are represented to-day have been already referred to, but it must be noticed that more than five orders, such as Ichthyosaurs, Plesiosaurs, and Deinosaurs, have long since 
become extinct. The reptilian branch of the great genealogical tree has been very severely pruned. It is outside our purpose here to give an account of the general characters of Reptiles in contrast to Amphibians beneath them, Birds and Mammals above them. It is enough to notice that Reptiles have scaly skins, breathe by lungs, are cold-blooded, and have large eggs with much yolk.

In this connection we may venture to suggest that there is little educational value in telling the pupils that "newts are Amphibians, but lizards are Reptiles," i.e. in making a dogmatic statement of what must at first appear to be a distinction without a difference. It is useful, however, to get the pupils to make for themselves a comparative study of two animals-newt and lizard-which are common in some parts of the country, and which can be, at the worst, bought for a small sum. Inspection will show that the newt has no scales, while the lizard is covered with them ; that the newt has no nails, while the lizard has them strongly developed; that the newt has a tail flattened from side to side and adapted for swimming, while the lizard has a cylindrical tail which is often more decorative than useful, and so on.

Similarly, it is very difficult for young students to believe that the reptiles-for the most part grovelling on the earth-can be related to the Birds which for the most part possess the air ; it is impossible to feel convinced of this without a study of the internal anatomy and the embryonic development-which is out of the question in school; but it is not absurdly sanguine to suppose that the school collection may include the skeletons of bird and lizard, a comparison of which would show a deep resemblance quite intelligible without naming a single bone; and in any case it is easy to look at a bird's foot and see that in its well developed scales it harks back to a reptilian characteristic.

British Reptiles.-There are only six reptiles in Britain,three lizards and three snakes.

(I) The common lizard-Lacerta vivipara.

(2) The sand lizard-Lacerta agilis.

(3) The slow-worm-Anguis fragilis.

(4) The adder or viper-Vipera berus.

(5) The grass snake-Tropidonotus natrix.

(6) The smooth snake-Coronella lavis. 
A beautiful green lizard-Lacerta viridis-occurs in Jersey.

Why is the total number so small? Because reptiles are warmth-loving animals, and Britain is not a warm country; because there are not very many reptiles in the whole European continent, of which Britain is an outlying corner; and because Britain must have been insulated from the Continent before some of the possible reptilian tenants had extended so far west or north.

As there are only six British reptiles, we may make a few notes on each of them.

(I) The common lizard-Lacerta vivipara-occurs throughout Great Britain, and has the distinction of being the only reptile in Ireland. It is a shy, harmless creature, feeding on insects, snails, and worms.

A good specimen is about six inches in length. The colour is very variable. It is brown or reddish above, with small darker and lighter spots. The under surface is orange to red with black spots in the male, yellow to pale orange below, with or without black spots in the female. The newly born young are almost black.

The young ones burst out of the eggs just as these are laid, or even before they are laid. From six to twelve are born at a time, like miniatures of the adults, not an inch in length. They subsist for a while on the remains of the yolk (which has passed into the body), but soon begin to catch small insects.

The common lizard is hardy, and may be found high up on the hills. It likes moist places and sunny places. It seeks winter quarters in October, and a number may be found together in one hole.

(2) The sand lizard-Lacerta agilis, which is restricted in Britain to the south of England-is very like the common lizard, but the rows of spots on its back and sides give it a longitudinally striped appearance. The ground colour is more or less green in the male, brown and grey in the female; the young are grey-brown above with white, black-edged spots, and whitish below. Its maximum size is about 8 inches.

The sand lizard lays five to eight white soft-shelled eggs in the ground, under leaves or the like, in May or June, and these are 
hatched in July or August. It stands captivity well, but it must have variety of food, water to drink, and a retreat to rest and hibernate in.

(3) The slow-worm or blind-worm-Anguis fragilis-is a snakelike limbless lizard, not uncommon in some of the wilder parts of Britain. The popular impression that it is blind is erroneous, for the eyes are well developed. Another false impression affirms its poisonousness. It is a shy, timid, harmless animal, and feeds on earthworms and slugs, sometimes also on insects and spiders.

A large blind-worm may be a foot long, but most specimens are shorter. The tail takes up nearly half the length. The colour is very variable, but it is usually brown above and blackish below, with a metallic sheen all over. Small roundish scales cover the body, and below

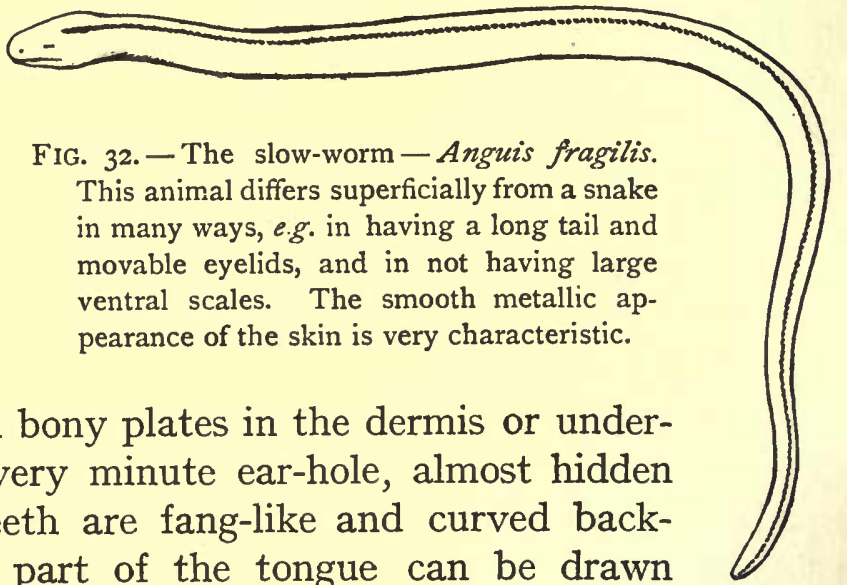
these there are thin bony plates in the dermis or underskin. There is a very minute ear-hole, almost hidden by scales. The teeth are fang-like and curved backwards. The front part of the tongue can be drawn back into the thicker posterior part.

As the specific name, fragilis, suggests, the slow-worm is apt to break in two. When captured it becomes stiff, with strongly contracted muscles, and a slight twist is enough to break off the tail. This self-mutilation may save the animal's life, and what is lost can be regrown.

About a dozen young ones are born at a time (in August or September). They burst out of the soft-shelled eggs as soon as these are laid, and emerge like miniatures of the adults about $\mathrm{I} \frac{1}{2}$ inch long. They double this in about six weeks, but they take four or five years to become full-grown.

Slow-worms are active during the day, and rest at night under moss or stones or in the ground. In autumn they retreat into winter quarters in some relatively warm dry place, and 

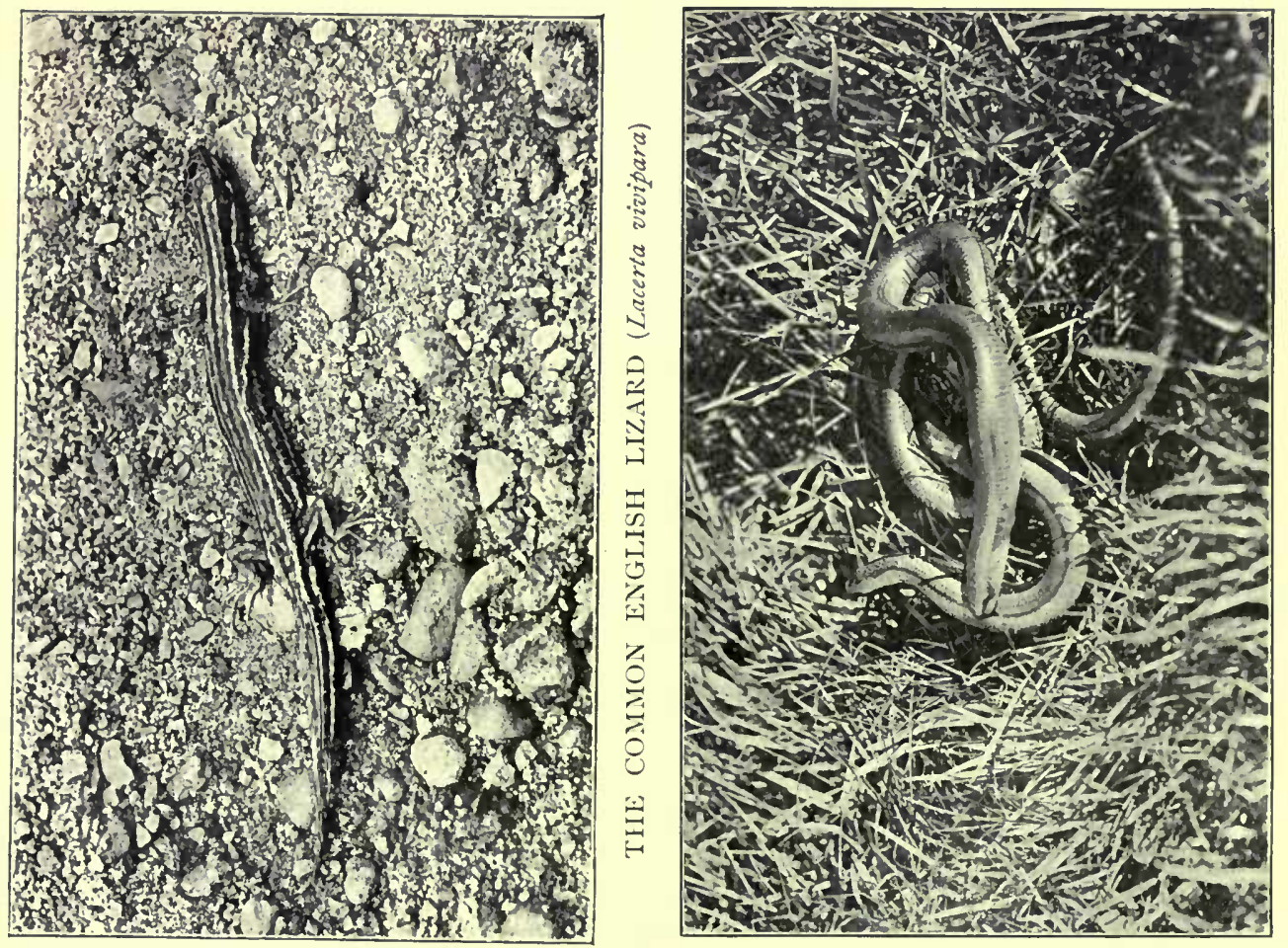

$$
\begin{aligned}
& =
\end{aligned}
$$

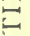

$$
\begin{aligned}
& \text { 恶 } \\
& \because \\
& 2 \\
& 0 \\
& 0 \\
& \text { E }
\end{aligned}
$$
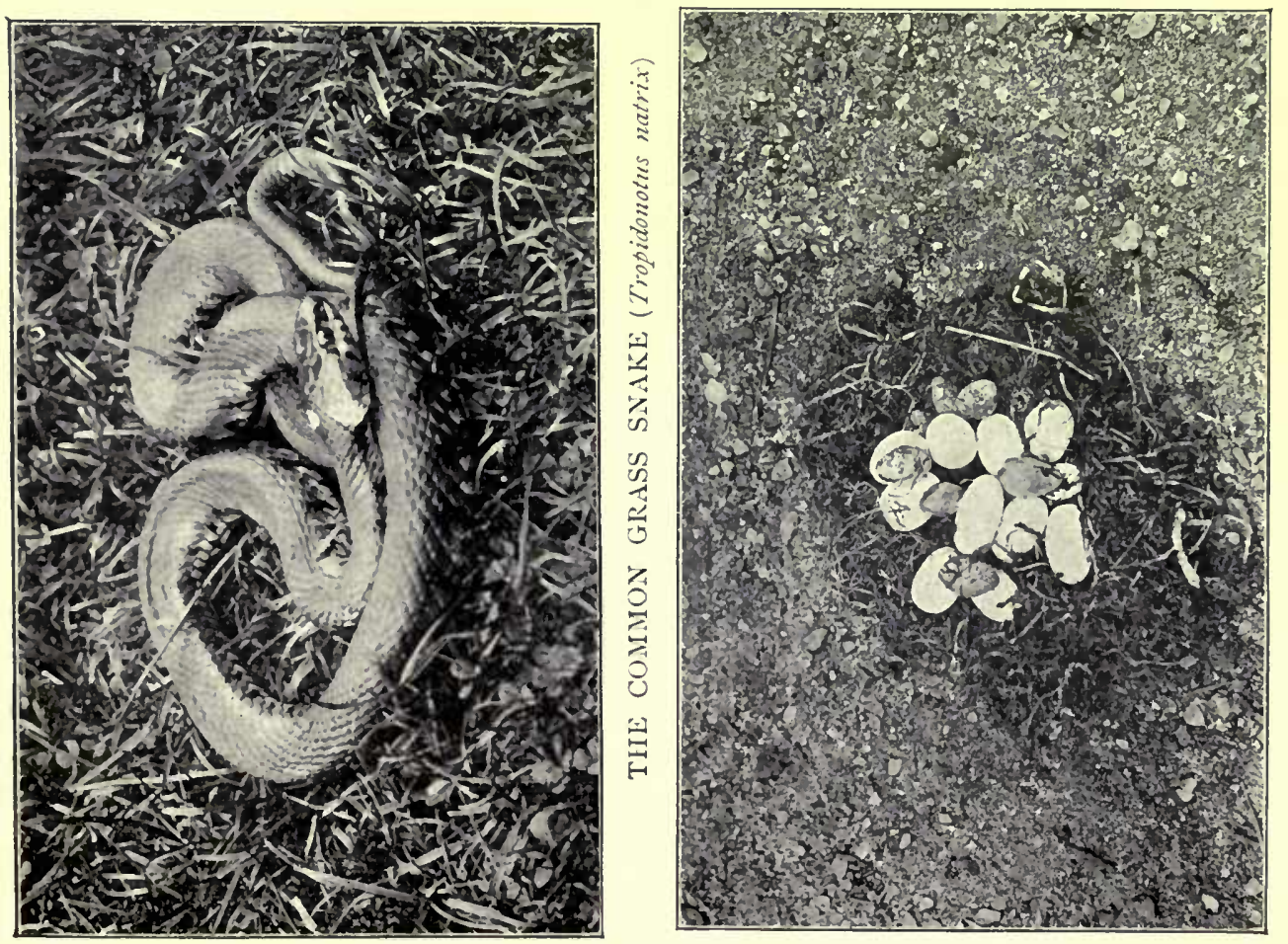

资 
as many as two dozen may be found together in a common burrow.

Why is the slow-worm not a snake? The most convincing reasons are beyond the reach of school-work. Slow-worms differ entirely from snakes as regards their skull, their scales, their ribs, and their soft parts, and they always show traces of the pectoral girdle and pelvic girdle, whereas snakes never show any trace of the former, and only in rare cases (boas and pythons) of the latter. It is easy to show, however, that the slow-worm has a long tail, while the snake has a short tail (without ribs), and that the slow-worm has movable eyelids, while these are quite rudimentary in snakes.

(4) The adder or viper-Vipera berus -is widely distributed in the wilder parts of Britain, especially on heaths and moors, and in mixed woods left between the fields. It feeds mainly on mice, which it paralyses with its poisonous bite.

An adder may attain a length of two feet or a little more, but a foot

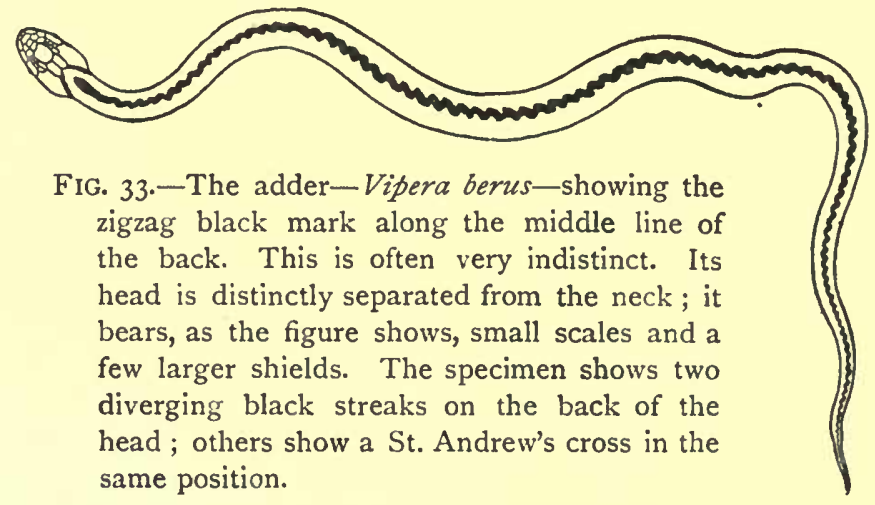
and a half is a

common length. The colour is very variable,-grey, brown, reddish, black, but there is usually a dark zigzag line along the middle line of the back and a dark St. Andrew's cross on the back of the head.

Adders are mainly nocturnal in their activities. During the day they often bask on a warm dry spot. They pair in spring, and bring forth young in midsummer. They hibernate all through the winter, and dozens are sometimes found together. The adder cannot be kept captive ; it starves itself to death.

(5) The grass snake-Tropidonotus natrix - is widely distributed in England and is the largest of the three British snakes, being often about a yard in length. It is quite harmless, and though voL. 1.-8 
it often hisses and makes a great fuss it never bites, having indeed no means of defence except voiding the ill-smelling contents of its cloaca and anal glands.

There are nineteen rows of scales as in the smooth snake (as compared with twenty-one in the adder); these scales are keeled as in the adder (not smooth as in Coronella). The usual colour is olive-grey or brown above, with black spots and narrow crossbands; black and white and grey below.

The grass snake likes moist meadows near water, for it feeds chiefly on fishes and frogs. It can swim well, and is able to climb on shrubs.

Grass snakes pair in May or June, and lay eggs in July or August, usually amid decaying vegetable matter. About three

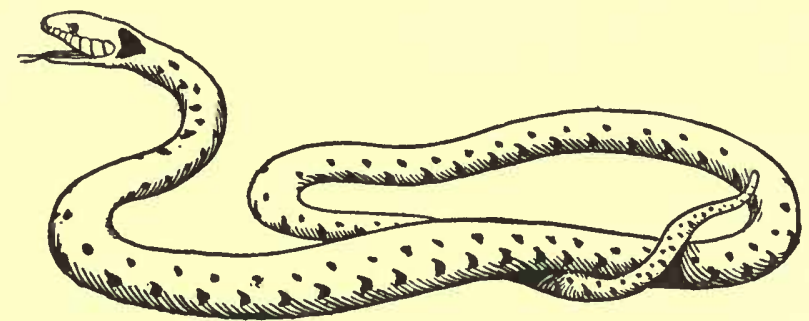

FIG. 34-The grass snake-Tropidonotus natrix. There are usually seven scales along the upper lip, as the figure shows, and the third and fourth of these border the eye. There is often a black collar behind the head.

dozen soft-shelled yellowish eggs, about an inch long, are laid at a time and cohere in a clump. The young are hatched at the end of summer or in autumn; they feed for a few weeks on insects and worms before they take to small frogs. They are readily drowned if they fall into water. The grass snake is easily kept in captivity and becomes very tame. It requires abundance of water.

(6) The harmless smooth snake-Coronella lavis-occurs as a rarity in a few counties of England, e.g. Hampshire and Dorsetshire. It is often very like the adder, and is about the same length, rarely exceeding two feet. "On closer inspection the differences are great enough, the harmless snake having smooth scales, and the top of the head being covered with large shields; while the viper has keeled scales, the top of the head being covered 
mostly with scales, a vertical (not round) pupil, and, moreover, when attacked usually coils itself into a spiral disc with the head standing out in the middle ready to strike." 1 It is quite harmless, and crushes in its coils the mice and lizards which it catches, being unable to paralyse them with a poisonous bite as the adder does. It usually hunts in the evening.

The smooth snake is viviparous, and about six young ones are born at a time.

The Greek tortoise-Testudo graca-and the closely allied Moorish tortoise- $T$. ibera-are often brought to this country, and in the warmer parts they seem to thrive in gardens. They are usually quite strict vegetarians, enjoying succulent food, and they certainly do not eat " black beetles," though they are often sold and bought for this purpose. They are entirely diurnal and enjoy the sun; they hibernate in winter. The pairing is in spring or summer; two to four hard-shelled eggs, like those of pigeons, are buried in the ground. Tortoises are very tenacious of life, and may live for more than half a century.

The tortoise may be taken as an illustration of effective armour. It can retract head and tail and limbs within the shelter of its arched shell, which is exceedingly strong. The Greek eagle breaks up the Greek tortoise by letting it fall from a great height (a habit which is said to have been fatal to the poet Eschylus), and it is interesting to compare this with what has been observed in regard to rooks, that they get into freshwater mussels by letting them fall from a height, and with the thrush's well-known habit of breaking snails' shells against stones.

A cleaned shell should be sawn across vertically to show the strong arch, and the inside of the upper half should be studied to show this at least, that the dorsal vertebræ and the ribs have become part and parcel of the shell, and that the contours of the epidermic horny scales (tortoise-shell) do not in the least correspond to the contours of the bony plates.

Suggested Study.-Different types of animals may be utilised educationally in different ways, thus the life-history of the frog is readily studied while that of a snake is not; birds have, so to 
speak, more observable habits than most fishes have; the skull of a cat or dog is a good subject for a school lesson, but that of a cod or flounder is not, and so on. The question is, what can be done most effectively with different kinds of material.

In regard to reptiles, we would suggest a study of a living grass snake, especially of one that has grown accustomed to being a pet. The study should have this particular object in view, to illustrate adaptation, i.e. how peculiarities of structure are fitted for peculiar conditions of life.

I. One may start from the fact that the body is greatly elongated. The trunk portion is relatively long, while the tail portion (without ribs on the vertebræ) is relatively short. Limbs are inconsistent with such a long body, and with a habit of creeping through brushwood and crevices of all sorts. Limbs and limb girdles have disappeared, save small vestiges of the hip girdle and even of hind-legs in a few cases, e.g. in boas and pythons. Technically expressed, the absence of limbs is correlated with the great elongation of the body. But it must be made clear that the elongation is in the trunk region of the body; it is not a matter of having a very long tail, as many lizards have.

2. The absence of limbs is compensated for by the presence of long ribs on all the precaudal vertebræ (sometimes nearly three hundred) except the first. The vertebræ of the tail have long transverse processes. The ribs are very movable forwards and backwards, and their lower ends are fastened to the large ventral scales which grip the roughnesses on the ground.

The snake, Ruskin says, "literally rows on the earth, with every scale for an oar; it bites the dust with the ridges of its body." The comparison with rowing is luminous, but perhaps it would be truer to call the ribs the oars and the ventral scales their blades. On a perfectly smooth surface it can make no headway, but in normal conditions the edges of a certain number of scales are fixed against roughnesses of the ground, the ribs are drawn together first on one side, then on another, the body is thus wriggled forward to the place of attachment, the front part shoots out as the hind part fixes itself, an anterior attachment is again effected, and thus the snake flows on. And what a wonderful locomotion it is! For the limbless serpent, as 


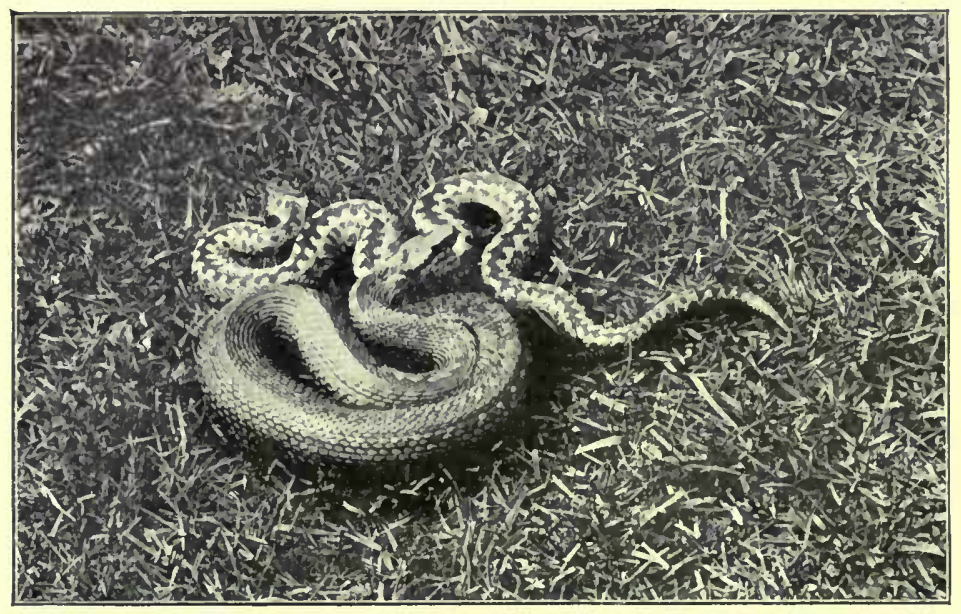

Photo by Uxiey Grabliam.

ADDERS (lipera berus), MALE AND FEMALE

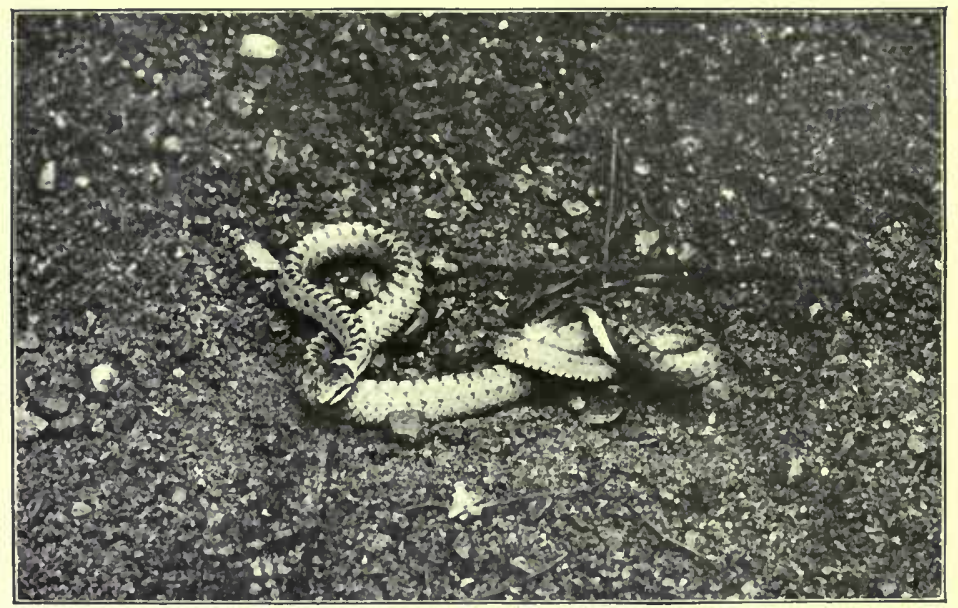

Pltoto by Oxley Grabham.

TIE RARE SMOOTH SNAKE (Coronella laris)

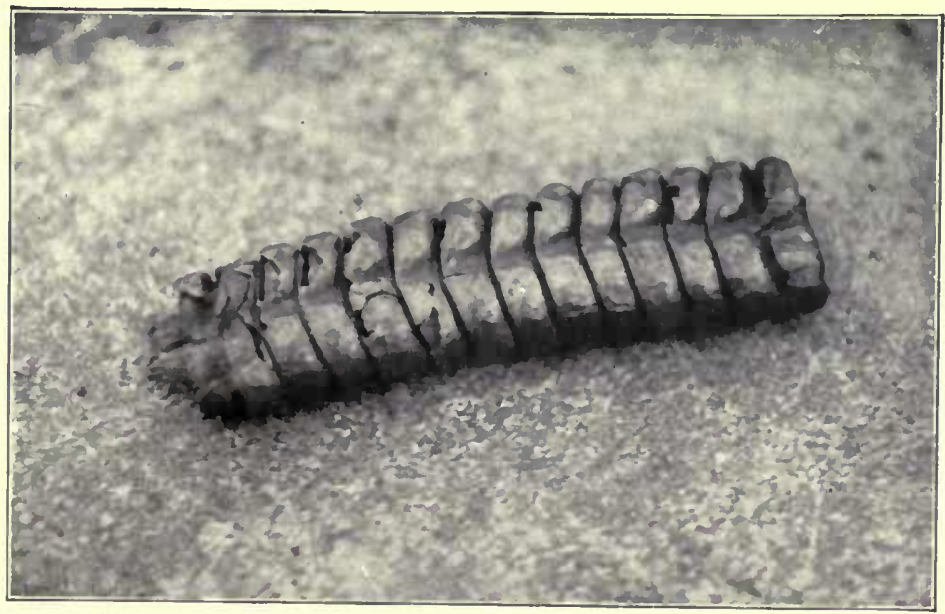

Phoio by W.S. Berricige, F.Z.S.

RATTLE OF RATTLE-SNAKF 
Owen said, "can outswim the fish, outleap the zebra, outwrestle the athlete, and crush the tiger."

To understand the matter clearly it is necessary to have a snake's skeleton. A set-up specimen will last for many years if it is carefully enclosed in a long box with a glass lid and a glass floor so that both sides can be seen. Delicate skeletal specimens should always be sealed up. Whenever it comes to touching the bones in demonstration the specimen's days are numbered. On the other hand, it is useful to have some stout snake's vertebræ threaded on a wire. It is then an easy matter to demonstrate, for instance, the highly developed ball-and-socket articulations.

3. Snakes are given to tackling prey which seems much too large for the size of their mouth. Thus it seems at first almost ridiculous that a grass snake should attempt to swallow a frog. In connection with this habit we find that the two halves of the lower jaw are not united in front except by ligament, and that many bones of the skull, e.g. of the upper jaw and palatal regions, are loosely attached to one another, though there is, of course, a rigid box protecting the brain.

If we watch a grass snake swallowing a frog-a sight best reserved for private edification-we see that it grips its victim so that the head is swallowed first; it moves forward the right half of the lower jaw, gripping with the left; it takes a new grip with the right half, and advances the left; it thus laboriously draws itself over the frog. The distention of the gullet region is almost as extraordinary as that of the mouth. The long windpipe, opens far forward in the mouth, and the glottis can be protruded a little between the tips of the lower jaw, so that the snake is not suffocated by its extraordinary swallowing. It need hardly be said that the popular impression that snakes lubricate their prey by covering them with saliva before they swallow them has as little foundation as most popular impressions. The grain of truth in the notion is that internal salivation helps the booty down.

4. In poisonous snakes some of the teeth have a groove down the front side, or a canal formed by the closure of a groove, and down this groove or canal the poison passes into the wound 
when the animal bites. The poison gland, whose duct opens at the base of the specialised teeth (or fangs) seems to be a specialised salivary gland, equivalent to the parotid of mammals.

When the snake opens its mouth to bite, the depressing of the lower jaw automatically raises the maxillæ bearing the fangs, so that the fangs pass into a striking position. (A wooden model can be made to show how one movable bone works on another.) Moreover, the opening of the mouth and the erection of the fang-bearing maxillæ serve to squeeze the poison-gland. When the tooth has a canal which opens near its tip the poison must pass into the depths of the wound. When the teeth are broken there are reserve fangs ready to take their place. We find, in short, one effective adaptation after another ensuring the snake's success.

5. The sense organs of snakes are interesting. The peculiar "stare," to which the credulous have ascribed a power of fascination, is partly due to the fact that the eyes are not in themselves movable, and partly to the absence of the upper and lower eyelids (seen as vestiges in the embryo). What is probably the equivalent of the third eyelid in many other animals forms a fixed transparent blind across the eye, and is covered by a single transparent watch-glass-like scale. Snakes have an internal ear and can hear well, but there is no trace of ear-hole or drum or Eustachian tube. The adder is not deaf, and it cannot stop its ear. The sense of smell is well developed, and the long slender bifid tongue, which has nothing to do with the poisoning, is a restless organ of touch.

Internally, too (though we shall not pursue the subject further), there are many interesting adaptations; thus the right lung is much larger than the left, as if there were not room for both in the narrow body cavity; the kidneys are not opposite as in most animals, but one behind the other.

A Grass Snake's Slough is sometimes found in the meadow or a viper's on the moor. What is it, what is its peculiarity, what is its significance? The outermost horny layer covering the scales dies away periodically, becomes worn, and is cast off several times a year. It is replaced by another layer like itself. It is not a "casting of the skin" that occurs, for this 
would be absurd; it is not a casting of the scales,-it is a casting of the outermost horny layer of the epidermis. The peculiarity of this moulting-for such it is-is that the whole slough remains coherent. The shedding begins at the lips, and the husk is turned inside out from before backwards, so that the tail is the part last moulted. No one can forget his first delight at finding a snake's slough, with its suggestion of ghostly chain-armour. It bears the impress of all the details of the scales, even of the watchglass-like scale over the eye.

In this connection it would be interesting to show the rattle of a rattle-snake, that remarkable musical instrument by which this deadly snake produces in its excitement a shrill whistlelike sound. The noise warns off animals such as peccaries, which are far too large for the rattle-snake to use. It may bite them and kill them, but this means fatigue and the risk of breaking a tooth, all to no purpose. When the rattle-snake moults, the horny covering of the tip of the tail is moulted but remains attached; at the next moult a second joint is interpolated between the first and the end of the tail. Thus the rattle "grows," sometimes gaining three joints in a year. The total number does not become large, because the terminal parts get broken or worn off. The rattle is usually procurable from dealers in natural history specimens.

The kind of study which we have thus tried to suggest by particular reference to the snake may be repeated in reference to slow-worm and lizard and tortoise.

Bibliography.-Hans Gadow, "Amphibia and Reptiles," vol. viii. of Cambridge Natural History (Macmillan \& Co., London, I90I). See also Bell's British Reptiles (London, I849); Leighton's British Serpents (Blackwood, Edinburgh, I90I); M. C. Cooke, Our Reptiles and Batrachians (Allen London, 1893). 


\section{CHAPTER XVI}

\section{The Study of Amphibians}

THE amphibians of to-day-such as frogs and toads, newts and salamanders - are the descendants of those vertebrates that long ages ago made the transition from aquatic to terrestrial life. Amphibians were the first animals to have fingers and toes, and the first vertebrates to have vocal cords. Some other acquisitions, such as lungs and a three-chambered heart, which are hinted at in the double-breathing mud-fishes or Dipnoi, are securely established in Amphibians.

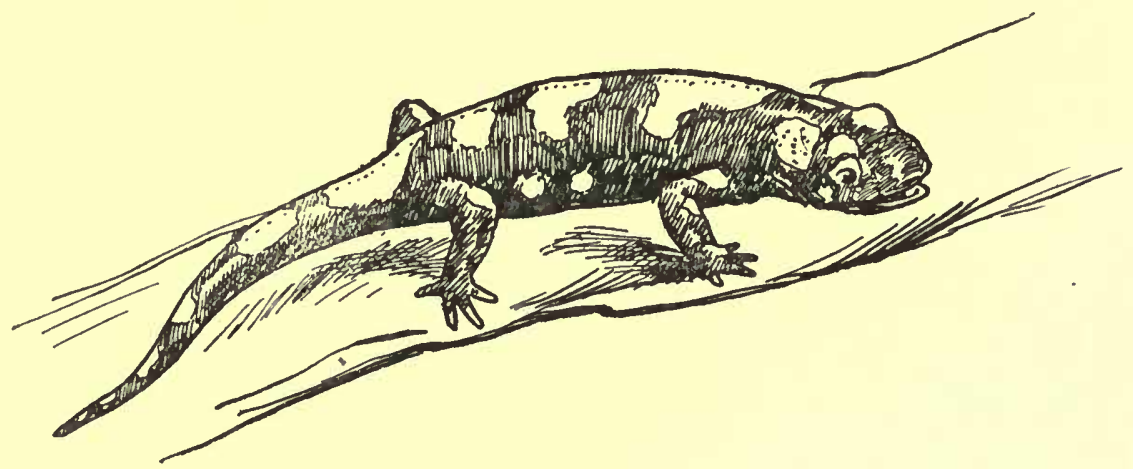

Fig. 35.-Spotted or fire salamander-Salamandra maculosa-a common amphibian on the continent, but not found in the British Isles. The ground colour is black with large irregular yellow patches. It is an interesting animal for a vivarium, and usually thrives if provided with a moist and cool retreat. It may be fed on earthworms, grubs, slugs, and woodlice. Like the toad and many other amphibians it secretes a poisonous juice from its numerous skin-glands. It may be described as viviparous, for the eggmembrane bursts before or just after birth, liberating larvæ about an inch long, which are able to eat from the first.

There is almost always a metamorphosis in the life-history, and the larvæ bear gills. These may be retained throughout life, but they disappear in the great majority, the breathing being effected by lungs and also through the skin. A hibernating 
frog depends altogether on this primitive cutaneous respiration, which is entirely lost in higher animals. Sometimes a newt is found without lungs, apparently thriving though breathing solely through the skin. It is instructive to note such cases of cutaneous respiration among vertebrates, partly because this method is common among invertebrates, partly because it makes it clear that respiration is simply the absorption of oxygen and the elimination of carbon dioxide. It matters little whether the blood vessels are spread out on the walls of a lung which is open to the outer world, or on the large surface of a feathery gill which is washed by the water, or in the moist skin. In regard to the possession of lungs, it should be noted that the nostrils, through which the air enters, open into the mouth; whereas the nostrils of fishes are blind, purely olfactory sacs, of no service in respiration, and without any connection with the mouth (except in mud-fishes, where the conditions are peculiar).

In existing amphibians there is rarely any exoskeleton, but some extinct forms had an armour of bony plates. In many cases, at least, the soft skin, which is rich in glands, seems to be unpalatable to various other animals, which leave amphibians severely alone.

The eggs of amphibians are small, numerous, usually pigmented, and with yolk towards one pole. They are almost always laid in water, and the youthful stages are almost always aquatic.

Amphibians differ from fishes in having digits, lungs, a threechambered heart, vocal cords, a naked skin, and so on. They agree with fishes in certain important respects, e.g. in having gill clefts used in respiration, in having gills, in showing (in youth at least) lateral sense organs like the lateral line of fishes, in usually having unpaired fins (in their larval stages at least). In these respects they differ from reptiles, and the usual nakedness of the skin has been already referred to. Without making too much of a business which is by no means so easy as it looks, it may be profitable to take a trout, a newt, and a lizard, and try to get the pupils to compile a statement of their resemblances and differences. 
British Amphibians.-There are only six :-

(I) The common frog-Rana temporaria.

[The edible frog-Rana esculenta-is occasionally found, e.g. in Norfolk, but it has probably been introduced for culinary purposes.]

(2) The common toad-Bufo vulgaris.

(3) The natter-jack toad-Bufo calamita.

(4) The crested newt-Triton cristatus.

(5) The common newt-Triton vulgaris.

(6) The webbed newt-Triton palmatus.

The toad may be distinguished from the common frog in many ways, e.g. by its wrinkled, rather dry skin, covered with wart-

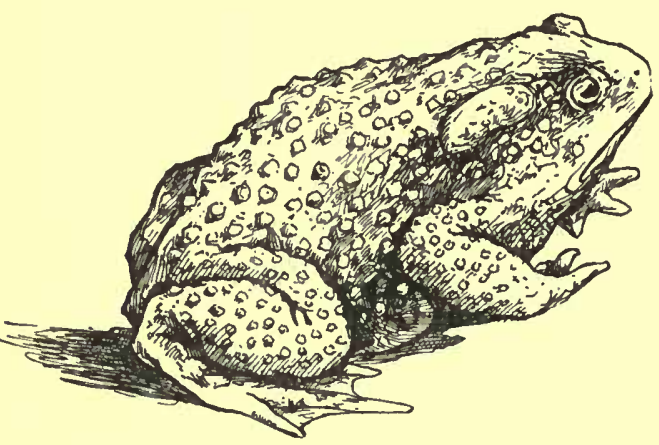

Fig. 36.-The common toad-Bufo vulgaris. The skin is rough, with wart-like glands from which a poisonous secretion exudes, and there is a particularly large gland behind the ear.

like poison-glands, by the different coloration, by the less developed web between the toes, by the absence of teeth, by the different mode of locomotion - more crawling and less jumping, by being an expert climber, by the marked nocturnal activity, by hibernating far from water, by laying the eggs in long strings. The toad is an exceedingly useful animal, destroying slugs and injurious insects ; it is gentle, harmless, and easily tamed ; it cannot in any sense squirt or spit poison. 
Our British newts are aquatic when young and at the breeding season, at other times they become terrestrial. The males develop a high median crest at the breeding time. Newts feed on insects, centipedes, earthworms, slugs, and the like, and hunt mostly at nights. The eggs are laid singly or in small groups on stones or plants in the water, and hatch in about a fortnight. The larvæ are not nearly so unlike the adults as tadpoles are unlike frogs; thus there is much less of a metamorphosis, the chief change being the absorption of the gills, the closing of the gill-clefts, the disappearance of the gill-chamber and of the delicate fringe round the tail.

\section{The Living Frog}

When the common frog is caught it resents this wildly, and even in the seclusion of a vivarium it continues to attempt the impossible. In a few days it becomes fairly tame, and may then be more profitably studied. It grows accustomed to being handled, and will take living maggots or small earthworms dangled before it.

The frog is characteristically a jumping animal, but it sometimes crawls along. It swims well, but it spends most of its time on land. It feeds on insects, slugs, and earthworms, catching these by rapidly throwing out the tongue, which is loose behind and fixed to the middle of the lower jaw in front. Just

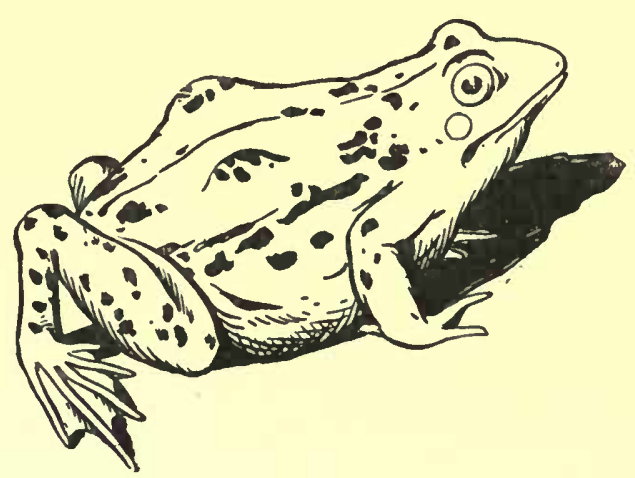

FIG. 38.-The common frog-Rana temporaria. The drum of the ear, flush with the skin, is seen behind the eye. A double hump on the back shows where the hip girdle is attached to the last free vertebra. In the figure the ankle-joint is raised high off the ground, showing the very long foot. before the deft act of capture the frog reveals some excitement in the rapid movements of the floor of the mouth.

Observations should be made on the resting frog as it sits 
squat, with a slight hump on the back (where the hip girdle articulates with the last free vertebra), with the hind-leg bent like a letter $Z$, the knee pointing forwards, the ankle backwards, the tips of the toes forwards, and so on.

It is very instructive to watch the respiration. When a frog is breathing the nostrils are alternately opened and closed, the under side of the throat is rhythmically lowered and raised, the mouth remaining tightly shut meanwhile, and the flanks of the body rise and sink.

The pupils should watch the different movements and time them, and draw inferences. (a) When the floor of the mouth is lowered, and the buccal cavity thus increased, air passes in by the open nostrils. There is a sort of suction-pump action. (b) When the nostrils and the opening of the gullet are closed, and the floor of the mouth is raised, the air is forced through the open glottis into the lungs. There is a sort of forcepump action. (c) When the pressure on the lungs is relaxed, and when the muscles of the sides of the body contract, air passes from the lungs to the mouth and out by the open nostrils.

"To tell the pupils that such and such is the case, and then request them to verify the statement is destructive alike of interest and of the beneficial results which are the aim of all science teaching. But it is quite legitimate, after all that is possible has been found out, to impart a little additional information by way of explanation of facts observed. For example, supposing that the respiratory movements of a frog be under notice, we may ask the class to describe the movements of the throat, nostrils, ear-drum, and flanks, to note the condition of the mouth, to time the frequency of the various movements, and describe their relation one to another; but we shall not be wrong subsequently, by the aid of a model and by blackboard diagrams, to get the class to reason out, with a little assistance, how the air is forced into the lungs by the compression exerted by the floor of the mouth cavity." 1

1 O. H. Latter, see references, p. 135 . 


\section{External Features}

As an exercise in precision of observation a study may be made of the frog's external features. In some cases it may be possible to suggest an interpretation of the peculiarities.

The absence of any neck region and of a tail ; the short forelimbs, almost thumbless; the swollen first finger, which is one of the marks of a male frog; the strongly developed hind-limbs with webbed feet and very long ankle region, in obvious adaptation to swimming and jumping; the absence of nails on fingers or toes ; the horny knob at the base of the big toe; the apparent hump-back where the hip girdle is linked to the backbone.

The wide mouth, the valved nostrils, the protruding eyes, the upper eyelid thick, pigmented, and slightly movable, the lower eyelid rudimentary and not movable, a third transparent eyelid drawn up from beneath and moving very freely, the circular drum of the ear flush with the skin, the slightly dorsal cloacal aperture.

It may be interesting to take up in detail some structure such as the skin, which may be contrasted with the corresponding structure in fishes and in higher animals. The frog's skin is very loose, there are large lymph spaces between it and the subjacent muscles. The transparent outermost layer of the epidermis dies away periodically and is shed, the pieces being swallowed by the frog. There is no hint of scales. There are numerous glands, whose secretion keeps the skin moist and makes it unpalatable. The skin contains abundant pigment cells, and the colour can change a little according to temperature, illumination, etc. The frog can breathe through its skin and absorb water through its skin. A higher animal can do neither.

\section{The Frog-A "Cold-blooded" Animal}

The frog may be taken as a convenient starting-point for some inquiry into an interesting but difficult matter,- the difference between "warm-blooded" and "cold-blooded" 
animals. The warm-blooded animals are the birds and the mammals ; they have an automatically working nervous arrangement by which the temperature of the body is regulated and kept constant. If we allow for certain intelligible exceptions (e.g. animals in fever, hibernating mammals, fledgling birds), warm-blooded animals are those which keep the temperature of their body constant, no matter what the external temperature may be. But cold-blooded animals, such as reptiles, amphibians, and fishes have not got the regulating mechanism referred to, and their body temperature varies directly with the temperature of their surroundings. Though not necessarily the same as that outside, the internal temperature varies directly with it, so that the animal becomes colder when the surroundings are cold, warmer when they are warm. "Cold-blooded" does not mean that the body temperature is necessarily very low; it means " of changeable body temperature."

\section{The Year's Life of the Frog}

It is profitable to try to induce the habit of picturing the life of an animal throughout the year. The frog is a good type to work with, for most of the chapters are familiar. There is the winter's rest under moss or in the mud of the pond-side,where the frogs lie inert, mouth shut, nostrils shut, with their heart beating slowly. There is the pairing and egg-laying in spring, and the juvenile life-lasting for about three months altogether-in the pond. The small fully formed frogs-about the size of the nail of our little finger-leave the pond in midsummer and make for the meadows and fields, sometimes migrating in crowds. They grow to about three-quarters of an inch in length by October, when those that survive take to winter quarters and hibernate.

Frogs have numerous enemies, so that, in spite of their enormous families, their numbers are kept down. They fall victims to birds, such as stork and buzzard; to mammals, such as fox and stoat; to the grass-snake; and, not least, to man both as epicure and as biologist. They are often stoned by country- 
boys at the breeding season, - a foolish and wantonly cruel proceeding.

\section{LIFE-HISTORY}

Pairing and Spawning.-After resting throughout the winter in the mud of the pond, the full-grown frogs become active again as spring approaches, and they at once proceed to pair. The pairing usually occurs in March in Britain, but it may be earlier or later according to the climate of the locality, and according to the earliness or lateness of the spring. The males utter their familiar "grook, grook," apparently calling to the females; a male mounts on the back of a female, grasping her under the breast, helped in this embrace by his swollen first finger; as the eggs are passed out from the female they are fertilised by microscopic sperms emitted by the male; these actively moving sperms bore their way through the envelope of jelly surrounding the egg, and one sperm enters into an intimate and orderly union with each egg.

The Eggs.-The frog's egg is a black sphere with a small whitish spot of yolk at the lower pole. Each is from 2 to $3 \mathrm{~mm}$. in diameter, and is surrounded by a spherical envelope of jelly from 8 to Io $\mathrm{mm}$. in diameter. From I000 to 2000 or more eggs are laid by one female, and they cohere in large masses, which rise buoyantly to the surface of the water.

Comparison with other Eggs.-The

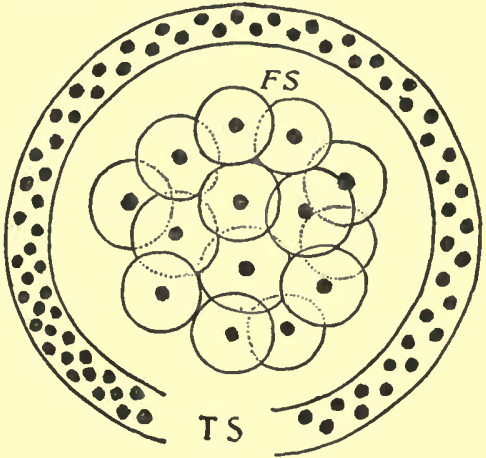

FIG. 39.-Diagram of frog spawn (F.S.) and toad spawn (T.S.). The dark spheres are the eggcells, which are surrounded by spheres of jelly in the case of the frog, and by a long ribbon of jelly in the case of the toad. The common frog may lay 1000 to 2000 eggs, and, as the water effects the gelatinous sphere, the whole mass swells up to the size of a toy balloon. The diameter of each sphere increases about ten times. The toad maylay 2000 to 7000 eggs in two strings, which may be teh feet long. As the parents move during the business of laying and fertilising, the strings become entangled among the water weeds. In a loose part of a string floating freely there may be three or four files of eggs, on a stretched part there are two files. frog's egg should be compared with the hen's egg. What is popularly called the yolk of a hen's egg is the real ovum, an 
enormous egg-cell dilated with yolk, and it of course corresponds to the frog's ovum. The difference is that there is relatively a large quantity of yolk in the bird's ovum, and that it is more strictly separate from the small drop of formative living matter which lies at the upper pole; whereas in the frog's ovum there is relatively less yolk, and it is not so definitely separable from the living matter which permeates it. Thus the bird's egg divides partially, the cell divisions being restricted to the minute drop of polar living matter, while the frog's egg divides wholly. The white of egg in a hen's egg is analogous with the envelope of jelly in the frog's egg, and both are produced by the glandular walls of the oviduct as the egg passes down. It is obvious that the frog's egg has no shell. In toad's spawn the eggs lie two or three abreast in two long mucilaginous strings. The comparison should go further, and the frog's egg should be compared with other eggs which can be shown in school, e.g. the eggs of fishes (the familiar roe of cod and herring, for instance), the eggs of the water-snail, the eggs of insects (such as a butterfly's), the eggs of the sea-urchin, and so on. It is useful to make a collection to illustrate the general fact that in all ordinary cases animals develop from eggs.

Practical Note.-Samples of the eggs of frogs and toads should be kept for demonstration-preserved in alcohol. At the spring season some eggs should be collected and kept in shallow dishes, such as milk-basins, with a few water-weeds to secure aëration and with occasional changes of water, best secured by a gentle drip from the tap. They should not be exposed to the glare of the sun, nor kept too much in the dark.

Uses of Gelatinous Envelope.-The spheres of jelly around the eggs are useful in various ways. They obviate overcrowding and act as buffers, saving the delicate eggs from being jostled by wind and other disturbances. They leave interstices in which small unicellular plants are often seen, along with minute animals such as water-fleas and rotifers. The minute plants liberate oxygen during the day, and absorb the carbon-dioxide given off by the developing eggs. Thus there is a mutually beneficial association, illustrating the "balance of nature" on a minute 

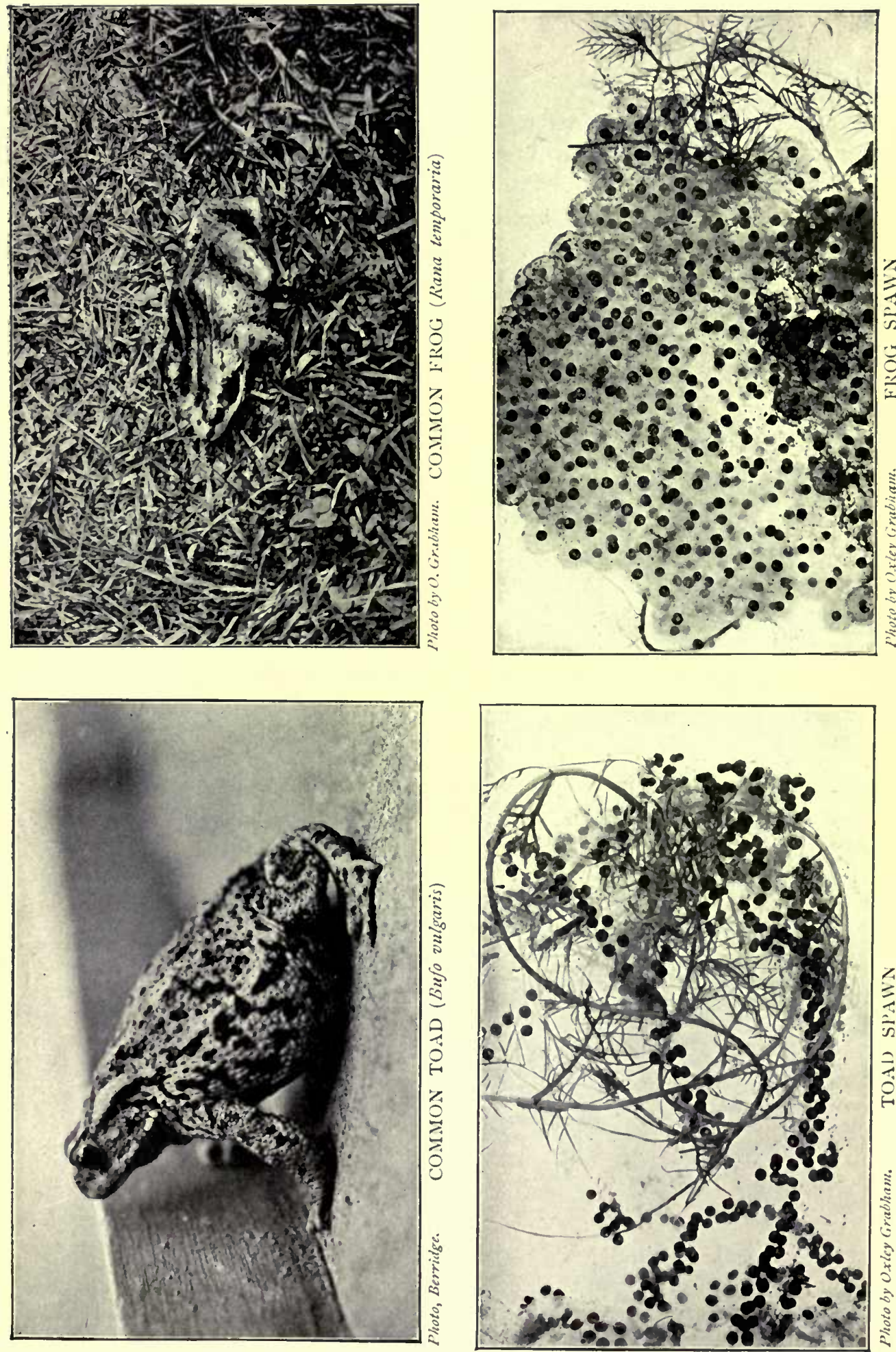

scale. The little animals often associated with the trog's spawn may help to loosen the envelopes and thus assist the emergence of the embryo frogs, but some appear to attack the latter. Furthermore, the slippery nature of the jelly may protect the eggs from water-birds, especially from those that are not broad-billed like the ducks. It is also noteworthy that only a few of the voracious smaller water animals attack frog-spawn,-perhaps because of some unpalatability in the jelly. There is interest in an inquiry
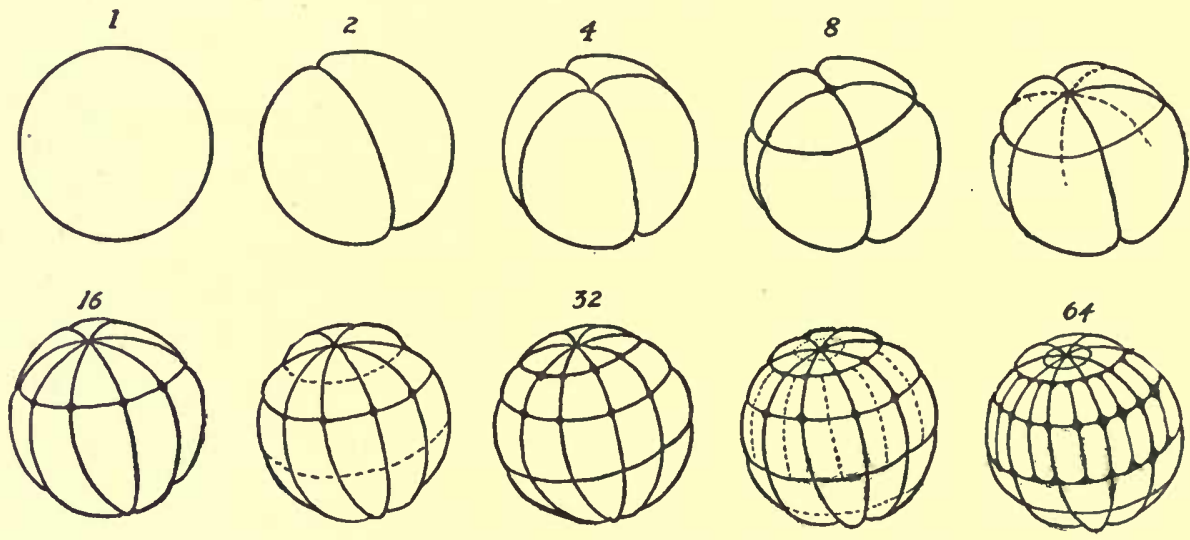

Fig. 40.-The division of the frog's eggs. (After Ecker.) The numbers (2, 4, 8, I6, 32, 64 ) indicate the number of cells into which the egg has divided. It should be noted that although there are 64 cells in the last figure on the second row, it is no larger than the unsegmented egg (I). G Growth has not begun. The first cleavage is vertical, dividing the egg into a right and left half; the second is also vertical, at right angles to the first, dividing an anterior from a posterior half; the third cleavage is equatorial, at right angles to the two preceding. With the help of a lens these early cleavages can be seen occurring. As division goes on there come to be numerous smaller cells in the upper part of the egg, and fewer, larger, yolk-laden cells towards the lower pole.

of this kind, for although there are some uncertainties, the general fact is clear, that the spheres of jelly are useful in many ways. They are instances of the fitness of minute details in organic nature. In many amphibians the gelatinous envelope serves to attach the eggs to water-weeds, but those of Rana temporaria float freely.

Early Development.-For about three weeks-the time required varying with the temperature-the eggs go on developing. Out of apparent simplicity comes obvious complexity, an embryo is formed. With a lens the egg may be seen dividing, as if it was voL. $1 .-9$ 
being cut with an invisible knife. It divides into a right and a left half, then into an anterior and a posterior half, then into a dorsal and a ventral half. By three cleavages at right angles to one another - the first two vertical and the third equatorialit divides into eight cells, the four in the upper hemisphere being somewhat smaller than the four in the lower hemisphere. Quickly it forms a ball of many cells, though it is not any larger than it was, for growth has not begun. The cells go on multiplying, and the embryo becomes a little larger. Gradually the important organs begin to make their appearance,-the dorsal nerve cord and the brain; the food canal; the dorsal supporting rod or notochord; the foundations of the rest of the skeleton; the beginnings of musculature, and so on. The embryo moves within its envelope of jelly, and wriggles itself free. It is " hatched."

The Newly Hatched Embryo.-The head is clearly distinct from the body; a dimple indicates the future position of the

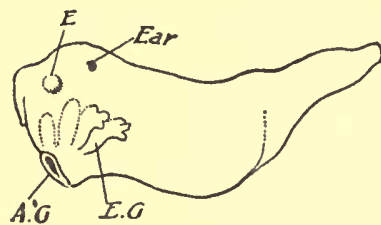

FIG. 41.-The newly hatched tadpole, showing the horseshoe-shaped cement gland (AG), the external gills (EG) slightly developed, the position of the eye $(\mathrm{E})$, which is not yet exposed, and the position of the ear. The bulging on the ventral surface indicates the mass of food-yolk within the body. mouth; a pit indicates the nostrils; a grooved crescent behind the mouth depression produces a gum-like slime which attaches the helpless embryo to waterweed; the tail is rudimentary; the eyes have not yet reached the surface (the eye of a backbone animal always begins as an outgrowth from the brain); a minute bud on each side of the head is the rudiment of the external gills, and vertical grooves beside it hint at the future gillclefts. The newly hatched embryo may be described as mouthless, tailless, limbless, gill-less, and eyeless.

Early Changes after Hatching.--The tail grows, and with a lens there may be seen a transparent tail-fin and wedge-like muscle segments. Three external gills bud out, the first large, the other two small. The mouth is opened and has fleshy lips; the other end of the food canal opens ; the nostril-pits open into the mouth; the gill-clefts open ; and the eyes become faintly visible. Hitherto the larva has been growing at the expense of its legacy of yolk; it now 
begins to feed on minute unicellular plants and on the particles of decaying plants and animals.

The First "Tadpole" Stage.-About a month after hatching, what is strictly called the first true tadpole stage is seen. A

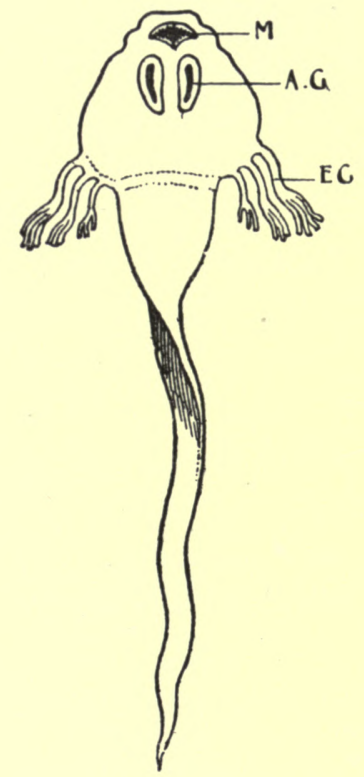

FIG. 42.-An older stage, a few days after hatching, seen from below. The external gills (EG) are now well developed. The adhesive gland (AG) has been divided into two. The mouth (M) has a pair of horny jaws, and the lips bear minute horny papillæ.

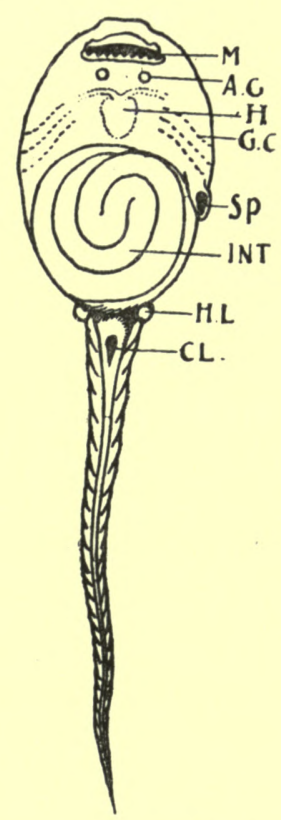

FIG. 43.-A later stage shows the intestine (INT) coiled like a watch-spring, the rudiments of the hind-legs $(\mathrm{HL})$ as a pair of small papillæ at the root of the tail in front of the cloacal aperture (CL), the spout-like opening or spiracle (SP) on the left side by which the water, taken in by the mouth and passed out through the gill-clefts (GC) into the gill-chamber, regains the exterior. The adhesive glands $(\mathrm{AG})$ behind the mouth (M) are now very small. The position of the two-chambered fish-like heart is indicated $(\mathrm{H})$.

fold of skin has grown over the external gills, forming a gillchamber, with a single aperture (or spiracle) to the left-hand side. The enclosed gills dwindle away and are replaced by a second set, often called "internal" gills, consisting on each side of four sets of small branched threads supported on four gill-arches. The general arrangement may be made clearer by examining any common bony fish, such as a haddock or a trout, which shows a 
gill-cover, a gill-chamber, gill-arches, and gill-filaments, but neither the gill-cover nor the gill-filaments of the tadpole are exactly equivalent to those of the ordinary fish. There is a great change in the mouth; it now has horny jaws, and the lips have many minute horny teeth,-each a single cell like a nightcap in shape, replaced by others beneath them as they get worn off. The animal is able to swim about actively, and the crescentshaped cement gland, after dividing into two widely separated circular discs, disappears. In regard to this short-lived organ, it may be noted that the term "sucker," often applied to it, is inappropriate, since there is no muscular adhesive action. The general change in shape is noteworthy, for after the gill-covering fold fuses with the skin behind (leaving only the spiracle open) the head ceases to be distinct from the body. The tadpole is now feeding upon larger booty, e.g. small insect larvæ and small worms, as well as pieces of plants, and the intestine is very long. It may be seen through the skin, coiled up like a watch-spring. At this stage the tadpoles in the aquarium may be fed on small quantities of mixed meat, on grated yolk of egg, and the like; but care must be taken to avoid fouling the water by putting in too abundant supplies.

The Second Tadpole Stage.-The hind-limbs bud out at the root of the tail The fore-limbs start at the same time, but

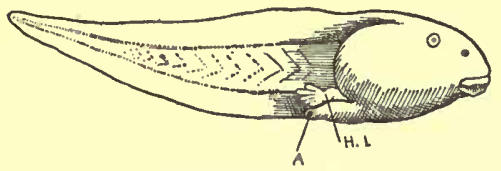

FIG. 44.-The second tadpole stage, nearly twice the natural size, showing the growing hind-leg ( $\mathrm{HL}$ ), the cloacal opening (A), the zigzag connective-tissue partitions between the muscle-segments in the tail, the bulging gill-chamber, etc. (After A. Milnes Marshall.)

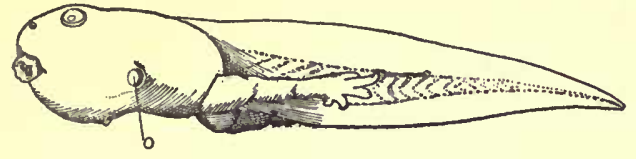

FIG. 45.-A later stage before the beginning of the metamorphosis. The hind-legs have grown considerably. The elbow of the fore-limb is projecting through the transparent gill-cover (o), in which a hole will soon be broken. It will be seen that the mouth has still its rounded suctorial character. (After A. Milnes Marshall.)

are retained within the gill-chamber until they are fully formed, when the right one breaks through the skin and the left one gets through the spiracle. In front of each limb there is a small 
cleft, sometimes called the "complementary spiracle." The mouth is somewhat lamprey-like, with horny "teeth" on the circular lip, and the jaws still bear the horny beaks somewhat like those of cuttle-fishes. Inside the mouth there are many long papillæ, possibly "taste organs." The gill-arches still bear delicate branching filaments to the outer convex side, and show a membranous filtering sieve on the inner concave side, but the gill-system is in process of disappearing, for the lungs have now developed. In an intricate way the circulation changes from being very like that of fish towards the adult amphibian arrangements. The tadpoles come often to the surface and take gulps of air ; they are learning to use their lungs. If they are prevented by a screen of gauze from coming to the surface they may become large tadpoles, and may be kept in this state for over a year. In the north, when the summer is very cold, the winter may come before the tadpoles have changed into small frogs.

The Metamorphosis.-Some three months or so after hatching the tadpoles change into little frogs, and this metamorphosis involves much reconstruction. The tail degenerates and is absorbed,- - a process analogous to inflammation taking place. The wandering amoboid cells or phagocytes of the body carry the debris of the tail to be utilised in construction in the body. A popular im-

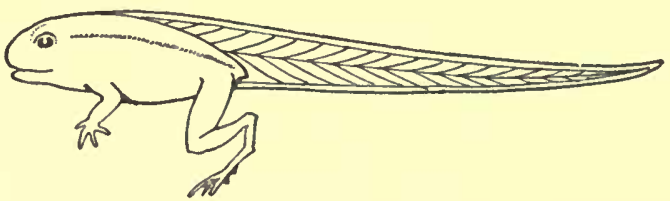

FIG. 46.-A tadpole undergoing metamorphosis more than two months after hatching. The tail is beginning to shorten, the gills are being absorbed and the gill-clefts closed up, the horny jaws are lost, the eyes become more prominent, and so on.

pression that tadpoles shed their tails is still widespread, but entirely erroneous. Loose tails sometimes found lying on the mud of the pool where tadpoles abound have been cut off by the powerful jaws of the larvæ of the large water-beetle -Dytiscus marginalis. But the changes are equally marked at the anterior end of the body. The horny armature of the jaws and lips is shed; the lips are absorbed and the mouth becomes wide; the eyes become at last free and get movable lids; the tongue becomes muscular enough to move; the in- 
testine becomes much shorter; the gills and gill-arches disappear (though parts of the gill-arches are utilised); the heart is now three-chambered; the lungs become the sole breathing organs

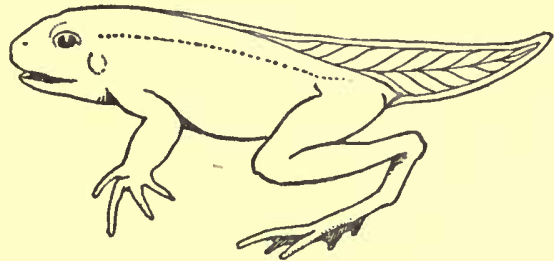

Fig. 47.-A stage between tadpole and small frog, about three months after hatching, The metamorphosis is nearly complete, but part of the tail remains unabsorbed.

(apart from the skin, which is always respiratory in Amphibians), and the young frogs, with a minute stump of a tail, leap ashore. They will drown in the aquarium if they are not allowed to leave the water.

Retrospect as to Food.-(I) At first the mouthless embryo subsists on its store of yolk. (2) It begins to eat minute organisms and particles in the muddy ooze. (3) It begins to attack larger animals and pieces of larger plants. (4) It has a fasting period about the time of metamorphosis, during which the supplies afforded by the tail are utilised in construction. (5) It is, as an adult, in the main insectivorous. If food is not abundant tadpoles devour other tadpoles, and the consequent reduction in the numbers kept in the aquarium is very familiar. In their later stages tadpoles may be utilised to clean up delicate skeletons, e.g. of a shrew or of a bat. Frank Buckland notes that in their most intense carnivorous period tadpoles will nibble at the toes of little boys who wade in the pools.

Retrospect as to Breathing.-(I) At first the gill-less tadpoles breathe through their skin, which is the most primitive mode of respiration, seen in animals like earthworm and leech, but entirely lost in animals higher than Amphibians. (2) Then there are three external gills. (3) These are replaced by a second set-“" internal" gills, which are really continuous with the first set. (4) Gills and lungs function together when the tadpole is about two months old, a state of affairs which may be compared with that in the double-breathing mud-fishes or Dipnoi, which have "lungs" as well as gills. (5) The adults breathe by lungs. (6) In the winter-rest the respiration is again wholly cutaneous. Cautiously and critically the teacher should try to 
look at this and similar life-histories from the historical point of view. In a general way, the individual development of the frog is a modified recapitulation, especially as regards stages in the making of particular organs, of the racial evolution of Amphibians.

Bibliography.-Quoted from O. H. Latter, British Association Report for I907, p. 547 ; Hans Gadow, "Amphibia and Reptiles," vol. vii. of Cambridge Natural History (Macmillan \& Co., London, I90I); G. A. Boulenger, Monograph on the Anura (Ray Society); A. Milne Marshall, The Frog (Cornish, Manchester); St. George Mivart, The Common Frog (Macmillan \& Co., London). 


\section{CHAPTER XVII}

\section{STUdy OF Fishes}

IF it be granted that Nature Study in school should be related to the peculiarities of the given region, it follows that a study of fishes should form an important part of the Nature Study in certain localities, e.g. in a fishing village or a fishing port. Where the main occupation of the community has to do with "fish," the Nature Study will not lose by also taking to do with " fish." The teacher must steer between the extreme of ignoring one of the most obvious contacts with nature, and the extreme of allowing a practically important subject of study to fill the horizon.

In many parts of the country, remote from the sea, the only fishes that can be used as direct subjects of Nature Study are freshwater fishes, such as trout and minnow, pike and perch. But here again there is no lack of interesting material.

If it be granted that Nature Study in school should be related to the course of the seasons, it follows that the migrations or annual movements of fishes, notably of the salmon and the eel, should be inquired into. It must be admitted that there are many obscure points in connection with the life-history of these two common fishes, but it is absurd to make this a reason for allowing the school children to remain quite in the dark as to the meaning of the "eel-fare," or of the salmon's journeying to and fro between fresh water and sea.

The aim of this chapter is to suggest three of the many ways in which fishes may be studied in school. We suggest a study (I) of the movements of the living fish; (2) of the external features: (3) of the life-histories of fishes.

\section{First Study : The Living Fish}

A study should be made of the movements of a fish, such as a small trout, in a rectangular glass tank. The movements 
must be unimpeded, and to choose a small fish is obviously a less expensive way of securing this than buying a large tank. A globular vessel is altogether unsatisfactory, because of the distorted image.

Movements.- $(A)$ Starting from observed facts of rapid and graceful swimming, one may first inquire into the way in which the body is adapted for cleaving the water. It is spindlelike, wedge-like, torpedo-like, boat-like, but different from all these. It is thicker in front than behind, broader above than below ; where is its centre of gravity? In many ways there is reduction of friction, e.g. in the gently curved contour, the absence of laterally projecting pieces, the pointed head, the tightly fitting jaws, the sunken lidless eyes, the absence of external ear. In the great majority of cases there is beneath the back bone a "swimbladder" or "air-bladder" containing gas, which makes the fish very buoyant.

The teacher who understands about the lines of boats and can make the matter plain, should follow up this question of the fitness of the fish-shape for cleaving the water. "In acquiring this perfect outward symmetry it is interesting to note that the forms of fishes may be said to have actually evolved the practical solution of the most theoretical problems of curves and displacement in relation to submarine motion. A study of the 'lines' of typical fishes by naval engineers has led to some most interesting results." 1

But without entering upon abstruse questions, it is feasible to get the pupils to make observations on the fitness of shape for use as illustrated in typical fishes. This would be a study in adaptation. The flatness of the skate should be contrasted with the flatness of the sole, flounder, and plaice; and the eel at one extreme should be contrasted with the globe-fish at the other.

$(B)$ By watching a typical fish swimming slowly, it will be possible to verify the following facts :-

(I) The chief organ of locomotion is the muscular posterior region of the body - the "tail," which is bent first to one side and then to the other. The muscles on one side contract, and the tail 
is curved towards that side; the muscles on the opposite side contract still more rapidly, and the tail is straightened. It is the second stroke which jerks the fish forwards. But while the posterior part of the body is curved to one side, the anterior part of the body is curved to the other. The efficiency of the swimming depends on the complementary action of the anterior and the posterior parts of the body. In a long slender fish, like an eel, the body is thrown into several curves. Another important point is that in the bending stroke-which is relatively slowerthe surface striking the water is reduced to a minimum, while in the straightening stroke-which is relatively more rapid-the surface striking the water is increased to a maximum. This may be illustrated by reference to "feathering" the oar in rowing.

The teacher may be able to follow up the matter in books, ${ }^{1}$ but the important point is to get the pupils to observe that the tail is the chief swimming organ in an ordinary fish, and that its action is like that of the stern-oar in sculling a boat.

The fish's tail really describes a complex curve, like a figure 8 , and produces a suction-current behind it. "There is a striking analogy between the movements of a fish's tail in swimming and the action of the screw of a steamer, but as a propelling organ the former is far superior to the latter. As we have seen, the tail of a living fish can so adjust its shape and surface that it alternately eludes and grips the water in accordance with the needs of particular strokes." 2 This self-adjusting, self-regulating power is one of the most striking characteristics of living creatures as compared with mere machines.

(2) The centre of gravity in a fish's body is high up, and a dead fish floats upside down. The chief use of the paired fins seems to be in balancing and in keeping the fish back up. The fore-fins sometimes help in steering, as in sharks, but it must again be noted that the chief steering organ is the tail. The fore-fins occasionally help in locomotion, as may be well seen in the I5spined stickleback-Gastrosteus spinosus. In skates and rays the enormous triangular fore-fins (or pectoral fins) are the only swimming organs, but this is very exceptional. Still more un- 
usual is the use of the pectoral fins for crawling on, as in the angler, or as parachutes (in the flying fishes).

The point to make clear here-if possible by direct observation-is that the movements of the paired fins do not usually count for much in locomotion. But they are (in many cases, at least) absolutely essential in enabling the fish to keep its normal position in the water.

(3) The unpaired fins act as vertical keels in the great majority of fishes; they steady the swimming, preventing woblling. Observation will show that they can be raised or lowered as is needed. This may be compared to the use of a movable keel in some yachts. In the pipe-fishes and sea-horses the unpaired dorsal fin is very mobile, and is the chief swimming organ.

(C) Breathing Movements.-Observation of the minnows or sticklebacks in the aquarium shows that the mouth is opened and shut many times in a minute, and that there is a corresponding closing and opening of the external aperture of the gill-chamber. The water sucked into the mouth-cavity is forced over the gills and passes out beneath the gill-cover. In the fishes named the breathing movements are unusually rapid; the number should be counted in other cases, such as trout and gold-fish. When a gold-fish is (ignorantly or carelessly) kept in water from which much of the dissolved oxygen has been removed (by being used up), the rate of respiration increases abnormally. The fish is beginning to suffocate. This is not an edifying spectacle, but is a common one.

\section{Second Study: The External Characters of Fishes}

It is often possible to get a number of perfectly fresh specimens of some small fish, such as trout, sprats, whiting, which can be used in class for the study of external characters. This kind of study is of use as an observational exercise, as a. lesson in precision. To master some things thoroughly gives the pupils confidence; it enables them to see more in things.

In studying the external features attention should be paid to the following points in particular :-

(a) Shape.-The typical shape suited for rapid locomotion, the flat shape suited for life on the floor of the sea, the eel shape 
suited for burrowing in mud and creeping through holes, and many other shapes.

(b) The paired Fins, their relative position. Note in the whiting, etc., that the hind (pelvic) fins are in front of the fore (pectoral) fins! There has been a strange shunting forwards.

(c) The unpaired Fins-dorsal, ventral, and caudal. Note the supporting fin-rays; count them. Notice the power of raising and lowering the dorsal and ventral fins. Distinguish hard

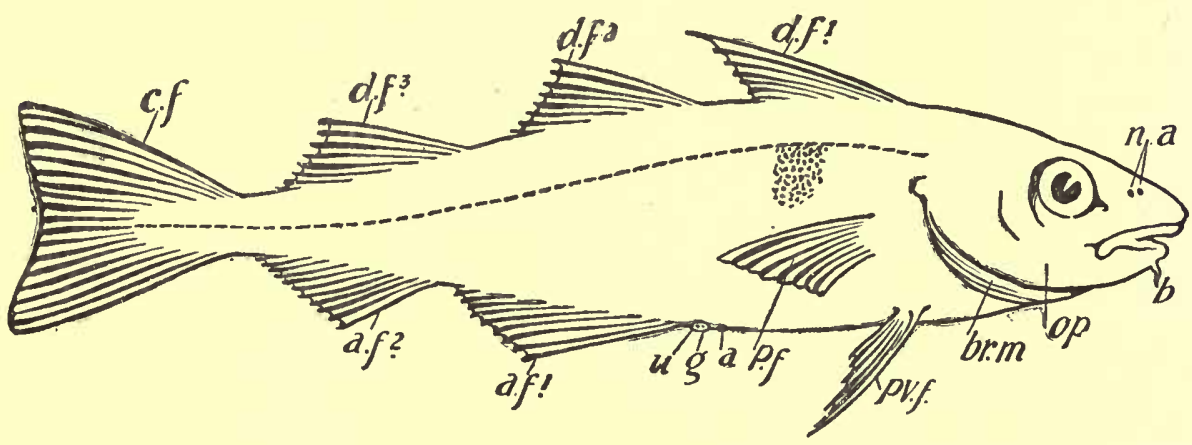

FIG. 48.-The external character of the haddock-Gadus ceglefinus. . There is a small tactile barbule (b) below the front of the lower jaw; the nostril (n.a.) has a double opening on each side; the gills are protected by a cover or operculum $(o p)$ supported by four bones, and extended behind in a flexible membrane (br.m) supported by bony rays. The sensory lateral line is shown, and an anterior patch of dark pigment in the skin. The pelvic fin ( $p v . f$.$) , which is equivalent to a hind-leg, has come to lie in$ front of the pectoral fin ( $\not . f$.$) which is equivalent to an arm. Paired fins are limbs$ without digits, and must be distinguished from unpaired fins, which are median extensions of the skin supported by fin-rays. In this fish there are three unpaired fins (dorsal fins) along the back $\left(d \cdot f^{1}, d \cdot f^{2}\right.$, and $\left.d . f^{3}\right)$, two unpaired fins (anal fins) on the ventral median line $\left(a . f_{.},{ }^{1} a_{.} f_{.}{ }^{2}\right)$, and a caudal fin $\left(c_{.} f_{0}\right)$. There are three openings close together in front of the first anal fin $(a, g, u)$ (anal, genital, and urinary), the openings of the food-canal, the genital ducts, and the ureters from the kidney.

spine-like fin-rays from those which are not spine-like. Notice on a dead stickleback the arrangement for locking the spines at the base. Notice peculiarly modified fin-rays, e.g. the "fishing-rods" on the back of the angler.

(d) The Shape of the Tail.-The apparently symmetrical type seen in most fishes; its stroke makes the fish go straight ahead without necessarily rising or sinking. The markedly unsymmetrical type of tail, seen in sharks, dog-fish, sturgeon, etc., much more developed in its upper portion than in its lower; 
its stroke tends to bring the head downwards, towards the floor of the sea. The unsymmetrical tail is usually associated with a ventral (not terminal) mouth, and with the habit of feeding at the bottom.

(e) In connection with the mouth-(I) The wide gape in many cases, reaching an extreme in the angler -Lophius piscatorius. (2) The position of the mouth, usually terminal, but ventral in the gristly fishes (skate, shark, etc.) and in the sturgeon. (3)The varied assortment of teeth, making a pavement over the jaw in the skate, hinged at the base in the angler so that they bend inwards very readily, unequal in size and sharpness in the catfish, very sharp in the eel, absent in the sturgeon, and so on. In a fish like the haddock, note the teeth on the roof of the mouth and still farther back on the wall of the pharynx. (4) The frequent presence of a white tongue, which does not contain any muscle, which

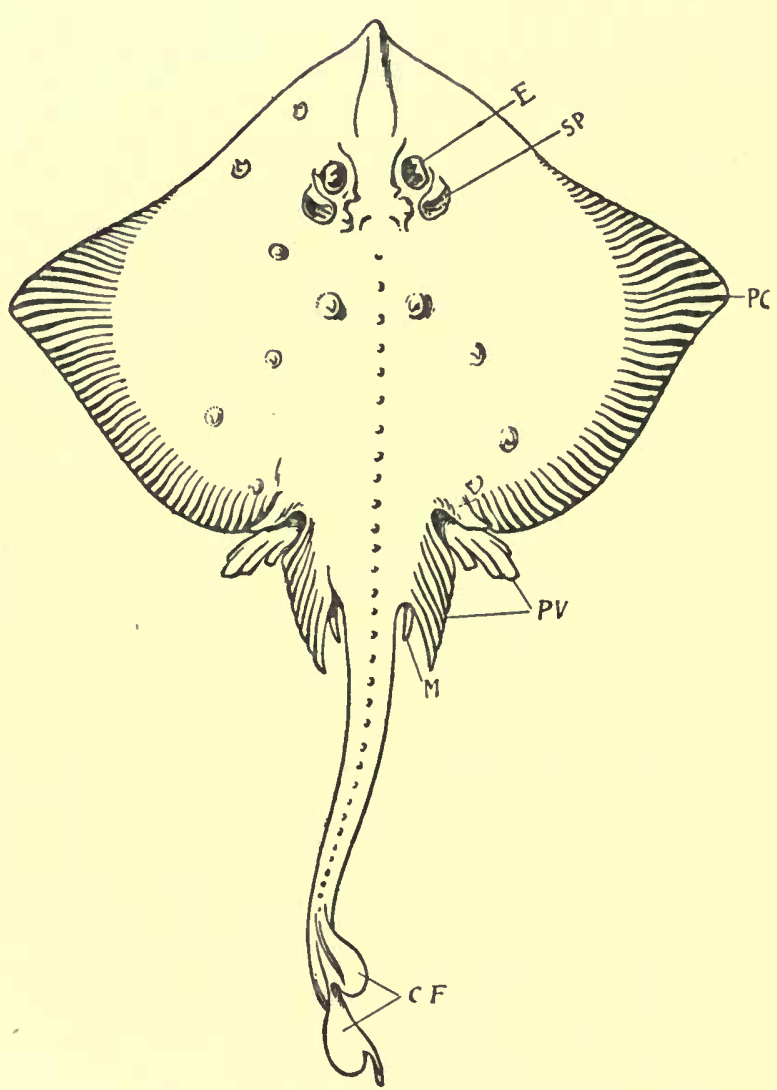

FIG. 49.-The dorsal surface of a skate-Raia clavataillustrating the study of external characters. Very remarkable is the flat shape of the body and the involved enormous extension of the pectoral fins (PC), which are in this case the organs of locomotion. The pelvic fins $(\mathrm{PV})$ are relatively small; the males are marked by an extra piece (M). In correlation with the flat body, which one may think of as flattened from above downwards, there is a reduction of the unpaired fins to a minimum at the end of the tail (CF). The skull is prolonged in front into a snout, which is greatly exaggerated in the saw-fish-Pristis, and the pectoral fin is connected in a remarkable fashion with the sides of the head. Behind the lidless eyes $(E)$ there are the spiracles (SP) by which water enters, passing out by the other gill-clefts which lie on the ventral surface. A few large skin-teeth or placoid scales are shown. The mouth, the nostrils, etc. are on the ventral surface. 
cannot move except along with the whole floor of the mouth. The first occurrence of a movable tongue is in the Amphibians.

$(f)$ Other points of interest in connection with the head(I) The nostrils of fishes are altogether smelling-organs. They have not anything to do with breathing. In almost all cases they are without any connection with the mouth. In most bony fishes, e.g. cod, there are two holes for each nostril.

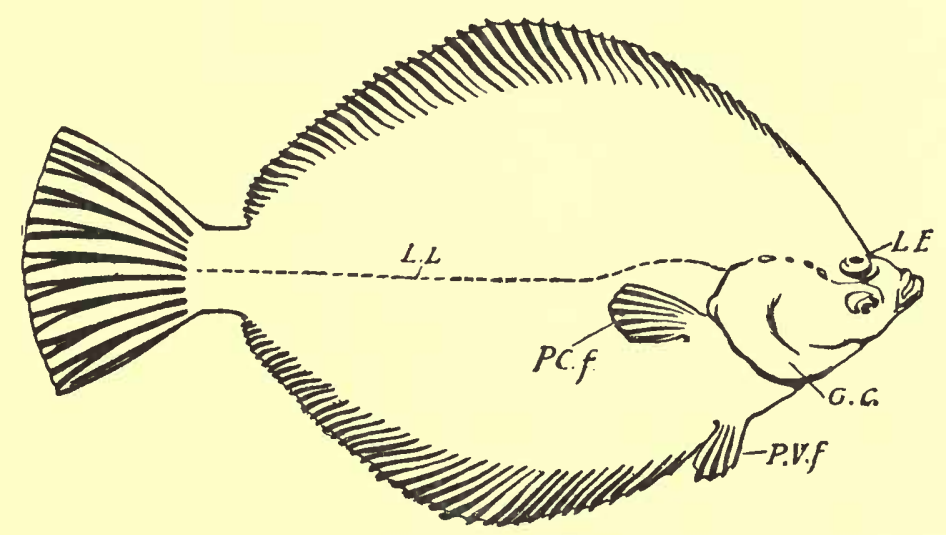

FIG. 50.-The plaice-Pleuronectes platessa-in illustration of the study of shapes and external characters. This flat-fish should be contrasted with the skate. It rests and swims on its left side; the skate on its ventral surrace. In its swimming-by curving the body as a whole, including the tail-the pectoral fins (P.V.f.) are quite unimportant as far as progression is concerned; in the skate the pectoral fins are the organs of progression-and the tail is unimportant. In the plaice the unpaired fins above and below are strongly developed, again in great contrast to the skate. The plaice has a bony skeleton, and its gill-clefts are overlapped by a gill-cover (G.C.) ; the skate has a gristly skeleton, and its gill-cleft opens directly on the surface. The young plaice are symmetrical, and swim like other young fishes, with the middle dorsal line upwards. They live near the surface. As the body grows it becomes unsymmetrical, as if it were forcibly compressed from side to side; the fish ceases to swim near the surface with the back up; the left eye (L.E.) comes round to the right side ; and the left side, turned away from the light, does not develop any pigment. The figure shows also the lateral line (L.L) and the pelvic fin (P.V.f.).

The eyes are practically lidless. (3) Except in gristly fishes, there is no external ear-opening or any external indication of the position of the ear, which is, however, well developed. (4) In gristly fishes, such as skate and dogfish, one of the gill-clefts opens dorsally behind the eye, and is called the "spiracle." In the main it aids the mouth, serving as an entrance for the water, which passes out by the other gill-clefts. In some circumstances 
water passes out by the spiracle. Senior pupils cannot fail to be interested in the vestigial gill, which lies on the wall of the spiracle. It is a remnant of a gill that was large enough to be of use in the ancestors of the present-day gristly fishes. The idea of a vestigial organ may be illustrated by referring to the useless letters in many words, e.g. the $o$ in leopard, or to the often useless buttons, etc., on the cuffs of a man's coat and on other places. (5) Hanging down from the front of the lower jaw in the cod there is a sensitive barbule, and small pore-like openings on the jaws and other parts of the head are also sense-organs, in part tactile. As an illustration of the frequently minute differences between related species, it may be shown that the cod -Gadus morrhua-has a long barbule; the haddock-Gadus aglefinus - has a short one; the whiting-Gadus merlangus-has none.

(g) The Gill Region.-In a dogfish there are five gill-clefts opening from the pharynx on each side of the neck. They are separated from one another by complete partitions, and these partitions bear numerous folds or plates. All the lamellæ or plates on one side of a partition constitute half a " gill." Where the gill-cleft opens into the pharynx there is a strong arch of gristle (the gillarch), the outer convex edge of which bears a fringe of gristly rods strengthening the partition.

The state of affairs in bony fishes is very different. (I) In a bony fish, such as a haddock, the gill-clefts open into a gillchamber formed by a movable fold or flap called the gill-cover. The gill-chamber opens to the exterior by a slit between the free margin of the gill-cover and the bodywall. (2) The partitions between the several gill-clefts have practically disappeared.

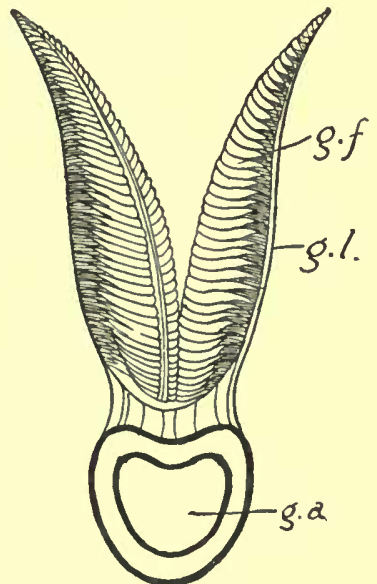

FIG. 51.-A section across the gill of a bony fish, showing two triangular gill-filaments $(g . f$.$) sup-$ ported by a gill-arch (g.a.). Each gill bears a double series of these filaments. The "impure" blood from the heart ascends one side of each filament, and after "purification" descends along another line (g.l.).

(3) The gill consists of a double series of triangular filaments projecting from the convex outer margin of the gill-arch. 
The gill-filaments composing a gill look very red because of their rich blood supply. The use of the numerous filaments is obviously that the blood is thus spread over a large surface, and is able more effectively to gain oxygen from the water and to part with its carbon dioxide. A gill may be compared to a much cut-up leaf, or to a country with a much cut-up coast line. To the inside of the gill-arch there is a series of gill-rakers which form a sieve or filter preventing food-particles from coming through the gill-clefts. Some gills should be neatly cut out and examined in a glass saucer. A little patience will be needed before clearness is reached in regard to the gill-clefts, the gillarches, the gill-filaments or lamella, the gill-rakers, the gill-cover, the gill-chamber, and the gills themselves.

(h) The Lateral Line.-Most fishes show a very distinct line running along each side of the body. It usually divides into several branches on the head. It is a canal protected by the scales, with groups of sensitive cells at intervals and with pores opening to the exterior. There is no doubt that it is sensory, and there is considerable evidence to show that it is an exceedingly delicate organ of touch. Somewhat similar are the "jellytubes" of the skate, etc., and the sensitive pits or spots very common on bony fishes. It is interesting to notice that the lateral-line system is found only in fishes and Amphibians. Indeed in many Amphibians it is confined to the larval stages. In higher animals its place is taken by the touch-spots and other nerve-endings in the skin.

(i) The Skin.-As an exercise senior pupils might be asked to compare the skin of a fish with that of a higher animal, such as a rabbit.

Under the term "skin" are included two very different layers, the outer epidermis and the inner dermis. The epidermis is always being worn away and is continually replacing itself. The dermis is a more permanent layer and it contains blood-vessels. It is easy to show that a scratch does not draw blood unless it gets through the epidermis.

In all animals higher than fishes the dermis contains connective tissue, blood-vessels, nerve-fibres, and muscle-fibres. In fishes there is very little development of muscle-fibres in the dermis. 


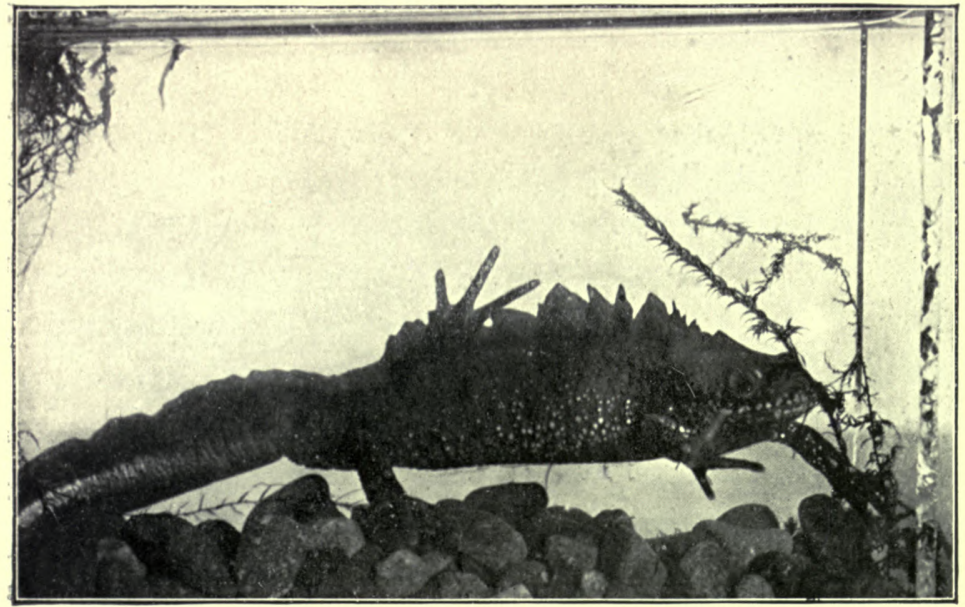

I'hoto by Oxiey Grabham. MALE CRESTED NEWT (Triton cristatus)

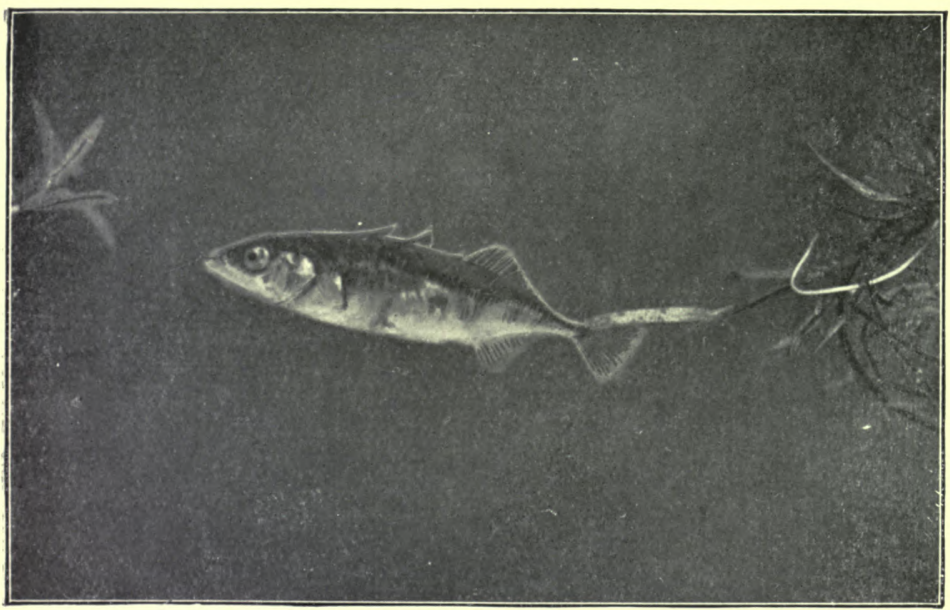

TIIREE-SPINED STICKLEBACK (Gastrosteus aculeatus)

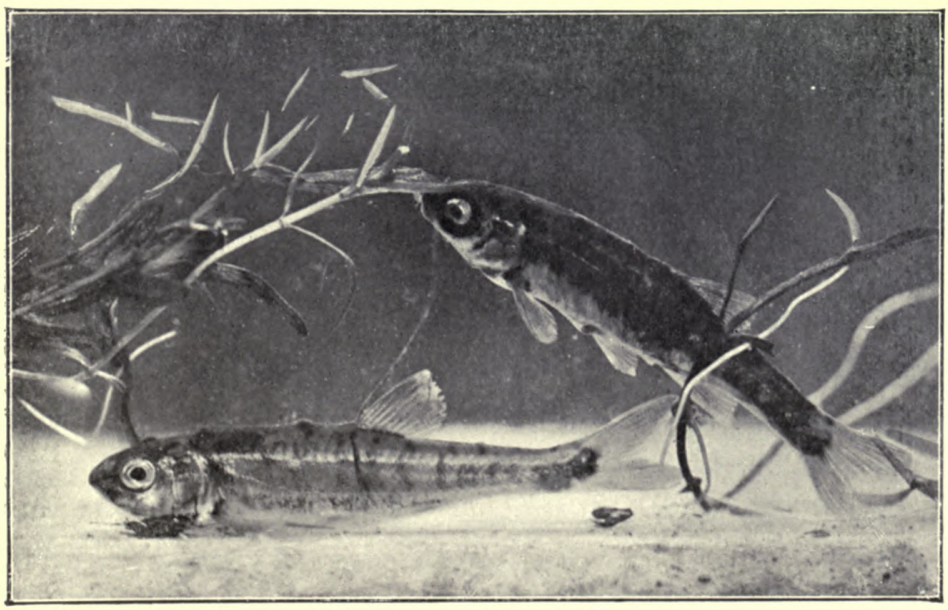



The epidermis of fishes is characteristically slimy. There are abundant glandular cells or mucus-cells, the living matter of which uses itself up in making slime.

The epidermis of fishes is transparent and comes off at touch ; the dermis is the seat of the coloration. The colour is mainly due (a) to various pigments contained in special cells (chromatophores) and (b) to a deposit of a waste product (guanin) in the form of minute granules or discs, which are very opaque and have great reflecting power. The silvery appearance and the rainbowlike lustre of many fishes are due to the guanin, and it is interesting to notice that this same substance is used in making artificial pearls.

Thus the skin of fishes is peculiar in having a very delicate transparent slime-producing epidermis, and in having a thin, practically non-muscular, dermis, with pigment and reflecting grains. But the most characteristic feature is the development of scales. These are so interesting and instructive that they may be considered separately.

(j) Scales.-A bird is known by its feathers, and a fish by its scales. Not only are the scales of fishes quite different from any other scales, but some fishes at least can be quite securely identified from their scales alone. A number of more or less constant peculiarities make up what we call the specific character of a herring, or a mackerel, or a flounder, or a stickleback, on the strength of which, indeed, each of these fishes has received a particular name, and in the sum-total of details one of the most reliable items is what one might be inclined to think the most trivial, namely, the minute structure of the scale. From a single feather on the moor a skilled ornithologist can sometimes say that such and such a bird has been there; from a square inch of skin an expert ichthyologist can sometimes identify his fish. All this means that a living creature is a distinctive unity through and through. We have spoken of this rather difficult subject here partly because the distinctiveness of fishscales illustrates the point particularly well, and partly because we wish to suggest that a teacher need never be afraid of the limitations of detailed study. If he has given some time to the practical study of the scales of fishes he can make this the voL. I. - IO 
subject of a school study which will probably remain as a seed in the mind when much, apparently more important, has sunk into oblivion. For besides the large idea that such a minute item as a scale on a fish's back has its distinctive individuality, like the fish as a whole, there is the profoundly interesting fact that the details of the scale form in some measure a record of the fish's life. The concentric rings on the surface of the scales of many bony fishes tell us the age of fish, as do the rings of wood in the stem of a tree. The close-set lines of growth correspond to winter or to wintry conditions; the wider lines of growth indicate a summer or a period of summer-like conditions. Thus a single scale might not only tell us of the presence of a certain kind of fish, and of no other; it might even tell us the age of the animal!

(I) In sharks, dog-fishes, skates, and other gristly fishes, the ("placoid") scales are complex structures. They are tipped with enamel, cored with dentine or ivory, and based with a small plate of bone. There are thus three kinds of hard tissue, of which enamel is the hardest and bone the least hard. The whole scale arises as a papilla of the skin; the enamel is made by the epidermis, the core and base by the dermis. If a scale of this type be carefully removed it often shows a small hole in the middle of the bony base; this is where the bloodvessels from the dermis enter the growing scale and feed the pulp in the middle of the ivory. These scales are often called skin-teeth or dermal denticles, and it is noteworthy that the teeth in the jaws of the gristly fishes have a similar structure and a similar development. In the well-known saw of the sawfish-Pristis, etc.-there are huge tooth-like scales in sockets on each side of the powerful weapon, which is an extraordinary prolongation of the front of the head. In skates it will be seen that large scales often occupy strategic positions of defensive or offensive importance. Thus they protect the eye and they make the tail an ugly weapon. The skin of shark or dogfish, covered with minute close-set scales, is used for polishing wood, for covering boxes, and the like. It is called "shagreen." One should demonstrate the fact that when stroked in one direction it is relatively soft and smooth, whereas it feels like the roughest 
sand-paper in the other direction. This is obviously due to the fact that the fingers slip over the enamel tips in the first case, and work against them in the second case.

(2) In the sturgeon-Acipenser-there are five longitudinal rows of very substantial bony plates, along with numerous small spines. In the spines and on the surface of the large scales the bone is usually replaced by a peculiar hard enamel-like substance called "ganoin." In the bony pike-Lepidosteus-of North America the whole body is covered with what may be called a chain-armour of four-sided bony scales articulating with one another. Here again the bony scale is covered with a layer of polished "ganoin."

(3) In the ordinary food-fishes, such as cod and herring, salmon and sole, the body is covered with thin transparent scales which are often called "soft." They overlap one another like the slates on a roof; they are embedded in, or sunk into the dermis; and their free portions are covered by the delicate transparent epidermis which is over the whole body. Though they are called soft-and they are usually flexible-they are built up of bone-cells, and in many fishes they become hard and spiny. Each really corresponds to the bony base of a placoid scale.

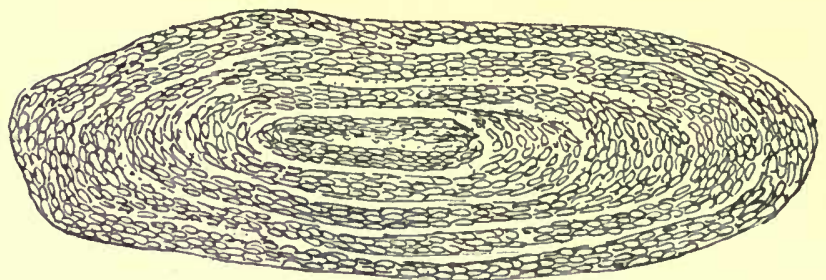

Fig. 52.-The scale of an eel-Anguilla vulgaris-showing lines of growth by which, in some fishes at least, the age of the fish can be determined. It may be noted that inside the ear-cavities of bony fishes there are hard ear-stones or otoliths, which increase in size as the fish grows older. Sections of these show concentric lines from which the age may be read. In the common eel the scales are so small that they are readily overlooked; they occur in curious groups embedded in the skin. In the conger eel there seem to be no scales at all.

Scales are absent in relatively few fishes, such as the electric fishes (and most Silurids); they are represented by minute papillæ in the cling-fish (Lepadogaster) and Antennarius (e.g. 
the " marbled angler" from the Sargassum weed). They are not always absent when they seem to be absent, and it is an instructive exercise to mount a small piece of the skin of the slippery eel, showing its minute but perfectly distinct scales. Even this demonstration alone would justify a school lesson on scales.

\section{Third Study: The Life-Histories of Fishes}

The study of life-histories is always fascinating, and those of fishes are among the most interesting. It must be remembered, however, that Nature Study is a definitely observational study of a particular environment, and that the teacher must not allow himself to be led too often along the pleasant path of telling "fairy-tales of science." We shall refer here to the lifehistory of the salmon and of the eel,-two very familiar fishes.

Life-History of Salmon.-Some of the children live by the sides of a salmon-river; they have seen the salmon leaping; they may have seen the female fish laying her eggs; they have seen the salmon caught-in different ways. If Nature Study means anything in such a place it means inquiry into the habits and lifehistory of the salmon, and from this we are not to be deterred though many of the problems that surround the salmon are still unsolved.

The eggs are laid in the winter months in the sandy and gravelly bed of the stream by the female salmon, and fertilised there by the male salmon. The eggs have many enemies, and many perish. Those that survive develop very slowly, taking three to four months to hatch. The eggs can be readily hatched in a little tub with sand at the bottom, if a slow flow of water is secured.

At first the young ones are very sluggish and lie among the stones, living on their legacy of yolk, which may last for fifty days. As the yolk becomes exhausted they become more active, and about eight weeks after hatching (i.e. in spring) the fry are about I inch long. They now grow quickly, feeding on minute creatures in the water, and by the end of a year they are somewhat trout-like "parr" about 4 inches long. 
In the second or third spring after their birth they put on their silvery "sea-jacket," are about seven inches long, and descend to the sea as "smolts." In the sea they feed voraciously, e.g., on young herrings and haddocks, and on the eggs of crustaceans, and grow large.

In fifteen to eighteen months or more they return to the rivers as " grilse," perhaps two to five pounds in weight, and they are able to spawn. Thus the story begins again. After spawning, the salmon are out of condition and have to return to the sea to regain their full vigour. It may be safely said that most, if not all, of the mature salmon's energy is accumulated during the time it spends in the sea. Although they develop slowly, they grow quickly, and they may live to a good age, attaining a weight of fifty to seventy pounds in very fortunate cases.

Attention may be directed to the colourchanges in the course of the life-history and in the course of the year, to the gymnastic feats of leaping, to the combats of the males, to the numerous risks that beset the salmon at different times, to the fact that they sometimes return to the same river, and so on. The life-history of the salmon should be contrasted with that of the flounder, the eel, the lamprey, and others.

Life-History of Eel.-In many parts of Britain the annual "eel-fare" is a familiar sight in spring. Myriads of young eels or
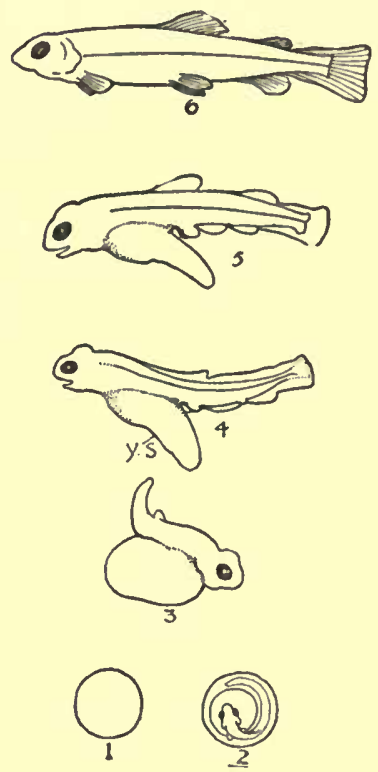

FIG. 53.-The early development of the salmon. The figures are nearly twice the natural size. I, The fertilised egg ; 2 , the egg just before hatching ; 3 , the newly hatched salmon with its yolksac ; 4 and 5 , the larval salmon nourishing from its yolk-sac ( $y . s$.$) , which$ gradually decreases as the body of the fish increases; 6 , the young salmon about six weeks old, when the yolk has been completely absorbed. elvers, 3 to 5 inches long, no thicker than knitting-needles, come swarming up the rivers from the sea. They are already at least a year old. They were hatched in deep water on the continental shelf to the west of Britain; they have had a fasting period of 
open sea life (when they were flat from side to side, transparent "glass-eels" about 7 inches long); they become less delicate, shorter, cylindrical, and coloured; they swarm up the rivers by day and rest at sunset; they ascend to slow-flowing reaches and

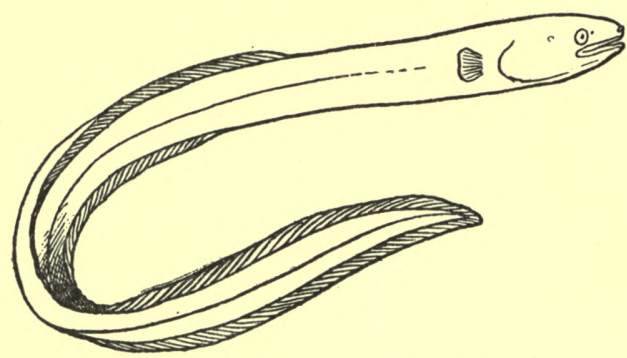

FIG. 54--A small specimen of the common eel-Anguilla vulgaris. There is a long median fin along the back and along the ventral surface. There are no pelvic fins. The gill-openings are very small.

to ponds; they grow large slowly, but never breed in fresh waters ; they return fully grown, five or six years old, to the seato the deep waters, and probably die after giving rise to a new generation.

References. - Bashford Dean, Fishes, Living and Fossil (Macmillan \& Co., London, I895); Pettigrew, Animal Locomotion (International Scientific Series, Kegan Paul \& Co., London, I874); T. W. Bridge, Cambridge Natural History, vol. vii. (Macmillan \& Co., London, I904); A. Gunther, Study of Fishes (A. \& C. Black, Edinburgh, I880). 


\section{CHAPTER XVIII \\ The LOWER Vertebrates}

THIS volume began with studies relating to Mammals and Birds, which are the two highest classes of backboned animals; then followed a short chapter on Reptiles, which occupy a median position among vertebrates; Amphibians and Fishes were then discussed, and thus we are now brought near the base or the beginning of the vertebrate series. But while it may be said in a general way that Mammals, Birds, Reptiles, Amphibians, and Fishes are the five classes of backboned animals or vertebrates, it is no longer possible to rest satisfied with this statement. There are still simpler vertebrates which cannot be ranked among Fishes, if the word "fish" is to mean anything precise. We therefore propose to conclude this section of the volume with a short reference to the vertebrates lower than Fishes, namely-

(a) Cyclostomes or round-mouths, e.g. lamprey and hag.

(b) Lancelets, e.g Amphioxus.

(c) Sea-squirts or tunicates, e.g. Ascidia.

\section{(a) Cyclostomes or Round-mouths}

In some parts of the country schoolboys are familiar with what they call " niners," small slippery, eel-like creatures with a horseshoe shaped mouth, which are found in slowly flowing reaches of streams. These "niners" are the young or immature stages of sea lampreys-Petromyzon marinus-or of freshwater lampreys (the lampern, $P$. Aluviatilis and the sand-pride, $P$. planeri). If some specimens can be captured uninjured they will be interesting temporary additions to the aquarium.

The sea lampreys are relatively large animals about a yard 
in length. They are carnivorous, and sometimes fix themselves to fishes, e.g. salmon, by means of their suctorial mouths, using

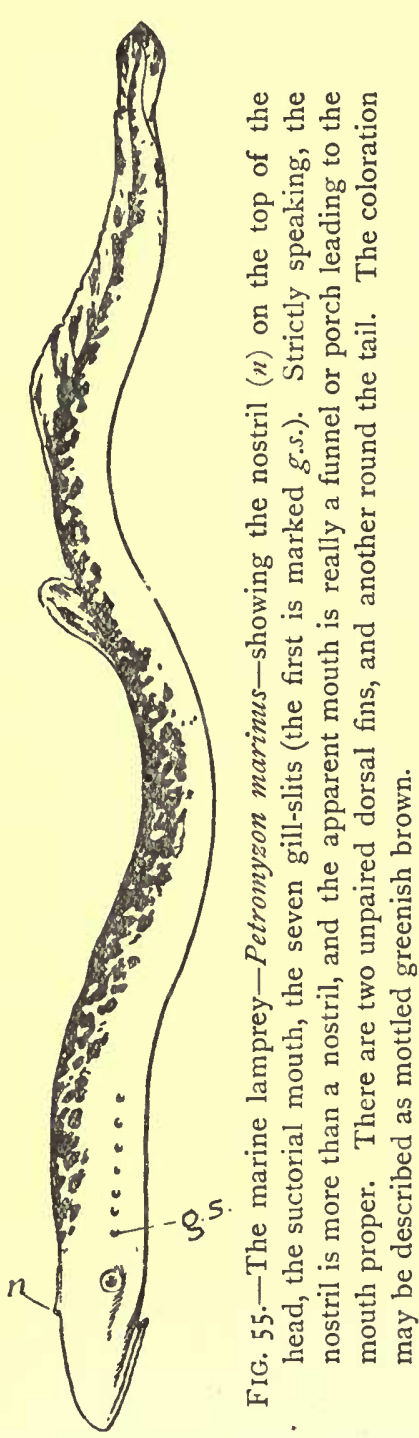
a piston-like "tongue" with horny teeth to scrape a hole in their victims. In spring they ascend the rivers to spawn, and may sometimes be seen making their way up stream. From a bridge one may sometimes see a lamprey resting at the bottom with its mouth fastened to a stone. The eggs are laid in the gravelly bed of the river, and thereafter the parents turn towards the sea, sometimes, at least, dying before they reach it. The young remain in the rivers for three or four years.

The river lampreys are smaller animals, from a foot to a foot and a half in length. Their habits are similar to those of the sea lamprey, except that . they keep to fresh water and spawn in the smaller streams. They seem to eat a good many insect larvæ, worms, and other small fry in the rivers.

The young lampreys and lamperns differ from the parents in many details, e.g. in the shape of the mouth, in having the eyes unexposed, in having different breathing arrangements, and in feeding on minute particles and microscopic animals. They differ so much from the adults that they were known for a long time by a different name-Ammocotes.

They remain in this larval state for three or four years, but in their third or fourth winter they undergo a rapid change and don the adult characters. The' mouth becomes funnel-shaped and acquires horny teeth; the eyes reach the surface; there are various deep-seated changes, and the creatures become carnivorous. The name "niner" or "nine-eye" (German, Neun- 
Augen) is singularly inappropriate for blind animals; the number has been suggested by the seven breathing openings on each side of the neck. Lamperns are often used for bait, and both lamperns and lampreys are used for food.

If a lamprey can be procured for demonstration there are many interesting features to be made out,-the scaleless slimy skin; the absence of paired fins; the two unpaired dorsal fins (in the young forms continuous with one another and with the tail-fin); the circular suctorial mouth and the piston-like muscular "tongue" (not in the strict sense a tongue), both beset with horny teeth; the unpaired nostril far back on the top of the head, like the blow-hole of toothed whales; the seven pairs of gill-clefts, and so on.

In some parts of Britain, e.g. on the coast of Northumberland, it may be possible to get from the fishermen a specimen of another remarkable Cyclostome-the glutinous hag-Myxine glutinosa. It is an eel-like pinkish animal, from I5 to 24 inches long. It lives in deep

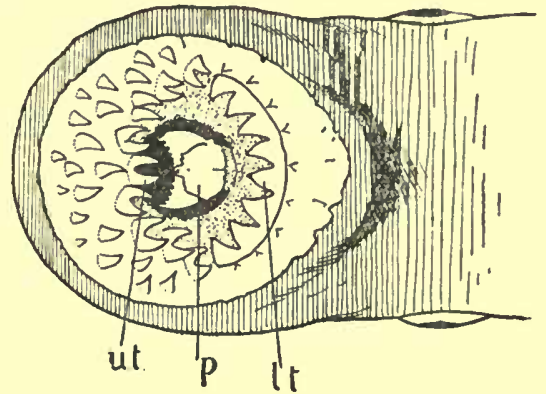

FIG. 56.-The funnel or porch to the lamprey's mouth. It has numerous horny teeth above and below the mouth proper (u.t., upper teeth ; l.t., lower teeth). The funnel is applied to the lamprey's victim, and adheres like a vacuum sucker. The toothed piston ( $p$ ), often called the tongue, works as a boring instrument, rasping off the flesh. Behind the funnel there is a hint of the eyes slightly protruded; their position is indicated on the preceding figure. water, often at a depth to which the light hardly penetrates. With this, and with its habit of burrowing in the mud, we may associate the absence of pigmentation in the skin (the pinkness being due to the red blood shining through), and the fact that the eyes are vestigial and do not reach the surface. It can swim gracefully and rapidly in eel-like fashion in search of prey, but so far as we know it seems to live a somewhat sluggish life. It eats the bait of the fisherman's long lines, and it sometimes enters and devours the cod, etc. which have been caught on the hooks. There is a piston-like "tongue," as in the lamprey. According to some, the hag also bores its way into free-swimming fishes, but the evidence is not satis- 
factory. Its popular name, the glutinous hag, refers to its power of secreting from its skin-glands large quantities of thick mucus. As the ancients said, the hag "could turn water into glue." The mucus is probably in part protective; it makes the hag difficult to seize-and is perhaps unpalatable. There are many very remarkable peculiarities in the hag, e.g. that the unpaired nostril opens into the back of the mouth. The development and early history remain practically unknown. Two good authorities (Cunningham and Nansen) have stated that hags below a certain size serve as males, producing milt or spermatozoa, but that they afterwards become females-producing ova.

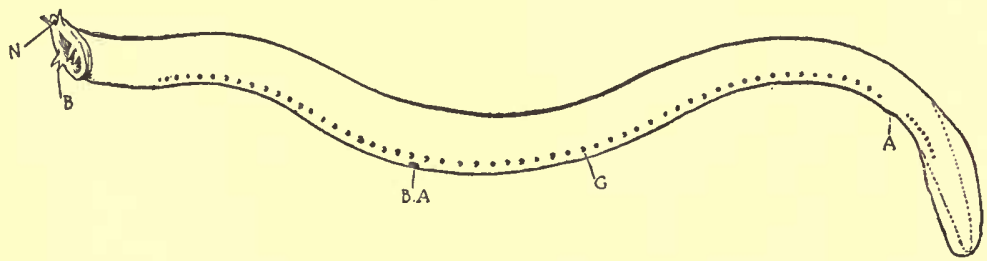

FIG. 57.-The hag-Myxine glutinosa. The smooth eel-like body bears on each side a row of mucus-glands $(G)$, which secrete the characteristic glutinous slime. Above the mouth opening is the unpaired nasal opening $(N)$ which leads into a canal conveying water to the back of the mouth. This is altogether unlike the blind paired nostrils of fishes, and the explanation of the state of affairs is beyond the scope of school work. The figure also shows the barbules (B); the breathing apertures by which water passes out after traversing the gill-pouches, and the anus (A).

If a hag can be procured some interesting points may be demonstrated,- the opening of the " nostril " above the mouth ; a stout bristle passed down this opening leads into the back of the mouth, and the water used in breathing passes in along this path ; two pairs of toothed combs on the piston-like "tongue" or borer, and a single, likewise horny, tooth on the roof of the mouth; four pairs of sensitive tentacles near the mouth and nostril ; the apparent absence of eyes; two exhalant breathing openings 3 inches or so behind the head; a row of minute pores at regular intervals down each side of the body-the openings of the mucus-glands, and so on.

Summary.-The round-mouths or Cyclostomes, represented in Britain by lampreys and the hag, occupy a level quite distinctly below that of fishes. Thus they are limbless and scaleless, without definitely developed jaws, and have peculiar pouch- 
like gill-sacs and unpaired nostrils. They form a small but very interesting class of Vertebrates,-undoubtedly very old-fashioned types. Like many other archaic animals, they have a wide geographical position. In the Old Red Sandstone of Caithness there is a dainty little fossil, usually under an inch in length, which seems to have distinct affinities with Cyclostomes, and is in any case " a strange relic of early vertebrate life" in Britain. It is called Palceospondylus, but the teacher will of course keep this name, not to speak of Petromyzon and Myxine, as luxuries for his private edification.

\section{(b) The Lancelets}

Occupying a lower rung of the Vertebrate ladder than the Round-mouths are sundry small and dainty creatures known as lancelets-Amphioxus, etc. As they are very rare in British waters (though exceedingly common in some seas, such as the Mediterranean), we must not do more than note their general position. They are in many ways simple primitive Vertebrates, for instance, in having a dorsal nerve-cord without a well - defined brain, in having a persistent unsegmented supporting

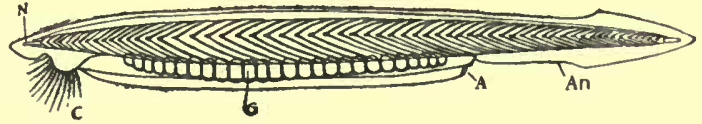

FIG. 57A.-Lateral view of lancelet (after Lankester); N, the tip of the notochord ; C, the cirri around the mouth; $\mathrm{G}$, the reproductive organs; $A$, the respiratory atriopore; An, position of anus. The zigzag lines represent muscle segments.

axis (notochord) without any trace of skull, and in having very numerous gill-slits without any hint of gills. In other ways the lancelets have diverged on a line of their own. From fishes they are widely removed by the absence of limbs, skull, jaws, brain, eye, ear, and some other important structures. Like other old-fashioned animals, they have a wide geographical distribution, and there are about a score of different kinds. They'mostly occur near the coasts in warm and temperate seas ; they are somewhat sluggish in habit; they feed on microscopic animals or organic particles which are wafted into the mouth. If a specimen be obtained for the school collection, it is instructive to show that the body-wall is built up of over fifty zigzag dovetailed muscleblocks like those seen on a fish. 


\section{(c) The Sea-Souirts or Tunicates}

The strange animals known as Tunicates or Ascidians, more popularly as sea-squirts, are well represented around our coasts. They are sometimes found attached to large sea-weeds or to the rocks near the low-tide mark, and on some coasts they are occasionally thrown up by storms. A typical form can be recognised. at once by the glassy tunic or " test" which covers the irregularly oval body. One end of the body is attached to stones or weed; the other is more tapering, and bears the mouth at the apex, and an exhalant aperture to one side. There is a suggestion of a double-mouthed leather bottle. During life water is continually being drawn in by the mouth-bearing microscopic food particles and oxygen with it-and passed out at the exhalant aperture. If irritated the animal often expels a jet of water with considerable force from the mouth or from both apertures, whence the name sea-squirt. The gelatinous test which covers the body is of much interest, inasmuch as it consists in great part of a substance practically identical with cellulose, the characteristic building material of plants. Thus in the most sluggish part of a sluggish animal we find a characteristic vegetable substance.

The Ascidians are difficult to understand; they are, so to speak, Vertebrates in disguise. Except in a few free-swimming forms their real nature is disguised by a degeneracy which befalls them in early youth. The larval Ascidian lives in the open sea, like a miniature model of a very young tadpole, swimming about by means of a delicate tail. It has most of the essential vertebrate characters, - a dorsal nerve-cord with a brain, a supporting rod or notochord in the tail region, gill-slits opening from the pharynx to the exterior, and an eye developing from the brain. But in most cases the promise of youth is unfulfilled; the larva after a short period of free swimming fixes itself by its head to stone or weed, settles down to sedentary life, loses tail and tailrod, nerve cord and eye, and becomes strangely deformed. They are much too difficult for ordinary school study, but if they are found on the beach or attached to the rocks the general fact should be made clear that they are animals which stumble on the 
border-line between Invertebrates and Vertebrates. On some shores, e.g. certain parts of the Clyde estuary, there is great wealth of what are called compound Ascidians underneath stones about low-tide mark. These are even more difficult to understand than ordinary sea-squirts, but they should not be missed, since they often have a quite remarkable jewel-like beauty.

Summary.-Below the level of fishes there are at least three classes of more primitive Vertebrates-each peculiar on its own line-the Cyclostomes, the Lancelets, and the Tunicates. The existence of these classes suggests that the vertebrate serieslike the other great series in the animal kingdom-began gradually in this sense, at least, that it was originally represented by forms somewhat like " niners" or Palcospondylus, or like larval lancelets or like larval tunicates, only very much simpler and without the special peculiarities which mark all these types. A reference to any good text-book on zoology will show that there are some remarkable more or less worm-like types, e.g. Balanoglossus, which serve still further to lessen the apartness of the Vertebrates.

Retrospect.-We have completed a survey of the backboned animals from a certain point of view, and we wish to conclude with two general suggestions. While classification or orderly grouping is only a very small part of nature study, it is a valuable part. Practice in classification is a good discipline; it is often an exercise in judgment as well as in precision, and it tends towards clear thinking. Why is a whale not a fish ? why is the sea-horse a fish ? why is a slow-worm a lizard, not a snake? why is a newt an amphibian, not a reptile ? and so on-these are not useless puzzles of our own making, they are commonsense questions quite useful in their way. Again, it is desirable as part of the $\mathrm{A} \mathrm{B} \mathrm{C}$ of education that there should be in the mind a general picture of the animal kingdom showing the relative position of the chief classes. This is often missed because the wood is lost in the trees. Yet it should be an elementary exercise to arrange on a table in an orderly way a score or so of handy specimens of common animals. It should be possible to have at least one cupboard with a glass door, whose shelves show at a glance the general "lie" of the great types of animals. With a little care and pertinacity it will be possible to secure 
an effective and interesting representative of each great class, and by and by the school will have a storeroom from which specimens can be drawn to replace those which have served their time on the shelves of the exposed cupboard. It should be an honour to a pupil to have a specimen which he has found deemed worthy of being, for a time, the representative of fish or bird, mollusc or insect in the school cupboard.

As to the plan of the school cupboard, various lucid arrangements are possible, and that will be best, ceteris paribus, which the teacher devises for himself. Thus we have seen a fairly successful and by no means dogmatic genealogical tree with the animals - some a little grotesquely-perched on or hanging from the branches. We suggest the following plan :-

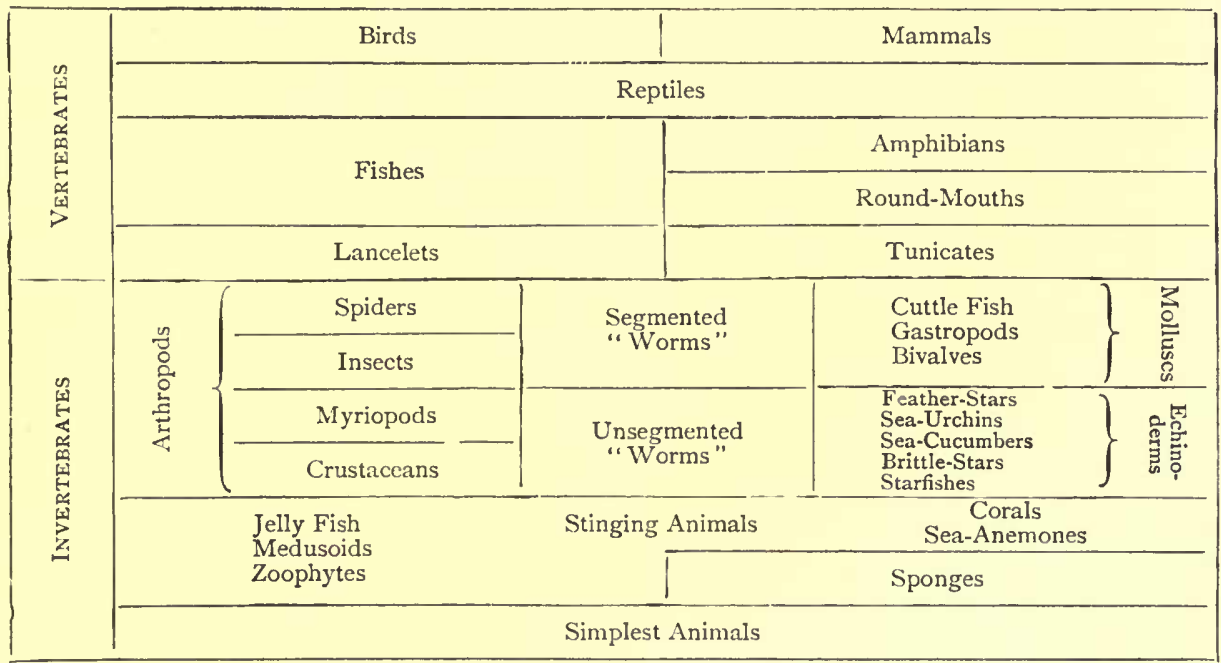

Besides the general mapping out of the animal kingdom,which should never require to be learned, but should rather be unconsciously impressed by frequent looking at the orderly cupboard, another general notion is that of gradual ascent. Why do we say that a Mammal is "higher" than a fish and still "higher" than a worm? We more or less consciously apply two standards: the higher animals are more complex, with greater division of labour, and they are more thoroughly unified by the nervous system. The bird is a more complex engine than an earthworm, and it has a more perfectly controlled unified life. 
Now it seems useful to try to make a curve showing in a graphic way with what types certain features made their appearance in the animal kingdom; showing the gradual increase of bodily complexity, especially as regards brains; showing the gradual increase of intelligence, of fulness and freedom of life, of parental care, of emotional activity, and so on. The teacher should elaborate this curve for himself, filling it with meaning, and he should, more or less, keep it to himself except in so far as the general ideas it expresses saturate through all his teaching. We may confine our illustration of it to Backboned Animals.

The uncompleted perpendiculars may indicate extinct types, lost races. The dotted line $\mathrm{W}$ indicates the level of the water, Amphibians marking the transition to terra firma. From the higher levels, however, there are returns to the water, e.g. sea-snakes, penguins, whales. In a general way it may be said that the complexity and unification of the body is indicated by the successive perpendiculars, as well as degree of intelligence, parental care, and so on; but it must be remembered that

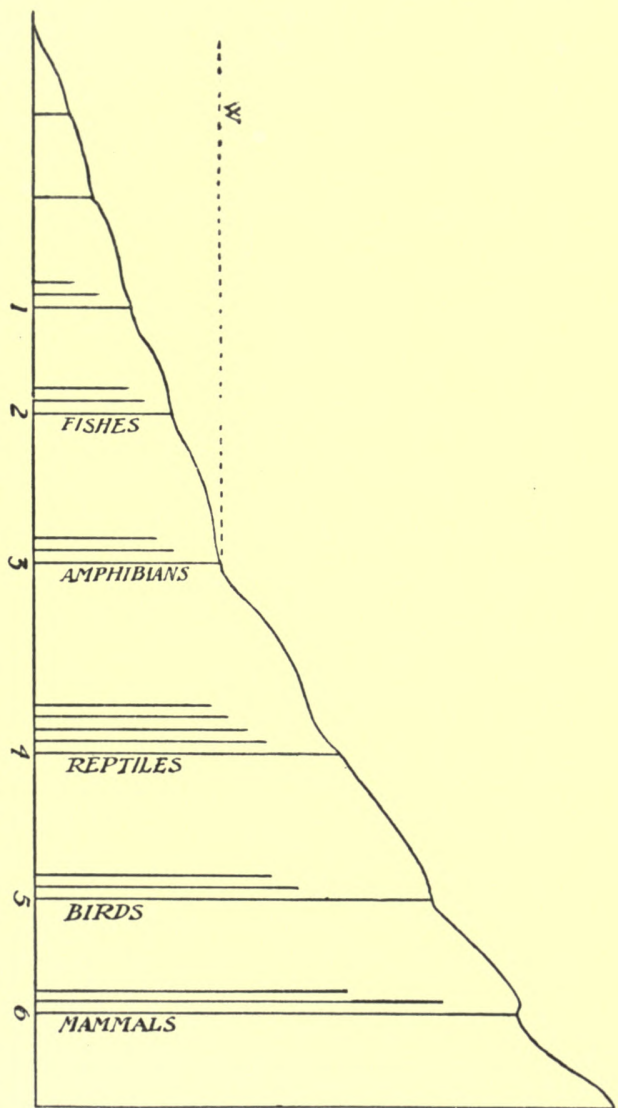

I. Indicates the level at which skulls are first seen.

2. Indicates the level at which jaws are first seen.

3. Indicates the level at which digits are first seen.

4. Indicates the level at which a four-chambered heart begins.

5. Indicates the level at which "warm-bloodedness" begins.

6. Indicates the level at which convolutions on the brain are first seen.

in each class there are always types which go very far along certain paths. 


\title{
I N S CTS，SPIDERS，W ORMS，\&C.
}

\author{
By Oswald H. Latter, M.A.Oxon. \\ Senior Science Master of Charterhouse School
}

\section{CHAPTER XIX}

EARTHWORMS

Habits.-Earthworms occur in great numbers in almost all soils, but especially in such as support abundant vegetation. Their presence is usually indicated by the little heaps of earth which they throw up at the mouth of their burrows. These heaps are known as "worm-casts," and are composed of soil which the worm has eaten and passed through its body, extracting from the material as it travels along the digestive organs such nourishment as it may contain. A further means of detecting the home of the worm is afforded by the habit which these animals possess of dragging leaves, leaf-stalks, small twigs and other similar objects into the opening of the burrow. The result of this action is that from each burrow there projects, more or less vertically into the air, a cluster of the above-named objects. In performing this operation, which is generally carried out at night or during the twilight, worms display considerable intelligence, for the leaf is nearly always seized by the more pointed end, which is, of course, the easier to drag into the hole. These collections of vegetable matter, in addition to providing a store of food which the worm can reach without exposing itself to risk on the surface of the earth during the hours of daylight, serve further to prevent the entry of enemies into the burrow, to keep the air within moderately moist, but at the same time to allow fresh air to enter, and so provide the ventilation necessary for breathing.

Large earthworms of convenient size for study may often be 
obtained by digging in any garden soil, or they may be collected in quantities on lawns or other plots of kept grass if search be made after sunset with the aid of a lantern, or in the very early morning. Warm damp nights are the best for such search. The worms will be found extended on the surface of the ground, their tail only in the burrow. To catch them it is necessary to tread very softly, so as to avoid shaking the earth, to pounce suddenly upon them with fingers and thumb, and then maintain a steady but not violent pull in order to extract the specimen without injury. It is probable that many examples will be found in the act of pairing. Another very effective method is to water soil in which worms are known by their castings to be present with dilute formalin ( $I$ per cent. of the 40 per cent. commercial solution is ample). This often causes the worms to rush up to the surface in numbers. If they are at once washed in fresh water they suffer no injury.

To keep earthworms alive a fair depth of good soil or leaf-mould should be placed in an earthenware vessel, such as a bread-pan (metal vessels seem to be harmful to the health of the worms), and be made moderately moist but not sodden. Some dead leaves may be strewn on the surface to prevent too rapid evaporation. Such soil contains sufficient food to maintain a good many worms for some weeks, and the leaves on the surface form a further supply if needed.

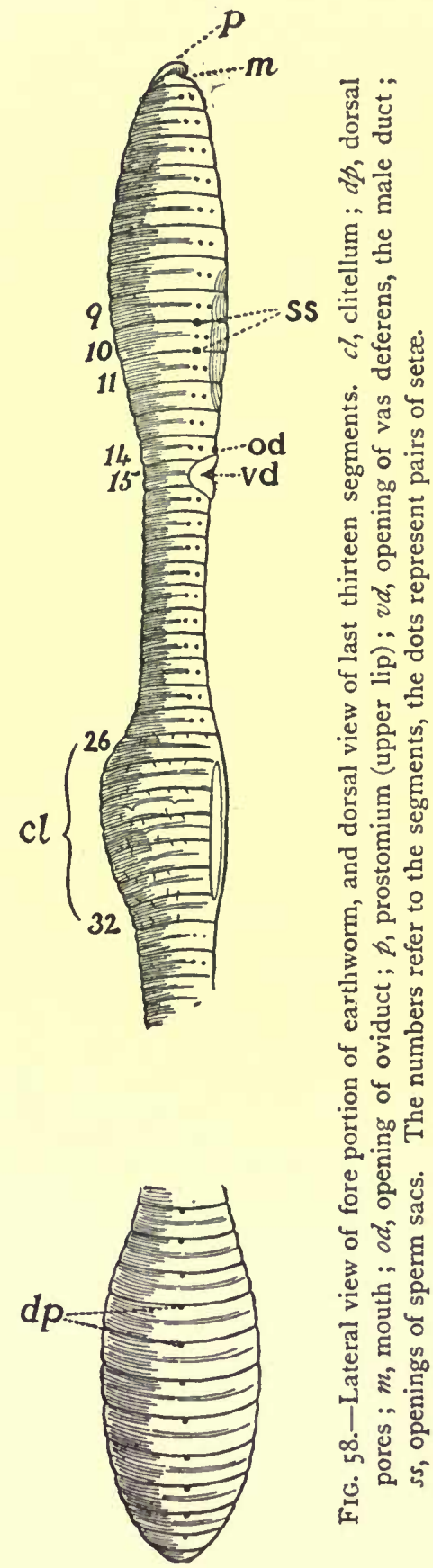


Shape.-The body is for the most part cylindrical in shape, and is marked out by a number of circular grooves into a corresponding number of rings or segments, which closely resemble one another. At the anterior end the segments become gradually of less diameter, so that the head extremity is finely tapered. This shape is of great service, for the sharply pointed tip is able to insinuate itself into extremely narrow crevices in the soil, and thus to bore a hole into which the rest of the body can pass without difficulty. On the other hand, the posterior end is flattened considerably, so as to be wider from right to left than any other portion of the body. The value of this modifica-

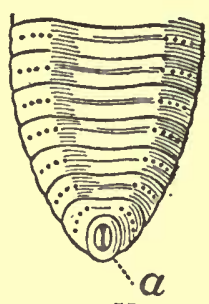

FIG. 59. - Ventral view of terminal segments of earthworms. $a$, anus. tion will readily be appreciated if an attempt be made to catch worms in the manner suggested above. At such times worms are to be seen in hundreds stretched out between the blades and roots of the grass; but they are not completely outside their burrow,--their broad tails are within its shelter, and maintain a firm pressure to right and left upon its walls. Thus they are securely anchored, and at the least alarm dart backwards into safety with the rapidity of stretched elastic. Their safety thus depends upon the tail being sufficiently wide to allow secure grip upon the lateral walls of the tunnel.

Breeding.-The body of an adult worm is swollen and thickened at a spot about one quarter of the total length from the front end. The exact position of this thickening differs in different species, but it usually begins near the 3oth segment and extends over about six segments behind this. The enlargement is popularly supposed to be a scar marking the place where the body has reunited after accidental bisection by a spade. Its true function, however, is concerned with the act of pairing. Subsequently the skin of this region produces a girdle of tough slime completely encircling the body, and thus resembling in shape a cask with both ends knocked out. Out of this girdle the worm wriggles backwards, and deposits within its cavity its own eggs and the fertilising male element received from another worm. When at length the worm has completely withdrawn its head from the girdle the two open ends of the latter close up owing to their 
own elasticity, and the structure is left in the ground as a lemonshaped cocoon containing about six eggs. The cocoons are about 4 inch or less in length, and each as a rule produces but one young worm, the remainder of the contained eggs perishing. The presence of the thickened band, which is known as the "cingulum" or " clitellum " " saddle" would form an appropriate and intelligible English equivalent) is therefore an indication that the worm has reached maturity. All earthworms are hermaphrodite, - that is to say, they possess both male and female organs. The male openings are situated on the right and left sides where these pass into the under side in the I5th segment, and can easily be recognised by the presence of thickened

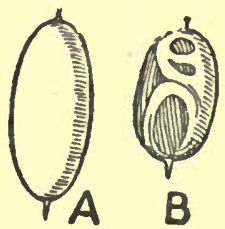

FIG. 60. - Cocoons of earthworm. A, full; B, empty. lips surrounding the actual holes. The female openings through which the eggs pass out of the body are in the corresponding places in the I4th segment, but are generally very difficult to detect.

Colour.-The colour of most of the commoner species of worms is more or less pinkish or purplish red. As in our own bodies so here the colour is not that of the skin itself, but of the blood which shows through the skin. It is an interesting fact that the red colouring matter is identical in character with our own, and has the same duty to perform, namely, to seize the oxygen of the air and to carry it to all parts of the body. In ourselves, of course, the oxygen is obtained as the blood courses through the lungs, whereas in the worm there is no special organ for breathing, but the oxygen of the outer air is absorbed direct through the skin. To render this possible the skin itself is extremely thin, and is kept constantly moist by its own slime; there is further, in every segment, a special set of blood vessels which pass very ciose under the skin so as to bring the blood as near to the surface as possible. These blood vessels start from the main blood vessel, which is visible through the skin as a dark red line up the middle of the back.

In addition to the prevailing red colour there is a beautiful play of "rainbow" colours all over the surface of the body. This iridescence is not due to any actual pigment, but to 
structural causes similar to those which cause the same appearance in soap-bubbles, "starred" ice or glass, and other colourless objects. In this instance the cause of the iridescence lies in the extremely thin, horny covering or " cuticle," which is outside the true skin and is perfectly transparent, but engraved with two sets of microscopic grooves crossing each other at right angles.

Movements.-When crawling along a worm does not wriggle from side to side as do snakes, but progresses in a straight line. This is accomplished by alternately length-

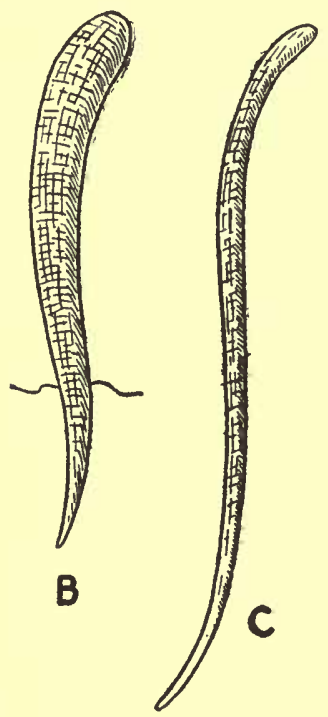

FIG. 61. - B, ordinary seta ; C, specialised (genital) seta of earthworm. ening and shortening the whole or successive regions of the body. But these rhythmic contractions would achieve no good resultnor do they on a perfectly smooth surface, such as wet glass-unless there were some means of obtaining a hold upon the soil. A firm grip is, however, secured by the use of small bristles which can be darted out from the lower surface. Each segment has eight of these bristles, arranged in pairs, two pairs on the right and two pairs on the left side. They can be plainly felt if a worm is pulled between the finger and thumb, and, being about $\frac{1}{16}$ inch long, they can be seen by the naked eye. This is best managed as follows :- hold the worm in the hand on a level with the eye, and allow it to crawl forward between the finger and thumb so that it reaches out into the air; as soon as the worm has got the front region of the body extended as far as it can it will dart out the bristles in the endeavour to get a hold upon something and to pull the hinder region forward. That is exactly what the worm does when naturally crawling on or through the earth; the front region is pushed forward, its bristles are then darted out and catch on inequalities of the surface like so many pegs, the hinder region is then pulled forward, pegged firm, and so on. In the region of the "saddle" and certain other segments between it and the head the bristles are longer, and differ in shape from those else- 
where. The precise use of these special bristles is not fully known, but it is probable that they are of use in working the cocoon off the body, and during the act of pairing.

The alternate elongations and contractions of the body are brought about by two sets of muscles which lie immediately below the skin and completely invest the animal all round. The outer set is arranged as a series of hoops round the body, the inner runs lengthways from head to tail. When the former are used they squeeze the body so as to make it thinner and longer ; at the same time they stretch out the other, longitudinal set of muscles; when these latter come into play they reverse the effect of the circular set, drawing the head and tail closer together, so that the worm becomes shorter but fatter. The action of the circular set may roughly be imitated by grasping a roll of putty in the hand and closing the fingers tightly ; the pressure so applied will cause the roll to become longer and thinner. If the putty were enclosed in a piece of elastic indiarubber tubing which was blocked up at each end, the pressure of the hand would simultaneously stretch out the tubing; on removal of the pressure the elastic material would resume its previous shorter condition, and so afford a fair representation of the behaviour of the longitudinal muscles. It is interesting to note that the longitudinal set is many times thicker and stronger than the circular; the value of the difference is evident when it is remembered that a worm's life often depends upon the speed with which the body can be shortened and withdrawn backwards into the burrow upon the approach of danger. Ability to lengthen itself rapidly is never of vital importance.

Defence.-To a soft-bodied creature, such as a worm, discreet retreat is undoubtedly the better part of valour ; but the animal is not entirely destitute of means of self-defence. The slime with which the whole surface of the body is covered renders the worm slippery and difficult to hold, so that escape is often accomplished from the beak of the thrush and other birds. But a large number of the foes of the worm are microscopic parasites, both plant and animal, which abound in the rich upper soil that is chiefly frequented by worms. Many of these minute enemies are caught and smothered in the slime, while some are actually 
destroyed by the antiseptic properties which it possesses. Should the first line of defence prove inadequate, the worm has in reserve a further weapon: from minute holes which open in the grooves encircling the body, one hole in the middle of the back in each groove, there gushes forth, when occasion demands, a watery fluid in which float numerous corpuscles possessing powers of independent movement. These corpuscles swarm around the microscopic foe and destroy it. This flow may be provoked artificially by putting a grain of some solid irritant, such as corrosive sublimate or cayenne pepper upon the skin of the worm. Simultaneously with the discharge of liquid from the dorsal pores, it will be noticed that the worm's body becomes much thinner both in front and behind the seat of irritation. The appearance is as though a couple of ligatures had been tied round the body in an attempt to isolate the affected segments from the rest. The effect of the constrictions is to apply considerable pressure to the fluids within the body, and so hasten their discharge.

Enemies from which the worm has no obvious means of escape, except by retreat, are the mole; certain subterranean slugs (Testacella) which may be distinguished by the possession of a small shell; the reddish, flat-bodied centipedes, the "Devil's coach-horse" beetles, and the grubs of some other beetles. Certain flies also lay their eggs upon the bodies of worms, and the resulting grubs devour the unfortunate victim.

Food and Senses.-The food, as already mentioned, largely consists of decaying vegetable and animal matter in the soil; but living leaves are often attacked if they chance to be within reach, those of the French bean being especial favourites. Since worms possess no teeth it is necessary for them to soften the substance of the leaf before they can tear bits off with their lips. For this purpose slime is poured over the leaf from the front portion of the body, and perhaps from the mouth. The slime has the power of rotting and partly digesting the vegetable tissue, so that subsequent removal by the lips becomes easy. This effect of the slime may be seen if a worm is made to crawl over a young leaf which is still attached to the plant; after a day or two the trail of the worm becomes evident as a brownish stripe 
across the otherwise green surface. Fat and animal grease of every kind is a very favourite article of diet. If some such substance is buried in the ground the worms throng towards it. It is thus evident that they have a sense of smell, though no definite organ for the purpose has been identified. The sense of taste, which is closely allied to that of smell, is possessed by the upper lip, which is a small projection beyond the first segment and above the mouth. It is thus probable that powers of smelling reside here also. Incidentally it may be mentioned that the shape of the upper lip is not the same in all earthworms, and the variations in its form constitute one of the features by which the different species are recognised.

With other. special senses the worm is not liberally endowed. It is absolutely deaf, but on the other hand is so extremely sensitive to vibrations of the soil that the would-be observer must approach most cautiously to avoid causing alarm. No doubt this acute perception is of value in giving warnings of the approach of the mole. Again, there are no eyes, but the skin as a whole, and especially in the front region of the body, can distinguish between light and darkness. This sensibility can be demonstrated by suddenly flashing a bright light, with the aid of a mirror, on to an undisturbed worm : the moment the light reaches the body the animal recoils.

Weather.-During periods of drought or of frost worms retreat from the surface into the deeper parts of the soil, often descending several feet in order to escape adverse weather. Here the animal empties its body of soil, and excavates a small chamber, in which it coils itself up into a close spiral and remains dormant until more favourable conditions set in. The walls of the chamber are often lined with small pebbles, the air between which is doubtless of value as a non-conductor of heat. It is often noticeable that after very heavy rains many worms are found crawling aimlessly upon the surface, and frequently in a moribund condition. It is not clear why they behave in this way : no doubt the moisture-sodden ground causes them some discomfort, possibly it may render breathing difficult by expelling the air from the interstices of the soil ; but since worms can survive immersion in water for several hours this factor cannot be of great importance. 
It should, however, be noted that the majority of such worms are found to be in a diseased condition, and suffering from the attacks of internal parasites.

Uses.-It is very doubtful if worms do any harm to the roots of healthy plants, notwithstanding the general belief to the contrary. But it is certain that they perform a very useful function in maintaining the soil in a state suitable to vegetation. Their burrows serve as ventilating tubes down which the air can travel and become available for respiration by the roots of plants; at the same time they open up drainage channels and prevent the surface from becoming waterlogged. The roots too find an easy path through the soil along the lines of the burrows even after the walls have more or less collapsed; moreover, the excrement with which the burrows are lined is earth peculiarly well suited to the root-fibres, being moist, loose, and chemically fertile. But perhaps the most important work done is that of tilling the soil, bringing up the deeper material and casting it upon the surface to be exposed to and sweetened by the air. Charles Darwin estimated that in every acre of soil of average agricultural quality there are about 50,000 worms; he further ascertained that each worm casts up about $20 \mathrm{oz}$. of earth annually. A simple calculation with these figures shows that about 28 tons of soil are annually brought by worms to the surface on every acre. When it is remembered that pasture land and all land laid down to grass of any kind cannot from the nature of the case be ploughed or digged by human husbandry, it is evident that the debt of mankind to these humble tillers of the earth is not small.

We have also to thank worms for the preservation of many objects of historic interest, such as coins, ornaments, weapons, and even the floors and remains of ancient buildings that have in course of time become buried by the soil thrown up as "casts." The disappearance of such things is of course hastened by excavations made by the worms below the surface, for the collapse of the tunnels inevitably causes objects resting on the surface to sink downwards.

Again, the deepening of the subsoil and the general denudation of land surfaces is largely the result of the industry of these 
animals. The acids present in the top soil find a ready path down their burrows, and so gain access to the solid rock beneath, and eat it away. While the "casts," whether thrown up on level or sloping surfaces, are dispersed by the wind or washed to lower situations by the rain, and thus the general attitude of continents is slowly but surely reduced.

There are in Britain twenty species of earthworms belonging to the family Lumbricida, and contained in five different genera. The features by which these genera are distinguished from one another are in many cases internal and not visible except after dissection. The external characteristics concern the shape of the upper lip (prostomium), the position of the clitellum, and of certain swellings termed "tubercula pubertatis" upon it, and the paired or unpaired arrangement of the bristles (setæ), the site of the male apertures, and a few other minute features whose determination is too difficult for treatment here.

The "brandling" (Eisenia fotida) is of frequent occurrence in dung heaps and richly manured soils. Its general colour is red, marked with purple or brownish-yellow rings. The length is about $3 \frac{1}{2}$ inches. The prostomium extends into but not across the first segment. The clitellum extends usually from the 26th to 32 nd segments, the tubercula pubertatis from the 28th to 3oth or 3Ist. The setæx are closely paired. The male apertures in the 15 th segment. Three other common earthworms for which there are no popular names are-

Allolobophora longus, A. chloroticus, and Lumbricus terrestris. The genus Allolobophora is distinguished externally from Lumbricus by the fact that in the former the prostomium does not, while in the latter it does, extend back so as to touch the furrow which divides the Ist from the and segment. Both alike have the male apertures in the $5_{5}$ th segment.

$A$. longus is smoky pink-grey in colour; from 5 to 7 inches long, and is common in

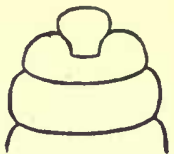

A

Fig. 62.-Prostomium and ist segments of - A, Allolobophora; L, Lumbricus. cultivated soil. Its clitellum extends from the 27 th and 28 th segments to the $35^{\text {th }}$; the tubercula pubertatis from the 32nd to $34^{\text {th. }}$ The setæ are closely paired. 
A. chloroticus may be green, yellow, or reddish; is from 2 to 3 inches long; occurs in rich soil, frequently in " spent" manure that has been put round the roots of trees. The clitellum is from the 29 th to $37^{\text {th }}$ segment; the tubercula pubertatis are small, and on the 3 Ist, 33 rd and $35^{\text {th }}$ segments. The setæ are closely paired.

Lumbricus terrestris is of a brown-violet colour in its dorsal anterior region, but reddish pink otherwise. Its hinder end is markedly flattened. It is very common in gardens and all cultivated soil. The clitellum reaches from the 3Ist or 32nd to the $37^{\text {th }}$ segment; the tubercula pubertatis from the 33 rd to 36 th. The setæ at the extremities are larger than those in the midregion, and are not so closely paired. The length may be as much as I2 inches.

Bibliography.-Darwin, Vegetable Mould and Earthworms; Marshall and Hurst, Practical Zoology; Hatchett Jackson, Forms of Animal Life (Rolleston); Howes, Atlas of Practical Elementary Biology; Latter, Natural History of some Common Animals; Davenport, Introduction to Zoology. 


\section{CHAPTER XX}

\section{THE Cockroach}

THE cockroach, or black-beetle, is now a very common insect. It frequents bakehouses, kitchens, and other places, such as warehouses and dockyards, where it can obtain both shelter and abundance of food. Being, however, a nocturnal animal, it is but seldom seen during the daytime, for then it is hidden in crevices and narrow dark recesses, into which its flattened and loosely jointed body enables it to retire without difficulty. Specimens for study can be obtained by the aid of "beetle traps" set in infested places, and baited with sugar moistened with a few drops of beer, or with the rind of cucumber, of which they are very fond.

The general colour of the insect is a dark blackish brown, well suited to concealment in the diurnal retreats. The head is rather hidden below the large shield-shaped prothorax; it carries a pair of long antennæ, which during life are kept constantly flickering over the surface upon which the animal is moving. At the side of the head is a pair of large compound eyes, and close to the insertion of the antennæ are two minute white spots, probably representatives of two of the three simple eyes (ocelli) found on the top of the head of many

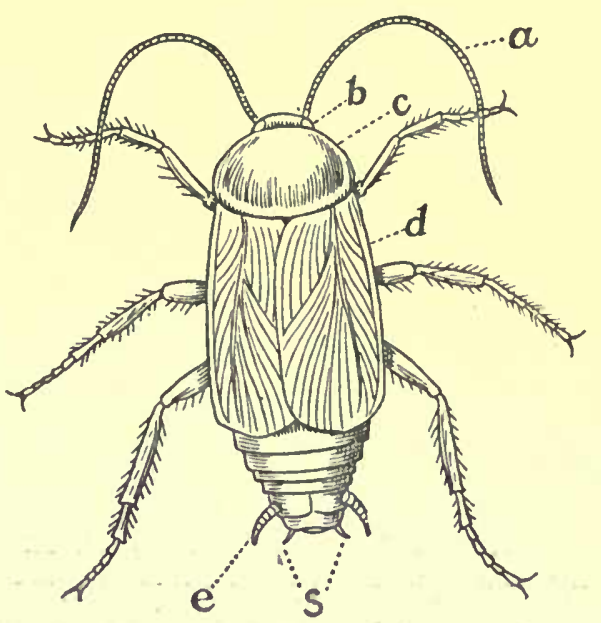

Fig. 63.- Male cockroach. a, antenna ; $b$, eye ; $c$, prothorax ; $d$, front wing; $e$, cerci; s, styles. insects. The mouth appendages occupy the ventral and posterior portions of the head. They consist of a flat upper lip, or labrum, 
which is not a true appendage (modified limb), attached to the lower border of the front of the head (clypeus). Behind this is a pair of strong mandibles, bearing three horny teeth near their tips, and roughened grinding surfaces near the base. With these the cockroach is able to feed upon almost anything that contains nourishment; leather, paper, hard crusts, the dead bodies of their fellows, and even the human skin is attacked by them. It is said that they devour bed-bugs; and on board ship they are sometimes a serious nuisance, owing to their attacks upon the
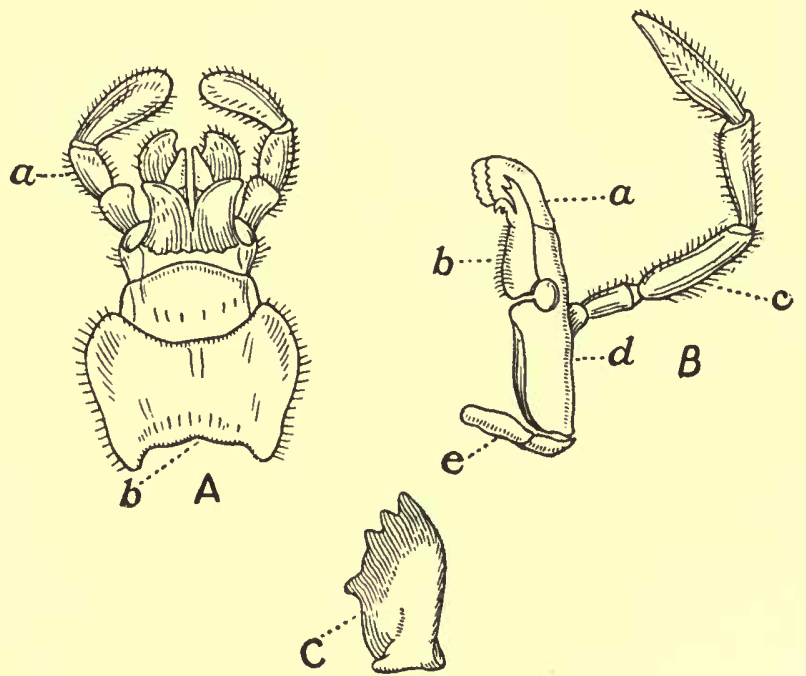

FIG. 64.-Mouth appendages of cockroach. A, labium : $a$, labial palp; $b$, line of attachment to head. $\mathrm{B}$, first maxilla : $a$, galea; $b$, lacinia; $c$, palp; $d$, stipes ; e, cardo. $\mathrm{C}$, mandible.

skin of sleeping persons. The mandibles, and also the first pair of maxillæ which immediately succeed them, meet their respective fellows in the middle line, striking inwards from right and left. The first maxillæ consist of a short horizontal " cardo" near to the head, a longer, vertical "stipes" from the outer side of whose distal extremity arises a 5-jointed palp. Beyond the origin of this tactile and probably gustatory organ there are articulated to the stipes two pieces, an outer "galea" and an inner "lacinia." The galea is deeply grooved along its inner face in order to afford a sheath in which the lacinia may lie, much as the blade of a pocket knife lies in the handle; at its extremity 
it bears a patch of closely set, short bristles. The lacinia has a number of long, sharp bristles on its inner border, and terminates in two claw-like teeth or hooks. It is used to help the mandibles in masticating the food. Behind the first maxillæ is the labium, or lower lip. This is composed of the two second maxillæ, united together in the middle line so as to form a flattened plate behind the mouth. The union affects only the portions which correspond to the cardines and stipites of the first maxillæ, called respectively the submentum and mentum; those representing the galeæ and laciniæ remaining free. On each side of the labium is a 3 -jointed palp.

The first thoracic segment (prothorax) is large, and, as already mentioned, forms a protecting shield over the head. The second and third segments (meso- and metathorax) are smaller and softer; and, in the full grown male, carry each a pair of wings. The front wings are rather hard and horny, and serve as covers to the hind pair rather than as organs of flight. The anterior part of the hind-wings is moderately rigid, so as to present a good cutting edge to the air, but the posterior portions are very thin, and when at rest are folded fanwise beneath the anterior part, and the entire hind-wing in turn is placed beneath the wing-cover (front wing). The females of the common cockroach are wingless, these appendages being represented merely by small triangular flaps; but in the larger American cockroach wings are present in both sexes.

Each segment of the thorax carries one pair of legs, of which the hindmost is the largest, the anterior the smallest. The first, or coxal, joint is large and much flattened, so that it can be closely applied to the ventral surface of the thorax, and thus present no obstacle to the passage of the insect along narrow crevices. The trochanter (second joint) is very small, and is followed by the femur and tibia, whose surfaces, especially those of the latter, are covered with stiff projecting bristles. These bristles are used as scrapers or combs in cleansing the body from dust and other foreign matter. The tarsus consists of six joints. On the lower side are soft white patches, resembling velvet, which prevent the foot from slipping on smooth surfaces. The last joint carries two sharply curved claws, and between these is a pad, 
the pulvillus, which produces a gluey substance to enable the insect to retain its hold on sloping or even on vertical objects. The abdomen is much flattened, and is softer than the thorax. It is composed of ten segments, but the hinder are telescoped within one another, so that in the female

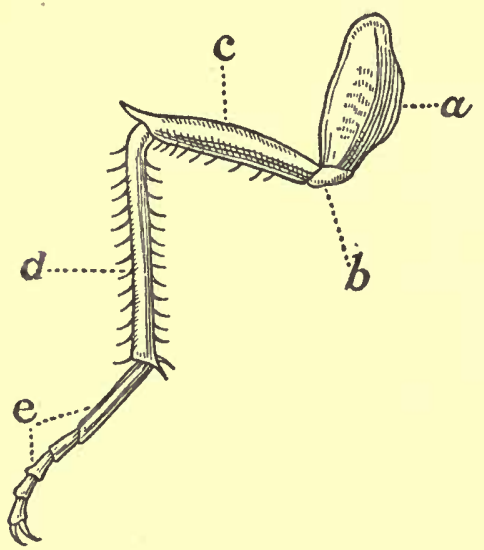

FIG. 65.-Leg of cockroach. $a$, coxa ; $b$, trochanter ; $c$, femur ; $d$, tibia ; $e$, tarsus. only eight are obvious from the dorsal side, those concealed from view being the 8 th and 9 th. The dorsal plate of the tenth is prolonged backwards, and is deeply notched posteriorly ; to its sides is attached a pair of short, jointed rods, the cerci which probably function as tactile organs. The ventral plate of the 9th segment bears in the male a pair of short styles, and by these the young wingless males may always be distinguished from females; while that of the $7^{\text {th }}$ is in the females produced backwards into a large boat-shaped structure in which the egg-capsule is moulded. The intersegmental membranes, and those between the several dorsal and ventral plates, are very thin and flexible. In that between the 5th and 6th segments there is situated dorsally a pair of sunken glands, from which is emitted a sticky fluid of peculiarly disagreeable odour. It is to these glands that the cockroach owes its evil scent. The respiratory openings (stigmata) are twenty in number, ten on each side, in the thin membranes between the dorsal and ventral plates: one pair lies between the pro- and mesothorax, one between the meso- and metathorax, and the remainder in the first eight segments of the abdomen. From these openings air is conveyed throughout the body by tracheal tubes, which are fine, much branched inward extensions of the external covering of the body.

The digestive system of the cockroach can be exposed without much difficulty if the specimen be fastened down on a weighted sheet of cork, or embedded in melted paraffin wax poured into a small dish, and then dissected under water. The dorsal plates 
should be removed from all the segments, care being taken not to cut deeply, for the internal organs lie close to the surface. The mouth leads by a narrow gullet into a large pear-shaped crop, on whose sides are two pairs of white salivary glands, each embracing a thin-walled receptacle. The saliva produced by these glands is conveyed forwards to the mouth by fine tubes which unite before discharging. While in the crop considerable changes are effected in the food by the action of the saliva and of the juices produced by the "liver" tubes, whose secretion passes forward into the crop. Immediately behind the crop is a small but firm and muscular gizzard. Within this organ are six large horny teeth, by which the food is finely crushed after leaving the crop; behind and between the teeth are numerous short bristles, which serve as strainers to prevent any but very minute particles from passing into the mid-gut. Close to the junction of the mid-gut with the gizzard are about seven blind, club-shaped tubesthe "liver" tubes, which both discharge a digestive fluid upon the food and also absorb the digested material and pass it into the blood. The mid-gut is succeeded by the intestine, whose commencement is marked by the attachment of numerous white thread-like tubes of excretory function. The intestine is rather closely coiled, and eventually passes into the rectum, which opens to the exterior at the anus, and which is provided with six longitudinal ridges the better to grasp and mould the fæcal residues to be expelled from the body.

The eggs of the cockroach are laid in batches of sixteen at a time, each batch being enclosed in a large, dark mahogany coloured capsule somewhat resembling a small bean-seed. This structure is formed in the peculiarly modified ventral plate of the $7^{\text {th }}$ segment, to which allusion has already been made. The eggs pass into it singly from the right and left ovaries alternately, and are placed upright in two parallel rows facing each other. Female cockroaches may often be seen with the egg-case protruding from the posterior end of the body, for they thus carry it about until they have found a suitable nook in which to deposit it. When the young are ready to emerge they push asunder the sides of the capsule, which are cemented together dorsally so as to produce a longitudinal ridge, and escape through the slit thus opened. 
Excepting the eyes, which are black, the young cockroach is almost colourless. In general form it resembles the adult, but is devoid of wings in both sexes. Very soon after hatching the skin is moulted for the first time; it is shed again about a month later, and for the third time at the end of the first year, and subsequently once a year only in the warm weather. Immediately

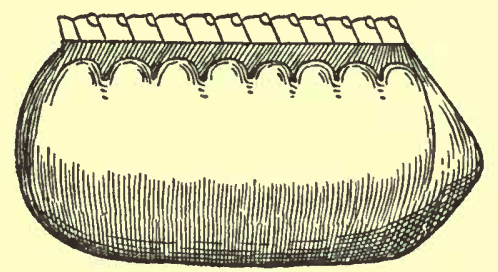

A

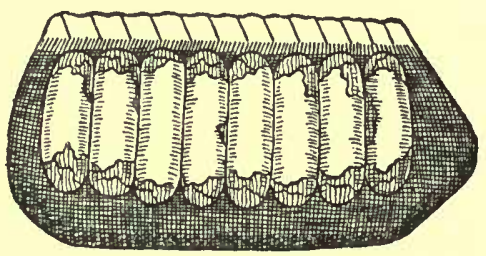

B

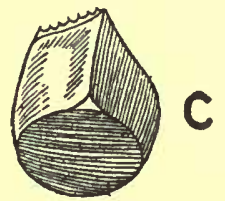

FIG. 66.-Egg-capsule of cockroach. A, side view ; B, cut open ; C, end-on view.

after each moult the skin is soft and pale, but it soon hardens and assumes a darker tint. Young cockroaches are, however, always paler than adults. It is said that maturity is not attained until the fourth year; but, in view of the rapid increase of individuals in infested places, it is difficult to believe that this is invariably the case.

The cockroach itself (Blatta orientalis) is not truly indigenous to this country, but was imported, probably by shipping, in the sixteenth century. Three allied species belonging to the genus Ectobia are, however, natives; but they are comparatively rare insects, much smaller than the cockroach, and not found about our dwellings. The large American cockroach (Periplaneta americana) is not uncommon in some of the warmer houses at the Zoological Garden, and is probably familiar to many persons. Other insects belonging to the same order are the Grasshoppers, Crickets, and Locusts, in all of which the hind-legs are adapted for leaping, and the Earwigs, which last are dealt with in the next chapter.

Biblography.-Miall and Denny, The Cockroach; Cambridge Natural History, vol. v. ; Burr, British Orthoptera ; Latter, The Natural History of some Common Animals; Marshall and Hurst, Practical Zoology ; Shipley and MacBride, Zoology; Hatchett Jackson, Forms of Animal Life (Rolleston). 


\section{CHAPTER XXI}

\section{EARWIGS}

Probably no insect is more widely known than the common earwig (Forficula auricularia). It is to be found at all seasons of the year, and in the warmer weather, especially in sandy districts, becomes so abundant as to be a nuisance in gardens and houses. It is an omnivorous feeder, eating the petals of flowers, ripe fruit and other sweet substances-it often is found in thousands on the "sugar" placed on tree trunks by collectors of moths - and also the dead bodies of other insects, as entomologists who have left "set" insects on exposed setting-boards know to their chagrin. The name "earwig" is due to a belief that these insects will crawl into the ears of persons asleep, and even penetrate to the brain. There is very little evidence in support of this idea, though the writer has actually heard of one case in which an earwig did enter the ear of a child and cause some inconvenience before it could be dislodged. It is, however, remarkable that in nearly all countries the popular name for the animal has reference to this reputed habit; e.g. "perce-oreille" in France, "Ohren-wurm " in Germany; and it is undeniable that earwigs are very fond of hiding in dark holes and crevices,-a hollow stick or piece of metal or rubber-tubing left on the ground for one night will often contain dozens of individuals next morning.

The head has a pair of compound eyes, but no ocelli. The antennæ are thread-like, and consist normally of fourteen joints, though a smaller number, perhaps the result of mutilation, is not infrequent. The jaws are of the ordinary type found in biting insects, and consist of a pair of strong mandibles, a pair of first and a pair of second maxillæ, the latter united to form the labium or lower lip. In general plan these jaws are not very different from those of the wasp. The prothorax is large and freely VOL. I. - I 2 
movable upon the mesothorax. In the adult the mesothorax carries a pair of short wing-covers (tegmina), and the metathorax a pair of elaborately folded and very delicate flight-wings, whose extremities when folded project for a little distance behind the wing-covers. The legs are set wide apart, and consist of the parts usual in insects, but the tarsus is composed of three joints only. The wings are very remarkable and characteristic. The front pair function merely as covers for the hind ; they are small and hard and of the same brown colour as the rest of the body. The hind pair when expanded are of considerable size and very thin, but when at rest are folded in a most complicated and beautiful fashion, and tucked away beneath the fore-wings with the exception of the small projecting portion. This piece alone is darkly coloured, and relatively firm. The concealment of the hind-wings is so complete that many people are unaware of their presence. It is, however, possible, with some care and patience, to unfold the wings and spread them out with the aid of the blunt end of a needle. The common earwig is rarely seen on the wing, for it hides by day and flies only at night. A smaller species (Labia minor) is commonly met with flying over flower beds at dusk, it being earlier in its habits. The attachment of the wings is peculiar, for the hard part of each is continued towards the mid-dorsal line until it meets its fellow. The folding is more elaborate than is found in any other insect. It is accomplished as follows. The lower radiating veins first come together, creasing the delicate membrane between them fanwise; a cross fold then is made rather near the basal hard part, and is followed by a second cross fold in the reverse direction close to a line of dilated spots on the divergent veins; a contraction then occurs close to the base, so that the whole folded structure is compressed, the softer parts passing below the hard; and finally, the abdomen is turned up and the nippers at its end employed to push all snugly " home."

The abdomen is composed of the usual ten segments, and terminates in a pair of horny pincers. The segments are most easily determined in a specimen distended by drowning in water. The separate dorsal and ventral plates which in life overlap each other then become plain, and the seven pairs of minute spiracles in the intersegmental membranes visible on the sides, whereas in 


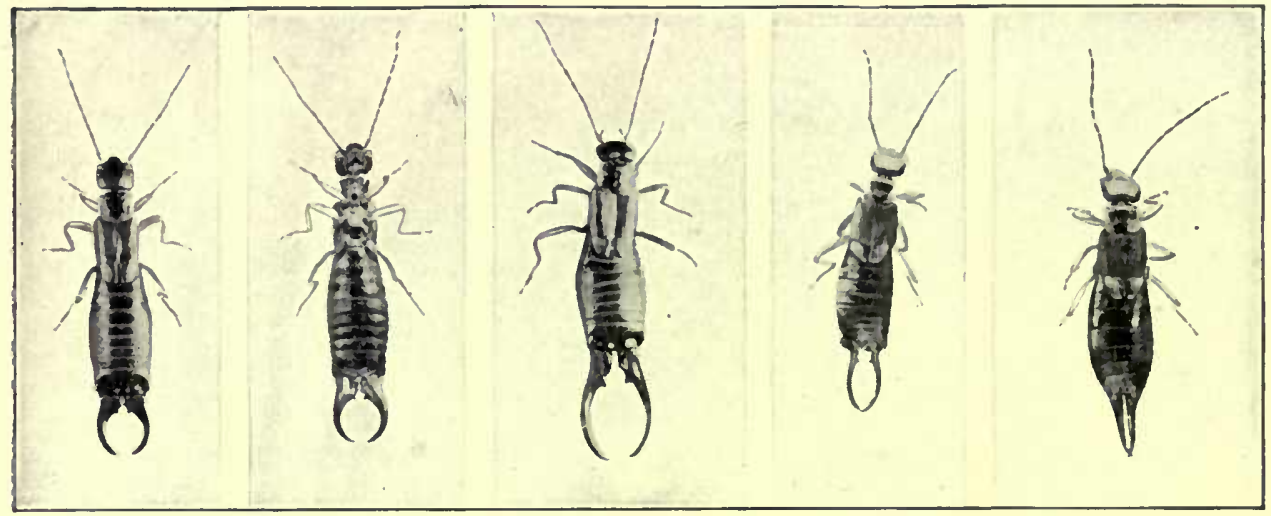

I-4. Male Earwigs. Note the variable size of the nippers. 2. Is seen from below. 5. Female larwig.

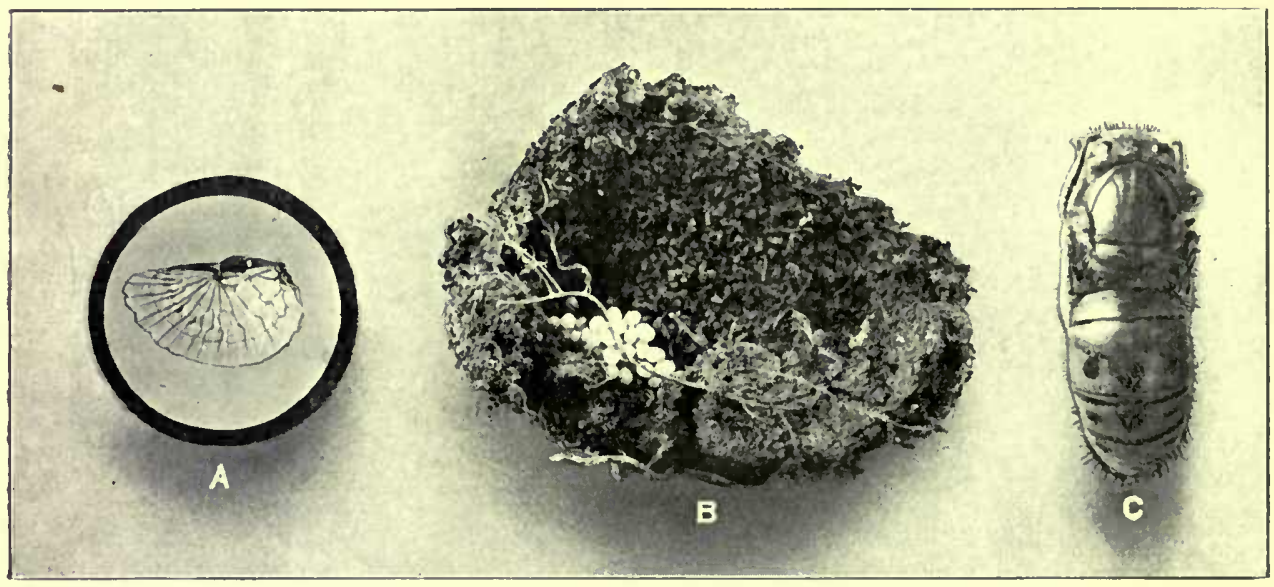

A. Wing of Earwig. $\quad \times 2$. $\quad$ B. Nest of Earwig containing about 40 eggs ; found in April. $\times 2$ C. Queen IVasp hibernating. Note how the legss and wings are tucked under the body.

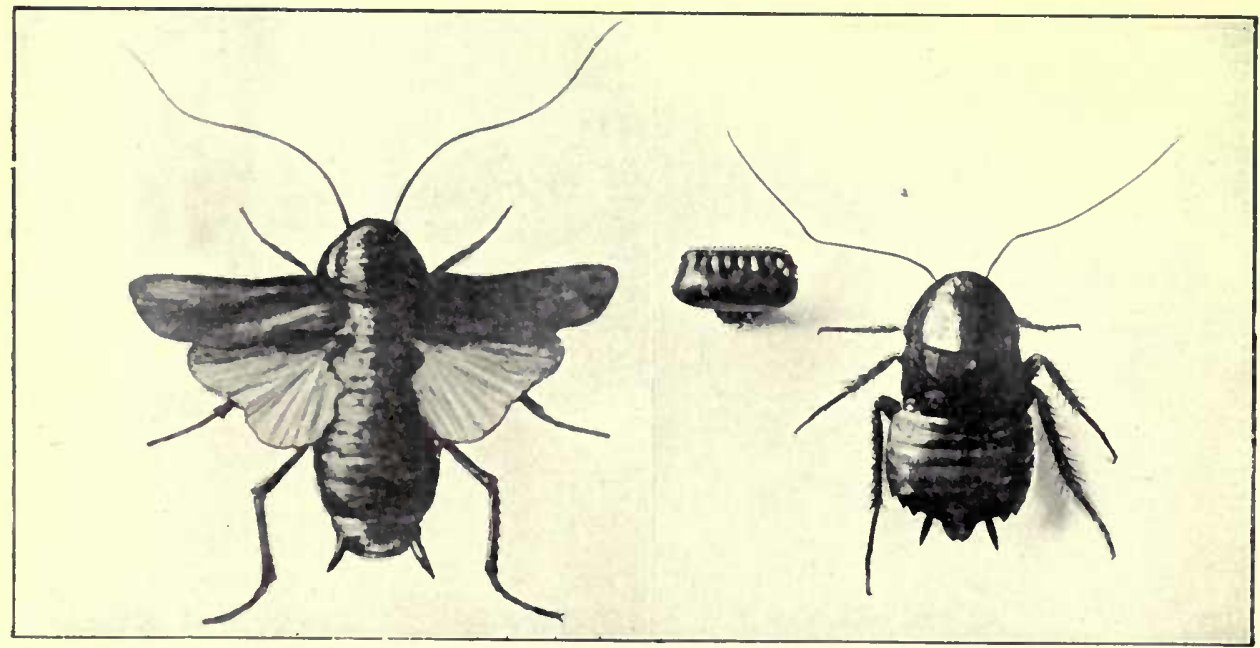

Photos by Hugh Main, South Woodford.

1. Male Cockroach with extended wingss. 2. Egrg Capsule of Cockroach. 3. Female Cockroach. 

life the three thoracic pairs of spiracles are alone easy to detect. The first dorsal plate of the abdomen is united, but not perfectly, with the thorax, - a feature of interest when we recall the complete union that exists in the same region of the wasp and other Hymenoptera, and that has given rise to the propodeum (vide p. I97). In the living animal the abdominal segments overlap each other like tiles, and thereby gain strength to resist external pressure; nevertheless the soft intervening portions render possible great distension and flexibility. The forceps differ in shape in the two sexes. In the female their " jaws" are almost straight, with roughened inner edges and crossing tips. In the male the "jaws" are curved into a semicircle, strongly toothed at their contiguous bases, but smooth on the curved part. The size, shape and proportions of the male forceps are extremely variable, as is so often the case with highly specialised organs; cf. the mandibles of the male stag-beetle. Reference has already been made to the use of the forceps in tucking away the flightwings beneath the tegmina, but that this is not their sole use is evident from the fact that wingless species of earwigs likewise possess these organs; nor is the nip that they can give when employed in defence sufficiently formidable to be of much value. It is possible that they are in some way concerned with the process of mating, but we find no recorded observations on this point.

The means of defence possessed by earwigs are of the passive order. Thanks to its skulking habits during the day, it escapes from many insectivorous creatures. But it also has a most disagreeable odour, which is very noticeable if a number of specimens are kept together in a small box or on any article in which these animals have congregated for shelter. This odour is produced by special glands situated on each side of the dorsal surface of the (apparent) second and third abdominal segments; the position of these glands is visible to the naked eye, being indicated by a slightly raised line which ends in a slight fold at the hinder edge of the dorsal plate of the segment. There is also on the dorsal surface of the segments a series of dark, smooth, short marks, two on each side of each segment, whose significance is unknown.

During the winter the insects bury themselves in the soil or 
in heaps of decaying vegetation. The eggs are laid in the spring, and hatch out in a few weeks' time. The female watches over her eggs, and collects them again into a heap if they are disturbed. There is no metamorphosis, for the young resemble the adult in general form, but have no wings, nor are the forceps of the same shape, nor the number of antennal joints so great. They grow rapidly, moulting the skin three or four times, and by August of the same year have attained to maturity. The female is said to evince some affection for her young, but on this point there is contradictory evidence. In fact, in spite of this insect being so very common, comparatively little is known of its life-history, and the opportunity is open for some one to fill in the large gaps in our knowledge.

Bibliography.-Burr, British Orthoptera; Cambridge Natural History, vol. v. 


\section{CHAPTER XXII}

\section{The Large Cabbage White Butterfly}

THE large cabbage white is one of the most common of our English butterflies, so much so that at times its larvæ do serious injury to crops of cabbages and other garden plants on which they feed. There are two broods and sometimes three in the course of the year, the perfect insect appearing first in May and June, and again in July, August, and, if the season be a late one, September ; or the third brood may appear in September if the immediately preceding conditions have been unusually favourable. There is therefore but little difficulty in procuring specimens at any time during the summer months.

Head.- The head of the butterfly is rounded; at its sides it carries a pair of large black compound eyes, and between these on the dorsal surface three simple eyes-the ocelli. These last are not easy to make out, because they are concealed among the hairs that clothe the head. From the front of the head above the eye there stand out a pair of antennæ, whose distal joints are rather abruptly different in shape from their predecessors, being shorter and stouter, so that the whole antenna is club shaped. This shape is a feature by which butterflies may easily be distinguished from moths; but the exact form of the "club" differs in different butterflies, e.g. in the now scarce Black-veined White the passage from long and narrow to short and stout joints is bridged by intermediate joints, so that the transition is gradual. All the uses of the antennæ are not fully understood, but there is little doubt that they contain sense organs which correspond with those of smell in ourselves, and in this manner they enable the opposite sexes to find one another. Projecting between the antennæ from the under side of the head is a pair of short, pointed, scale-clad palps - the labial palps; these consist of three joints, but are so densely covered with hairy scales that the fact may 
escape notice: the function of the palps is uncertain. Rolled up beneath the head is the long and delicate proboscis, which is capable of being unfurled and used as a tube for sucking nectar from flowers. This structure is part of the first maxillæ-there is no trace of mandibles; but to which part of the maxillæ of simpler insects, e.g. wasps, it corresponds is a matter of dispute. It is, however, noteworthy that the proboscis is composed of two half-tubes, placed hollow to hollow, separable for undergoing cleansing, but capable of close opposition when desired for sucking; and further, that the galea (the outer of the two pieces in which the maxillæ terminate) of simpler insects possess a long slot upon the inner face, i.e. they are short half-tubes. It is therefore not unreasonable to hold that the proboscis represents a much elongated pair of galea,- the view held by some entomologists.

Thorax.-Of the three segments of the closely compacted thorax the middle one is the largest. The details of the structure of the thoracic skeleton are too complex for treatment here, and the features are difficult to determine, in consequence of the presence of an abundant covering of black hairs. The three pairs of legs belong one pair to each segment. They are all ordinary walking or clinging legs, with two claws at their tips. In some butterflies, e.g. the peacock, tortoise-shell, and other vanessids, white admiral, purple emperor, all fritillaries, the meadow browns and their allies, the first pair of legs are reduced in length, have no claws, and are apparently employed as sense organs. The tibiæ of the first and second pair have articulated spurs on their middle as well as at the end; from the third pair these middle spurs are absent, the skippers being the only British butterflies in which they are here present. The two pairs of wings are attached respectively to the second and third segments. When fully spread their expanse from tip to tip is about $2 \frac{1}{2}$ inches. The front wings are rather longer, narrow, and less round at their angles than the hind, and the former overlap the latter to some extent, so that in flight the two wings of one side are pressed together as they strike the air, and beat as though united into one. In both sexes the general colour of the upper side of the wing is white, the colour being due to the 
thousands of minute overlapping scales (whence the name Lepidoptera-Butterflies and Moths; Greek, lěpis =scale), which cover both surfaces. In the male the tip of the front wing has a very narrow black border, which widens out as it reaches the front angle and passes more than half-way along the outer edge, gradually fading out before reaching the hind angle ; in the female the expanded portion of the black colouring is rather more extensive, and there are in addition two large black spots on the surface of the wing, one above the other, and separated by about as much white as their own width, situated rather more than halfway from the shoulder to the outer edge; below the lower of these spots, and almost touching it, there is also in this sex a clubshaped black streak whose point is directed towards the shoulder. On the hind-wing both sexes have a black spot on the front edge, in a line with the two on the fore-wing of the female; this spot is larger in the female, and has the appearance of being two spots coalesced. The lower side of the wing is alike in both sexes, the male as well as the female having the two black spots upon the fore-wing, but none of the other black marks,
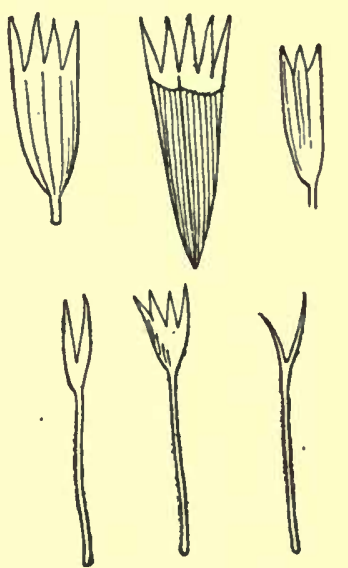

FIG. 67. - Scales from the wing of a butterfly. excepting a small part of that on the hind-wing, appear. The general colour of the under side, especially of the hind-wing, is greenish yellow in a fresh specimen. When at rest the insect raises the wings, without any folding or creasing, over its back, so that right and left meet, and only the greenish under side of the hindwing is visible. The insect is thus to some extent concealed when upon the foliage of plants. The wings are strengthened by veins or nervures, of which the most anterior are the strongest. The precise arrangement of nervures, or wing-venation, is of great importance in the classification of Lepidoptera, and should be examined by all who intend to make a serious study of the group. Details are not easy to see so long as the scales of the wing are in position; but this difficulty may be overcome by one or other of these methods: (I) brush off the scales with a moist 
paint brush, the wing lying meanwhile on a moistened sheet of glass; (2) soak the wing in "eau de javelle" (hypochloride of potash), after a preliminary dip into weak alcohol, an operation which quickly removes all scales, but must be discontinued as soon as these are off, and the whole wing will be rotted by the liquid; (3) steep the wing in benzene, and so render it transparent. This last has the advantage of not injuring the specimen in any way, for the benzene quickly evaporates and leaves no trace of having been used. But with a little patience venation can generally be made out without resorting to any of these methods, especially if the under side of the wing be examined, for there the veins are more prominent.

Abdomen.-The abdomen is almost black, and covered with close hair-like scales. It probably consists of the usual ten segments, but of these only eight are visible dorsally, and seven ventrally in the male, and seven or six respectively in the female. The remaining segments are invisible because they are withdrawn inside the terminal segment, and greatly modified in connection with the reproductive organs. Respiratory stigmata leading into tracheal tubes are present on the sides of each of the visible segments, except the first. Similar openings are also present in the thorax, but there is doubt as to their number.

Life-history. - The eggs are to be found in May, and again in late July and August. They are laid in patches of fifty to a hundred or more upon the under (usually) side of the leaves of cabbages and other cruciferous plants, and occasionally on "Nasturtium" (Tropaolum) and Mignonette. The egg-shells are flask shaped, delicately sculptured upon the surface, and waterproof. The young caterpillars emerge about ten days after the eggs have been laid, biting their way through the shell with their strong mandibles, and in a short time set to work devouring the substance of the leaf. They feed ravenously and grow rapidly, moulting their skins four or sometimes five times as the exo-skeleton becomes too small for the growing internal organs. Prior to each moult a small carpet of silk is spun over a portion of the leaf, and upon this the larva rests, obtaining a firm foothold and anchorage for the husk shortly to be abandoned. The fullgrown caterpillar is about $2 \frac{1}{2}$ inches in length, and, as it differs 


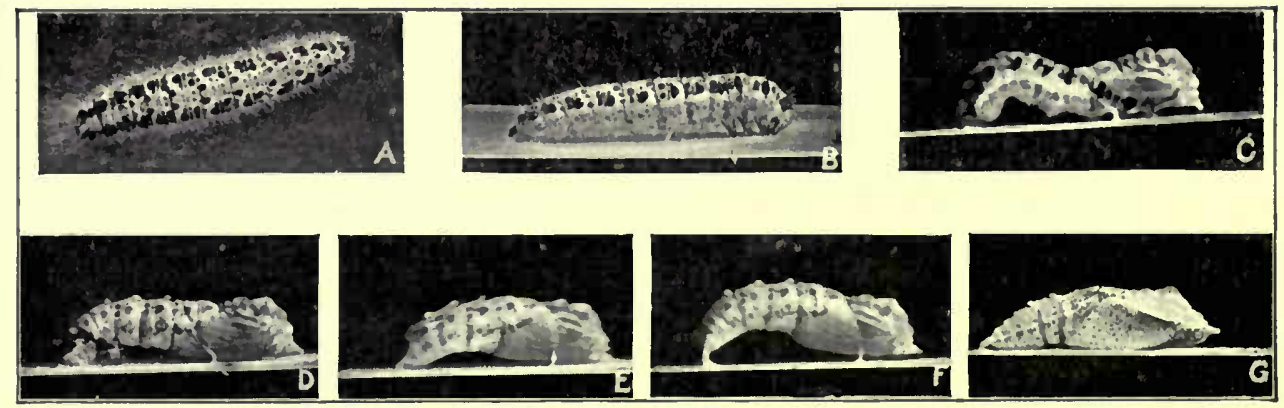

A. Full-grown Larva of Large Cabbage IVhite Butterfly. B. Larva preparing to pupate. C, D. Successive phases in removal of larval skin. E, F. Freshly formed pupa in act of fixing tail (cremaster) to silken pad. G. Pupa in position in which it rests until the butlerfly emerges.

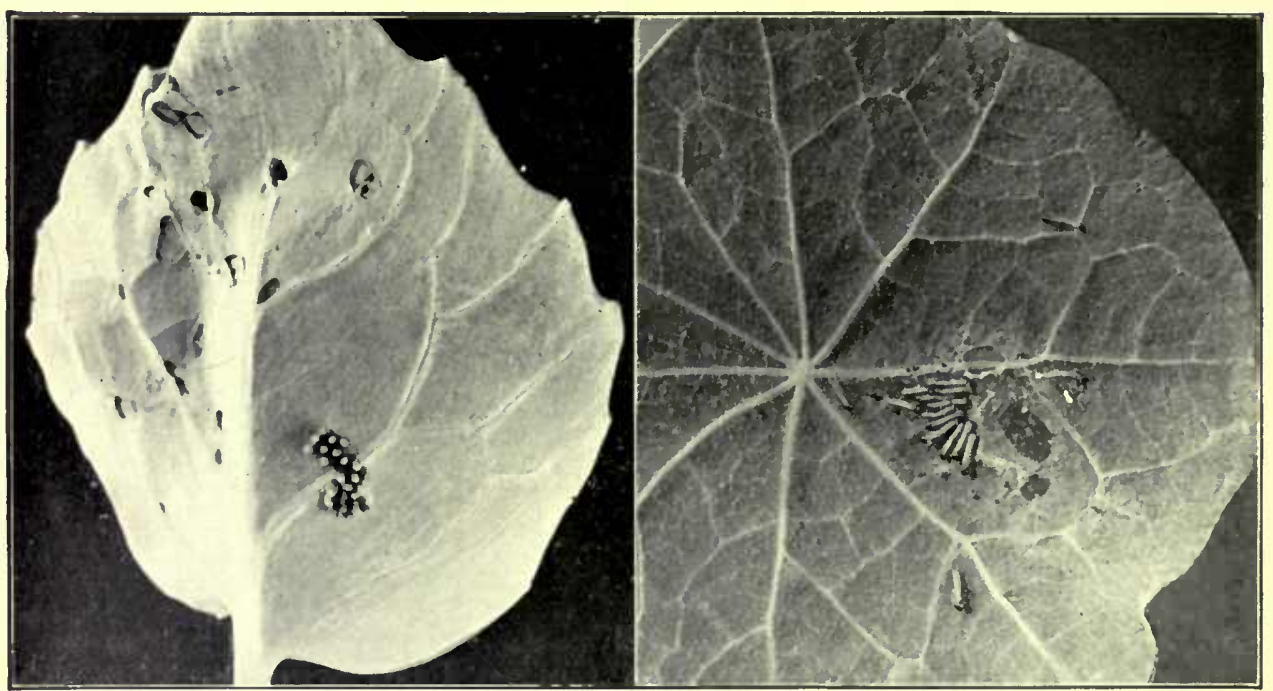

Batch of Eggs of Large Cabbage WHITE BUTTERFI. $\times 2$.
Young Larvi of Large Cabbage

WIITE BUTTERFI. $\times 2$.

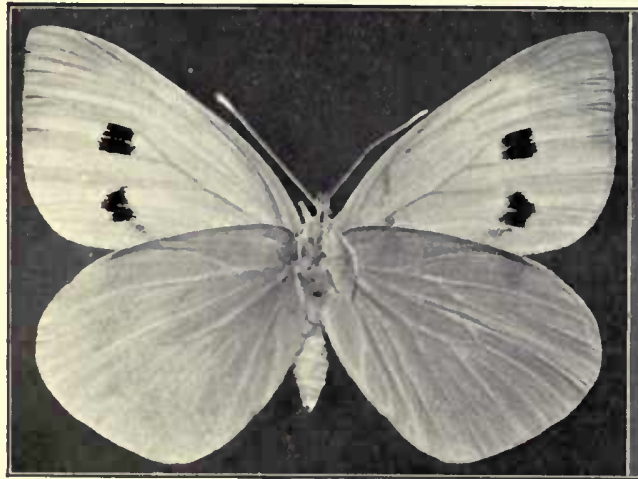

Under Side.

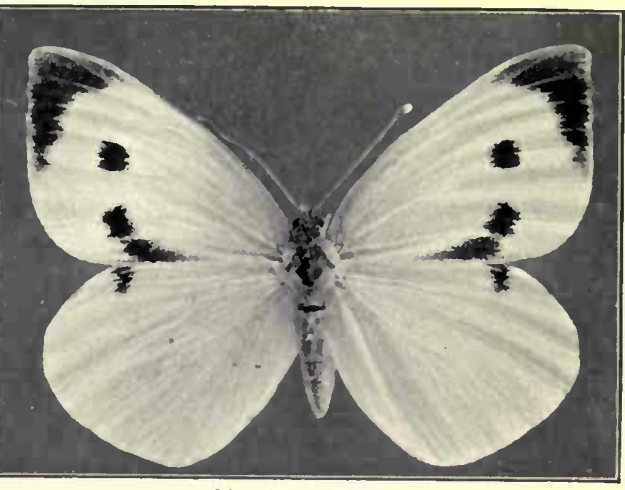

Upper Side.

LARGE CABBAGE WIITE BUTTERFLY (FEMALE). $\times$ I. Photos by Hugh .Iain, South Woodfort. 

in no important respect from the younger larvæ, is convenient for examination. It consists of a head and thirteen segments. The head is of a slaty-brown colour with black spots, its under side is yellowish. It is very hard, a firm skeleton being required for the attachment of the muscles which move the mandibles, on which so much work falls during larval life. Low down there projects from the front of the head a pair of very short antennæ, on each side is a group of five minute "simple" eyes arranged in a curve. A magnifying glass is needed to see these structures. The mandibles, the most conspicuous of the jaws, are hard and horny, and work across from right and left to meet in the middle line. The two pairs of maxillæ are too small for detailed treatment here. Behind the mouth, projecting from the edge of the lower lip, is a pointed pimple-the spinneret-from which the silk is exuded in a liquid condition when required. The liquid silk is manufactured in two tubes, one on each side of the body, which open together at the spinneret. In some caterpillars, e.g. the silkworm, these glands are of enormous length, as many as five times the length of the body. It is from these tubes that the "silk-gut" used by anglers is prepared. The hardening of the naturally discharged silk is not merely a process of drying, but rather of coagulation; a kindred phenomenon is the clotting of blood. There are two other tubes opening close to the mouth ; these come from the salivary glands, and discharge a digestive fluid on to the food as it is being cropped. When handled the larva will often emit, partly from its mouth and perhaps partly from the salivary glands, a greenish fluid of disagreeable odour.

The thirteen segments composing the rest of the body are all much alike; their general colour is yellowish green with black spots and blotches, but along the middle of the back and on each side at the level of the spiracles is a line of clearer yellow. The whole surface is covered with fine whitish hairs. The first three segments each bear a pair of true jointed legs, ending in a curved claw ; the joints are very short and require a magnifying glass for their determination. These three segments form the thorax. The next two segments have no legs of any sort; the third, fourth, fifth and sixth of the abdomen each have a pair of "false-legs" or " claspers," and there is a fifth pair of claspers of slightly 
different shape at the extreme hind end. The claspers are nonjointed, fleshy outgrowths, and are furnished with rows of little hooks round their soles for securing firm foothold.

All lepidopterous larvæ, except a very few aberrant legless forms, have six true legs upon the thorax; also they never have claspers upon the first two abdominal segments, but the condition of the other abdominal segments varies in different sub-groups, the number of claspers being often much reduced, e.g. in the " Looper" caterpillars (Geometers). The fact that in Lepidoptera the first two segments of the abdomen are always destitute of claspers is important, for the larvæ of certain sawflies (Hymenoptera) are very similar to true caterpillars in appearance, but may be distinguished by the possession of a pair of claspers upon the second abdominal segment.

On the sides of the body are nine pairs of spiracles. These are moderately conspicuous openings in the yellow lateral line; they occur one pair on the first thoracic, and a pair on each of the first eight abdominal segments. Traces of such openings can sometimes be seen on the other thoracic segments, but they are not now functional.

During larval life immense stores of fat are accumulated within the body, for this is the main feeding period, comparatively small quantities of food being consumed by the butterfly itself. Indeed, there are many lepidopterous imagines which are quite incapable of taking food.

Pupation.-When full fed the larva quits its food plant, and, after a short journey over the ground, climbs up a wall or fence or tree trunk, and there spins once again a little silken platform similar to that already constructed at each moult, but in addition places a girdle of silk round the middle of the body, attaching each end to the vertical surface selected. The larva rests with its head uppermost, though occasionally the body is horizontally placed, and with the hindmost claspers securely attached by their hooks to the silken platform. During this period of rest the length of the animal becomes decidedly less. After some hours the skin cracks open in the dorsal region of the thorax, and by a series of spasmodic jerks and wriggles is worked off down towards the tail. The form now assumed is known as the chrysalis or 
pupa, and is very different from the larva. At first it is quite soft, and its skin semitransparent, and at this period it is quite easy to make out that it possesses two pairs of short wings, three pairs of moderately long legs, a pair of long antennæ, and a proboscis; for all these appendages are for the first hour or so of pupal life capable of being lifted by a needle. A little later, however, they become glued down to the surface of the body, and, though still quite recognisable, are not so easy to detect. It is thus evident the pupa resembles the imago far more closely than does the larva. The hardened pupa is only about one inch long, and is of remarkable shape : at its anterior end is a sharp spike flanked at its base by two smaller projections; on the dorsal surface, which is directed outwards away from the surface of attachment, is a series of similar pointed elevations, of which that from the middle segment of the thorax is the most pronounced; and from the third abdominal segment the very conspicuous conical projections stand out laterally. Thus the whole pupa is very angular in aspect. On the sides of the head can be seen a pair of oval eyes; above these start the jointed antennæ, which are folded down on to the ventral surface and run down parallel with the front border of the fore-wing. Down the midventral line lies the proboscis, extended backwards beyond the wings, and between this and the antennæ parts of the legs are visible, the remaining portion being concealed beneath the wings. The fore-wings cover the hind, so that the latter are usually quite invisible, the former extending down on to the fourth abdominal segment ventrally; they are marked with longitudinal curved rows of black spots, and have a series of larger spots round the posterior margin.

The ten abdominal segments can be recognised, though the two most posterior are somewhat compressed. Paired respiratory stigmata are visible and functional upon the sides of the second to seventh segments inclusive, and there is the mark of a closed pair on the eighth. Upon the ventral side of the fourth to the sixth segments scars of the larval claspers are visible. There are no openings whatever to the digestive system, for no food is taken, nor does any excrement of any kind leave the body of the pupa. At the extreme hind end of the body is a rather square- 
cut projection, the cremaster, whose minute spines are used for attachment to the silken platform when the larval claspers are cast off; it represents the flap covering the anus of the larva. The possession of mouth parts, legs and wings by an animal at a time when it neither takes food nor moves from one place is cause for surprise. The probable explanation of the phenomenon is that at some remote period the pupa was not inert and stationary, but active and capable of using all these organs. There are many insects, e.g. grasshoppers, cockroaches, etc., which go through no pupa stage, but reach the adult condition by a series of gradual changes accomplished at each moult, and in these the young as they leave the egg are not caterpillars, but in general bodily form resemble the adult, except for the absence of wings. Such insects have no " metamorphosis." Then, again, the dragon flies possess an active pupa which exhibits no very marked differences from the larva, but on leaving the water this pupa gives origin to the perfect insect by a single abrupt change accomplished at one moult. This state of affairs is known as " partial metamorphosis," there being only one sudden change of form ; whereas in the lepidoptera the metamorphosis is "complete" with the two sudden changes,- the first when the larva. turns to the pupa, the second when the pupa to the imago.

Moreover, there is reason to suspect that at some period the present lepidopterous pupa was the final form, and that the

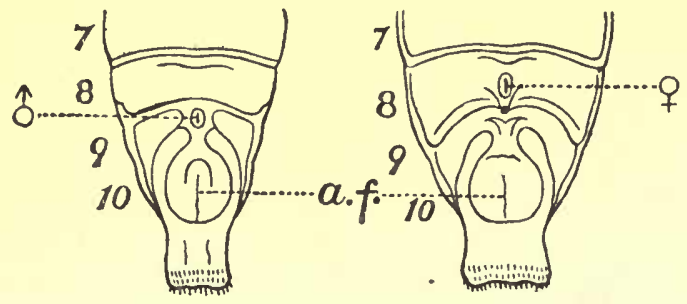

FIG. 68.-Terminal segments of male (left) and female (right) pupæ. $t$, male organ ; + , female organ; a.f., anal furrow. The numbers are those of the segments. and ninth abdominal segments. If the pupa be a male there is on

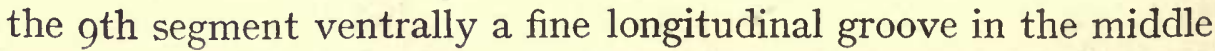
line on a slightly raised area and provided with two oval lips on the is a later development; for the pupæ possess external organs of reproduction differing in the two sexes, so that it is possible to distinguish male from female chrysalids. These external sexual differences are to be looked for on the ventral side of the eighth imago, as we now see it, 
right and left. If, on the other hand, it be a female, a similar structure is visible on the 8 th as well as on the 9th segment. In this connection it is useful to remember that it is the eighth segment which has the rudimentary, functionless respiratory stigmata. It is difficult to see any explanation of this phenomenon other than that at one time the pupa was sexually mature, i.e. was the end of the life-history.

Many larvæ, especially of the autumn brood, after making all preparations for pupation, fail to accomplish the change; for just when this is due, or rather overdue, to take place there emerges instead through the skin of the unfortunate larva a number of small grubs, which at once proceed each to spin its own yellow cocoon on or close to the now dead caterpillar. These are the grubs of a small ichneumon fly (Microgaster glomeratus) which have lived as parasites within the caterpillar, and have at length killed it and devoured all that lay within the skin. The ichneumon fly itself is a small four-winged fly provided with a piercing ovipositor, with which the eggs are inserted into the skin of the caterpillar's back. This little parasite is one of the chief agents in preventing the excessive multiplication of caterpillars, and is one of the gardener's best friends.

The colour of the pupa is liable to wide variation, and within a fairly large range of tints is more or less in conformity with the colour of the surface to which the larva has attached itself. For example, pupæ on a tarred shed are very dark, while those on a white window-frame are very pale. Interesting experiments in this direction can be made by lining the sides and roof of breeding-cages with differently coloured stripes of paper and noting the colour effect produced upon the pupæ, and also if the larvæ exhibit a preference for or prejudice against any particular colours. It has been recorded that pupæ attached to a red brick wall were always upon the mortar between the courses and never upon the bricks themselves; but this might have been the result of a preference for a material and not necessarily for a colour. It appears that it is the whole skin of the larva that is sensitive to the colour of the surroundings, and an adaptive development of pigment results by some mechanism 
that is not fully understood. The eyes are not the percipient organs in this matter.

During the pupal stage extensive rearrangements of the internal organs take place, and some of the tissues break down into a pulpy mass from which are elaborated the new muscles and other organs peculiar to the imago. In other words, a large series of changes have been compressed into the brief compass of the pupal life, so that now the modifications necessary to convert a biting and crawling larva into a sucking and flying imago are accomplished during the one long period of repose. The autumn-formed pupæ pass through the winter in that condition. When the imago is ready to emerge the colour of the pupa changes a little; eventually the skin of the anterior region breaks open and the butterfly crawls out, wet and limp and with small crumpled wings that are full of fluid. Drops of a pinkish fluid are usually discharged from the posterior end soon after emergence. These contain the nitrogenous waste matter which has been formed and accumulated during the important tissue changes of the pupal period. The wings soon lengthen out, hanging down with their edges parallel with the abdomen. After a few hours they dry, the liquid within disappearing, and soon after this has taken place the butterfly flits away.

BibliogRaPhy.-Miall, Round the Year; Meyrick, Handbook of British Lepidoptera; Poulton, Trans. Entom. Soc., Iondon, I892; Poulton, The Colours of Animals; Cambridge Natural History, vol. vi. 


\section{CHAPTER XXIII}

\section{WASPS}

WASPS are perhaps the most generally feared and detested of all insects. The painful effects of their sting and the unwelcome attentions which they bestow upon our viands indoors and upon our ripe fruit in the garden combine to bring them into evil repute,-more so than they really deserve.

As in all insects, the body of the wasp is clearly divisible into three main parts, the head, the thorax, and the abdomen; there being a distinct neck between the head and thorax, and a waist between the thorax and abdomen. ${ }^{1}$ Again, all insects, at any rate when full grown, possess antennæ on their heads, three pairs of legs attached to the thorax, and, in most cases, wings also ; moreover, the abdomen is plainly marked out into segments (rings).

By this combination of characters, then, it is possible to distinguish between insects and other animals which in some respects resemble them. For example, a spider is not an insect because (I) it has no division (neck) between head and thorax, (2) it has no antennæ, (3) it has four pairs of legs, (4) its abdomen is not segmented; a centipede is not an insect, because, although it possesses a neck and antennæ, yet it has no separation between thorax and abdomen, and has many more legs than three pairs. But ants, bees, beetles, bugs, butterflies, cockroaches, crickets, dragon-flies, flies, earwigs, fleas, gnats, grasshoppers, and moths are all true insects, and in the main arrangement of their bodies and limbs resemble the wasp.

"The name "insect " has reference to these "cuts into" the body, being derived from the same Latin word as "section," " dissect," " bisect," " vivisect," which all convey the idea of " cutting." Similarly " entomology," or the study of insects, is derived from the same Greek word as " anatomy," " epitome," " tome," in which the same meaning is present. 
With the majority of insects a wasp is not likely to be confounded; but inasmuch as there are some beetles, flies, and moths which closely resemble wasps in general shape, and in the arrangement of the yellow and black markings with which the body is decorated, it will be well to indicate the points of difference. Firstly, then, wasps possess a sting; this weapon is not found in any of the above-named mimics. Further distinctions lie in the characters of the wings. Both front and hind-wings of the wasp are thin, transparent, and membranous; when in use the two wings of one side are locked together by a series of minute hooks which are situated on the front edge of the hind-wing and become engaged in a grooved ledge upon the hinder border of the front wing; when at rest the wings are placed parallel and dorsal to the abdomen, and the front wing undergoes one fold along its whole length, so that its posterior half underlies the anterior, and the width of this wing is thereby halved. In beetles the front wing is hard, horny, and opaque, and serves as a cover and protection to the hind-wing, which is the chief instrument of flight; when at rest the hind-wing is folded in a complicated fashion both longitudinally and transversely. Flies possess but one pair of wings (the front); these are not folded at all, and generally stand out at an angle from the body, i.e. they are not brought parallel to the abdomen when at rest. The "Clearwing" moths, which resemble wasps, have a dark opaque band along the apex of the wing; the front and hind wings are not united by hooks, and when at rest there is no folding of either wing. There are, of course, many other structural differences between these insects, but the above will suffice for our purpose.

It is probable that birds and other insect-eating animals learn by experience that wasps possess a sting which produces painful effects. The conspicuous coloration of the wasps serves as a warning to such animals not to repeat their early experiments. Thus yellow-and-black has unpleasant associations, and the harmless beetles, flies, and moths referred to above probably derive advantage and enjoy comparative immunity from attack by passing under the colours of the really dangerous wasp which they mimic. 
There are two chief groups of wasps-Solitary and Socialdistinguished by various structural features which need not detain us, and also by habits and domestic economy. The Solitary or mud-wasps construct small mud cells for the reception of their eggs, and provide a store of caterpillars for the benefit of the grub. These caterpillars are paralysed, but not killed, by the sting of the female, and remain in this helpless condition until the growing grub devours them. Each female mud-wasp works entirely alone, and, having constructed and provisioned one or more cells in crevices in masonry, holes in posts, doorlocks, window-latches or other similar spots, takes no further interest in her work and progeny. All these Solitary are smaller than the Social wasps, and of a paler yellow colour; moreover, there are among them but two conditions of sex, perfect females and males; there are no "workers" (sterile females). On the other hand, the Social wasps live in great communities, whose members co-operate for the common welfare; their nests are constructed of wood-pulp (wasp-paper), and are either placed underground or suspended from the branch of a tree, according to the species; each nest is founded by a perfect female ("queen"), and her offspring alone form the population, which comprises sterile females or "workers," perfect females or "queens" of the next year, and males or drones. It is these Social wasps that are so commonly known, and to these we will confine ourselves in considering the anatomy.

The head carries a pair of large "compound" eyes, which occupy the greater part of the right and left sides. Each eye is shining and black in colour; the margin nearest to the middle of the front of the face is deeply notched, and the bay thus formed is more or less, according to the species, occupied by a strip of yellow colour. If examined under a magnifying-glass, the surface of the eye is seen to be divided up into a large number, many hundreds, of minute hexagonal areas (facets), each of which is in reality the surface of one eye-element. These facets are transparent; the black appearance is due to dense masses of dark pigment which surround the deeper parts of each underlying eye-element, and which prevent light that has entered at one facet from reaching the sensitive portion of any other vol. $1 .-13$ 
than the appropriate element. It is probable that each of the many hundreds of component eyes receives a picture of a small portion of the surrounding view, the action being comparable to that of a "pin-hole" camera ; and inasmuch as the eyeelements are distributed over the curved sides of the head a fairly complete panorama is obtained. In addition to the two compound eyes, there are situated upon the summit of the head three small "simple" eyes (ocelli),

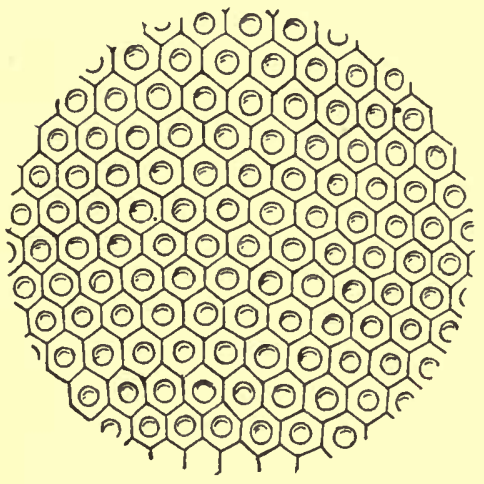

FIG. 69.-Part of the compound eye of a wasp, much magnified. arranged in a triangle. Projecting from the front of the head, between the compound eyes, are the antennæ. These are delicate organs of touch, as may readily be determined by watching the behaviour of a living wasp ; they are also possessed of the sense of smell, and perhaps too of hearing. The first joint, that next the head, is longer than the rest, and is known as the "scape"; the remaining joints are set at an angle on the scape, and together constitute the "flagellum" or "flail." The flagellum of "queens" and workers contains eleven joints, while that of drones contains twelve. Thus there are in all thirteen joints in the antenna of the male, but only twelve in that of the females. The front of the scape is yellow in all sexes of those wasps which build nests on trees, but is so only in the males of ground-wasps. Thus a worker-wasp with a yellow line on the front of the scape may at once be known to come from a nest that is above ground, and probably well situated for observation. The area between the two eyes and below the antennæ is known as the "clypeus."

Jaws.-Sunk into the ventral portion of the posterior surface of the head is a large and deep depression, in which is lodged the greater part of the jaw apparatus. The depression has no limiting wall in front, so that its contents can be thrust forward to project in front of the clypeus. The jaws consist of three pairs of appendages or limbs, modified to subserve feeding, namely, 
the pair of mandibles, the first pair of maxillæ, and the second pair of maxillæ, of which the last-named are united to form a single structure, the labium. The mandibles are the most anterior of the jaws; they are yellow in colour, and are hinged on to the head a little way below the bottom of the compound eyes, and form on the right and left sides movable boundaries to the anterior part of the above-mentioned depression. Each is actuated by powerful muscles, which cause it to bite against its fellow in the middle line. The movement is thus from side
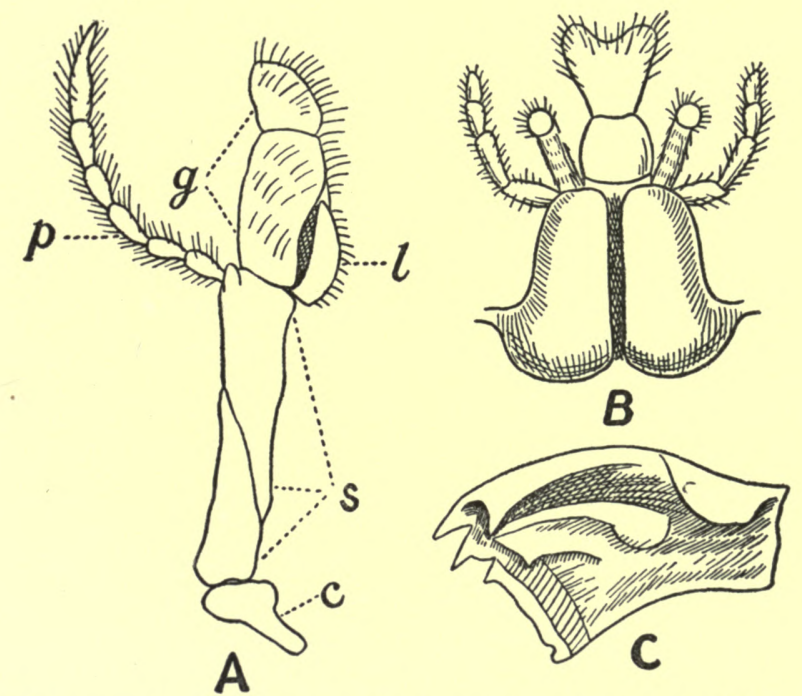

FIG. 70.-The mouth appendages of a wasp. A, Ist maxilla: $c$, cardo ; $s$, stipes ; $g$, galea ; $l$, lacinia ; $p$, palp. $\mathrm{B}$, labium. $\mathrm{C}$, mandible, seen from inner side.

to side and not up and down, as is the case in our own jaws or in those of any back-boned animal. The free extremities of the mandibles are provided with strong horny black teeth, which are used for cutting, scraping, or tearing, and behind the upper of these, and separated from them by a groove, is a row of small knobs resembling a coarse file, which is employed in crushing substances from which juicy food can be extracted. Immediately behind the knobs is a number of fine hairs, which perhaps function as a strainer and prevent solid matter from passing into the mouth. About half-way along the inner, hollow face is a strong transverse ridge; the teeth of the other mandible 
can work right up to this ridge; and when at rest frequently are held thus, one mandible overlapping its fellow for some distance. Since wasps possess no gizzard or other grinding machine along the course of their alimentary canal, all mastication must be accomplished before swallowing takes place; moreover, the food supplied by the workers to the grubs requires to be reduced to a pulpy condition before it is administered. When the teeth are in use, one set against the other, there is a gap left between the main portions of the mandibles. Into this space, and practically filling it, there projects from the clypeus a small brown oblong structure, the labrum or upper lip, whose lower

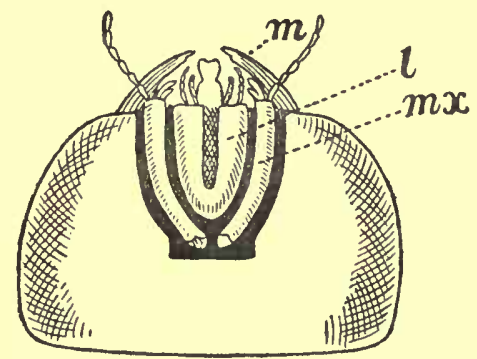

A

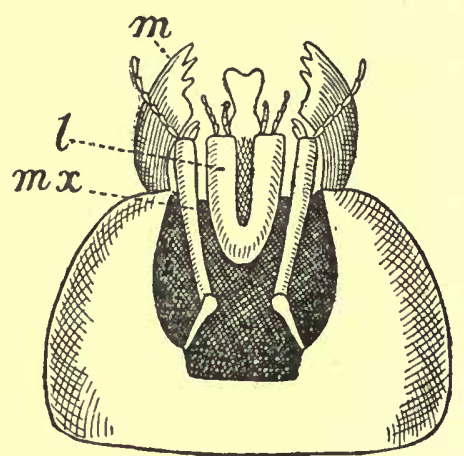

B

FIG. 7I.-Diagram of under side of head of wasp, showing the mouth apparatus.

A, retracted; $\mathrm{B}$, protruded. l, labium; $m$, mandible ; m.x. ('stipes of) Ist maxilla.

free end is slightly notched, while the upper attached end is drawn out to right and left into a pair of divergent prongs. Thus the whole labrum when isolated is $\mathrm{V}$-shaped. Its entire surface is closely beset with bristles. The remainder of the mouth parts, namely, the two first maxillæ and the two united second maxillæ (labium), are lodged in the deep depression to which reference has already been made. Their structure, though in the main resembling that of the corresponding organs in the cockroach, is considerably modified, and too complex for detailed treatment here. In order to see these appendages it is best to remove the head and pin it face downwards on a cork, and then examine with a hand magnifying-glass while moving and separating the appendages with a needle. 
If a freshly killed wasp be decapitated and the severed head be turned face downwards, the action of the maxillæ will often continue for some time, and may be watched under a hand magnifying glass. It will then be seen that the whole of both pairs of maxillæ is alternately thrust forward, so that the tongue and apical portions project beyond the teeth of the mandibles, and are then drawn back again, the palps meanwhile being kept in a constant state of flickering motion. The precise action of each individual portion is very difficult to make out, if, indeed, it is known ; but the total effect of the movements is to produce a sucking, pumping action upon objects held between the mandibular teeth, and to force the extracted juices along a tube whose walls are made up by the several portions of the mouth apparatus.

Thorax.-A short and slender neck unites the head to the thorax. This is composed of three segments, the pro-, mesoand metathorax, and, attached to the last of these, the truly first segment of the abdomen, technically known as the propodeum. ${ }^{1}$ The first segment of the thorax is black and short, being merely a narrow ring whose sides-which are very large -and floor are thick and hard; the roof is detached from the sides, and extends backwards to the insertion of the fore-wings; it has a yellow stripe on each side. The sides and floor commonly come away with the head when the latter is detached, bearing with them the first pair of legs. The middle segment is much larger, and carries ventrally the second pair of legs, and laterally the first pair of wings. It has two yellow spots, one at the attachment of the wing and one just below it on each side; a portion of it which projects backward dorsally and is separated by a shallow groove bears two further yellow spots. The last segment, which is very short, is firmly united to the preceding, and bears the third pair of legs and the second pair of wings. The propodeum extends from the third segment to the "waist." Both it and the third segment proper may or may not, according

${ }^{1}$ In wasps, ants, bees, and their allies, the "waist" is really between the first and second abdominal segments ; but notwithstanding this, the apparent first (real second) segment of the abdomen is always spoken of as the first, while the true first (now attached to the metathorax) is not counted, but described as the propodeum of the thorax. 
to the species, be spotted with yellow. The whole surface of the thorax is covered with bristles of some length, which are probably tactile in function.

The thoracic exo-skeleton is exceedingly hard, and further, has hard processes extending into the internal cavity. Now, the chief function of a skeleton, whether external or internal, is to afford firm points of attachment for muscles, and to constitute a series of rigid rods which may play the part of levers in bringing about motion of the several parts, or locomotion of the entire individual. Hence the great hardness of the thorax to which the organs of locomotion, the legs and wings, are attached is a mechanical consequence of the presence of the powerful muscles by which these organs are moved.

The wings are thin membranous expansions of the exoskeleton, supported by a system of firmer "veins" or " nervures" of definite arrangement. The "veins" along the front margin of the extended fore-wing are much stouter and less flexible than the remainder; moreover, the fore and hind-wing of each side are united, as already stated (vide p. I92). Hence, when a down-stroke is made by the wings the front edge remains rigid, but all the posterior portion yields to the pressure of the air below and is bent upward, so that a forward thrust results upon the under surface of the wings, and so the insect is driven forward. The action can be imitated by folding a sheet of paper two or three times along one of its edges, so as to render that edge stiff, and then dropping it (flat side horizontal) from above the head: the paper will not fall vertically, but will travel obliquely forwards and downwards in the direction towards which the stiffened edge is turned. The main muscles for moving the wings up and down are not attached to the wings themselves, but to portions of the thoracic skeleton itself. Their action is such that when the thorax is made shorter fore and aft, but deeper dorso-ventrally, the wings are depressed; and conversely when the thorax is made shallower dorso-ventrally but longer from neck to waist, the wings are elevated. This movement can be brought about in a freshly killed wasp by removing the head and abdomen, then (I) place the scar whence the head has been removed on the table and press with a pencil point upon the 
upturned end (propodeum); the pressure will make the thorax shorter but deeper, and will depress the wings; (2) place the thorax in its natural attitude, and press upon its highest point; this will render the thorax longer but shallower, and produce elevation of the wings.

The three pairs of legs are all of similar structure, and differ but slightly in length; the anterior being the shortest, the posterior longest. Each leg is composed of nine joints: the part next to the thorax (coxa) is short and flattened; the next (trochanter) is very small, is sunk into its articulations, and thus affords a degree of freedom of movement approximating to that obtained by a ball-and-socket joint; this is followed by the thigh (femur), a long and rather swollen portion standing almost horizontally at right angles to the body, then the shin (tibia), which is straight and about the same length as the thigh, and lastly the ankle (tarsus), composed of five joints, and terminating in two curved claws. The limbs are virtually hollow, jointed tubes, the articulations between the successive portions being formed merely by thinner and therefore more flexible bands of the ordinary chitinous exo-skeleton. The cavities of the limbs are occupied by muscles which pass from one joint to the next through the articular ring, and which by contracting bend one joint upon the next in this or that direction. By appropriate bending or extension of the successive joints the foot can be moved in almost any direction. When the insect walks the first pair of legs pulls the body forward; the second pair partly pulls and partly pushes, the former process at the beginning and the latter at the end of a "step," but is chiefly for the purpose of balancing and sustaining the body; the third pair pushes the body onwards. The legs are moved in the following order. The first and third of the right side move forwards at the same moment as the second of the left, and then the first and third of the left and the second of the right are simultaneously advanced. Thus the animal is always supported on at least three points. In fact, its walking apparatus might be termed a pair of tripods, used alternately. The claws in which the legs terminate give a secure hold upon chance inequalities of the path travelled over, and between them is a pad which secretes a sticky 
substance by which the animal can adhere to smooth vertical or even inverted surfaces.

In addition to their locomotor function, the legs have the important duty of keeping the body clean and free from particles of dust and other foreign objects. A wasp or any other insect may often be seen to pass its legs over various portions of the body, and then rub the legs so used together, or between two others, or pass them between the mandibles. The first procedure is in order to entangle the dust lying on the body in the bristles

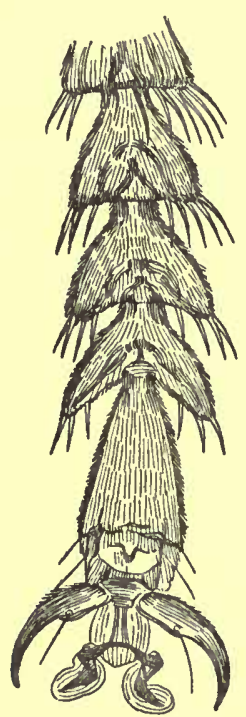

FIG. 72. which cover the tibia, and especially the tarsus, the second is to remove the matter so collected and drop it to the ground. The bristles which cover the legs all point away from the body and towards the claws, and thus tend to work the dust particles off and not on to the body. Those upon the ventral side of the tarsal joints are worth detailed description : between the two claws are two stout bristles starting from the dorsal side of the adhesive pad, but reaching to the ground in front of it; behind the pad on the ventral side are four similar bristles, two on each side, lying straight behind the claws and nearer to the margins than the two dorsal bristles; the fourth tarsal joint carries four such bristles upon each side, the third five, the second six, the first (a long joint often called the "metatarsus") seven. Now, since the transverse width of these several joints is approximately the same, it follows that in passing from the fifth to the first joint one encounters a succession of combs or rakes whose teeth become gradually more and more closely set. Hence, when the leg is used as a cleanser, a coarse rake goes over the surface first, and is followed by four other rakes of increasing fineness, so that the larger particles of dust are first removed and then the more minute. In addition to these stout bristles there are many very fine ones, which cover the edges and ventral surface of all the tarsal joints; while the metatarsus has, beyond those already mentioned, some five-and-twenty coarse bristles along the length of its under side, and a similar arrangement occurs 
upon the tibia. The finer bristles together constitute a very perfect brush for the removal of the minute specks that may pass between the rake-teeth. At the distal extremity of the tibia of the third leg are two movable spurs, - one, the inner, decidedly larger than the other; these are closely beset with brush-and-comb bristles, and overhang a similarly provided shallow depression in the proximal part of the metatarsus. If another leg is placed into the depression, its surface is simultaneously cleaned all round by the brush and comb of the spurs upon one side and that of the depression on the other. The second pair of legs carries a similar arrangement upon its tibia, but the two spurs are of equal size and join the tibia a little farther back from its extremity. The first pair, on the other hand, has only one spur, and that is joined to its tibia at about one-third of the length of the latter from its lower end ; and further, has no bristles except upon its concave face directed towards the metatarsus, and here, as also in the metatarsal depression, there is an extremely fine comb. This contrivance is used solely for cleaning the all-important sense organs, the antennæ. Similar antenna combs are

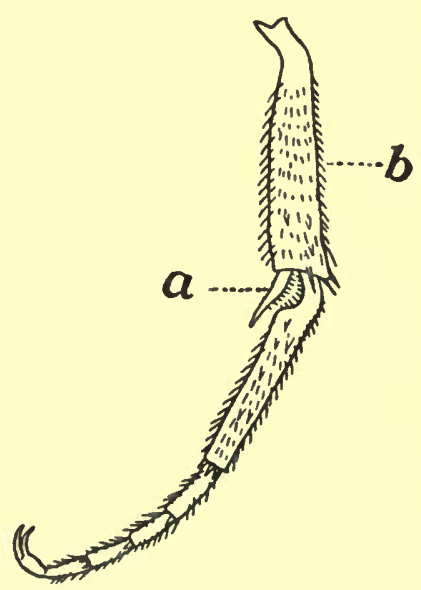

FIG. 73.-Front leg of wasp. $a$, antenna comb ; $b$, tarsus. possessed by ants and bees, and any one of these insects may be seen to make frequent use of the apparatus, especially if confined and sprinkled with a little dust.

Abdomen.- The abdomen is composed of six visible segments in the female, but of seven in the male. These are roughly annular in shape, consisting of dorsal and ventral semicircles, and overlap one another so as to be capable of considerable extension or compression, after the manner of a telescope. The first segment is abruptly cut off anteriorly, but the posterior segments gradually taper off, so that the apex of the abdomen is sharply pointed. The segments are decorated with yellow and black markings, whose pattern differs in the several species, and, indeed, is not constant among members of the same species. 
Within the terminal segments of the abdomen are hidden, two in the male and three in the female, other segments greatly modified in shape, and forming the reproductive clasping apparatus of the male, and the sting and its accessories in the female.

Sting.-The sting consists of three long pieces, which can be thrust out from the end of the abdomen by means of a com-

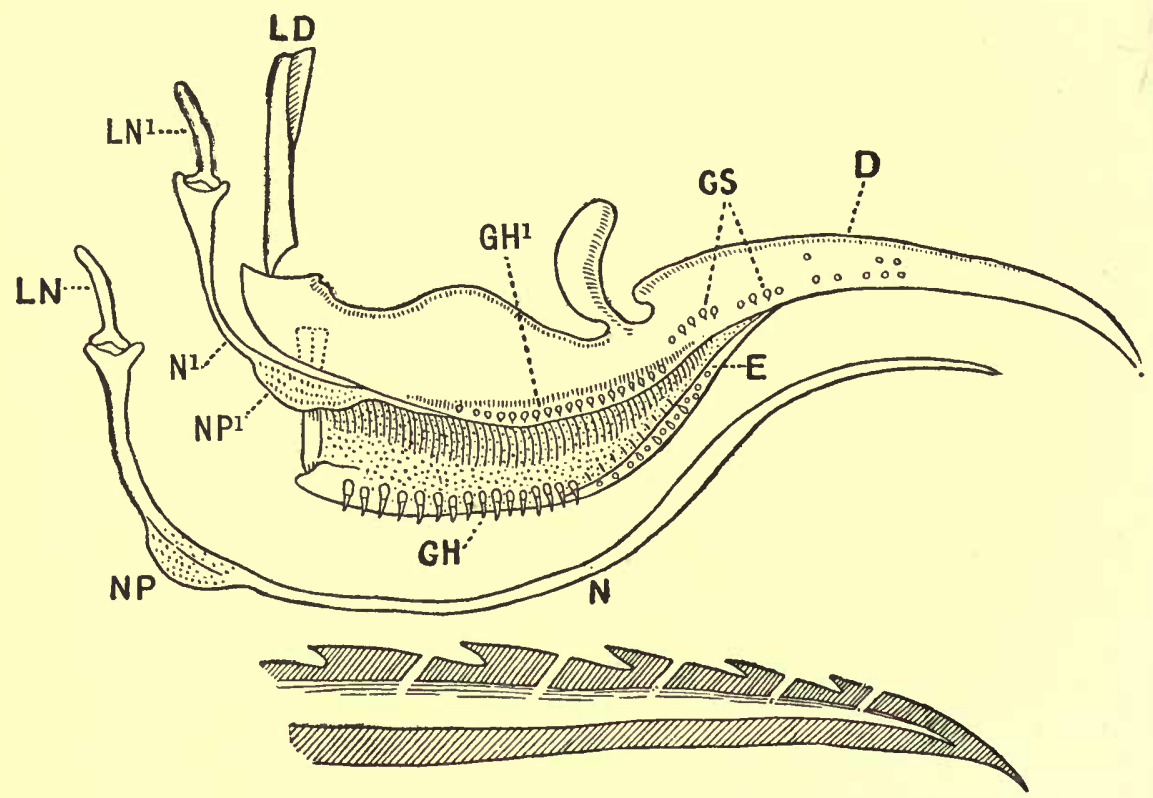

FIG. 74.--Sting apparatus of wasp, and (below) tip of one needle, showing poison channel and its outlets through the bases of the barbs. D, director; E, in-turned edges of director ; $\mathrm{GH}, \mathrm{GH}^{\prime}$, guiding hairs of left and right sides ; GS, guiding studs inside $\mathrm{D}$; $\mathrm{LD}$, lever of left side for extension of $\mathrm{D} ; \mathrm{LN}, \mathrm{LN}^{\prime}$, levers for extension of right and left needles ; $\mathrm{N}^{\prime}, \mathrm{N}$, beyond tip of $\mathrm{D} ; \mathrm{N}$, right needle withdrawn from $\mathrm{D}$; $\mathrm{NP}, \mathrm{NP}^{\prime}$, enlargements on needles: (?) pistons for sweeping poison onwards.

plicated set of levers and muscles lodged within. The largest of these three is the part that can be seen darted out when a wasp attempts to sting; it is a hollow, sharply pointed organ, the cavity being open ventrally along the broader anterior region and also at the point. Within it lie two three-sided, bayonetshaped " needles" bearing six barb-hooks at their apices. These needles are the true stinging organs, the larger outer structure, though capable of piercing the skin, serves chiefly to ensheathe, 
support, and direct the delicate needles within, and is therefore known as the "director." When a sting is inflicted a hole is first made by the "director," the needles are then slid along inside their sheath, so that they issue side by side from the hole at its extremity and penetrate more deeply into the flesh of the enemy. The opposed faces of the needles are channelled each by a deep half-pipe gutter, so that the two together enclose a tube between them; into the anterior end of this pipe poison is discharged by a tube leading backwards from a bag, the poison bag, in which this liquid is formed; the poison is forced along between the needles and escapes into the inflicted wound through minute canals perforating the base of the barbs, which serve for the time to anchor the needles in the flesh. In the cavity of the " director" are rows of projecting studs, which guide the outer edge of each needle and prevent any dislocation of the parts.

Breathing.-A living wasp, even when quite undisturbed, maintains a constant in-and-out telescopic kind of motion of the abdominal segments, as though threatening to sting. These movements are in reality concerned with respiration. Insects do not breathe through the mouth, but through a number of holes (stigmata or spiracles) on the side of the body. In the wasp there are six of these breathing holes on each side of the abdomen, and three on each side of the thorax. The abdominal stigmata can just be seen with the unaided eye if the specimen be well stretched out; one is situated on each side in the black part of the dorsal semicircle of each segment near its ventral edge where it overlaps the ventral semicircle, and is itself overlapped by the dorsal part of the preceding segment. The thorax also possesses three pairs of stigmata, one belonging to the prothorax, the second to the mesothorax, and the third to the propodeum ; these, however, are by no means easy to see, owing to the overlapping of the hard parts of the thorax. The stigmata lead into tubes, called tracheal tubes, which are connected on each side by longitudinal air-vessels and penetrate into all the tissues of the body, conveying air direct to all parts by means of the numerous ramifications into which they subdivide. These tracheal tubes are really delicate, inward extensions of the external 
skeleton; their walls are provided with a closely wound spiral thickening which serves to keep them open and give elasticity against external pressure. Every muscular contraction compresses more or fewer of these tubes and drives air out of them,

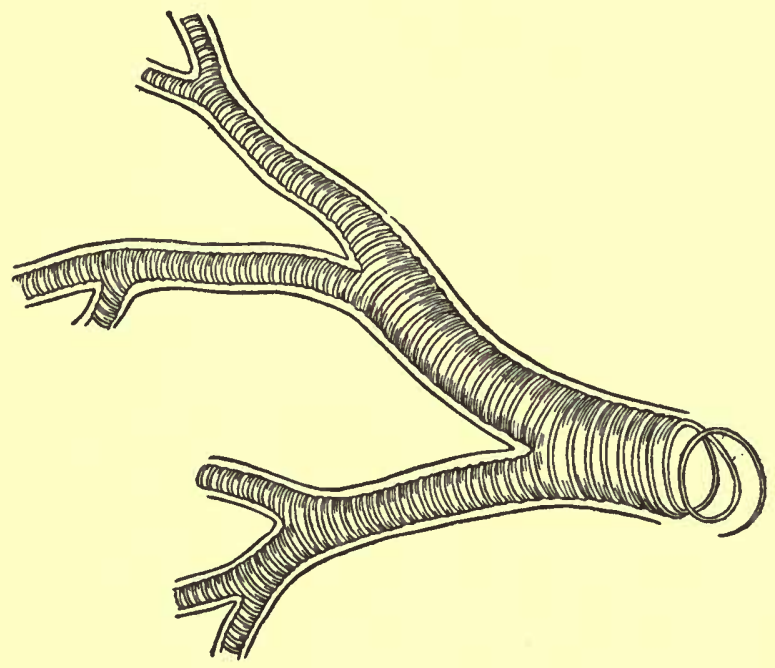

FIG. 75.-Tracheal tube of an insect. while every relaxation allows the tubes to expand again and to receive fresh supplies of air in consequence of the atmospheric pressure outside. This is what is accomplished by the abovementioned rhythmic movements of the abdomen. Inasmuch as the oxygen of the air is thus carried direct to the tissues, it follows that the blood is to a large extent relieved of the function which in ourselves and many other animals it possesses, namely, of conveying oxygen from special respiratory surfaces to other parts. Hence it is not surprising to find that the blood system of wasps and other insects is but feebly developed. The details of the internal anatomy are, however, beyond the scope of this work.

Life-history and Social Economy.-As already stated, the population of a wasps' nest towards the end of the summer comprises the "queen" foundress of the society, workers and drones, and in addition young virgin "queens" destined to continue the race in the following year. In early autumn these young " queens" leave the nest, mate with a drone, and thus fertilised seek out sheltered quarters in which to pass the winter. The remainder of the community perishes at the onset of winter. Hibernating "queens" may often be found in curtains, strawthatched roofs and other similar situations, during the winter. In this state the wings are brought down on to the ventral side of the 
body between the last pair of legs and the abdomen, the antennæ also are held down under the first pair of legs, and all the legs themselves are folded close up to the body, the mandibles alone serving to support the body by a firm grasp upon some shreds of suitable material. The attitude, excepting that of the mandibles, is precisely the same as that occupied during a previous period of quiescence, namely, when a pupa (chrysalis) enclosed in a cell of the comb. During hibernation "queens" can with impunity withstand more than 20 degrees $\mathrm{F}$. of frost.

Warm days in early spring arouse the sleeping "queens" to activity. In April and May these insects may be seen flying along hedge banks and walls in search of suitable building sites, such as an old mousehole or crevice between two stones. The position of the selected spot is carefully noted and surveyed, and the work of founding a new colony then begun. By means of the mandibles and feet, soil is removed and carried pellet by pellet outside the entrance until a small chamber is excavated. A journey is then made to some neighbouring fence or gatepost, from whose weathered surface woody fibre is scraped by the mandibles and carried home, there to be worked up

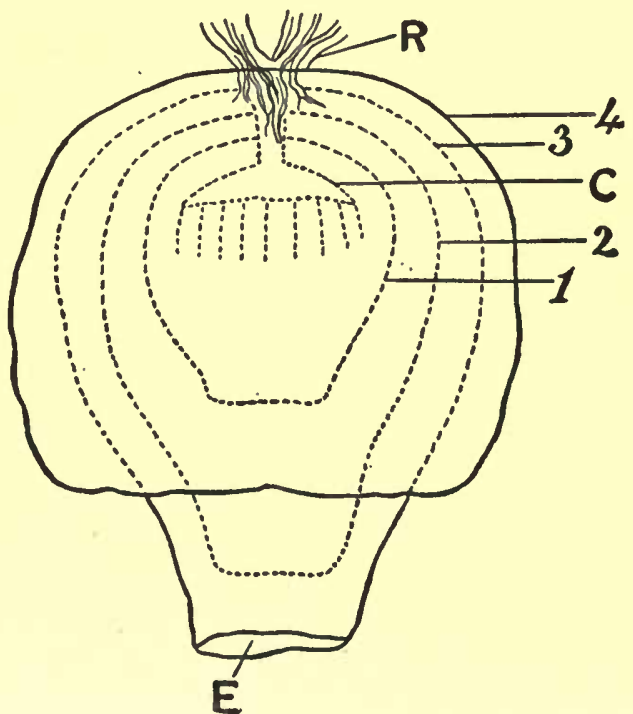

FIG. 76.-Diagram of wasps' nest at an early stage. $\mathrm{C}$, comb made by queen; $\mathrm{E}$, entrance; $R$, root to which nest is suspended; $1,2,3,4$, first to fourth wrappings. into "wasp-paper" and applied to some convenient rootlet in the roof of the chamber. Time after time is this process repeated, until a small platform of "paper" has been constructed. From the centre of this a vertical pillar of the same material is carried downwards; at the lower extremity of this first four, but eventually some thirty hexagonal cells, all opening downwards, are built, forming the first, roughly circular disc or "comb." 
Meanwhile from the summit of the pillar a balloon-shaped covering has been made, surrounding the comb and permitting access to it at the bottom only through a circular hole. A second and a third covering of similar shape are added outside the first, narrow air spaces separating each from its neighbour. These wrappings protect the comb and its contents from enemies, drops of moisture, and especially from chill by virtue of the non-conducting property of the enclosed air. In one of the angles of each cell the "queen" deposits a single egg, glueing it firmly in place. After a few days - the length of time depending upon the temperature-there hatches from the egg a small white legless grub, which, however, does not entirely quit the egg shell, but hangs head downwards from it, keeping the last segments of the body still within the shell, and thus avoids falling headlong out of its cradling cell. The grubs possess jaws, and are fed by their mother on such animals as caterpillars, flies, aphides, and carrion of every kind, while she sustains herself chiefly on the nectar of flowers and other sweet substances. As the grubs grow they twice cast off their skins as these become too tight for the body, and thrust the empty husk up against the roof of the cell. When first completely free from the egg shell they assume a slightly curved attitude, so as to press against the walls of the cell and thus maintain their position; in this they are helped by a special leg-like sucker at the end of the abdomen, and also by the mandibles. Eventually they become so large that almost the entire surface of the body impinges upon the cell walls, while the head may project downwards beyond the margin. As the increasing size of the grubs demands it, the cells are made longer by the queen adding fresh "paper" to their rims. Eggs and grubs in all stages of development can be obtained from the combs of wasps' nests taken in August and September. A fully grown grub consists of thirteen segments, excluding the head, is white, fleshy and legless; it has lateral breathing holes, and maintains a series of regular movements up and down within the cell in order to promote the outward and inward flow of air. The head carries a pair of small eyes, and a pair of mandibles, whose shape in the youngest larvæ differs from that assumed subsequently in having the median of the three teeth very long 
and sharply pointed. There is no posterior opening of the digestive system, but the indigestible portions of the food accumulate in the last portion of the gut and are removed with it at the moulting of the skin. The larva, having reached its full size, spins a silken cocoon which lines the inside of the cell and covers the open end with a white projecting dome ; it then casts its second skin, and becomes a pupa or chrysalis. The pupal skin is very thin and transparent, and through it can be seen the as yet soft body of the imago or perfect insect, with its legs, wings, antennæ, and other parts ; these organs are indeed present in the pupa itself, but are not glued down to the sides of the body as they are in the pupa of a moth or butterfly. No food is taken during pupal life, but extensive alterations in the muscles and other internal organs are effected at the expense of stores of fat laid up within the body by the larva. After a few days the imago is ready to emerge, and, casting off the pupal skin, she attacks the dome-shaped end of the cocoon with her mandibles, and bites her way out. For a short time her body is damp, the colours dull and the wings soft, but in a few hours the final vigorous condition is reached, and the "worker," for such she is, is ready for duty. The length of time from the deposition of the egg up to the emergence of the imago is about a month. So soon as the "queen" has reared her first batch of workers she forthwith abandons the task of building cells and collecting food, but devotes the whole of her energies to the work of laying eggs. Henceforth she never quits the nest, her worker offspring relieving her of all other duties. The strength of the nest now rapidly increases : the workers add further cells to round the margin of the first comb until its diameter is some four or five inches; below this, and suspended from it by numerous pillars, a second similar comb is added, and so on up to as many as ten or twelve combs one below the other, if the season be favourably hot. Meanwhile many additional coverings are added outside those first made by the queen, layer upon layer until the wrappings are perhaps an inch in thickness. The earlier and smaller coverings are cut away as the circumference of the growing combs spreads outwards, and their material is employed elsewhere. The whole fabric of the nest is composed of wood-fibre worked 
up into pulp by the mandibles of the workers and moulded by the same organs into "wasp-paper." Nearly any fence or gate post that has not been tarred or painted may be seen to be streaked with little scars running parallel with the "grain" of the wood, and caused by wasps gathering building material. The wrappings and their enclosed air have so great a power of resisting the passage of heat, that the occupants of a large nest which was placed by the writer for some hours in a hot oven were in no way incommoded, but their development accelerated. The entrance to the nest is always at or near the bottom, and all the cells of every comb face downwards towards it, though a few at the margins are often rather obliquely set. Room is left sufficient for the passage of the wasps between the successive combs, and between their margins and the external wrappings; these intervals are measured by the wasps while at work, the hind-legs being extended for the purpose. The thickness of the sheets and cell-walls is gauged by tapping the antennæ on each side simultaneously, much as we gauge the thickness of materials between finger and thumb. Each cell may be used thrice for grub rearing, as may be proved by extracting from the roof the cast-off larval and pupal skins of its successive tenants. Hence in a comb of five or six inches diameter there will be found round the circumference (the newest part): (I) small cells containing eggs or very small larvæ for the furst time; passing towards the centre of the comb, and arranged approximately in concentric circles, occur; (2) cells containing larger and larger grubs, for the first time; (3) "capped" cells containing pupæ, or imagines ready to emerge, also for the first time; (4) empty cells from which wasps have emerged; (5) cells occupied by eggs or very small larvæ, for the second time; (6) cells with larger grubs, for the second time, and so on. Every comb is begun at its middle, which is therefore its oldest part. When cells have been used thrice they are cut down and their material used again, the foundation (top) only being left. Sometimes the mouths of old cells are covered up with wasp-paper, and so an airspace enclosed ; this is especially the case in the two oldest combs at the top of the nest. All the débris of the nest and much of the excreta of the wasps are discharged on to the soil below the 


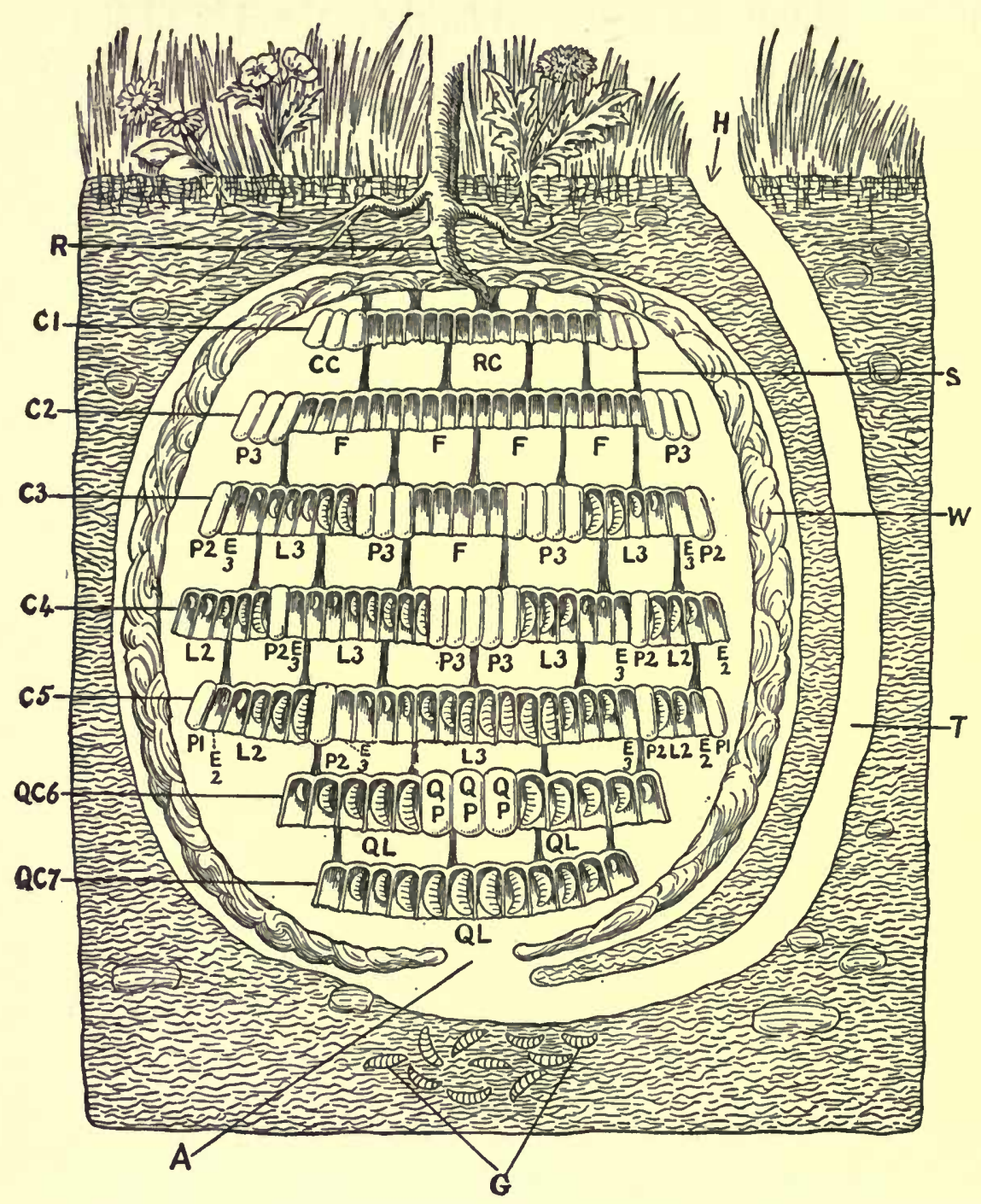

Fig. 77.-Diagram of wasps' nest towards the end of summer. A, entrance to nest ; $\mathrm{C}_{1}-\mathrm{C}_{5}$, first to fifth combs; $\mathrm{CC}$, cells closed with wasp paper $; \mathrm{E}_{2}, \mathrm{E}_{3}$, cells containing eggs for the second and third times respectively; $F$, cells that have thrice been tenanted by grubs and are now discarded for breeding purposes; G, larvæ of a dipterous fly acting as scavengers of the débris that is ejected from the nest; $\mathrm{H}$, hole in ground by which wasps approach $\mathrm{A} ; \mathrm{L}_{2}, \mathrm{~L}_{3}$, cells containing larvæ in various stages of growth for the second and third times respectively; $\mathrm{P}_{1}, \mathrm{P}_{2}, \mathrm{P}_{3}$, "capped" cells containing pupæ (or imagines ready to emerge) for the first, second, and third times respectively ; $Q C 6, \mathrm{QC}_{7}$, sixth and seventh combs containing royal (queen) cells only; $\mathrm{QL}, \mathrm{QP}$, cells containing larvæ and pupæ respectively, which are to give rise to young queens; $R$, root to which nest is suspended; RC, cells used thrice and now reduced in height; $S$, pillars of wasp paper suspending comb to comb ; $T$, tunnel from $H$ to $A$; W, wrappings.

VOL. I. $-\mathrm{I} 4$ 
entrance, and then serve as food for the grubs of small flies which act as scavengers. The eggs of these flies are laid upon the outer wrappings, and may there be seen as small white specks. In the later part of summer, combs containing " royal" cells of extra large size are added below the rest. In these cells the young queens of the next generation are reared. At this season the population is at its maximum, amounting to several thousands, indeed so many as 60,000 individuals may be reared in one nest during a single season; hence the supplies of food brought into the nest are abundant, and it seems that it is the quantity rather than the quality of the food which determines whether any one fertilised egg shall give rise to a " queen " or merely to a worker. It not infrequently happens that some of the larger, better fed workers lay eggs. These eggs, however, are not fertilised, for the workers are incapable of being impregnated, and produce, as do the unfertilised eggs deposited by the "queen," drones only.

At the end of the season, as food supplies become scarce, many of the grubs are devoured by the hungry workers. Eventually the whole establishment falls a prey to mice, earwigs, beetles, and many other creatures, and disappears. The whole duration of its existence is but a few months, namely, from April to November at the longest. From what has been stated regarding the diet of wasps, it will be seen that though they inflict much damage upon fruit crops, yet they are very useful as scavengers, and in destroying numerous insects that are harmful to horticulture.

The seven species of British wasps (Vespa) may be distinguished by the following characters :-

I. The Hornet (Vespa crabro) : thorax reddish brown, not black. A much larger insect than any of the others. Nest built in hollow trees, outhouses, or occasionally in banks, but near the surface.

2. Vespa vulgaris: thorax black and yellow; lateral yellow stripe on first thoracic segment straight and parallel-sided. Face short, base of mandibles almost touching eyes. Scape of antenna of $q$ (queen) and $\not{q}$ (worker) black. Yellow blotch in concavity of eyes hollowed out. Median black line on clypeus of variable size, but not flanked by two other black 
spots. Tibiæ often spotted with black. Nest underground, deep.

3. Vespa germanica: colour of thorax and scape and shape of face as is $V$. vulgaris, but lateral yellow stripe on first thoracic segment decidedly convex ventrally. Yellow blotch in concavity of eyes not hollowed out. Median black line on clypeus
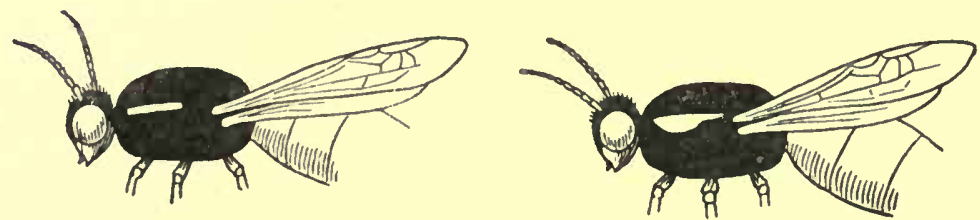

FIG. 78.-Diagram to show specific difference in shape of yellow lateral stripe on thorax on $V$. vulgaris (left) and $V$.germanica (right).

of variable size, but always flanked at lower end by two black spots. Tibiæ usually entirely yellow. Nest underground, or in thatched roofs, etc.

4. Vespa austriaca: colour of thorax and shape of face as in (2) and (3) ; scape yellow in front in 9 . Abdomen glossy, and tibiæ with long projecting hairs. Rare; $\Varangle$ not known.

5. Vespa rufa: colour of thrrax, shape of face as in three preceding, but the black markings on abdomen are blurred with reddish brown and not sharply defined. Abdomen glossy. Nest underground. Not uncommon. ${ }^{1}$

6. Vespa sylvestris: face long; a distinct interval between the base of the mandibles and the eyes. Scape of antenna yellow in front in $q$ and $\forall$, as well as in $\delta$ (drone). Clypeus yellow, with only a small central black spot. Tibiæ with long projecting hairs. Nests on branches of trees, bushes, etc.; occasionally underground, near surface, or in old tins, pots, etc. Common.

7. Vespa norwegica: colour of thorax as in (2), etc.; shape of face, scape of antennæ and tibiæ as in (6). Clypeus with broad black central line, often dilated in middle so as to be anchor shaped. Abdomen generally reddish at base. Nests on branches of bushes and shrubs, occasionally on trees. Fairly common.

${ }^{1} V$. austriaca and $V$. rufa are probably dimorphic forms of the same species. The former is the ancestral type, which still holds its own in Ireland, but has been almost completely displaced by the latter in England. 
Bibliography.-Cambridge Natural History, vol. vi. ; Latter, Natural History of some Common Insects; Saunders, Aculeate Hymenoptera; Marchal, Arch. de Zool. Expér. et Gén., (3) iv., I986; Janet, Mém. Soc. Zool. France, viii., I895; Etudes sur les Fourmis, les Guêpes et les Abeilles, Limoges, 1895; Avebury (Lubbock), Ants, Bees and Wasps.

END OF VOL. I. 




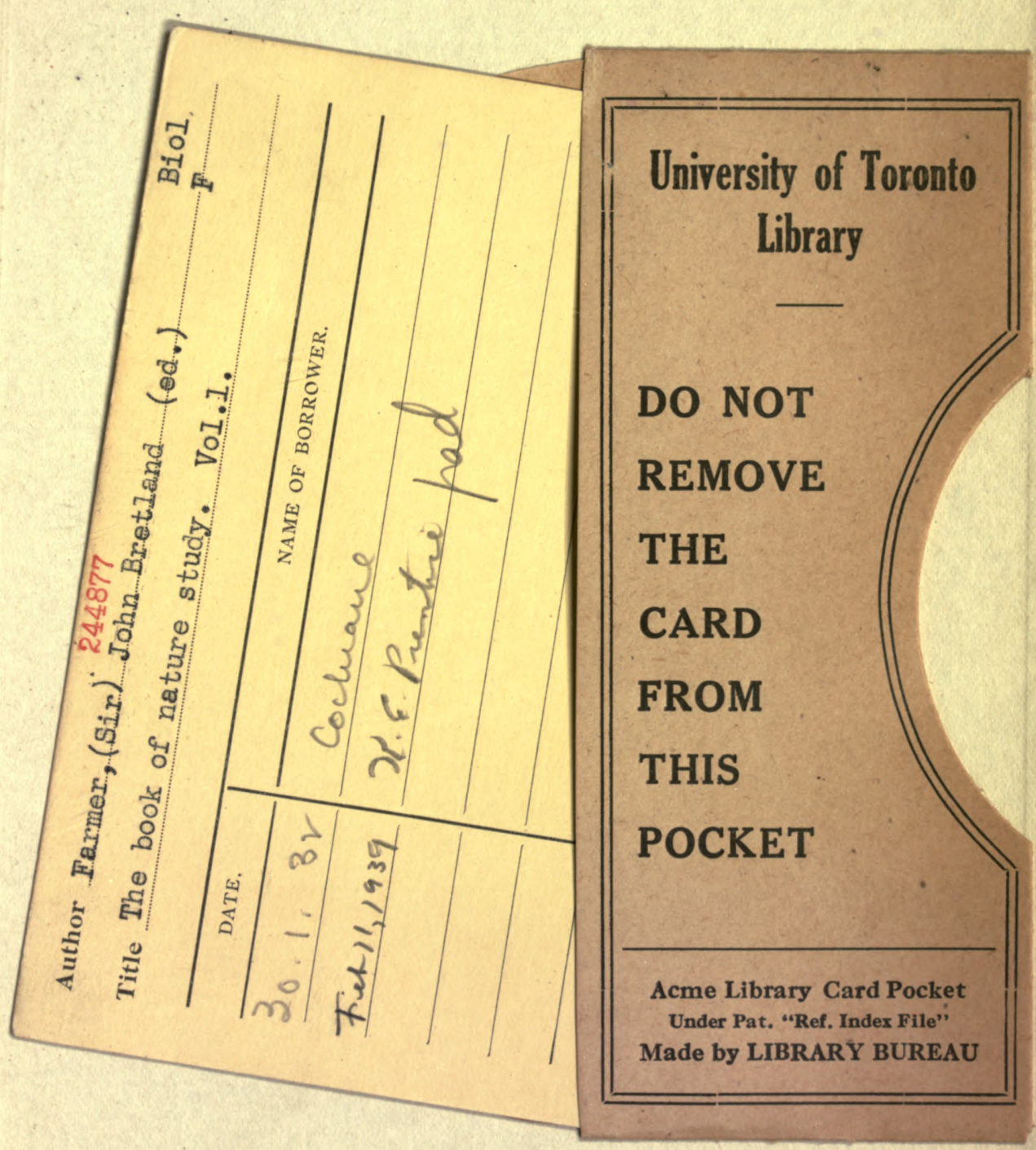


